\title{
The shadow of hierarchy in marine fisheries governance
}

Citation for published version (APA):

Espinosa-Romero, M. J. (2021). The shadow of hierarchy in marine fisheries governance. [Doctoral Thesis, Maastricht University]. Boekenplan. https://doi.org/10.26481/dis.20210622me

Document status and date:

Published: 01/01/2021

DOI:

10.26481/dis.20210622me

Document Version:

Publisher's PDF, also known as Version of record

\section{Please check the document version of this publication:}

- A submitted manuscript is the version of the article upon submission and before peer-review. There can be important differences between the submitted version and the official published version of record.

People interested in the research are advised to contact the author for the final version of the publication, or visit the DOI to the publisher's website.

- The final author version and the galley proof are versions of the publication after peer review.

- The final published version features the final layout of the paper including the volume, issue and page numbers.

Link to publication

\footnotetext{
General rights rights.

- You may freely distribute the URL identifying the publication in the public portal. please follow below link for the End User Agreement:

www.umlib.nl/taverne-license

Take down policy

If you believe that this document breaches copyright please contact us at:

repository@maastrichtuniversity.nl

providing details and we will investigate your claim.
}

Copyright and moral rights for the publications made accessible in the public portal are retained by the authors and/or other copyright owners and it is a condition of accessing publications that users recognise and abide by the legal requirements associated with these

- Users may download and print one copy of any publication from the public portal for the purpose of private study or research.

- You may not further distribute the material or use it for any profit-making activity or commercial gain

If the publication is distributed under the terms of Article $25 \mathrm{fa}$ of the Dutch Copyright Act, indicated by the "Taverne" license above, 


\section{The Shadow of Hierarchy in Marine Fisheries Governance}

María José Espinosa-Romero 
(C) 2021, María José Espinosa-Romero

Cover design: Margret Reijnders I Creatieve Communicatie and Karla Rivas I omedg.com

Cover drawing: Jorge Torre

Publisher: Boekenplan, Maastricht

ISBN: 9789086665273

All rights reserved. No part of this publication may be reproduced, stored in a retrieval system, or transmitted in any form, or by any means, electronic, mechanical, photocopying, recording, or otherwise, without the prior permission in writing, from the author. 


\title{
The Shadow of Hierarchy \\ in Marine Fisheries Governance
}

\author{
Dissertation \\ to obtain the degree of Doctor \\ at Maastricht University, \\ on the authority of the Rector Magnificus, \\ Prof. Dr. Rianne M. Letschert \\ in accordance with the decision of the Board of Deans, \\ to be defended in public \\ on Tuesday 22 June 2021, at 16:00 hours
}

by

María José Espinosa-Romero 


\section{Supervisor}

Prof. Dr. J. C. Seijo, Marist University of Merida

\section{Co-Supervisors}

Dr. J. Marotta

Dr. M. Natorski

\section{Assessment committee}

Prof. Dr. J. Kraker (Chair)

Prof. Dr. M. Bavinck, University of Amsterdam

Prof. Dr. L. Lijnzaad

Prof. Dr. R. Sumaila, University of British Columbia

\section{Financial support}

Comunidad y Biodiversidad, A. C. 
To Minelia E José Manuel 


\section{Acknowledgements}

Living the PhD was an exciting life and learning experience. I am very grateful to all my companions who supported me in this process.

Juan Carlos Seijo, it was a privilege to have you as my promoter and to cross our paths again; your academic and fisheries expertise contributed significantly to this thesis and my development as a researcher. I always felt inspired and confident to continue my research after our meetings. Julieta Marotta, many thanks for your kind support in all aspects of the $\mathrm{PhD}$, from research questions, to methods, to the concerns and challenges a $\mathrm{PhD}$ student goes through. I enjoyed and learned from our time together; and I was always inspired to see you balancing life, academic work, and relationships with a smile. Michal Natorski, many thanks for our theoretical discussions, all the information you shared with me, and the collaborative writing we did for our chapter. They challenged and sharpened my thinking and academic skills.

Joop de Kraker, Liesbeth Lijnzaad, Maarten Bavinck, and Rashid Sumaila, many thanks for being the members of the assessment committee. Your contributions strengthened the final version of this research.

To all the staff at Maastricht School of Governance and UNU-Merit, thank you so much for your support and patience over these years. Mindel Van de Laar, many thanks for your guidance, openness, and straightforwardness; they were always timely and helpful to navigate the PhD process. To the GPAC coordination team, especially Shivani Achrekar, Charlotte Mueller, Cristina Mancigottti, and Paris Cosma, many thanks for helping us, GPAC students, with all the logistics during our visits to Maastricht. Your support and smiles make our PhD journey smoother and nicer. It was great to meet you all.

Combining the $\mathrm{PhD}$ with a full-time employment required a great deal of support from my colleagues at Comunidad y Biodiversidad, A.C. Jorge Torre, many thanks for giving me the flexibility to combine work with the PhD. I know it was not easy, but we made it through. Thanks for listening to me during the low and high emotional peaks of the $\mathrm{PhD}$ process and for always reminding me that doing a $\mathrm{PhD}$ is a privilege and I was very fortunate. Also, thank you for making the cover of the book. It was a nice surprise to see that you used a Vincent van Gogh palette of colors, because I am a big fan of Van Gogh paintings. I went to his museum every single time on my layovers in Amsterdam on my way to Maastricht. Brenda Cardenas, 
many thanks for your kind support and friendship; all our conversations about the Mexican legal framework and experiences I went through as a PhD student, as well as your support at work and with my databases, were significantly helpful in this journey. Stuart Fulton, many thanks for the proof reading of all the chapters of my thesis. I learnt a lot from your feedback and increased my confidence at writing in British English. Rebeca Fernández many thanks for your support with the cover and the repository of documents for COBI's website. Verónica Hernández, María José Brambila and Karen Munguía, many thanks for your support with administrative matters. Melissa Cabrera, Natalia Bates, Mariana Suasnavar, Fernanda Fitzmaurice, María Fernanda Marín, Gabriela Cuevas, Lorena Rocha and Francisco Fernández, many thanks for your kind support with the data collection and for answering all questions about the data. To all COBI staff, many thanks for your kind support and the feedback you provided me on the presentations of the thesis.

I am very grateful to the people who commented on my ideas, presentations, and manuscript drafts. Frank van Laerhoven, Ratana Chuenpagdee, Joeri Scholtens, Lane Fargher, German Ponce, Maria José Barragán, Minerva Arce, Silvia Salas, Miguel Ángel Cisneros, Lina Santos, José Alberto Zepeda, Nemer Narchi, Alejandro Espinoza, Senador José Narro, Leobardo Batista, and Orlando Pérez many thanks for your feedback, information, contacts, and cheering up. All that helped to continue my work and develop my thinking in this field. Adrian Salinas, the librarian from the Lower Chamber Library, thank you for helping me identify the core documents of the Mexican legal framework I used in this research.

To the friends I made in Maastricht. Gillian McFarland and Purity Njagi, we know the $\mathrm{PhD}$ can be a lonely endeavor; many thanks for your support and friendship. Traveling this journey together was always comforting and encouraging. Mauricio Céspedes, Gonzalo Neyra, and Daniel Little, I had so much fun with you seeing and experiencing the beautiful Maastricht. Allison, Elisa, Laura, and Jeroen, thanks for hosting me, for our dinners, conversations, and the relaxing time we had together after school hours.

Over the last years, I experienced unplanned changes and extraordinary events, including the COVID-19 pandemic. My special thanks to my family and friends, who are always there. Minelia and José Manuel, your unconditional love and trust always raise my spirit to follow my dreams. Jose Manuel Jr, many thanks for your company and for taking care of Chel and my house during the travels to Maastricht. It was lovely to have you around that year when I was going through different changes. 
Ale, Paulina, Ivana, Renata, Nikito, Mayú, and Mamatina, many thanks for the care, warmth, and laughs you always bring to my life. Víctor Fernández and Sander Jobse, many thanks for letting me stay at your places on my layovers in Amsterdam and London. Life feels easier and funnier when we are together. Karla Amador, many thanks for being such a good friend, your calls and visits during the $\mathrm{PhD}$; we always grow together. Fabricio Vargas, many thanks for our time together; our laughs and talks always inspire me to move forward. Juan Ignacio Álvarez, many thanks for inspiring and reminding me the peace and joy I am to live this process. Maru Anaya and Jaime Martínez, many thanks for your friendship and for keeping an eye on me during this pandemic and the PhD. And Chel, thank you for the unconditional love and company, our walks and runs together, with sunrises and sunsets, always refreshed my mind as I conducted this research. 


\section{Contents}

Acknowledgements ............................................................................................ vi

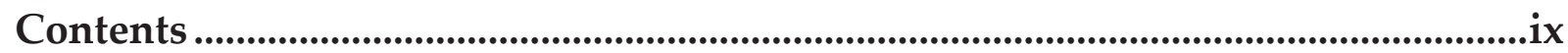

Acronyms.................................................................................................................................

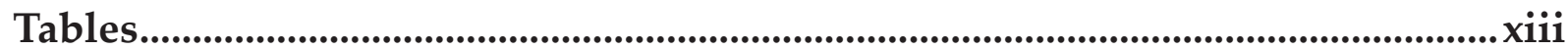

Figures ................................................................................................................................ xiv

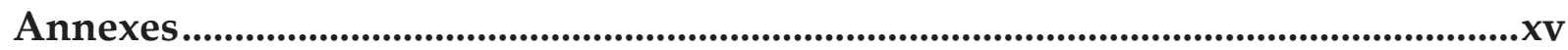

Abstract ........................................................................................................................ xvi

Chapter 1. Introduction ........................................................................................................1

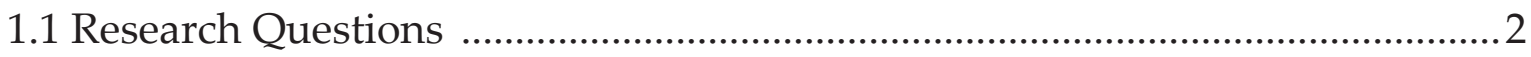

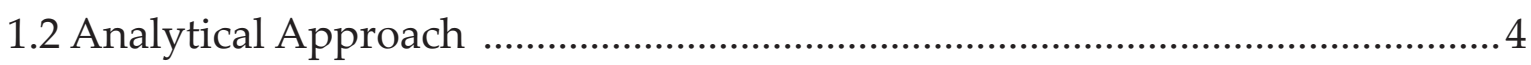

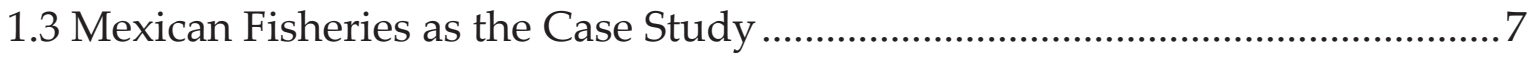

1.4 Methods and Data Sources ...........................................................................

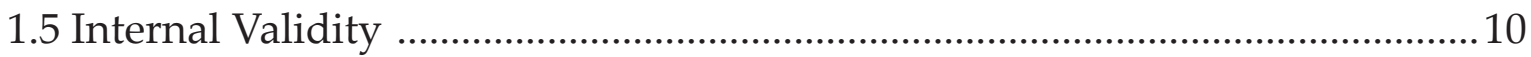

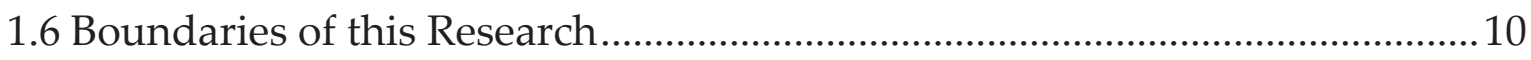

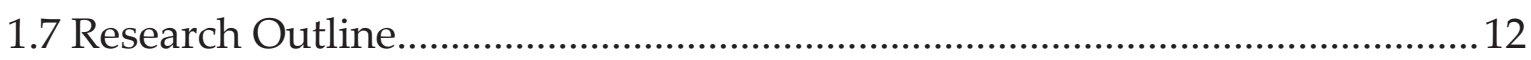

Chapter 2. The State in Marine Fisheries Governance ...................................................13

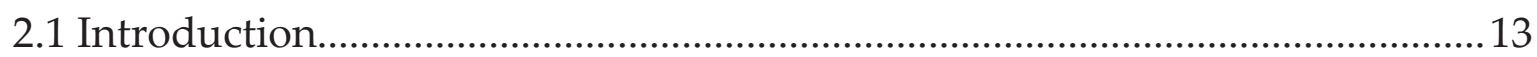

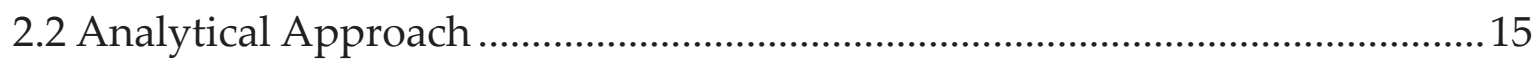

2.3 Methods and Data Sources ……………………….......................................18

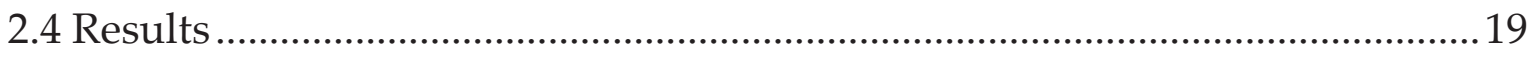

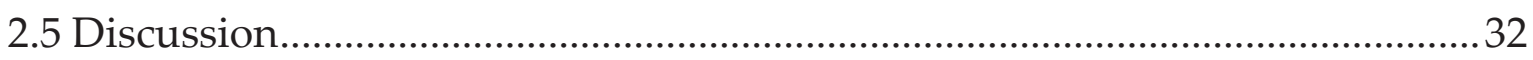

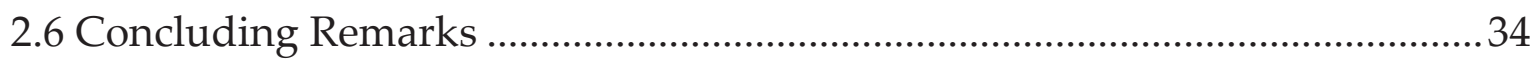

Chapter 3. A Hundred Years of the Shadow of Hierarchy in Mexican Fisheries 36

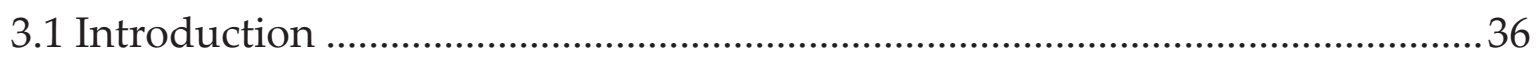

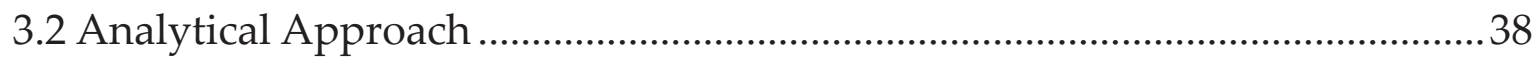

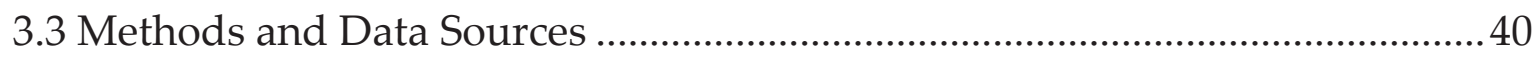

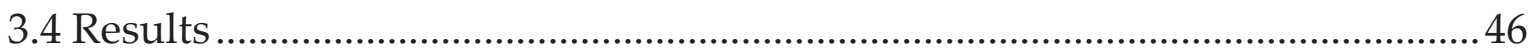

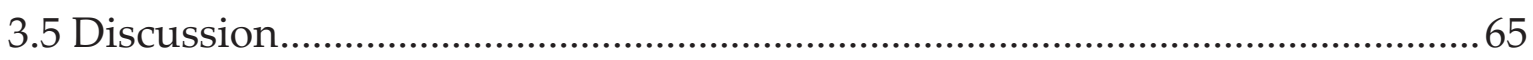

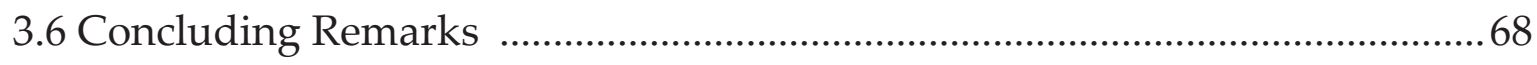


Chapter 4. The Shadow of Hierarchy in the Governance of Fishing Practices.....69

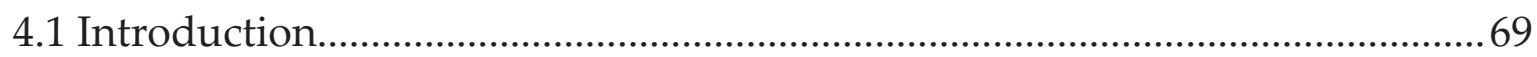

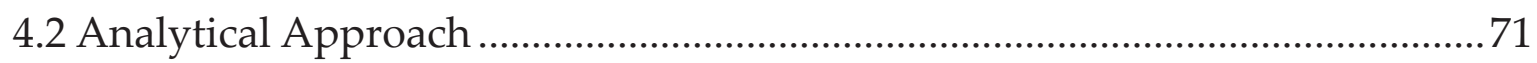

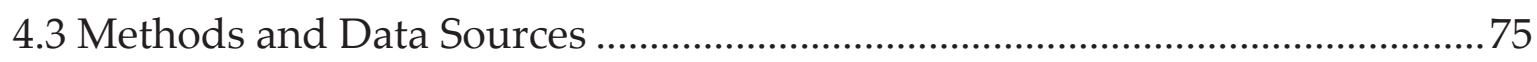

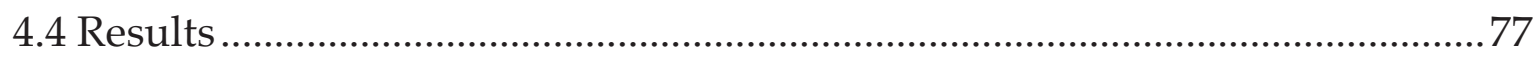

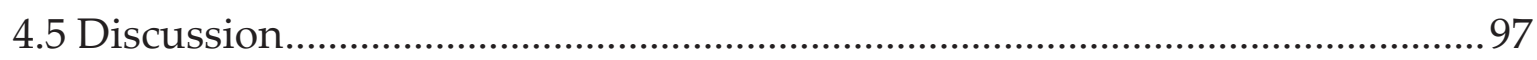

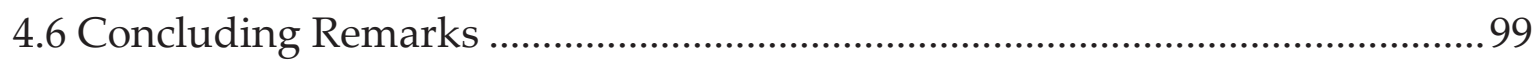

Chapter 5. The Shadow of Hierarchy in the Governance of Fisheries

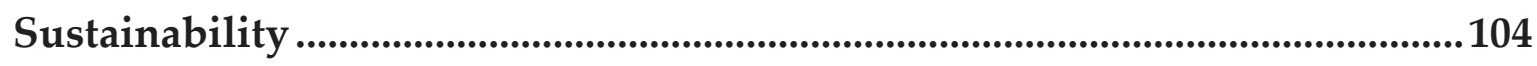

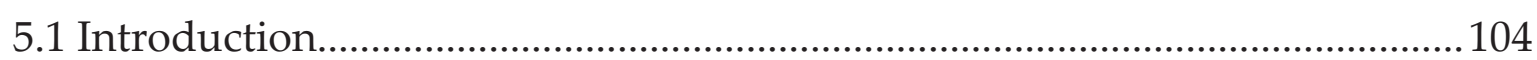

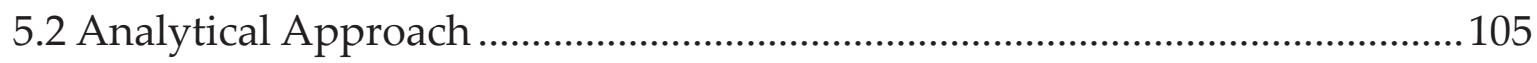

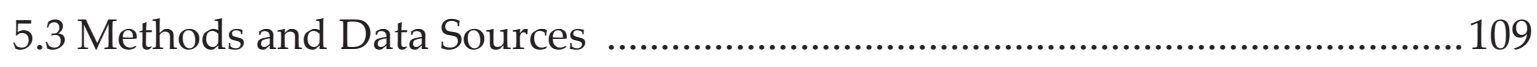

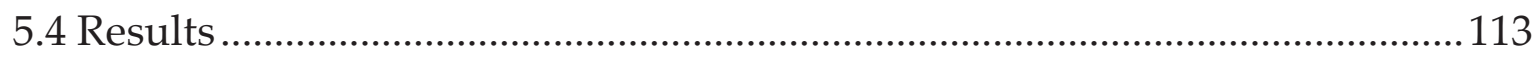

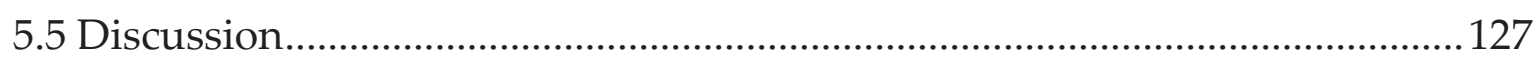

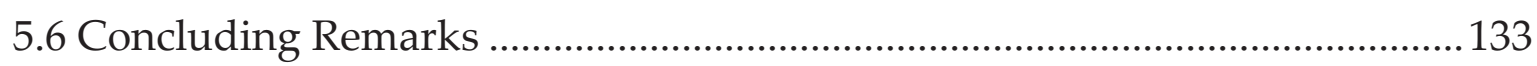

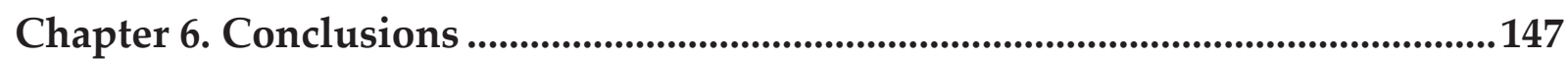

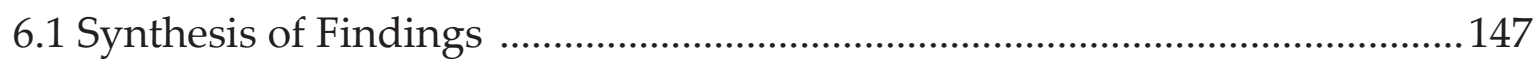

6.2 The Complementarity of Theoretical Approaches ..........................................152

6.3 Research Contributions …………………………….....................................154

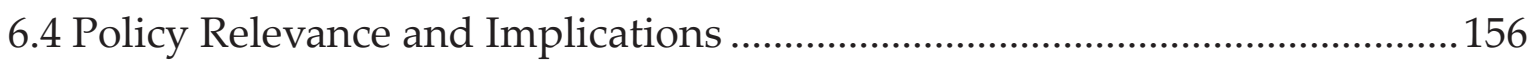

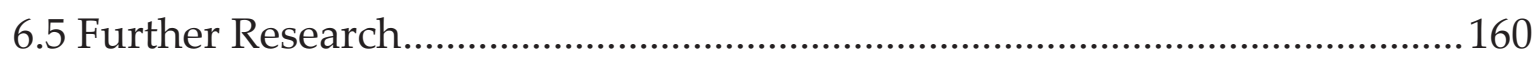

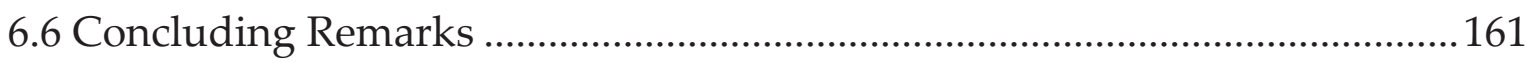

References..........................................................................................................................162

Summary in English ........................................................................................................187

Resumen en Español ..........................................................................................................190

Biography of the Author .......................................................................................................193 


\section{Acronyms}

CABs

CITES

CPR

COFI

CONAPESCA

EAF

ETP species

EEZ

FAO

FEDs

FIPs

Ecolabelling guidelines

HDI

INAPESCA

IPOA-IUU

ITQs

MEY

Mexican Constitution

Morena

MPAs

MSC

MRS

MSY

NFC

$\mathrm{Nm}$

NOMs

PRI

RBF

RFMOs

RI
Conformity Assessment Bodies

Convention on International Trade in Endangered Species of Wild Fauna and Flora

Common-pool Resources

Committee on Fisheries

Comisión Nacional de Acuacultura y Pesca. National Commission of Aquaculture and Fisheries

Ecosystem Approach to Fisheries

Endangered, Threatened, and Protected species

Exclusive Economic Zone

Food and Agriculture Organization of the United Nations

Fish Excluder Devices

Fishery Improvement Projects

Guidelines for the Ecolabelling of Fish and Fishery Products from Marine Capture Fisheries

High Human Development Index

Instituto Nacional de Pesca y Acuacultura. National Research Institute for Fisheries and Aquaculture

International Plan of Action to Prevent, Deter, and Eliminate Illegal, Unreported, and Unregulated Fisheries

Individual Transferable Quotas

Maximum Economic Yield

Political Constitution of the United States of Mexico of 1917

Movimiento de Regeneración Nacional

Marine Protected Areas

Marine Stewardship Council

Máximo Rendimiento Sostenible

Maximum Sustainable Yield

National Fisheries Charter, Carta Nacional Pesquera

Nautical miles

Normas Oficiales Mexicanas, Mexican Official Standards

Partido Revolucionario Institucional, Revolutionary Institutional Party

Risk-based Framework

Regional Fisheries Management Organizations

Recruitment Impairment 
RNIIPA

SENASICA

SDGs

SSF Guidelines

SCM Agreement

SSP approach

TAC

TURFs

TEDs

The Compliance

Agreement

$\mathrm{UN}$

UNCLOS

UN Fish Stocks

Agreement

VMS
Red Nacional de Información e Investigación en Pesca y Acuacultura, National Network of Information and Research for Fisheries and Aquaculture

Servicio Nacional de Sanidad, Inocuidad y Calidad Agroalimentario, National Service for Food Safety and Food Quality.

Sustainable Development Goals

Voluntary Guidelines for Securing Sustainable Small-Scale Fisheries in the Context of Food Security and Poverty Eradication

Agreement on Subsidies and Countervailing Measures

Situation, Structure, Performance approach

Total Allowable Catch

Territorial Use Rights in Fisheries

Turtle Excluder Devices

Agreement to Promote Compliance with

International Conservation and Management Measures by Fishing Vessels on the High Seas

United Nations

United Nations Convention on the Law of the Sea

Agreement for the Implementation of the Provisions of the United Nations Convention on the Law of the Sea of 10 December 1982 relating to the Conservation and Management of the Straddling Fish Stocks and Highly Migratory Fish Stocks

Vessel Monitoring System 


\section{Tables}

Table 2-1. Conceptualization of governance modes: hierarchical, co-governance, and self-governance

Table 2-2. Themes and sub-themes used for the codification of scientific publications

Table 3-1. Provisions of the legal framework used for the analysis of the institutional setting for the co-existence of governance modes 44

Table 3-2. Themes and subthemes for the codification of fisheries laws 45

Table 3-3. Management tools for the regulation of fisheries in Mexico 56

Table 3-4. Summary of overarching goals for fisheries governance within the Mexican legal framework

Table 3-5. Coexistence of governance modes in Mexican fisheries 62

Table 4-1. Models of the state involvement in a governed domain .72

Table 4-2. Relevant actors identified in the legal framework for the governance ....79

Table 4-3. Legislative process for the enactment of fisheries laws (1925-2007).........81

Table 4-4. Public investment for industry development (1917-1982)

Table 5-1. Institutional setting for different resource types to cope with high exclusion, information, monitoring and enforcement costs. 107

Table 5-2. Themes and subthemes for the codification of information collected from the National Fisheries Charter (NFC) and third-party assessments (2000-2019). 112

Table 5-3. Species reported as overexploited in the NFC (2000-2018). 118 


\section{Figures}

Figure 3-1. State agencies in charge of fisheries governance within the Mexican bureaucracy

Figure 3-2. Legal framework applicable to fisheries governance for the last 100

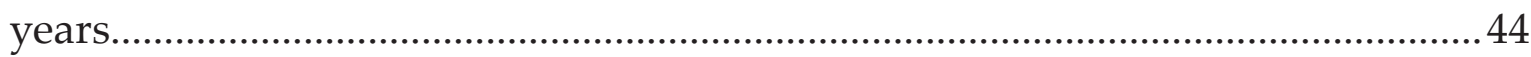

Figure 4-1. Regulations of fishing practices during political periods of Mexico .......88

Figure 5-1. Types of fishing rights in Mexico..............................................................115

Figure 5-2. Map of the Mexican EEZ, coastal provinces, and relevant fishing sites..116 Figure 6-1. Complementarity and interrelations among the three theories (i.e., interactive governance, social practices, and institutional impact) and their key elements 


\section{Annexes}

Annex 4-1. The historical variety of the state involvement in Mexican fisheries governance.

Annex 5-1. Mexican fisheries situation, structure, and performance according to the National Fisheries Charter (NFC).

Annex 5-2. Fisheries situation, structure, and performance according to third-party assessments for FIPs and MSC certifications (2000-2019). 


\begin{abstract}
This research investigates the shadow of hierarchy in marine fisheries governance, using Mexican fisheries as the case study. The shadow of hierarchy refers to the use of non-traditional hierarchical forms through which the state indirectly influences governance in order to achieve policy outcomes. Although the shadow of hierarchy has been investigated in different policy arenas, it remains understudied in the fisheries domain. To contribute to this research gap, this study identifies and deepens on the analysis of three meta-governance functions performed by the coastal state in the governing of fisheries and fleets within its jurisdiction. These meta-governance functions are: i) the creation of coexisting governance modes; ii) the steering and shaping of the general patters of fishing; and iii) the development of institutional settings for fisheries sustainability. This research applies three theoretical approaches (i.e., interactive governance, social practices, institutional impact) to understand the meta-governance functions from different and complementary perspectives. The results illustrate the autonomy of the coastal state to govern fisheries in the shadow of hierarchy. As shown in the case of Mexico, the state has the power to retract and expand its shadow, within its jurisdiction, according to its priorities and capacities. Although the state is immersed into different modes of governance, the state preserves its capacity to indirectly influence governance systems, in order to compensate for losing day-to-day command and control in fisheries governance. It does so by regulating the boundaries of actors' participation, the cognitive practice of fishing, and the institutional settings for different resource types in order to ensure sustainability.
\end{abstract}




\section{Chapter 1. Introduction}

The modern state is immersed in diverse governance modes. The nature of what the state does and reaches changes over time (Huber et al., 2015; Pierson, 2004) and indirectly influences the diversification of governance modes - forms in which public, private, and social actors organize and interact (Scharpf 1997, p. 195). The shadow of hierarchy is understood as the use of non-traditional hierarchical mechanisms through which the state indirectly influences the organization of governance modes (Scharpf, 1997, pp. 200-202). This research investigates the shadow of hierarchy in marine fisheries governance, using Mexican fisheries as the case study.

The concept of shadow of hierarchy is anchored in the actor-centred institutionalism framework and interaction-oriented policy research, which in conjunction consider policies as the outcome of the interactions of resourceful and boundedly rational actors. This means that actors, who are often constituted in larger organizations, are largely bounded by the institutionalized norms within which they interact (Scharpf 1997, p. 195). These norms shape their competences, action resources, but also their purpose and cognitive orientations (bounded rationality) (Simon, 1957). The shadow of hierarchy assumes that state influences such institutional norms (Scharpf 1997) and therefore indirectly influences the self-organization of actors to achieve policy outcomes (Jessop, 1997, p. 575). It also assumes meta-governance dynamics by positioning the state as a meta-governor (Jessop, 1997, p. 575) of governance modes, which are not found in practice as pure forms, but in combinations (Whitehead, 2002).

Meta-governance is thus a concept used to define state functions performed in the shadow of hierarchy. These functions include the definition of governance rules, the organizational knowledge, the distribution of power resources, the shaping of the self-understanding of actors' identities and preferences (Jessop, 1997, p. 575), and the ensuring of desirable outcomes (Bell \& Hindmoor, 2009, p. 47). Then, through the exercise of the meta-governance functions, the state decides about the extension, nature, and persistence of hierarchical forms of authority even when other forms of governance (i.e., co-governance and self-governance) seem to dominate (Jessop, 1997, p. 575). Moreover, the performance of these functions, nested in the shadow of hierarchy, generally implies shifts from unitary centralized state control to a more decentralized and fragmented state, where steering is performed by segmented executive agencies (Richards \& Smith, 2002, p. 36), and responsibilities and functions are distributed among public, private, and social actors (Jessop, 1997, 2009; Scharpf, 
1994). The state remains as a central point of reference despite its limited involvement in the everyday management performed by other public, private, and social actors. Therefore, the state redirects its functions or power and is involved in governance in more complex and diverse relationships (Lister \& Marsh, 2006:255).

In the marine fisheries field, scholars agree that state intervention remains relevant in different settings (e.g., Anthony \& Campbell, 2011; Grafton, 2000; Ostrom, 2010; Pomeroy \& Berkes, 1997). However, the shadow of hierarchy, remains understudied. To address this gap, this research presents the analysis of existing literature to identify the meta-governance power of the state in marine fisheries, performed in the shadow of hierarchy (Chapter 2). Moreover, this study undertakes empirical research to deepen the investigation of three meta-governance functions, using the Mexican fisheries as the case study. The three meta-governance functions investigated are: i) creation of co-existing governance modes (Jessop, 1997, p. 575; Scharpf, 1997, pp. 200-202) (Chapter 3); ii) definition of the general patterns of fishing (Pierre, 2000, p. 3) (Chapter 4); and iii) ensuring fisheries sustainability for different type of resources (Bell \& Hindmoor, 2009, p. 47) (Chapter 5).

\subsection{Research Questions}

This study centres its attention on How is the shadow of hierarchy performed by the state in marine fisheries governance? It specifically investigates this phenomenon through the analysis of meta-governance functions performed by the state to indirectly influence fisheries governance. The following sub-questions are addressed:

- What are the governance modes and what are the governing functions of the state?

- How does the state create coexisting governance modes?

- How does the state steers and defines the general patterns of fishing?

- How does the state create the institutional setting for fisheries sustainability?

The initial sub-questions What are the governance modes and what are the governing functions of the state? allows to identity in existing literature, the functions the state performs in different governance modes, in order to identify the functions that reflect the shadow of hierarchy, performed at the meta-governance level. In addition, these sub-questions provide an understanding of governance modes. Therefore, this research identifies the determinants influencing the emergence of governance modes and the reported performance of such modes. 
The sub-question How does the state create coexisting governance modes? refers to the first meta-governance function of the state investigated in this study. According to the literature review the coastal state possesses the regulatory power to influence (directly or indirectly) fisheries governance. This power was granted by the United Nations Convention on the Law of the Sea (UNCLOS) in 1982. Through its exercise, the state can, and has, retained and ceded (partially or fully) the governing of marine fisheries to public, private and social actors. With different degrees of power devolution, the state supports the self-organization of diverse governance modes. Generally, governance modes in marine fisheries are analysed for particular periods of time, and as if they were independent or in the transition from one to another (e.g., Chuenpagdee \& Jentoft, 2018). This research analyses them as coexisting and uses Mexican fisheries to identify the mechanisms established by the state to support the coexistence of governance modes. Moreover, this research identifies the actors the state chooses as partners for the governing of fisheries, and the governing functions that the state retains and cedes to non-state actors.

The sub-question How does the state steers and defines the general patterns of fishing? refers to the second meta-governance function investigated in this research. It is based on the fact that the state by delegating power to public, private, and social actors for the governing of fisheries, makes its influence in governance more indirect. The expectation is that the state, in order to compensate for the weakening of direct control on actors, uses its regulatory power to frame the cognitive and material parameters of fishing. This in order to guarantee the regularity of actions without directly commanding actors' individual actions. In this manner, the state facilitates indirect coordination of actors and creates the framework for regulating the expectations regarding appropriate actions for otherwise autonomous actors. To explore this meta-governance function of the state, this research analyses the legal framework and implementing regulations established for Mexican fisheries to illustrate how the state steers the general patterns of fishing.

The sub-question How does the state create the institutional setting for fisheries sustainability? refers to the third meta-governance function investigated in this research. It is based on the fact that the state is the actor able to shape non-state actors' opportunities and behaviour in order to achieve desirable outcomes related to the public interest, such as fish conservation and fisheries sustainability (Jessop, 1997, p. 505; Scharpf, 1997, p. 202), which for instance are mandated by the UNCLOS. Given the nature of marine resources (i.e., different degrees of mobility and uncertainties associated), the analysis of policy outcomes require the consideration, not only of 
actors, but also, of different types of resources. Therefore, the investigation of this meta-governance function uses Mexican fisheries to explain the institutional setting developed for different types of resources in order to ensure desirable outcomes, i.e., fisheries sustainability. In addition, this analysis accounts for the complementary efforts performed by private and social actors to contribute to fisheries sustainability. The expectation is that these efforts are performed in the shadow of hierarchy, under the institutional settings established by the state.

By illustrating how the state performs the three meta-governance functions, this research demonstrates the shadow of hierarchy and autonomy of the state to define, expand, and retract its indirect intervention in fisheries governance.

\subsection{Analytical Approach}

Three theoretical approaches are applied to address the research questions: interactive governance (Kooiman, 2003), social practices (Shove, 2009; Shove et al., 2012), and institutional impact (Schmid, 1987). These theories provided different and complementary perspectives for the analysis of meta-governance functions performed by the state, in the shadow of hierarchy, in the fisheries domain. The application of the theories is summarized as follows.

Interactive governance theory was applied to the literature review (Chapter 2), to address the questions What are the governance modes and what are the governing functions of the state? Interactive governance is anchored in governance studies and has a focus on the interactions of public, private, and social actors to solve societal problems and create societal opportunities. It embraces the formulation and application of the principles that guide such interactions as well as the institutions that enable and control them (Kooiman et al., 2005, p. 17). The application of this theoretical approach to fisheries allows to explain actors' interactions and institutional settings at different scales (i.e., local, regional, and global) and geographies (i.e., North and South) (Bavinck et al., 2005a; Kooiman et al., 2005; Kooiman et al., 1999). According to interactive governance theory, governing takes place within three ideal types of governance modes: hierarchical, co-governance, and self-governance. Each mode has different and unique features. In hierarchical governance, governing is generally, but not necessarily, conducted by the state and is characterized by a top-down style and vertical-type interventions. In co-governance, governing is shared with private, public, and social actors (Kooiman, 2003; Kooiman et al., 2005; Kooiman et al., 2008), often through formal institutional arrangements (Berkes, 2002; Pinkerton, 1989). In self-governance, governing is left to communities or groups, who take care 
of themselves, outside the purview of the state (Kooiman, 2003; Kooiman et al., 2005; Kooiman et al., 2008). In real life, governance modes exist in hybrid forms, as suggested in the shadow of hierarchy literature (Kooiman \& Jentoft, 2009; Whitehead, 2002), and change in response to political, economic, or ecological aspects internal or external to the fishing industry (Chuenpagdee \& Jentoft, 2018). The three governance modes framed the identification in existing literature of the governing functions performed by the state in different governance modes, the meta-governance functions performed in the shadow of hierarchy, the determinants influencing the emergence of governance modes, and the reported performance of governance modes.

Interactive governance was also applied to address the question How does the state create coexisting governance modes? Two dimensions were included in this analysis: governance modes and governance orders. Governance modes are explained above. Orders are defined in three layers. The first order refers to the day-to-day operations and problem solving. The second order refers to institutional design or making, which should enable the first order. The third order refers to the establishment of values, norms, and principles that guide the choices and institutions (Kooiman, 2003; Kooiman \& Bavinck, 2005; Kooiman et al., 2005). The two dimensions (governance modes and orders) are widely applied to the analysis of fisheries (small- and large-scale) in different geographies, (e.g., Chuenpagdee \& Jentoft, 2018; Jentoft \& Chuenpagdee, 2015c; Kooiman et al., 2005) to conceptualize the interactions between public and private actors, in different governance modes and the orders at which they occur (Kooiman, 2003, 2005; Kooiman et al., 2005). In this research, modes and orders are assumed to be part of a larger governance system and frame the analysis of the legal framework of Mexican fisheries. This analysis explained how the state chooses to retain and cede governing functions to non-state actors in co-existing governance modes, as well as the actors to partner with.

Social practices theory (Shove et al., 2012) is used to investigate the question How does the state steers and defines the general patterns of fishing? Some authors already drawn attention to the concept of practices as a meta-governance mechanism to 'secure governmental influence, command, and control within governance' (Whitehead, 2003, p. 8), yet it remains underdeveloped in the literature. The steering of practices encompasses different symbolic and material dimensions to establish general parameters of actions instead of focusing on specific actions. The process of shaping is usually performed in regulatory activity visible in different legislative acts. By shaping practices, the state retains its indirect influence on actors and indirectly intermediates in dispute resolutions by creating a framework of reference 
for actors' actions. The diversification of governance modes in fisheries is expected to increase the employment of regulatory activity to shape the patterns of fishing to compensate for the decrease of direct control. To facilitate the analysis of practices, this analysis uses the typology developed by Shove et al. (2012). In this account, the three elements of practices are: meanings, competences, and materials. Meanings include symbolic values, ideas, aspirations, and motivations; competences encompass formally accredited and/or intangible capacities, skills, know-how, and techniques; and materials involve artefacts, things, technologies, tangible physical entities, and the stuff of which objects are made (Schatzki, 2002; Shove, 2009; Shove et al., 2012). The analysis of these key elements of practices identified in the Mexican fisheries legal framework and implementing regulations illustrate how the state retains the capacity to influence the steering and codification of fishing practices.

The situation, structure, performance (SSP) approach of institutional impact theory from neo-institutional economics (Schmid, 1987, pp. 5-23) is used to address the question How does the state create the institutional setting for fisheries sustainability? Seijo (1993) previously applied the SSP approach to explain the institutional setting established by the state and a coastal community for the governing of the Mexican lobster fishery (Panulirus argus). This research uses the three elements of this approach (i.e., situation, structure, and performance) to frame the analysis of fisheries sustainability as the desired outcome of governance schemes created for different type of resources. Situation refers to the inherent attributes of the individuals, community, or goods to be used or harvest. In the context of this research, situation refers to fish resources types. Caddy and Seijo (2005) and Seijo et al. (2010) suggest three types of resources according to their mobility: sedentary (species with low mobility), straddling (shared stocks that migrate through, or occur in, more than one exclusive economic zone-EEZ), and highly migratory (species moving in the high seas) species. A fourth type of resource, mobile resources within an EEZ, is introduced in this research as a new category given the relevance of this type of fish resources in coastal states with wide littorals. ${ }^{1}$ The second component of the SSP approach is structure, which refers to institutions - fishing rights and rules that influence the opportunities of users and their power to have access to resource use. Rules can be formal (i.e., state regulations) and informal (e.g., community- or industry-based), and include the specifications for fisheries (i.e., input and output controls ) and governance aspects (i.e., monitoring, and enforcement). Performance is the outcome of applying insti-

\footnotetext{
1 Countries with the longest coastlines: 1. Canada, 2. Norway, 3. Indonesia, 4. Russia, 5. the Philippines, 6. Japan, 7. Australia, 8. the United States, 9. Antarctica, 10. New Zealand, 11. China, 12. Greece, 13. the United Kingdom, 14. Mexico (World Atlas, 2018).
} 
tutions (structure component) to specific contexts (resource types). As mentioned above, fisheries sustainability is the performance investigated in this research. In addition to the analysis of state intervention, the elements of the SSP approach allow to understand the realities in which private and social efforts take place in the context of natural resources that are under public trust according to national legal frameworks and the UNCLOS.

The three selected theories for this research are complementary. The interactive governance provides the understanding of the shadow of hierarchy in terms of state influence on actors' interactions in different governance modes (i.e., hierarchical, co-governance, self-governance), orders (i.e., day to day operations, institution making, objectives definition) and scales (i.e., local, national, global). Social practices theory, move beyond actors' interactions, to analyse the shadow of hierarchy in the definition of the general patterns of fishing, specifically through the regulations of the three elements of social practices: meanings, competences, and materials. The analysis of these three elements shows in greater detail how the state defines institutions and objectives (second and third orders of governance in interactive governance, respectively) for specific fisheries to indirectly influence the actions of the collective, even in non-hierarchical forms of governance. Finally, the institutional impact theory, applies an institutional perspective to investigate how the state indirectly influences the outcomes (i.e., fisheries sustainability) of fisheries governance. This theory adds two layers of analysis to the study: i) the analysis of institutions (i.e., state regulations and complementary customary rules developed by non-state actors) for different types of resources (i.e., sedentary, mobile within the EEZ, straddling, and highly migratory stocks) and ii) the corresponding performance (i.e., fisheries sustainability). The application of the three theories provided different perspectives, which expanded the understanding of the coastal state shadow in the marine fisheries governance.

\subsection{Mexican Fisheries as the Case Study}

This research applies a case study approach to investigate the shadow of hierarchy in marine fisheries governance. Case studies are extensively used for the analysis of actors and institutions within different governance modes to understand fisheries and other common-pool resources (CPR) governance (Cox, et al., 2016; Poteete, et al., 2010). This research uses particularly the case of Mexican fisheries, to understand and exemplify how the coastal state performs, in the shadow of hierarchy, three meta-governance functions within its jurisdiction (i.e., territorial waters, EEZ, and national fleets). 
The Mexican fisheries setting allows the investigation of meta-governance functions in a context of coexisting governance modes established for different fish resource types (Bennett, 2017; Espinosa-Romero et al., 2014, 2017) where the state plays a (central) position (Zepeda-Domínguez et al., 2019; Zetina-Rejón et al., 2020), through changes in governance and political regimes over time (e.g., Alcalá-Moya, 2003; Espinoza-Tenorio, et al., 2011).

In 1982, Mexico as other coastal states endorsed the UNCLOS to declare marine fish resources within the EEZ under state jurisdiction for their sustainable and equitable use. However, already since 1917 the Mexican Constitution of the Political States of Mexico (Mexican Constitution) (DOF, 1917) had recognized state jurisdiction over marine fish resources within territorial waters, and given the state a central role in this policy domain. Accordingly, Article 27 of the Mexican Constitution gives the power to the Executive to transfer the use (not the property) of these resources to citizens and corporations who are able to extract them in accordance with the fisheries laws. Moreover, the participation of non-state actors has been acknowledged since 1925, when the first fisheries law was promulgated. To date, the Congress has enacted eight fisheries that establish the overarching goals for fisheries governance as well as the distribution of competences among state and non-state actors. Not only the Congress, but also the President has the power to influence fisheries governance through the law implementation and the establishment of specific regulations (Alcalá-Moya, 2003; Espinoza-Tenorio et al., 2011). Therefore, the analysis of the legal framework and implementing fisheries regulations allows the understanding of the state indirect influence in marine fisheries through the creation of alternative and coexisting governance modes, the steering the patterns of fishing practices, and the creation of institutional settings for ensuring fisheries sustainability.

Fisheries are important for the Mexican state due to their social and economic relevance. Mexico has one of the longest coastlines in the world $(11,122 \mathrm{~km})^{2}$ and within the 200 nautical miles $(\mathrm{nm})$ of EEZ ${ }^{3}$ it has valuable marine fisheries (e.g., abalone, lobster, shrimp, sea cucumber, octopus, snappers). Approximately $80 \%$ of the total production is for domestic consumption and the remaining catch is exported mainly to the United States, Spain, Vietnam, and Japan (CONAPESCA, 2017). In the 1980s, Mexico became one of the 20 most important fish producers of the world (Vázquez-

\footnotetext{
${ }^{2}$ Countries with the longest coastlines: 1. Canada, 2. Norway, 3. Indonesia, 4. Russia, 5. the Philippines, 6. Japan, 7. Australia, 8. the United States, 9. Antarctica, 10. New Zealand, 11. China, 12. Greece, 13. the United Kingdom, 14. Mexico (World Atlas, 2018).

3 The EEZ was first enacted in 1976 through the Regulatory Law for Paragraph 8 of Constitutional Article 27 (DOF, 1976), and later in 1986 through the Federal Law of the Sea (DOF, 1986).
} 
León, 1998) and currently is the 13th-largest producer globally and the third in Latin America (FAO, 2020). ${ }^{4}$ Fisheries play a pivotal role for the Mexican population, particularly for coastal communities economies (OECD, 2006), where they represent an important source of income, employment, and food. Official registers account for approximately 300,000 fishers (Botello et al., 2010) and 10,000 communities with fewer than 15,000 inhabitants (INEGI, 2010) where fisheries represent the main if not the only economic activity.

\subsection{Methods and Data Sources}

This research applies two qualitative methods to address the research questions: systematic document analysis (Bowen, 2009; O'Leary, 2014) and thematic analysis (Matthews \& Ross, 2010). These methods allow for the understanding of social realities and phenomena through documents, and were applied to the literature review and empirical research to understand the meta-governance functions of the state in marine fisheries governance.

Coding techniques (deductive and inductive) (Matthews \& Ross, 2010) were used to analyse different data sources (Matthews \& Ross, 2010). The data sources collected for this research are: i) scientific publications, ii) legal framework of Mexican fisheries, iii) the documents for the enactment of Mexican fisheries laws, iv) fisheries regulations, and v) fisheries assessments.

Scientific publications include peer review publications and specialized books of fisheries governance and CPR governance, which were analysed in the literature review.

The legal framework, documents for the enactment of fisheries laws, and fisheries regulations were collected from the Mexican Congress archives and the official gazette (https://www.dof.gob.mx) for the period 1917-2019. The starting year relates to the year in which marine fish resources came under state jurisdiction according to the Mexican Constitution. The legal framework includes: the Mexican Constitution, three maritime laws, and eight fisheries laws with their corresponding amendments. The documents for the enactment of fisheries laws include: bills, resolutions by the Congress commissions, and legislators' discourses during Congress plenary sessions. Fisheries regulations include: official agreements for specific fisheries and the six editions of National Fisheries Charter (NFC) published by the state.

\footnotetext{
4 Marine capture production (2014-2016): 1. China, 2. Peru, 3. Indonesia, 4. the Russian Federation, 5. the United States of America, 6. India, 7. Vietnam, 8. Japan, 9. Norway, 10. Chile, 11. the Philippines, 12. Thailand, 13. Mexico (FAO, 2020).
} 
Fisheries assessments were collected for the period 2000-2019. The starting year refers to the time when the NFC was published for first time. This document has the inventory of commercial species and information related to the stock distribution, status, and management. Fisheries assessments include: information of the NFC and third-party assessments conducted for certified fisheries and Fisheries Improvement Projects (FIPs), using the international standard for sustainable fishing of the Marine Stewardship Council (MSC).

\subsection{Internal Validity}

The use of different sources of data and the consultation with experts incorporated into this research, address its internal validity and reduce the ambiguity of results. The documents from the legislative process for the enactment of the laws (i.e., initiatives, resolutions, and debates of legislators), as well as historical documents of Mexican fisheries policies, provided contextual information for a better understanding of the legal framework and fisheries regulations (Chapter 3 and 4). For the analysis of the institutions and performance of Mexican fisheries (Chapter 5), the third-party assessments, the NFC, and fisheries regulations enabled a holistic understanding of the institutional setting and performance of Mexican fisheries.

Preliminary results of this research were presented to the Commission of Agriculture, Livestock, Fisheries, and Rural Development of the Senate, ${ }^{5}$ and to one expert in Mexican fisheries laws and governance, ${ }^{6}$ to ensure an adequate interpretation of the legal framework and fisheries regulations. In addition, the results of all chapters were presented to Comunidad y Biodiversidad, A. C. ${ }^{7}$ to receive feedback on the analysis of the legal framework and fisheries performance assessments.

\subsection{Boundaries of this Research}

This research analyses three meta-governance functions with a focus on one single state as a coastal state. The case study of Mexican fisheries exemplifies the shadow of hierarchy within the coastal state jurisdiction context. Therefore, this study focuses on the analysis of the domestic legal framework and fisheries regulations applicable to territorial waters, EEZ, and fleets with the Mexican flag. The international dimension (i.e., binding and non-binding international agreements) is present and incorporated as follows. Chapter 4 analyses fishing as a social practice. As part of

\footnotetext{
${ }^{5}$ Presentation on $12^{\text {th }}$ August 2019.

6 Prof. German Ponce. Centro Interdisciplinario de Ciencias Marinas del Instituto Politécnico Nacional. Meeting on $3^{\text {rd }}$ October ,2019.

7 Presentation on $12^{\text {th }}$ June 2020.
} 
this analysis, the meanings (a key element of social practices) of fishing are investigated through the review of the legislative process (i.e., bills, technical resolutions, legislative debates) for the enactment of fisheries laws. Therefore, the analysis mentions the binding (i.e., UNCLOS) and non-binding (i.e., the Code of Conduct for Responsible Fisheries) agreements that the state refers to, during the legislative process, for shaping the meanings of fishing and state intervention in governance. In addition, Chapter 5 considers the institutional setting for different resource types, including straddling and highly migratory fish stocks. Therefore, the analysis conducted for this chapter includes domestic regulations that incorporate the international agreements that are applicable to the Mexican fleet extracting these resources. For example, in the case of the tuna fishery, domestic regulations incorporate the agreements (e.g., the bycatch limits, observer programs, and vessel storage limits) established by the Inter American Tropical Tuna Commission (IATTC) - Regional Fisheries Management Organization (RFMO) for this fishery.

Although this research has an international dimension as explained above, it does not focus its analysis on how the international framework limits the shadow of hierarchy of the coastal state or how the shadow of hierarchy is performed at supranational scale. Therefore, it does not analyse the entire international framework Mexico is part of and the influence of the Mexican state on international binding agreements (e.g., UNCLOS, Agreement to Promote Compliance with International Conservation and Management Measures by Fishing Vessels on the High Seas (The Compliance Agreement)) and non-binding ones (e.g., Code of Conduct for Responsible Fisheries). These are important topics that require further studies.

The analysis of institutional performance for different marine resource types includes the third-party assessments that use the MSC standard. It does not include the analysis of assessments that use other international standards such as the Monterey Bay Aquarium and Fairtrade, which are also applied to Mexican fisheries. These standards were not considered in this research, because they are not yet applied to all of the resource types analysed in this study.

Finally, this research investigates the shadow of hierarchy through the exercise of three meta-governance functions of the state. However, additional meta-governance functions show the shadow of hierarchy, such as ensuring democracy, accountability, and legitimacy (Bell \& Hindmoor, 2009, p. 47). These functions were not considered in this study and are worth exploring in further research. 


\subsection{Research Outline}

The book is composed by six chapters. Chapter 1 introduces the research topic, research questions, analytical approach, the case study, qualitative methods and data sources, as well as the internal validity and the boundaries of this research.

Chapter 2 presents the literature review for the understanding of governance modes and the meta-governance power of the state in marine fisheries. This literature review is accompanied with empirical research, using Mexican fisheries as the case study, to illustrate how the state performs three meta-governance functions (Chapter 3, 4, and 5), nested in the shadow of hierarchy. Chapter 3 investigates how the state influences the creation of coexisting governance modes. Chapter 4 investigates how the state steers and defines the general patterns of fishing. Chapter 5 analyses how the state develops institutional settings for fisheries sustainability performance.

Chapter 6 presents a synthesis of findings from the literature review and the three empirical chapters. It also reflects on the complementarity of theoretical approaches, the academic contribution and policy relevance, as well as elements for further research. Finally, it presents the concluding remarks of this study. 


\section{Chapter 2. The State in Marine Fisheries Governance}

\subsection{Introduction}

This chapter provides a literature review of the state and its indirect influence in marine fisheries governance. In most societies, the state remains the most important social, economic, and political force (Pierson, 2004). Weber (1978, pp. 54-56) described the ideal state in the twenty first century (modern state) as a political organization with continuous operations. As such, the state has a monopoly on the use of physical force to enforce its order. It is through its power to legislate that the state controls the administrative and legal order and organizes its administrative staff in a hierarchical manner, by granting rights and duties (Hill, 2009; Pierson, 2004; Weber, 1978).

The current understanding of what the state is, does, and reaches changes over time (Huber et al., 2015; Pierson, 2004), primarily because the state is immersed in new modes of governance (e.g., co-governance, self-governance), in which non-state actors (i.e., markets and civil society) interact in different forms to fill and replace state functions (Risse, 2015). This creates fuzzy boundaries between the intervention of the state, markets, and civil society (Rhodes, 2012). The emergence of governance modes partially occurred because states could no longer address complex societal problems alone (Kooiman, 1993; Osborne, 2010). Moreover, in 'areas of limited statehood', where the state is weak or absent, governance might be the only way of providing collective goods (Risse, 2015).

Traditionally, the assumptions underlying alternative governance modes are: i) their emergence is not necessarily led by the state; ii) they limit state intervention; and iii) they are more effective than state hierarchies in particular contexts. Hierarchies, however, are still alive and important in diverse situations, especially for dealing with conflicts and accountability issues (Bell \& Hindmoor, 2009). Moreover, the state often performs non-traditional hierarchical forms to indirectly influence governance, known as the shadow of hierarchy (Scharpf, 1997, pp. 200-202). The state thus steers non-hierarchical governance modes, for example by shaping the boundaries and rebalancing power of public, private, and social actors' intervention; ensuring the compatibility of governance modes; and assuming political responsibility in the event of governance failure (Jessop, 1997, p. 575). These indirect forms of influencing governance are generally sustained by tangible and intangible power resources, such as legal rules, bureaucracy, and money, as well as information and 
expertise (Barnett \& Finnemore, 1999). The state, thus, uses its superior hierarchy and different relevant power resources, that have inbuilt different mechanisms and associated policy tools, to indirectly influence the self-organization and behaviour of actors.

To facilitate the understanding of the state presence and indirect influence in fisheries governance, this literature review particularly traces the governing functions the state performs, or is called to perform, within different governance modes (i.e., hierarchies, co-governance, self-governance). This in order to identify those functions that are performed in the shadow of hierarchy, and analyse how limited or expanded the state intervention is. In addition, this literature review analyses the determinants influencing the emergence and the reported performance of such governance modes in order to understand the context in which state intervention takes place.

Marine fisheries represent an ideal setting to conduct this analysis, because whilst most marine fish resources are under state jurisdiction (UN, 1982), governance modes continue emerging, evolving, and co-existing (e.g., Chuenpagdee \& Jentoft, 2018). Thus, the state changes, adapts, and interacts in a diversified manner with different actors to cope with overexploitation as well as with the high exclusion ${ }^{8}$ (Schmid, 1987), information (Hilborn \& Peterman, 1996), and enforcement costs (Anderson \& Seijo, 2010) associated with marine fisheries. This analysis is particularly relevant for marine policy to understand state contributions, in indirect forms and under different governance modes, to sustain fisheries and ensure food security, income, and employment for many people, especially for coastal communities in developing countries. Particularly, in the face of increasing overexploitation $-10 \%$ of fish stocks were reported as overfished in 1974 and 34\% in 2017 (FAO, 2020).

In 1968, Garret Hardin, concerned about overexploitation of natural common-pool resources (CPR) (i.e., fisheries, forests, irrigation systems), called states to action to avert the tragedy of the commons - a situation in which users of these resources, motivated by their self-interest, extract resources until they collapse, even when the situation is not beneficial for them as individuals and for society as a whole (Hardin,

\footnotetext{
8 The high cost of excluding unauthorized fishers from exploiting the resource. It means that the use of an existing fish stock is difficult to limit only to those who have the right to fish (Schmid, 1987).
} 
1968). ${ }^{9}$ Hardin proposed two solutions to the tragedy of the commons, ${ }^{10}$ namely state regulation or privatization. ${ }^{11}$ These solutions supported previous theories on overexploitation and privatization already investigated by fisheries economists (Gordon, 1954; Scott, 1955). According to Poteete et al. (2010), these solutions significantly influenced the way CPR were governed in the following decades, bringing states and markets to the centre. In the 1990s, Elinor Ostrom and scholars challenged Hardin's solutions and tragedy of the commons. They empirically demonstrated that users of CPR self-organize to craft and enforce institutions to overcome the overexploitation, often with little or no participation of the state or the market (Ostrom, 1990). Moreover, studies of co-governance (e.g., Chuenpagdee \& Jentoft, 2018; Jentoft \& Chuenpagdee, 2015c; Kooiman et al., 2005) and co-management (e.g., Berkes \& Nayak, 2018; Jentoft, 1989; Pomeroy \& Berkes, 1997; Symes, 1997) show that not only the state, the market, or society on their own, but constellations of these actors govern CPR to avert the tragedy of commons. Under the assumption of coexisting governance modes for fisheries, this review of existing literature investigates state presence and indirect influence in fisheries governance.

Section 2.2 explains the analytical framework used to address this research gap. Section 2.3 describes the methods and publications included in this literature review. Section 2.4 presents the results and Section 2.5 discusses the results in the context of the analytical framework and the research questions, and introduces further research. Finally, Section 2.6 concludes with the main remarks of this chapter.

\subsection{Analytical Approach}

This research uses the three ideal governance modes suggested by Kooiman (2003) for the interactive governance theory to investigate the presence and indirect influence of the state in fisheries governance. The application of these governance modes helps frame and explain the interaction of actors to address problems and opportunities related to fisheries, in different contexts and geographies (e.g., Jentoft \& Chuenpagdee, 2015c; Kooiman et al., 2005; Bavinck et al., 2005a). The modes

\footnotetext{
9 When Hardin postulated this position, he referred to an open-access situation, in which resources are used by anyone who wants to, and are not controlled or managed at all (Bromley, 1991).

${ }^{10}$ The assumptions underlying Hardin's propositions were that states had sufficient information and appropriate means to induce cooperative behaviour (for the state regulation solution) (Ostrom, 1990) or that the costs of excluding individuals without rights for using the common-pool resources are less than the benefits of privatization (for the privatization solution) (Grafton, 2000).

${ }^{11}$ In her work Beyond Markets and States, Elinor Ostrom points out the dichotomous way of seeing the world at that time, in which states generated public goods and markets private goods, and in which existing institutional arrangements effectively crafted and enforced by society to govern common-pool resources (i.e., self-organization) were not accounted for (Ostrom, 2010).
} 
are hierarchical, co-governance, and self-governance. In their ideal form, they have unique features, strengths, and weaknesses. In practice, they exist in hybrid (combined) forms and change in response to political, economic, or ecological aspects internal or external to the fishing industry (Chuenpagdee \& Jentoft, 2018; Kooiman et al., 2008). These modes often emerge to cope with the intrinsic characteristics of fisheries mentioned before - the high exclusion ${ }^{12}$ (Schmid, 1987), information (Hilborn \& Peterman, 1996), and enforcement costs (Anderson \& Seijo, 2010), as well as with the willing or unintentional free-rider behaviour associated with different degrees of resource mobility (Anderson \& Seijo, 2010; Seijo et al., 1998). These governance modes support related theories on fisheries and CPR governance (i.e., fisheries co-management and CPR self-organization). This chapter conceptualizes governance modes as follows, and their characteristics are summarized in Table 2-1.

Hierarchical governance. According to Kooiman and Bavinck (2005), this is the most classical and predominant mode of governance. It is typified by a top-down style and vertical interventions (Kooiman, et al., 2008; Kooiman, 2003). The state is usually, but not necessarily, the actor that steers this governance mode (Chuenpagdee \& Jentoft, 2018). It is also common in the market sector (Kooiman \& Chuenpagdee, 2005). Institutions are formal (Mahon et al., 2005) and expressed in policies and laws (Kooiman \& Bavinck, 2005). This mode often relies on technical knowledge and science (Pascual-Fernández et al., 2005), particularly in natural sciences and economic disciplines (Chuenpagdee \& Jentoft, 2015; Sowman, 2015).

Co-governance. In its ideal form, no single actor is in control (Kooiman \& Bavinck, 2005). Governing takes place within a partnership between the state and non-state actors (Chuenpagdee \& Jentoft, 2018; Kooiman et al., 2008), including fishers (Jentoft, 1989), researchers, communities (Jentoft et al., 1998), and representatives of the public interest (Sen \& Nielsen, 1996), such as those representing fish populations (Wilson et al., 2004). Power and responsibility sharing as well as joint decision-making occur through formal and informal institutional arrangements (Berkes, 2009; Pomeroy \& Berkes, 1997; Symes, 1997; Viet-Thang, 2018). Interactions are horizontal (Kooiman, 2003; Kooiman \& Bavinck, 2005) and vertical (Berkes, 2009). Diverse sources of knowledge are recognized (Berkes, 2009), including social and natural sciences, as well as local and indigenous knowledge (Chuenpagdee et al., 2005; Hurley \& Manel, 2015). Co-management is a recognized and influential form of co-governance (Kooiman \& Bavinck, 2005) and thus is included in this analysis.

\footnotetext{
${ }^{12}$ The high cost of excluding unauthorized fishers from exploiting the resource. It means that the use of an existing fish stock is difficult to limit only to those who have the right to fish (Schmid, 1987, 2004).
} 
Self-governance. Actors govern and take care of themselves. They do not depend on external interventions, including those of the state (Kooiman, 2003). Interactions and institutions are informal and fluid, nested within families, groups, organizations, and society sectors (Kooiman \& Bavinck, 2005; Mahon et al., 2005). Self-governance relies mainly on local knowledge. Social norms and reciprocity ensure individuals behave in the interest of collective goals (Ostrom, 1990). According to Ostrom et al. (2006), in successful self-governance, users cope with two social dilemmas (appropriation and provision $)^{13}$ to avert the tragedy of the commons. CPR self-organization is a recognized form of self-governance (Kooiman \& Bavinck, 2005) and therefore included in this analysis.

Table 2-1. Conceptualization of governance modes: hierarchical, co-governance, and self-governance

\begin{tabular}{|llll|}
\hline \multicolumn{1}{|c|}{ Characteristics } & \multicolumn{1}{c|}{ Hierarchical governance } & \multicolumn{1}{c|}{ Co-governance } & Self-governance \\
\hline Institutions & $\begin{array}{l}\text { Formal, expressed in laws } \\
\text { and regulations }\end{array}$ & Formal and informal & Mainly informal \\
Interactions & Vertical, interventionist & Horizontal and vertical & Horizontal \\
Structure & Bureaucracies & Networks, partnerships & Self-governed groups \\
\hline Knowledge type & $\begin{array}{l}\text { Technical, emphasis on } \\
\text { natural sciences and } \\
\text { economics }\end{array}$ & $\begin{array}{l}\text { Technical (natural and social } \\
\text { sciences) and traditional/local } \\
\text { knowledge }\end{array}$ & Traditional/local \\
\hline
\end{tabular}

Source: Own elaboration based on interactive governance, co-management, and self-organization publications cited in this section.

According to the interactive governance theory, governance modes have three elements that contribute to the overall capacity for governance of a system: the governing system, the system to be governed, and the interactions between the two (Kooiman et al., 2008; Kooiman et al., 2005). This chapter focuses on the analysis of the governing system. Particularly, on the governing functions (e.g., regulation, enforcement, assessment) that the state performs within the three governance modes, which are sustained by power resources, such as legal rules, bureaucracy, and money, as well as information and expertise (Barnett \& Finnemore, 1999). The analysis of governing functions helped trace the shadow of hierarchy, or indirect influence of the state for the self-organization or functioning of governance modes (Scharpf, 1997, pp. 200-202).

\footnotetext{
${ }^{13}$ According to Ostrom et al. (2006), successful self-governed users cope with two social dilemmas (appropriation and provision) to avert the tragedy of the commons: the appropriation dilemma, which refers to the collective (rather than independent) action of appropriators (users) of resources to obtain higher joint benefits or reduce joint harm, and the provision dilemma, which refers to the investment of time and resources by individuals for the maintenance of the system (Ostrom et al., 2006:9-14).
} 
This study also identifies the determinants that influence the emergence of governance modes. It uses the classification of Huber et al. (2015) for determinants of state transformation to frame the analysis: international, domestic, and state-based. International determinants refer to those international interventions, impositions, threats, and pressures that can drive state or governance modes. Domestic determinants refer to domestic capacities, natural resources, or conditions in place. Statebased determinants refer to those state capacities or conditions that allow states to do, or not do, certain duties.

The reported outcomes of governance modes supported the analysis on performance. The approach suggested by Chuenpagdee et al. (2005) was used to expand the focus of performance on commercial target species and account for ecosystems (e.g., associated species and habitats), social (e.g., food security) and governance outcomes (e.g., distribution of benefits, power distribution, the protection of the vulnerable). These dimensions were identified in existing literature for the analysis of performance.

The expectations of looking at these dimensions (state governing functions, shadow of hierarchy, determinants, and reported performance) are that governance modes do not limit state intervention, but rather, that the state adapts to these modes, often supports their emergence, and remains as a key point of reference in fisheries governance. In addition, by acknowledging that governance modes are suitable for different contexts and fisheries, the expectation is that the state will support the coexistence of modes.

\subsection{Methods and Data Sources}

This systematic document review (Bowen, 2009; O'Leary, 2014) includes the analysis of 74 theory-developing and theory-testing scientific publications (peer-reviewed articles and books) to identify the governing functions of the state, determinants, and performance of governance modes, based on empirical case studies. Those publications that included only one case study were not incorporated in this review.

The publications include those of interactive governance published in the MARE series of Springer, because they analyse the institutional settings and actors' interactions within the three governance modes (i.e., Chuenpagdee \& Jentoft, 2018; Jentoft \& Chuenpagdee, 2015c; Kooiman et al., 2005). Publications also include those of fisheries governance (e.g., Caddy \& Seijo, 2005), fisheries co-management (e.g., Chuenpagdee \& Jentoft, 2007; Pomeroy \& Berkes, 1997; Sen \& Nielsen, 1996; Viet-Thang, 
2018; Wilson et al., 2006), and CPR governance (Anthony \& Campbell, 2011; Fleischman et al., 2014; Grafton, 2000; Mansbridge, 2014) published in the Web of Science Core Collection, as well as specialized books (e.g., Garcia et al., 2014c; Ostrom, 1990; Ostrom et al., 2006) that include information on state governing functions, determinants, and performance of governance modes. Publications include artisanal and industrial fisheries on subnational and supranational scales in different geographies (north and south). International agreements - binding and non-binding - were found to be determinants of governance modes in the literature review. Therefore, they were reviewed to clarify their purpose in the context of fisheries governance.

This systematic document review includes the themes and subthemes presented in Table 2-2. Themes and subthemes are based on the analytical framework described in the Section 2.2 for the analysis of state governing functions, determinants, and reported performance for each governance mode. The software AtlasTi was used to conduct the data collection and analysis.

Table 2-2. Themes and sub-themes used for the codification of scientific publications

\begin{tabular}{|ll|}
\hline \multicolumn{1}{|c|}{ Governance modes (themes) } & \multicolumn{1}{c|}{ Sub-themes } \\
\hline $\begin{array}{l}\text { Hierarchical } \\
\text { Co-governance }\end{array}$ Self-governance & $\begin{array}{l}\text { Governing functions of the state. Those functions conducted by the state to } \\
\text { govern fisheries. From these functions, those that reflected the shadow of } \\
\text { hierarchy (indirect influence of the state) were identified. }\end{array}$ \\
& $\begin{array}{l}\text { International determinants. Interventions, impositions, threats, and pressures } \\
\text { that can drive state or governance modes } \\
\text { Domestic determinants. Domestic capacities, natural resources, or conditions } \\
\text { in place } \\
\text { State-based determinants. Capacities or conditions that allow states to do or } \\
\text { not do certain duties } \\
\text { Reported performance. Information on the sustainability including } \\
\text { commercial species, ecosystems (e.g., associated species and habitats), social } \\
\text { (e.g., food security), and governance outcomes (e.g., distribution of benefits, } \\
\text { power distribution, the protection of the vulnerable) }\end{array}$ \\
\hline
\end{tabular}

\subsection{Results}

The literature review shows that the state is present and adapts to the three fisheries governance modes (i.e., hierarchies, co-governance, and self-governance). It is through the exercising of governing functions that the state defines and expands its shadow of hierarchy. Most publications investigate governance modes as if they are independent. However, it is when looking at the three governance modes as part of one system that the meta-governance power of the state is more evident. For example, the state has the faculty to retain power or devolve it to public, private, and social actors involved in fisheries governance. Thus, the state has the autonomy to decide when to command and control the governing of fisheries and when to share 
or devolve power to users. Moreover, the state provides different types of resources (e.g., information, financial resources, enforcement and surveillance) to indirectly support the functioning and self-organization of coexisting governance modes (see Viet-Thang, 2018). Furthermore, the analysis of determinants and performance also shows the presence and indirect influence of the state in the three governance modes.

The following section presents the state governing functions, determinants, and performance for each governance mode to illustrate the state presence, adaptation, and shadow of hierarchy in fisheries governance.

\subsubsection{Hierarchical Governance}

\section{Governing functions of the state}

The literature agrees that for marine fisheries functioning under this governance mode, regulation and control are the most important tasks that the state undertakes. The state regulates, through policies, the allocation of fishing rights, and fisheries regulations (Jentoft et al., 2005; Kooiman \& Bavinck, 2005; Kooiman \& Chuenpagdee, 2005). The latter are often based on input and output controls (Jentoft, 1989) - input controls limit access to fishing effort ${ }^{14}$ whilst output controls limit extraction. ${ }^{15}$ States have also the means of force to sanction the lack of compliance of rules (Jentoft, 1989). Given the negative impacts of subsidies (Caddy \& Seijo, 2005; Schuhbauer et al., 2017; Seijo, 2005), since World War II the state has been required to regulate and eliminate harmful subsidies that contribute to overcapacity and overexploitation (Chuenpagdee \& Jentoft, 2018; Garcia et al., 2014b; Schuhbauer et al., 2017). The literature suggests that the state needs to ensure the resources, infrastructure, and procedures to address the issues and challenges of marine fisheries, as well as to assess institutions' effectiveness (Chuenpagdee \& Jentoft, 2018) and their impact in different areas (Jentoft et al., 2005). For highly migratory species that move beyond the exclusive economic zones (EEZ), negotiations on input and output controls occur among coastal states extracting those species within the regional fisheries management organizations (RFMOs) (Barkin et al., 2018; Garcia et al., 2014a) . The state intervenes in the design of international fisheries policy (and the adoption into national policy) to address issues of global concern (e.g., overexploitation) through forums such as the Committee on Fisheries (COFI) of the Food and Agriculture Organization (FAO) of the United Nations (UN) (Garcia et al., 2014a).

\footnotetext{
${ }^{14}$ Regulate the number of users, vessel requirements, gear types, seasons, and access to fishing grounds (Jentoft, 1989).

${ }^{15}$ Regulate the catch by determining a total allowable catch and allocating the catch through individual quotas (ITQ) (Jentoft, 1989).
} 
The hierarchical mode of governance shows the regulatory power of the state, as well as other resources (e.g., subsidies, infrastructure) the state has to bind and support the functioning of actors in other forms of governance.

\section{Determinants}

International. The nature of binding international agreements (Bavinck et al., 2005b) influences what the state must comply with for fisheries governance (Jentoft et al., 2005). The most influential international agreement for hierarchical governance is the United Nations Convention on the Law of the Sea (UNCLOS), endorsed by coastal states in 1982 (Bavinck \& Chuenpagdee, 2005). The UNCLOS provides a legal order for the seas and for living marine resources, including fisheries, through the increasing jurisdiction of the coastal state with the aim of promoting equitable and efficient use of resources, as well as the conservation and protection of the marine environment. Other examples of binding agreements that are mentioned in the literature include the United Nations Agreement for the Implementation of the Provisions of the United Nations Convention on the Law of the Sea of 10 December 1982 relating to the Conservation and Management of Straddling Fish Stocks and Highly Migratory Fish Stocks (UN Fish Stocks Agreement), the Agreement on Subsidies and Countervailing Measures (SCM Agreement), the Doha Trade Round of Negotiations on Rules (for regulating fisheries subsidies), the Convention on Biological Diversity (for sustainable development), and the Convention on International Trade in Endangered Species of Wild Fauna and Flora (CITES) (for biodiversity protection) (Bavinck and Chuenpagdee, 2005; Garcia et al., 2014a, 2014b; Suárez de Vivero et al., 2005). International organizations such as the UN and the World Bank have supported the state in the development of financial and policy capacities to govern fisheries (Suárez de Vivero et al., 2005).

Domestic. Although evidence of overfishing has been visible since the 1940s (Garcia et al., 2014a) and raised by scientists since the 1950s (Gordon, 1954; Hardin, 1968; Scott, 1955), fisheries were at that time in a developing phase. Thus, the priority of the state was to develop new technologies to find fishing grounds and resources (Jentoft et al., 2005) within territorial waters. In the late 1970 and early 1980s, countries started to unilaterally declare EEZs, and when UNCLOS was endorsed, coastal states took a more prominent role in the development and regulation of national fleets within the EEZ, especially in developing countries (Garcia et al., 2014a). 
State-based. State capacity in terms of information, expertise, financial resources (Moran \& Wright, 1991), staff (Kooiman \& Bavinck, 2005), legislative power as well as the relevance of fisheries within the public administration (Jentoft et al., 2005) influences the performance of hierarchical governing functions. Kooiman \& Bavinck (2005) argue that states in Europe and North America are more likely to have this capacity than states from the Global South. The latter often reports limited resources, a lack or overload of authority, and doses of corruption, which often limits the implementation of an effective hierarchical governance.

\section{Performance}

The literature agrees that state intervention is relevant in fisheries. However, it is also claimed that the hierarchical state intervention has not reverted fishery crises (Chuenpagdee \& Jentoft, 2018; Jentoft, 2005b; Jentoft et al., 1998) and the state carries most of the responsibility for fisheries failures on its shoulders (Symes, 1997). According to the literature, the state in the hierarchical mode is relevant for conflict resolution (e.g., Scholtens, 2016), the regulation of fisheries, particularly markets (Chuenpagdee \& Jentoft, 2018) and industrial fleets (i.e., straddling populations and the high seas) (Johnson et al., 2005), the elimination of harmful subsidies (Chuenpagdee \& J entoft, 2018; Schuhbauer et al., 2017), and the empowerment of small-scale fishers (Chuenpagdee \& Jentoft, 2018). However, as a promoter of fisheries development (Jentoft et al., 2005), the state often supersedes pre-existing rights (Grafton, 2000), disempowers local communities, replaces local knowledge and long-standing institutions (Pascual-Fernández et al., 2005a; Suárez de Vivero et al., 2005), and sets short-term rather than long-term goals (Barkin et al., 2018).

The analysis of the literature also suggests that the state often intensifies overexploitation and power imbalances through the allocation of fishing rights and regulation of input and output controls. The allocation of fishing rights generally benefits private interests, especially those of industrial and highly valuable fisheries (e.g., Barkin et al., 2018; Mahon et al., 2005; Suárez de Vivero et al., 2005). Input controls proved to be insufficient and frequently incentivized fishers to increase fishing power, causing overcapacity (Townsend \& Shotton, 2008), whilst output controls (e.g., individual transferable quotas (ITQs)) brought new challenges such as concentration and displacement, derived from rights allocations (Pinkerton and Davis, 2015; Young et al., 2018). 
Moreover, recent studies about state allocation of marine subsidies show a major imbalance in distribution. Small-scale fisheries, for instance, receive about $16 \%$ of the total amount of subsidies for fisheries (USD35 billion), which means that industrial fisheries receive four times the amount received by small-scale fishers. In addition, these studies show the predominance of capacity-enhancing subsidies, ${ }^{16}$ which often exacerbate fishing overcapacity. From the total amount of subsidies reported in 2019, 63\% (USD22.2 billion) correspond to capacity-enhancing subsidies, and the largest percentage (22\%) corresponds to fuel subsidies (including fuel tax exemption). In addition, almost $90 \%$ of capacity-enhancing subsidies go to industrial fisheries, increasing their capacity and competitive advantage over small-scale fisheries (Schuhbauer et al., 2017; Sumaila et al., 2019; Sumaila \& Schuhbauer, 2018).

Assessments of highly migratory fish stocks, which are governed through the international arrangements negotiated among the states extracting these resources, within the corresponding RFMOs, show that in 2010, 66\% (32 out of 48) of the assessed stocks were depleted ${ }^{17}$ or overfished ${ }^{18}$ (Cullis-Suzuki \& Pauly, 2010). In 2016, although this percentage decreased to $52 \%$, depleted and overfished stocks continued (Cullis-Suzuki \& Pauly, 2016). The assessments of RFMOs show that these organizations are failing at enforcing regulations whilst performing effectively at developing and integrating science into decision-making (Cullis-Suzuki \& Pauly, 2010).

The literature suggests that the state often lacks sufficient resources in terms of staff, budget, information, and expertise. This lack of resources hinders the capacity of the state to operate hierarchical mechanisms in a way that induces cooperative behaviour (Ostrom, 1990). According to Jentoft (1989), bureaucrats seem to have more mandates than resources to operate; this represents a challenge for addressing the local and seasonal issues of fisheries in different regions. As for other CPRs, in developing countries officers enforcing laws and regulations are often hired with such low salaries that accepting bribes becomes a common practice for complementing their income (Ostrom, 1990; Viet-Thang, 2018). In addition, the state is often distant from the daily problems of coastal fishers, which brings issues of compliance, because fishers perceive their interactions with the state as external and intermittent (Jentoft et al., 2005) and often do not accept the command and control forms the state often brings. This lack of acceptance increases when fishers are told to do something that does not make sense in

\footnotetext{
16 Boat construction, port construction, fisheries development, marketing infrastructure, buyback programmes, fisher assistance programmes, and tax exemptions, assigned to the country's fishing fleet (Sumaila, Skerritt, et al., 2019).

${ }^{17}$ When biomass is below the biomass at maximum sustainable yield (MSY).

${ }_{18}$ When fishing mortality is greater than fishing mortality at MSY.
} 
terms of the way they visualize their problems, know their industry, and understand nature (Jentoft et al., 1998). The relationship between the state and small-scale fishers is often seen as assistentialism; where the state provides resources (e.g., infrastructure) and opportunities (e.g., jobs, protection), and the fishers benefit in exchange for votes or other forms of loyalty (Cavaleri-Gerhardinger et al., 2015).

Hierarchical governance thus requires state capacity, resources, and a focus on the public interest (i.e., protecting the vulnerable, protecting resources and ecosystems) (Suárez de Vivero et al., 2005) to be effective. In the absence of these elements, its intervention results is insufficient to address the issues marine fisheries face, such as overexploitation, power imbalances, and the high costs associated with marine fish resources (e.g., exclusion, information, and enforcement costs).

\subsubsection{Co-governance}

\section{Governing functions of the state}

Co-governance in its pure form implies that no single actor is in control. However, scholars of the co-management theory (e.g., Pomeroy \& Berkes, 1997; Viet-Thang, 2018) recognize the superior hierarchy of the state in this governance mode and the variation of partnership arrangements, power sharing, and integration of local and centralized management systems (Pomeroy \& Berkes, 1997). In this governance mode, the state shares the steering, regulating, and enforcing functions with non-state actors (see Berkes, 2009; Jentoft, 1989; Townsend \& Shotton, 2008) often through formal institutional arrangements (Berkes, 2002; Pinkerton, 1989) embedded in social contracts (Jentoft, 2004) and management plans (see Townsend \& Shotton, 2008). The state builds partnerships (Berkes, 2009) and networks (Symes, 1997) to raise resources (Viet-Thang, 2018) and increase legitimacy and effectiveness (Jentoft et al., 2005). The state provides expertise (e.g., leadership and technical expertise) (Viet-Thang, 2018) but also acknowledges the capacity and expertise of others, by, for example, introducing different information sources such as traditional and local knowledge (Berkes, 2009), into decision-making (Grafton, 2000; Viet-Thang, 2018). The state ensures that management rules fit with local situations and resource boundaries (Pomeroy \& Berkes, 1997; Viet-Thang, 2018), and addresses problems and issues beyond the scope of local arrangements (Pomeroy \& Berkes, 1997).

In addition, the state influences the formation of fisheries associations and can bridge communication among fishing associations, communities, and other levels of governance (Berkes, 2002; Pinkerton, 1989). The state can support the solving of 
abuses of local authority and other conflicts by providing appealing mechanisms and regulatory standards (Pomeroy \& Berkes, 1997; Viet-Thang, 2018). The state can also support the creation of favourable environments for participation, trust building, and problem solving (Berkes, 2009) as well as participate in spaces created by others (Chuenpagdee \& Jentoft, 2007). The state helps with the monitoring and enforcement of rules (Pomeroy \& Berkes, 1997; Viet-Thang, 2018) and can set economies of scale and scope for these services (Grafton, 2000). The mechanisms the state generally uses for operationalizing co-governance include decentralization (Pomeroy \& Berkes, 1997; Symes, 1997), organization of fishers (Pomeroy \& Berkes, 1997), Territorial Use Rights in Fisheries ${ }^{19}$ (TURFs) (Afflerbach et al., 2014; Villanueva-Poot et al., 2017), ITQs (Chuenpagdee \& Jentoft, 2015; Jentoft \& Chuenpagdee, 2015a), individual transferable grounds (see Caddy \& Seijo, 2005; Seijo, 2005), and marine protected areas (MPAs) (Chuenpagdee \& Jentoft, 2018).

In summary, the state intervention is present and diverse in co-governance. It shows to be of a superior hierarchy and its indirect influence is through the power devolution, the provision of resources (e.g., knowledge, expertise, legal, financial) and management tools (TURFs, ITQs) to support the self-organization of actors and their engagement in the governing of fisheries.

\section{Determinants}

International. Funders and organizations provide resources, knowledge, actors, and standards for fisheries co-governance (e.g., Hurley \& Manel, 2015). Philanthropists, for example, support local projects and national government agencies, often through partnerships with civil society organizations (also called 'non-governmental organizations'). In addition, the FAO and the UN support the involvement of non-state actors in international debates and policy development agendas (Pictou, 2018) that used to be attended only by the state.

Binding and non-binding international agreements have promoted the development of co-governance by recognizing the participation of public, private, and social actors in fisheries governance. For example, the International Labour Organization Work in Fishing Convention No. 188, which is a binding agreement, establishes decent work requirements for the fishing industry (Garcia et al., 2014a, 2014b; Suárez de Vivero et al., 2005). The non-binding agreements that acknowledge the participa-

\footnotetext{
${ }^{19}$ A spatial form of right in which individuals or a group of fishers are granted exclusive access to harvest a single or a group of species within the geographical area (Afflerbach, Lester, Dougherty, \& Poon, 2014).
} 
tion of non-state actors include the Code of Conduct for Responsible Fisheries, the Voluntary Guidelines for Securing Sustainable Small-Scale Fisheries in the Context of Food Security and Poverty Eradication (SSF Guidelines), and the Agenda 2030 for Sustainable Development, particularly the Sustainable Development Goal (SDG) 14, which refers to fisheries and the marine environment. It is important to note that although these non-binding agreements refer to shared responsibility with nonstate actors, most responsibilities are directed to the state (Bavinck \& Chuenpagdee, 2005). In addition to the international agreements, the globalization of production, trade, and regulation influence the emergence of new interactions between, and interventions by, global and local actors in fisheries governance. For example, the international standards and certification schemes encourage the participation and diversification of actors (e.g., markets, civil society organizations) in pursuing fisheries sustainability (Pascual-Fernández et al., 2005b).

Domestic. Concerns related to domestic fisheries such as overexploitation, illegal fishing, and conflicts between users (e.g., artisanal vs industrial fisheries) (Chuenpagdee \& Jentoft, 2007; Sen \& Nielsen, 1996) drive the engagement of different actors in co-governing fisheries.

According to studies of co-governance, the ability of fishers and fishing organizations to self-organize and craft institutions for sustainable resource use (Pomeroy \& Berkes, 1997) as well as their increased empowerment, negotiation capacity (Jentoft \& Chuenpagdee, 2015b), willingness, and aspirations to take responsibility in the governing of fisheries increase fishers' inclusion and participation in governance (Sen \& Nielsen, 1996). Fishing cooperatives, for example, are currently a platform for devolving power and responsibilities among individual fishermen or boats (Jentoft, 1989).

In addition, the literature recognizes that civil society organizations engage in co-governance by bringing resources (e.g., funding), expertise (e.g., technical expertise, project management skills), and actors (e.g., experts, state, and fishers) in different levels of governance (e.g., local, national) (Berkes, 2009; Espinosa-Romero et al., 2014; Garcia et al., 2003; Wilson et al., 2006). Civil society organizations often represent the public interest, in defence of natural ecosystems (Kooiman \& Chuenpagdee, 2005) and the interests of marginalized groups, by promoting social and environmental justice (Fleischman et al., 2014; Scholtens, 2016). In the policy arena, they often balance power, usually concentrated in the state (Suárez de Vivero et al., 2005). However, these organizations are often criticized for having donor priorities 
in their agendas and for politicizing poverty with little impact on structural aspects and cases (Espinosa-Romero et al., 2014; Scholtens \& Bavinck, 2018).

State-based. States with limited resources (financial and technical) but strong relational capacity (Viet-Thang, 2018) and willingness to share power and authority (Kooiman \& Bavinck, 2005) build partnerships, coordinate networks, and involve other actors in the governing of fisheries (Sen \& Nielsen, 1996). They convert command and control relationships into persuasion-negotiation relationships (Viet-Thang, 2018). In Chuenpagdee and Jentoft (2007), co-governance practitioners from developing countries revealed that the state promoted the transition to this mode of governance, with the support of external agents, such as international agencies and civil society organizations. Finally, the wide (or absolute) discretion (Jentoft et al., 2005) provided by legal frameworks gives autonomy and flexibility to the state to co-govern fisheries with other actors. However, this also becomes a limitation if bureaucrats do not have the willingness to share power or support co-governance initiatives (Townsend \& Shotton, 2008).

\section{Performance}

Co-governance is applied at the national level (Delaney, 2015; Viet-Thang, 2018) and in specific fisheries or sites (e.g., Espinosa-Romero et al., 2011), from sedentary species (Monnereau \& McConney, 2015) to mobile species (Gutierrez et al., 2011), and from small-scale fisheries (Chuenpagdee \& Jentoft, 2018) to industrial fisheries, in developing and developed countries. Although most co-governance cases have been investigated since the 1980s (Berkes, 2009), the practice of power sharing has been reported since 1890 in the Lofoten Islands cod fishery in Norway (Jentoft \& McCay, 1995) and since 1901 in Japanese inshore fisheries under the Japan Fisheries Act (Berkes, 2009; Lim et al., 1995).

Gutierrez et al. (2011) in the analysis of co-governance performance shows that this governance mode thrives in benthic and demersal fisheries, especially when accompanied by MPAs, TURFs, or community or individual quotas. In this study, countries with high human development indexes (HDI) outperformed those with low and medium HDI; and industrial fisheries outperformed artisanal fisheries as a result of their stronger mechanisms for enforcement. This study also shows less success of co-governance in multi-species and pelagic fisheries. The analysis of co-governance in coral reef ecosystems by Wakumota et al. (2012) shows improvements in target commercial species and socio-economic dimensions. The analysis of co-gover- 
nance schemes for the adoption of Fisheries Improvement Projects (FIPs) (Cannon et al., 2018), ecolabelling, and certification schemes show improvements in fish stocks and changes in actors' behaviour towards sustainable fishing (Cochrane, 2018). In addition, the increasing collaboration of the state with scientific and conservation organizations within RFMOs has supported the postulate that participation improves governance, in this particular case, through the improvement of information and rules for species and habitats of particular concern (Haas et al., 2020).

Co-governance often improves the compliance with rules (Berkes, 2009), the enforcement activities to reduce illegal fishing (Wamukota et al., 2012), and increases social learning, trust building (Berkes, 2009), community empowerment, and community buy-in (Jentoft et al., 1998). However, the contribution of non-state actors occurs at lower levels of decision-making (Sen \& Nielsen, 1996), for example, through fundraising, legal support, and technology transfer, but with little influence on policy formulation (Berkes, 2009). Co-governance is likely to bring redundancy of governing functions. According to Berkes (2009), the issue of redundancy is not yet investigated in this mode of governance. However, the expectation is that redundancy brings resilience, especially in developing countries where co-governance evolves in an environment of weak institutions and where users are learning how to become competent co-governors (Berkes, 2009). For example, at preparing meetings, listening and respecting others' opinions, and working out commitments and consensus (Espinosa-Romero et al., 2011; Jentoft, 2005b).

According to the literature, co-governance does not guarantee fairness in resource sharing, poverty reduction, and empowerment of marginalized groups (Berkes, 2009). Moreover, the lack of representation of non-state actors, such as those representing small-scale fisheries, is still present and often leads to weak collaborations, limited understanding of the resource (e.g., marine reserves in the Philippines and octopus fishery in Portugal) (Chuenpagdee \& Jentoft, 2018), and negative impacts on equity and communities (e.g., fisheries in Bangladesh, Cambodia, Indonesia, and the Philippines) (Berkes, 2009; Wilson et al., 2006). While co-governance initiatives may help build collaboration between fishers and the state, in other cases they create conflicts within communities (e.g., village headmen and village committees such as in the case of Malawi) (Chuenpagdee \& Jentoft, 2018) by favouring elites, and it can be as impersonal to local concerns as management by the state can be (Jentoft et al., 1998).

The state promotes the formation of associations to co-govern fisheries. These organizations often transform their original objectives (e.g., ITQs in Norway) (Berkes, 
2009), especially when industrial and private interests dominate these associations, as an unintended consequence of the implementation of market-driven schemes in fishing organizations (e.g., ITQs) (Berkes, 2009). Additionally, men holding state positions often promote the associations, which are also usually dominated and managed by men, thus women are often disadvantaged in fisheries in terms of receiving support and participating in decision-making (Pascual-Fernández et al., 2005a). Co-governance implementation through ITQs is largely applied in developed and developing countries, and is particularly successful in countries and fisheries in the north (e.g., New Zealand, Canada, Iceland). However, ITQs present challenges in terms of allocation and often displace marginalized groups such as indigenous and subsistence user groups. Furthermore, fishers do not always comply with the quotas and misreport their catches (Young et al., 2018).

In summary, the state intervention is present in co-governance and the extent of its intervention varies and relies on its relational capacity and willingness to share power as well as on actors' readiness to co-govern. The information on performance shows the arenas in which this governance mode is more likely to succeed (e.g., benthic and demersal fisheries) and the opportunities for improvement (e.g., issues of power and inclusivity).

\subsubsection{Self-governance}

\section{Governing functions of the state}

The reported governing functions for this governance mode include the legitimization of local institutions (Grafton, 2000; Ostrom, 1990), ensuring they fit the local conditions (Anthony \& Campbell, 2011) and the provision of exclusivity to users (Grafton, 2000) through fishing rights, including TURFs (Sosa-Cordero et al., 2008; Villanueva-Poot et al., 2017). The state provides resources to self-governed groups, including expertise for defining the boundaries of resources, financial support (Viet-Thang, 2018), the monitoring of resource use, enforcement mechanisms to prevent outsiders from using the resources or breaking the rules (Anthony \& Campbell, 2011; Grafton, 2000; Viet-Thang, 2018), and assessment of the effectiveness of this governance system (Anthony \& Campbell, 2011; Viet-Thang, 2018). In addition, during conflicts the state can provided neutral information and mechanisms for negotiation (e.g., the court system) (Mansbridge, 2014; Viet-Thang, 2018) to break perverse situations (Anthony \& Campbell, 2011; Ostrom, 1990). 
The state can also impose solutions (or threaten to) if parties do not come to agreements (Mansbridge, 2014). It can also function as a bridging organization to connect local groups and institutions with other actors (even those with conflicting interests) and levels of governance. It can facilitate spaces for deliberation, discourse, and dialogue at the community level (Anthony \& Campbell, 2011). In this type of governance the state should recognize the values and principles that matter to fishers and their communities within governance systems to enable and empower self-organization (Chuenpagdee \& Jentoft, 2018). The state can help transform the perceptions of the costs and benefits of different solutions, and the interests of individuals in ways that lead to cooperative behaviour (Grafton, 2000). The state may choose to deregulate, devolve power, and incorporate self-regulatory capacities in this governance mode (Kooiman \& Bavinck, 2005, p. 21).

The governing functions of the state reported in self-governance studies suggest a more indirect influence of the state; however, the shadow of hierarchy is evident through the provision of resources, the legitimization of rights and institutions, and the linkage of this governance modes with other layers of governance.

\section{Determinants}

International. Although self-governance is a capacity created within local communities, the increasing research on small-scale fisheries (Chuenpagdee \& Jentoft, 2018; Jentoft \& Chuenpagdee, 2015c) and the publication of the SSF Guidelines raised the attention on self-governance potential for the governing of fisheries (Chuenpagdee \& Jentoft, 2018). This form of governance has also become more visible since Elinor Ostrom and other scholars (e.g., Ostrom, 1990, 2010; Ostrom et al., 2006) conducted extensive empirical research on self-governance for CPRs, including fisheries, in the 1990s (Viet-Thang, 2018). This academic contribution challenged the conventional paradigm of CPR governance (based on regulation and privatization) and led to Elinor Ostrom winning the Nobel Prize in Economics in 2009. In addition, international organizations such as the World Bank and the International Union for Conservation of Nature finance programmes to support the development of community-based policies that recognize self-governed groups (Pascual-Fernández et al., 2005a).

Domestic. Ostrom (2009) identified ten characteristics of users and resource systems referring to domestic determinants that increase the likelihood of the emergence and success of self-governance. These characteristics refer to the natural system (e.g., resource boundaries and productivity of the system), the number of users and their 
capacities (e.g., leadership, social capital, common knowledge of the system, capacity to make predictions about the system), the dependence of users on the resources, and the full autonomy of users to craft and enforce their rules. The eight design principles for long enduring institutions that lead to successful self-governance over time (Ostrom, 1990) complement these characteristics mentioned above. Seven of the eight design principles relate to domestic determinants. They refer to the clear definition of boundaries (users and the CPR), the fit of the rules to local conditions, the ability of users to modify and monitor rules, the capacity of users to be accountable to the group (community, users), the existence of effective systems of graduated sanctions and conflict resolution, as well as the embeddedness of self-governance within multiple layers of governance. In addition, the literature suggests that the ability of fishers to work politically, to have their interests represented (Scholtens, 2016) and to communicate their common vision and shared goals (Chuenpagdee \& Jentoft, 2018), especially if they live in isolated communities (Sosa-Cordero et al., 2008), are key elements in supporting the emergence and legitimization of self-governance.

State-based. State willingness to recognize, legitimize, and facilitate self-governance is needed for this governance mode to take place. Whilst local empowerment and non-state actors' engagement are considered good attributes for governance, the state does not always received them well, especially when they challenge state authority and affect other resource users (Chuenpagdee \& Jentoft, 2018). The state has argued that fishers do not have the right to restrict access to fishing and thus qualified community efforts as inappropriate and even illegal (Salas, et al., 2015). If the state officials presume that they are the only ones with the authority to set the rules, it is very difficult for users to sustain a self-governance in the long run. This occurs because local fishers and outsiders who wish to get around the rules created by locals, can go to the state to get local rules overturned (Ostrom, 1990).

\section{Performance}

Successful examples of self-governed sustainable fisheries and other CPRs are in place (Ostrom 1990), where formal open-access coexist within systems of customary rules that effectively define who fishes, where, when, what, how, and how much (Ostrom, 2009, 2010). Sedentary species such as shellfish fisheries are well represented in this governance mode. Self-governance may be difficult or impossible to achieve in large-scale systems (e.g., tuna fishery), because the dependence on the resource, instead of thriving sustainable resource use, often leads to overexploitation, 
given the industry's commercial incentives, as demonstrated by Epstein et al. (2014) and Fleischman et al. (2014). The literature also reports that self-governance might not be as efficient at protecting biodiversity (Chuenpagdee \& Jentoft, 2018) when the scale of the resource or the problem is larger than the authority or scale of the community (Pascual-Fernández et al., 2005a).

Large power devolution also cause problems of unaccountability and inequality when communities marginalize groups or when they neglect issues of public interest such as environmental protection (Viet-Thang, 2018). In addition, there is evidence of local fishery management systems that are repressive, unfair, and ineffective in conflict resolution; where local authority can be illegitimate and undemocratic (Jentoft, 2005a).

In summary, although state intervention is minimal and indirect in self-governance, this mode requires the state to legitimize local rules and rights, but also to monitor these systems to ensure desirable outcomes on fish resources and ecosystems, as well as on equality and fairness.

\subsection{Discussion}

Three assumptions underlying governance studies are explored in this literature review on fisheries governance: i) governance modes limit state intervention; ii) the emergence of governance modes is not necessarily led by the state; and iii) alternative governance modes are more effective than hierarchies in diverse contexts and situations. The literature shows agreement on the relevance of state presence, adaption, and superior hierarchy in all governance modes, especially to ensure the public interest. Through the exercising of diverse governing functions, the state extends its shadow and indirectly influence governance modes (e.g., resource provision, legitimization of local institutions, and power devolution). Although the state is not positioned as the actor leading the emergence of alternative governance modes (i.e., co-governance, self-governance), existing literature recognizes the state as a relevant force in the emergence and endurance of governance modes. For example, state legitimization of alternative governance modes influences the perspective and compliance of actors with respect to customary rules. In addition, the analysis of the performance of governance modes shows that no one size fits all to cope with all marine fisheries types and challenges (e.g., overexploitation). In addition, this analysis shows the relevance of the state as a meta-governor in ensuring desirable outcomes, because all governance modes prove to bring benefits but often unintended consequences for fish resources and users. 
The main findings for the three dimensions (governing functions, determinants, and performance) analysed in this literature review are presented below.

Governing functions. The literature shows state direct intervention in the hierarchical governance mode and indirect influence in alternative governance systems (e.g., provision of resources). The literature generally presents analysis of governance modes (hierarchical, co-governance, and self-governance) as if they are independent or in transition from one to another (Chuenpagdee \& Jentoft, 2018). However, existing literature misses the understanding of governance modes as co-existing and embedded in a larger system. When looking at the governance modes in this manner, the governing functions performed by the state make more evident its superior hierarchy and the extension of its shadow in the governing of fisheries. For example, the state meta-governs and indirectly influences alternative governance modes by deciding the extension of power devolution. This means that the state exercises direct control over marine resources and is able to concede power to private and social actors for particular functions, to support the governing of marine fisheries. Through different degrees of power delegation, alternative governance modes formally coexist and benefit from state available resources, such as financial support, conflict resolution mechanisms, and enforcement. Other meta-governance functions that appear in existing literature relate to how the state aligns private and collective interests to the public interest to ensure desirable outcomes, and ensures the compatibility of governance modes and their linkages to larger governance systems. The shadow of hierarchy approach can guide research to deepen the understanding of the state indirect intervention in fisheries governance.

Determinants. International binding (e.g., UNCLOS, UN Fish Stocks Agreement) and non-binding agreements (e.g., Code of Conduct for Responsible Fisheries, SSF Guidelines) and organizations recognize the relevance and potential of non-state actors and therefore of alternative governance modes (Pictou, 2018). However, agreements and duties are mainly directed to the state, assuming its superior hierarchy to address issues of public interest (e.g., sustainability, biodiversity conservation, human rights). In addition, the state continues to be the dominant actor who influences policy at the supranational level, which then translates into national and subnational agendas. Moreover, state-based determinants (e.g., legal power, relational capacity, willingness to share power and legitimize other forms of resources) can support or hinder the coexistence of alternative governance modes (see Chuenpagdee \& Jentoft, 2018). For example, the state supports the self-organization of other forms of governance by devolving power to non-state actors. However, if the state is unwilling or not able to do 
so, the efforts of alternative governance modes can fail and be catalogued as illegal by the state or other fishery users (Salas et al., 2015).

Performance. The evidence on performance shows that the three governance modes have existed for years and that no one size fits all. Different governance modes are suitable for different resource types or situations. Hierarchical systems are recognized as necessary for industrial fleets and highly migratory species, market abuse prevention, and international conflict resolutions. Co-governance flourishes in benthic and demersal fisheries whilst self-governance in local communities and smallscale fisheries. The available knowledge on the performance of governance modes provide guidance for the state to take a proactive, rather than an adaptive, approach for the governing of fisheries (Cochrane, 2002; Seijo, 2005), through the implementation of hybrid governance systems, which combine the three modes, to reduce the risk of overexploitation in marine fisheries that continues to increase over time.

Overall, the three governance modes of interactive governance theory were useful in framing the presence, adaptiveness, and indirect influence of the state in fisheries governance. The shadow of hierarchy under which governance systems are performed is largely investigated in the public policy field, and represents a niche for research for marine fisheries studies. Viet-Thang (2018) initiated this work in co-governed systems, using resource provision (e.g., supporting resource boundaries definition) as the meta-governance function through which the state indirectly influences co-governed fisheries (e.g., Vietnam, Japan, Norway). Further research is recommended to analyse how the state architects and governs hybrid systems as well as how to ensure coordination and desirable outcomes from these systems to overcome overexploitation and ensure fisheries sustainability.

\subsection{Concluding Remarks}

This literature review shows the state presence, adaption, and indirect influence in marine fisheries governance. Furthermore, it shows the exercising of meta-governance functions, such as power devolution and resource provision, through which the state shows its superior hierarchy and the extension of its shadow in alternative governance modes (i.e., co-governance and self-governance). The analysis of determinants shows that the state uses its capacities (e.g., relational), resources (e.g., legal, financial, expertise) and willingness to devolve power, to support the emergence and persistence of alternative governance modes. Because governance modes prove to be suitable for different resource types or situations, this research recommends that the state takes a proactive approach to design and coordinate coexisting gover- 
nance modes to address the continuing overexploitation of marine fisheries. States will benefit from this hybridization, especially in those cases where the state is weak and non-state actors are ready to become competent partners. Chapter 3 focuses on the shadow of hierarchy, with particular attention to how the state creates coexisting governance modes, using Mexican fisheries as the case study. 


\section{Chapter 3. A Hundred Years of the Shadow of Hierarchy in Mexican Fisheries ${ }^{20}$}

\subsection{Introduction}

This chapter explains the shadow of hierarchy by looking at how the state creates coexisting governance modes, using Mexican fisheries as the case study. The shadow of hierarchy is present in marine fisheries through the meta-governance functions that the state performs to indirectly influence governance modes (i.e., hierarchical, co-governance, self-governance). An example of those functions is the mobilization of resources (e.g., information, the monitoring of resource use, platforms for conflict resolution) to support co-governed fisheries in coastal communities (see Viet-Thang, 2018). According to public policy scholars, the shadow of hierarchy is also explained by other meta-governance functions such as the organization of governance rules for other governance modes to coexist, for balancing the bargaining power of different groups, and for aligning these groups interests to the public or third parties' interest (e.g., environmental concerns) (Jessop, 1997, p. 575; Scharpf, 1997, pp. 200-202). This chapter investigates how the state uses its legal framework to create the coexistence of governance modes to fulfil its overarching goals for marine fisheries.

The International Law of the Sea gives the coastal state the power to build the institutional setting for the conservation and management of marine living resources as well as for the protection of the marine environment. Although some coastal states declared unilaterally territorial waters and exclusive economic zones (EEZ) (e.g., Chile, Peru, Ecuador) to protect their interests, the formalization of their rights and duties in the ocean took first place with the endorsement of the Convention on the Territorial Sea and Contiguous Zone in 1958 that came into force in 1964 (UNAM, 2002). This Convention declared three nautical miles (nm) as territorial waters. Years later, with the endorsement of the United Nations Convention on the Law of the Sea (UNCLOS) in 1982, territorial waters were expanded (from three to $12 \mathrm{~nm}$ ) and the EEZ of $200 \mathrm{~nm}$ established. The rights and duties of the coastal state over marine fisheries increased; the coastal state acquired the ownership of territorial waters and the jurisdiction for the exploration, exploitation, and conservation of marine resources in the EEZ (UN, 1982, p. 43). The binding nature of the UNCLOS confined

\footnotetext{
${ }^{20}$ This chapter is co-authored with Dr Julieta Marotta. Affiliation: United Nations University (UNU-Merit) and Maastricht University - Maastricht Graduate School of Governance (MGSG).
} 
the governing of fisheries to coastal states ${ }^{21}$ and provided a legal order to ensure the equitable and efficient use of these resources within the territorial waters and EEZ (UN, 1982, p. 25).

Marine fisheries, as explained in Chapter 2, are natural common-pool resources (CPR) that are part of larger ecosystems and contribute greatly to the food security, employment, and wealth of coastal states (FAO, 2020). However, these resources are at risk when food security, employment, and wealth are valued over their conservation and preservation. This risk is tangible; overfished stocks continues to increase (FAO 2020). ${ }^{22}$ Even when the UNCLOS gave power to the coastal state to protect marine resources, states alone have not been able to cope with overexploitation (Chuenpagdee \& Jentoft, 2018; Jentoft, 2005b; Jentoft et al., 1998; Symes, 1997). Consequently, states allow the intervention of other actors to transform the governing of fisheries from a state-based system to cooperative, network, and partnership-based systems (e.g., Chuenpagdee \& Jentoft, 2018; Symes, 1997). The extent to which different actors formally participate in the governing of fisheries and contribute to overarching objectives falls under the state autonomy, which delimits the power of action of actors to intervene in ensuring, for example, the conservation of species and ecosystems.

The law is the instrument through which the state rules and controls the exploitation of marine fisheries under its jurisdiction, generally through the allocation of fishing rights, the regulation of management tools (e.g., seasonal closures, quotas, refuge zones), and the creation of sanctions for cases of non-compliance (Cochrane, 2018). Additionally, through the law, the state formalizes and sets the boundaries of other actors' participation, often preserving its superior hierarchy, and its power to retain or cede governing functions.

This chapter analyses How the state uses the law for the creation of coexisting governance modes. In order to do so, it uses the theoretical framework of interactive governance and the Mexican fisheries as a case study to analyse the following research questions: Which governing functions does the state retain and cede to other actors for the governing of fisheries? and Which actors does the state partner with for the governing of fisheries?

\footnotetext{
${ }^{21}$ States that consented to be bound by UNCLOS and for which this Convention is in force (UN, 1982, p. 25). UNCLOS ended the era in which oceans were considered an issue for the international community ruled by the principle of mare liberum (Suárez de Vivero et al., 2005).

22 In 1974, 10\% of the stocks reported overexploitation. In 2017, 34\% (FAO, 2020)
} 
This chapter departs from the assumption that the state supports the self-organization of co-existing governance modes, and shows how this meta-governance function takes place in the shadow of its hierarchy. It focuses on the analysis of domestic laws enacted to regulate fishing activities conducted in territorial waters, the EEZ, and by national fleets operating on the high seas. Therefore, this chapter does not analyse the international institutional arrangements negotiated among coastal states in other layers of governance (e.g., regional fisheries management organizations (RFMOs)). In addition, this chapter does not elaborate on the implementation and performance of the institutional setting, which is addressed in Chapters 4 and 5.

Section 3.2 explains the analytical framework used to address the research questions. Section 3.3 describes the methods, case study, data sources, and coding approaches used in this chapter. Section 3.4 presents the results found empirically in Mexican fisheries. Section 3.5 discusses the results in the context of the analytical framework and introduces further research. Finally, Section 3.6 concludes with the main remarks of this chapter.

\subsection{Analytical Approach}

The concept of the shadow of hierarchy combines actor-centred institutionalism and interaction-oriented policy research, to consider policies as the outcomes of the interactions among resourceful and bounded rational actors. These actors are generally constituted in larger organizations; and their capacities, preferences, and perceptions are largely shaped by institutionalized norms within which they interact (Scharpf, 1997, p. 195). These norms shape their competences, action resources, but also their purpose and cognitive orientations (bounded rationality) (Simon, 1957). The shadow of hierarchy positions the state as a meta-governor with the power to indirectly influence these institutional norms (Scharpf 1997) for the self-organization of governance modes (i.e., networks, partnerships, co-governance) to achieve policy outcomes (Jessop, 1997, p. 575). Hence, the state uses its hierarchical order to shape the preferences of actors towards the public interest (e.g., environmental concerns), balance the bargaining power of actors, and regulate the setting in which different governance modes occur (Scharpf, 1997). Thus, coexisting governance modes are fashioned within the shadow of hierarchy (Whitehead, 2003). Scharpf (1997) recognizes that, although different forms of associations (collective, self-organization) produce policies that can be effective, the capacity of these associations to contribute to problem solving at large is due to the fact that they are performed in the shadow of the hierarchy of the state. 
According to interactive governance theory, governing takes place within three ideal types of governance modes: hierarchical governance, co-governance, and self-governance (Kooiman, 2003; Kooiman et al., 2005, 2008), which have different features. In hierarchical governance, the state generally, but not necessarily, governs and its intervention has a top-down style. In co-governance, private, public, and social actors govern fisheries (Kooiman, 2003; Kooiman et al., 2005, 2008), often through formal institutional arrangements (Berkes, 2002; Pinkerton, 1989). In self-governance, communities or groups govern and take care of themselves, outside the purview of the state (Kooiman, 2003; Kooiman et al., 2005, 2008). In real life, governance modes exist in hybrid forms and change in response to political, economic, or ecological aspects internal or external to the fishing industry (Chuenpagdee \& Jentoft, 2018; Kooiman et al., 2008). In this research, the three governance modes frame the analysis of how the Mexican state creates coexisting governance modes as part of a larger governance system.

According to Chuenpagdee and Jentoft (2018), governance should be analysed in the context of three orders of application, i.e., orders of governance. The first order refers to the day-to-day operation and problem solving. Its functioning should be enabled by the second order, in which institutional design occurs in ways that correspond with a third and meta-order. In the third order, values, norms, and principles are established (Kooiman, 2003; Kooiman \& Bavinck, 2005; Kooiman et al., 2005; Kooiman \& Jentoft 2009). Orders allows for the investigation of how the state combines the three governance modes, at different orders, in order to explore how actors with agency are engaged in the governing of fisheries.

The legal framework of Mexican fisheries is used to investigate the two dimensions (i.e., governance modes and governance orders), because it is the formal instrument that the state uses to control societal behaviour through the establishment of mechanisms that fulfil specific goals (Pérez-Nieto Castro, 2012). It also expresses a public policy decision and addresses the position of the state and other actors at a specific moment of time and in a specific matter. Hence, legal frameworks provide valuable data about which actors become state partners, the interests represented, and the groups that are sufficiently effective at influencing the state to obtain formal participation (Hill, 2009). 


\subsection{Methods and Data Sources}

\subsubsection{Methods}

This research uses a case study approach (Corbin, 1998, p. 11; Yin, 2009) to address the research question How does the state use the law to create coexisting governance modes? Case studies (Corbin, 1998, p. 11; Yin, 2009) are extensively used for understanding of fisheries governance (Cox et al., 2016; Poteete et al., 2010). As explained in Chapter 1, Mexican fisheries are the setting selected because it presents a case where the participation of different actors is present due to the relevance of fisheries for the economy and culture (Bennett, 2017; Espinosa-Romero et al., 2014, 2017; Sánchez \& Roelants, 2011). Therefore, the case selected provides a setting to investigate fisheries governance and understand how the state designs and adapts the institutional setting, i.e., legal frameworks, to create coexisting governance modes. In order to be able to analyse the evolution of the coexistence of governance modes over time, this study analyses the time period from 1917 to 2019.

A systematic document analysis (Bowen, 2009; O'Leary, 2014) is the method applied to the analysis of the legal framework of Mexican fisheries, which represents the main source of data in this chapter. This qualitative method allows for the understanding of the social reality through documents (Bowen, 2009; O'Leary, 2014) and helped identify the coexistence of governance modes and orders for Mexican fisheries.

Coding techniques (deductive and inductive) (Matthews \& Ross, 2010) were applied to review the provisions of the legal framework. A deductive approach to coding was used for the first review of the provisions of the legal framework (i.e., fisheries laws) using the three governance modes of the interactive governance theory. Then, an inductive approach was used to identify the list of themes (governing functions conducted by the state) and subthemes (characteristics) for the three governance modes (i.e., hierarchical, co-governance, self-governance) applicable to the Mexican fisheries. Once themes and subthemes were identified, redundancy was eliminated to finalize the list of codes. Table 3-2 presents the list of themes and sub-themes. AtlasTi software allowed the systematic coding process of the legal provisions of the Mexican fisheries' legal framework.

To validate the analysis presented in this chapter, results were presented to the Commission of Agriculture, Livestock, Fisheries, and Rural Development of the Sen- 
ate, to Comunidad y Biodiversidad, A.C. ${ }^{23}$ and to one expert in Mexican fisheries laws and governance. In addition, results were presented at the Third World Congress of Small-Scale Fisheries 2018, the MARE Conference 2019, and the UNU-Merit Conference 2020 to validate and receive feedback on the analytical framework and empirical results.

\subsubsection{Case Study Description: Mexican Fisheries}

Mexico is the selected case study to investigate How the state uses the legal framework to create co-existing governance modes. Mexico provides an example of a state in which fisheries (small-scale and large-scale) contribute to the socio-economic development of the country with a risk of overexploitation $-70 \%$ of fish populations are fully fished and 17\% overexploited (DOF, 2012a). Fisheries have a pivotal role for coastal communities and local economies (OECD, 2006); they employ approximately 300,000 fishers (Botello et al., 2010), and sustain around 10,000 communities with fewer than 15,000 inhabitants (INEGI, 2010), which strongly rely on marine resources.

Through the legal framework, the state recognizes the relevance of securing fisheries for sustaining employment, income, and food for many people in Mexico. According to Article 133 of the Political Constitution of the United States of Mexico of 1917 (hereinafter referred as Mexican Constitution), the legal framework for fisheries governance comprises the Mexican Constitution and the specific laws (national fisheries laws and the maritime zone laws), which are aligned to the UNCLOS and corresponding binding and non-binding international agreements Mexico is part of (Nava-Escudero, 2016).

Different ministries have been responsible for implementing the legal framework for fisheries governance, representing different levels of autonomy in the sector. In 1982, the Ministry of Fisheries was created and represented the highest level of autonomy fisheries has had within the Mexican bureaucracy. Its creation was due to political, financial, and administrative motivations. At that time, the fishing industry was growing (Hernández-Fujigaki, 1987; Martínez-Martínez \& González-Laxe, 2016), UNCLOS negotiations were in place and Mexico had an active role, the optimal exploitation of resources was a priority (López-Chavarria, 1997), and there was the potential capture of international funding to support fisheries development (Alcalá-Moya, 2003). Several research agencies were created in order to support fisheries administration (Cuéllar-Lugo et al., 2018; López-Chavarria, 1997; Secretaría de

\footnotetext{
${ }^{23}$ Non-profit organization with 21 years of experience working on Mexican fisheries, www.cobi.org.mx.
} 
Pesca, 1976). Figure 3-1 presents these research agencies and ministries in charge of fisheries.

Figure 3-1. State agencies in charge of fisheries governance within the Mexican bureaucracy

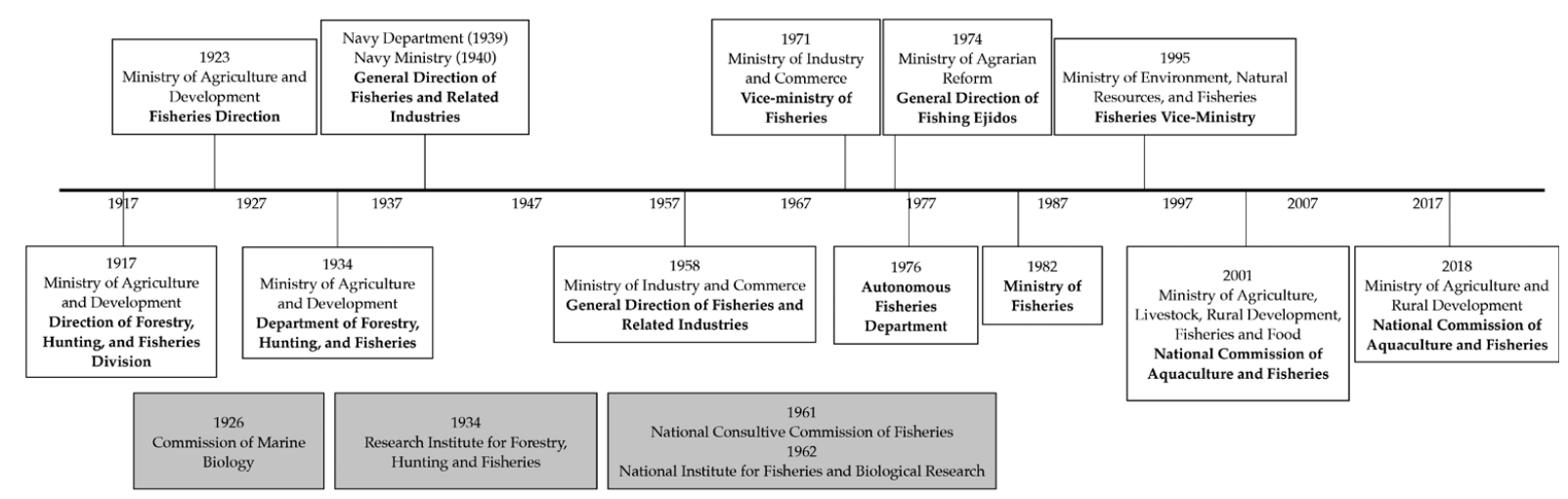

Source: Own elaboration based on Cuéllar-Lugo et al. (2018); López-Chavarria (1977); Secretaría de Pesca (1976). In bold the agencies in charge of fisheries administration. In grey blocks, research agencies.

For the context of Mexico, this analysis is timely and relevant. The Congress and Executive Administration, currently dominated by the leftist party Movimiento de Regeneración Nacional (Morena), proposed "the fourth transformation"24 of Mexico, which entails constitutional and other legal reforms, including the creation of a new fisheries law. The elected president included the creation of the new fisheries law within the 2018-2024 Plan for the Nation (MORENA, 2018). This analysis presents a hundred years of learnings and state interventions in fisheries that can inform the fourth transformation, specifically the new fisheries law, in order to use past experience to build a robust governance system that leads to desirable outcomes for fisheries.

\subsubsection{Data Sources: Legal Framework with Fisheries Implications (1917-2019)}

Since 1917, Mexican fisheries have been regulated by the state in order to preserve the unique natural and social setting. The legal framework comprises the Mexican Constitution, eight national fisheries laws, and the maritime zone laws, which are aligned to UNCLOS and corresponding binding and non-binding international agreements Mexico is part of (Nava-Escudero, 2016).

\footnotetext{
${ }^{24}$ For the current president of Mexico, the first transformation is independence. The second is the reform that separates the Church from the state. The third is the revolution; the Mexican Constitution was promulgated after it. The fourth is meant to be a pacific one.
} 
The Mexican Constitution marks the beginning of the time frame of "national ownership of surface, water, and subsoil rights" (Haber et al., 2008, p. 14). It is considered the "first coherent expression of ideology emerging from the 1910 Revolution" (Raymond-Duncan, 1963, p. 200) and represents the core legal document used in this research. With the incorporation of Article 27, the Mexican Constitution views private property as privileges granted by the state, and not as rights granted to people (Parise, 2017, p. 201). Article 27 regulates lands and waters. The direct ownership of these resources is vested on the state, which has the right to transfer the dominium (i.e., privatization) or use (i.e., concession system for inland and sea waters) to individuals or corporations (DOF, 1917). This privilege of the state "enabled state relocation of goods in defence of public interest" (Parise, 2017, p. 201). Hence, the state became the legitimate owner with the capacity to allocate goods to Mexican citizens and Mexican corporations. Article 27 also limits the possibility of foreigners becoming legitimate owners (DOF, 1917).

Three maritime laws have fisheries implications: 1) the Law of the Nation's Exclusive Fishing Zone ${ }^{25}$ enacted in 1967 (DOF, 1967); 2) the Regulatory Law for Paragraph 8 of Constitutional Article $27^{26}$ enacted in 1976 (DOF, 1976b); and 3) the Federal Law of the Sea $^{27}$ enacted in 1986 (DOF, 1986b), which adopts the provisions of UNCLOS endorsed in 1982.

Eight specific fisheries laws and 23 reforms have been enacted (DOF, 1925, 1932, 1948a, 1950, 1972, 1986a, 1992b, 2007a), which establish the institutional setting for distinctive approaches for fisheries governance (Espinoza-Tenorio et al., 2011; Hernández \& Kempton, 2003). For example, the law decreed in 1972 (Federal Law for Fisheries Development) has a focus on fisheries development and the law of 2007 (General Law for Sustainable Fisheries and Aquaculture) on sustainability, decentralization, and actors' participation (Espinoza-Tenorio et al., 2011). Figure 3-2 presents the legal framework included in this chapter in chronological order.

\footnotetext{
${ }^{25}$ It declares an exclusive zone for fishing purposes of 12 nautical miles (nm) (DOF, 1967).

${ }^{26}$ It declares unilaterally $200 \mathrm{~nm}$ as an exclusive economic zone (EEZ) (DOF, 1976b).

${ }^{27}$ It defines the territorial waters $(12 \mathrm{~nm})$ where the Mexican state has full sovereignty as well as the EEZ $(200 \mathrm{~nm})$ where the state has jurisdiction for infrastructure development, marine resource and environment conservation, economic use of the sea, and scientific research (DOF, 1986b).
} 
Figure 3-2. Legal framework applicable to fisheries governance for the last 100 years

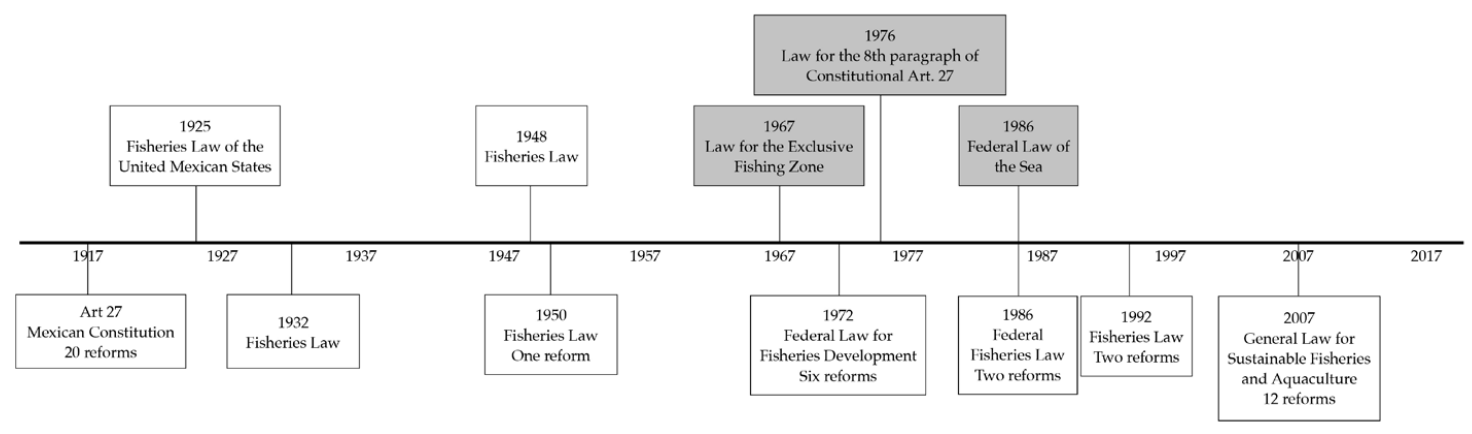

Source: Own elaboration based on publications of the Official Gazette. The Mexican Constitution has had 20 reforms, 11 of which apply to fisheries. The eight fisheries laws have had 23 reforms. In grey squares, the three maritime zone laws.

The legal documents (Mexican Constitution, maritime zone laws, fisheries laws and corresponding reforms) were collected from the Congress archives and Official Gazette website (http://dof.gob.mx). Relevant legal provisions (enumerated in Table 3-1) were selected for the analysis of governance modes and orders, established within the Mexican legal framework.

Table 3-1. Provisions of the legal framework used for the analysis of the institutional setting for the co-existence of governance modes

\begin{tabular}{|c|c|}
\hline Legal framework & Provisions \\
\hline 1917 Mexican Constitution & $1,2,27,73$ \\
\hline \multicolumn{2}{|l|}{ Maritime zone laws } \\
\hline 1967 Law of the Nation's Exclusive Fishing Zone & 2,3 \\
\hline $\begin{array}{l}\text { 1976 Regulatory Law of Paragraph } 8 \text { of Constitutional } \\
\text { Art. } 27 \text { in relation to the Exclusive Economic Zone }\end{array}$ & 4 \\
\hline 1986 Law of the Sea & 1,6 \\
\hline \multicolumn{2}{|l|}{ Fisheries laws } \\
\hline 1925 Fisheries Law of the United States of Mexico & $1,4,6,7,10,11,15,16,17,20,21,22,23,24,25$ \\
\hline 1932 Fisheries Law & $2,3,4,5,6,7,9,10,13,14,15,16,17,20,21,23,28$ \\
\hline 1948 Fisheries Law & $1,6,7,8,9,10,11,12,13,16,17,19,21,25,26,27,29,30,31$ \\
\hline 1950 Fisheries Law of the United States of Mexico & $2,4,7,8,9,10,11,13,15,16,18,21,24,26,30,32,35,55$ \\
\hline 1972 Federal Law for Fisheries Development & $\begin{array}{l}1,6,7,8,9,10,11,13,15,16,17,18,19,20,25,33,40,49 \\
55,56,58,61,70,74,75\end{array}$ \\
\hline 1986 Federal Fisheries Law & $\begin{array}{l}1,10,11,12,13,14,15,16,17,18,20,24,27,37,40,41,55, \\
59,62,63,68\end{array}$ \\
\hline 1992 Fisheries Law & $1,3,5,6,7,8,9,10,13,14,21,12,59$ \\
\hline $\begin{array}{l}2007 \text { General Law for Sustainable Fisheries and } \\
\text { Aquaculture }\end{array}$ & $\begin{array}{l}1,4,8,9,10,11,13,14,17,20,21,22,24,25,26,27,29,30, \\
31,32,34,37,38,39,43,46,47,50,51,55,59,62,64,66,67, \\
68,70,72,77,101,119,119 \text { Bis, } 110,121,122,151,152\end{array}$ \\
\hline
\end{tabular}

\subsubsection{Data Analysis}

The data were analysed by following a systematic document review approach. The themes for governing functions (i.e., hierarchical governance, co-governance, and 
self-governance) and subthemes (i.e., the way in which the governing functions can be conducted according to governance modes) guided the codification of the legal provisions (see a description in Table 3-2). The themes for governing functions within hierarchical governance are those that appeared in all the fisheries laws (i.e., objective definition, institution making, knowledge production, enforcement and surveillance). The themes for co-governance are all the governing functions shared with other actors (i.e., objective definition, institution making, knowledge production, enforcement and surveillance, and the provision of incentives). The themes for self-governance represent the governing functions conducted by the state in support of self-governance (i.e., legitimization of institutions, respect of the right to fish, allocation of fishing rights, as well as technical and financial support). The governing functions found for each governance mode were categorized according to the orders of governance.

Table 3-2. Themes and subthemes for the codification of fisheries laws.

\begin{tabular}{|c|c|c|}
\hline Governance mode & Themes & Sub-themes \\
\hline Hierarchical governance & $\begin{array}{l}\text { Governing functions of the state: } \\
\text { Knowledge production. Refers to the } \\
\text { generation of information and science }\left(1^{\text {st }}\right. \\
\text { order) } \\
\text { Enforcement and surveillance. Refers to } \\
\text { inspections, sanctions, and administrative } \\
\text { processes applied for the compliance of } \\
\text { institutions ( } 1^{\text {st }} \text { order) } \\
\text { Institution making. Refers to fishing rights } \\
\text { and regulations of management tools ( } 2^{\text {nd }} \\
\text { order) } \\
\text { Objective definition. Refers to environmental, } \\
\text { developmental, and social goals for fisheries } \\
\left(3^{\text {rd }} \text { order) }\right.\end{array}$ & $\begin{array}{l}\text { Characteristics of hierarchical } \\
\text { governance: } \\
\text { One federal agency is mainly in charge } \\
\text { Coordination among federal agencies } \\
\text { Devolution of power to lower state levels }\end{array}$ \\
\hline Co-governance & $\begin{array}{l}\text { Governing functions shared by the state with } \\
\text { non-state actors: } \\
\text { Knowledge production. Refers to the } \\
\text { generation of information and science }\left(1^{\text {st }}\right. \\
\text { order) } \\
\text { Enforcement and surveillance. Refers to } \\
\text { inspections, sanctions, and administrative } \\
\text { processes ( } 1^{\text {st }} \text { order) } \\
\text { Incentives provision. Refers to loans provision } \\
\text { and awards ( } 1^{\text {st }} \text { order) } \\
\text { Institution making. Refers to fishing rights } \\
\text { and regulations of management tools ( } 2^{\text {nd }} \\
\text { order) } \\
\text { Objective definition. Refers to the definition of } \\
\text { fishery-specific objectives ( } 3^{\text {rd }} \text { order) }\end{array}$ & $\begin{array}{l}\text { Characteristics of the mechanisms } \\
\text { through which the state shares } \\
\text { governing functions with non-state } \\
\text { actors: } \\
\text { Mechanisms for actor's engagement } \\
\text { Mechanisms for ceding governing } \\
\text { functions to other actors }\end{array}$ \\
\hline
\end{tabular}




\begin{tabular}{|lll|}
\hline Governance mode & \multicolumn{1}{c|}{ Themes } & \multicolumn{1}{c|}{ Sub-themes } \\
\hline Self-governance & $\begin{array}{l}\text { Governing functions performed by the state } \\
\text { to support/facilitate self-governance: }\end{array}$ & $\begin{array}{l}\text { Characteristics of the governing } \\
\text { functions performed by the state: }\end{array}$ \\
& Fishing rights allocation $\left(1^{\text {st }}\right.$ order $)$ & $\begin{array}{l}\text { Preference for self-governed groups } \\
\text { when issuing rights, allocation of fishing } \\
\text { rights of high commercial value species } \\
\text { to self-governed groups, allocation of } \\
\text { territorial use rights in fisheries (TURFs) } \\
\text { for self-governed groups }\end{array}$ \\
& $\begin{array}{l}\text { The provision of equipment and } \\
\text { infrastructure, technical assistance, and } \\
\text { capacity building }\end{array}$ \\
& $\begin{array}{l}\text { Right to fish for subsistence } \\
\text { Legitimization of local institutions based } \\
\text { on traditional knowledge }\end{array}$ \\
\hline
\end{tabular}

Note: In parenthesis, the order of governance for each governing function.

\subsection{Results}

The legal framework shows the shadow of hierarchy of the Mexican state through the design and adaption of the legal framework for the coexistence of governance modes. The Mexican case shows that the state has created a hybrid system since 1925. This means that the state instead of establishing institutions for a particular governance mode to occur in its pure form, the state maintains its hierarchical position and makes different combinations for governance modes to occur in different orders of governance to cope with the diverse needs of the fishing sector. For example, in the third order of governance, the state is generally the sole actor that defines the objectives for fisheries governance. In the second order (institution making) and the first order (implementation), the state includes mechanisms for co-governance and self-governance to coexist under the shadow of its hierarchy.

The following sections explain the institutional setting (Sections 3.4.1 to 3.4.4) and the actors engaged (Section 3.4.5) in each order and governance mode, as expressed by the legal framework.

\subsubsection{Institutional Setting for Creating Coexisting Governance Modes}

The Mexican Constitution and maritime zone laws set a hierarchical mode of governance. According to Article 27, the exploitation, use, and development of marine and inland water resources within the national territory can only be practiced under concessions granted by the federal executive, which will be subject to the restrictions and requirements of the corresponding laws (i.e., fisheries laws) (DOF, 1917; Rabasa, 2007). Marine and inland waters are of state dominium, which is imprescriptible and non-transferable (DOF, 1917, 1945b, 1960). Since 1976 the state jurisdiction has ap- 
plied to a EEZ of 200nm (DOF, 1976a). However, the Mexican Constitution includes mechanisms for the coexistence of hierarchies with co-governance and self-governance modes. Examples of these mechanisms are the concessions for resource use (DOF, 1917), within which local users define customary rules to complement those of the state; the recognition and protection of self-governed groups' rights (ejidos, ${ }^{28}$ communities, cooperatives) (DOF, 1992a); the preferential use of natural resources given to indigenous groups and peoples (DOF, 2001c); and the faculty of the Congress to create laws that involve coastal provinces, municipalities, and the private and social sectors in fisheries and aquaculture matters (DOF, 2004b).

The three maritime laws assume the hierarchical position of the Mexican state, as they establish the spatial extension of state jurisdiction. The Law of the Nation's Exclusive Fishing Zone creates a $12 \mathrm{~nm}$ zone for fishing purposes (DOF, 1967). The Regulatory Law of Paragraph 8 of Article 27 expands the area of state jurisdiction from 12 $\mathrm{nm}$ to an EEZ of $200 \mathrm{~nm}$ for exploration, exploitation, preservation of the marine environment, and scientific research (DOF, 1976b). The Federal Law of the Sea establishes the areas within the EEZ where the state has jurisdiction for the conservation and use of marine resources, preservation of the marine environment, and scientific research according to UNCLOS (DOF, 1986b). No mechanisms for integrating other actors or supporting self-governed groups are included in these laws.

The eight fisheries laws demonstrate the combination of modes and engagement of different actors in the different orders since 1925. The following section explains how the state exercises this power of combination and delegation in governance orders, using the governing functions presented in Table 3-2.

\subsubsection{First Order of Governance: The Day-to-Day Functions of Fisheries Gover- nance}

This is the order of governance in which the laws show mechanisms for all governance modes to occur, for the exercising of day-to-day functions, such as enforcement and surveillance, knowledge production, and incentive provision.

\section{Hierarchical governance}

The legal framework shows that the state participates in the day-to-day functions and its autonomy to dabble and retract from these operations. The explanation of how the

\footnotetext{
${ }^{28} \mathrm{~A}$ type of distribution and possession of the land that was institutionalized after the Mexican Revolution
} and that consists in granting land to a local group of people for exploitation. 
state steers, coordinates with other federal agencies, and devolves power to lower state levels for the governing of fisheries at this order of governance, is presented below.

The state steers and controls the enforcement and surveillance of regulations, according to the eight fisheries laws. It expands its shadow of hierarchy through the inclusion of different mechanisms for federal agency coordination, devolution to lower state levels, and the participation of non-state actors.

The state has led the knowledge production in fisheries since 1950. The state created the (now called) National Research Institute for Fisheries and Aquaculture (INAPESCA) in 1962, and formally included it in the law of 1972 as the department of sciece that provides advice to the ministry in charge of fisheries, particularly for the establishment of regulations and fishing rights (DOF, 1972). INAPESCA has had different levels of autonomy, from being a branch of the ministry in charge of fisheries (DOF, 1972) to being a deconcentrated administrative body (property and budget) with regional centres (DOF, 1986a), and a decentralized agency (legal autonomy, property, and budget) (DOF, 2012d). The state has also created the following mechanisms to integrate and share information: the National Fisheries Registry, created to keep a record of fishers, vessels, gear types, and diving equipment, among other elements (DOF, 1950); the National System of Fisheries and Aquaculture, created to organize, update, and disseminate information on fishing and aquaculture activities (DOF, 2007a); and the National Inventory of Commercial Species (DOF, 1972), which later became the National Fisheries Charter (NFC, Carta Nacional Pesquera in Spanish), that includes the distribution, status, and management advice for fish populations. The NFC developed first by the Ministry of Fisheries (DOF, 1986a) and later by INAPESCA (DOF, 2007a), became a binding instrument for the ministry in charge of fisheries in 2007 (DOF, 2007a).

The state also conducted other functions that correspond to this order of governance, which were included only once in fisheries laws. These functions are the exploitation and commercialization of resources (DOF, 1972) and the establishment of transparency schemes for administrative processes including permits, concessions, and INAPESCA research reports (DOF, 2007a).

Coordination among federal agencies. The coordination among federal agencies is explicit in the laws and shows the expansion of the shadow of hierarchy within the state bureaucracy, to address broader functions and themes of fisheries governance. 
In addition, the analysis of the legal framework shows that the state has the power to delegate or concentrate the governing functions within one or several federal agencies.

Two laws include the coordination for enforcement and surveillance operations among the ministry in charge of fisheries and the Navy Ministry (DOF, 1972, 2007a), the National Defence Ministry (DOF, 1972), and the Ministry of Hygiene and Sanitation (DOF, 2007a). The coordination with the latter applies to the monitoring and enforcement of living, fresh, or frozen products transportation (DOF, 2007a, 2012e).

In terms of knowledge production, two laws mandate coordination, the first with the National Council for Science and Technology to conduct research on aquatic flora and fauna (DOF, 1986a), and the second with the Ministry of Environment to update the NFC (DOF, 2007a).

Coordination for other governing functions includes the establishment of fees and other legal provisions (DOF, 1925, 1932, 1948a, 1950,1972) as well as the establishment of franchises for fisheries-related industries (DOF, 1972) with the Ministry of Finances; the promotion of auctions (in markets) for fishing products and sub-products with the Ministry of Commerce and Industry Development (DOF, 1986a); the conservation of protected areas and species with the Ministry of Environment (DOF, 2007a); and the recognition and awarding of best practices with the Congress and INAPESCA (DOF, 2018e).

Delegation of power to lower state levels. The analysis of the legal framework shows that the state expands its shadow vertically, through the engagement of lower state levels. It also shows the state autonomy to delegate and concentrate power.

For example, in the Mexican case, the first fisheries law (DOF, 1925) promulgated after the Mexican Constitution devolved power to lower state levels. Subsequent laws concentrated power in federal agencies. Then, after the Constitutional amendment of 2004, in which the Congress receives the faculty to create laws that include coastal provinces, municipalities, private and social actors in fisheries matters, the fisheries law (DOF 2007a) re-expands the shadow of hierarchy through the involvement of coastal provinces and municipalities.

While power devolution was concrete and mandatory in the law of 1925, it is broader and non-mandatory in the law of 2007. According to the law of 1925, municipali- 
ties and local authorities participated in enforcement and surveillance in the absence of the federation, and received $25 \%$ of the amount collected from fines. However, the law of 2007, provides the option to coastal provinces to support enforcement and surveillance activities as well as to create and update information systems, generate information for the NFC, and integrate provincial councils for the participation of communities and users in fisheries management and the operation of a fund for fisheries and aquaculture development. Municipalities can also participate, as for example, by integrating fisheries information systems (DOF, 2007a).

The way hierarchical governance is set for fisheries governance is consistent with the shadow of hierarchy. It is being exercised within the context of multi-level governance, with a central agency delegating functions to subnational agencies, and among federal agencies, with the option of recentralizing at any time (Peters, 2010; Peters \& Pierce, 2004).

\section{Co-governance}

As mentioned above the state creates mechanisms for engaging in or ceding to nonstate actors governing functions.

Actors' participation in day-to-day governing functions. This section explains the mechanisms through which the state engages non-state actors in the day to day operations.

In terms of enforcement and surveillance, the laws of 1925 and 1932 mandate a financial contribution in the form of a guarantee for concession holders to comply with regulations and share enforcement and surveillance costs. Fishing rights did not have any legal effect if this guarantee was not paid. In addition, the guarantee was lost when breaking rules or when concessions expired, and concession holders had to report that all the obligations were fulfilled (DOF, 1932). The law of 2007 mandates the design and implementation of the Integrated Programme for Enforcement and Surveillance of Fishing and Aquaculture in collaboration with users and indigenous communities (DOF, 2007a).

Additionally, the 2007 law includes the space for academia and the fishing sector to contribute to the NFC, the National Programme of Scientific and Technological Research for Fisheries and Aquaculture, and applied research projects (DOF, 2007a). Furthermore, this law includes the creation of the National Network for Fisheries Information and Research and the Technical and Scientific Advisory Committee, in which researchers are involved, to support fisheries research and management. 
Actors have been engaged in financial support allocation (i.e., loans, endowments, and an award for sustainable fisheries) for fishers to acquire equipment, develop their industry, or recognize their best practices (DOF 1972, 2007a). The law of 1972, for example, creates an endowment for the development of fishing cooperatives, which is operated by a Technical and Investment Committee in charge of loan applications and payments. This Committee was integrated by federal agencies, parastatal banks, the Confederation of Fishing Cooperatives, and the Confederation of Farmers. Article 75 of the law of 1972 exemplify the above.

Art 75. The Technical and Investment Committee will be integrated by a president - the Minister of Industry and Commerce; a vice-president - Vice-Minister of Loans of the Finance Ministry; a second vice-president - Vice-Minister of the Ministry of Industry and Commerce; a secretariat, who will be designated by the National Confederation of Cooperatives of the Mexican Republic; a member designated by the Navy Ministry; a member designated by the Ministry of Hydraulic Resources; a member designated by the National Confederation of Farmers, and one from the National Bank for Cooperative Development. This committee shall session, at least once a month. The attributions of the Committee are to provide loans, supervise its application, and provide the instructions for payments and extensions... (DOF, 1972)

The law of 2007 includes the creation of an endowment for fisheries and aquaculture development, which has to be operated by a mixed committee, integrated by public (federal and provincial government agencies), private, and social organizations of fishers. Additionally, this law also creates the sustainable fisheries and aquaculture award that recognizes best practices in Mexico, which is co-organized and awarded by the Ministry, the Congress, as well as public and private actors (DOF, 2007a).

Actors leading day-to-day governing functions. This section explains the mechanisms through which the state cedes governing functions to non-state actors.

The law of 1925 allowed citizens to report crimes and misdemeanours against the law to contribute to enforcement and surveillance. They received $25 \%$ of the money charged in fines. The law of 1950 re-engages citizens in enforcement activities without economic rewards (DOF, 1952).

For knowledge production, the laws include authorizations and permits for Mexican citizens and foreigners (DOF, 1948a, 1950, 1986a, 1992b, 2007a), as well as the elaboration of agreements with third parties (DOF 1986a, 2007a) to conduct fisheries 
science and exploration (DOF, 1986a). They also mandate that right holders shall register their catch and fishers' information to be shared with government agencies and authorized inspectors (DOF, 1925, 1992b) and to become part of research studies and projects (DOF, 1992b). Moreover, four laws establish that resolutions for concessions will be based on the information provided by applicants in relation to the nature of the project, the financial investment, and the time required to recover the investment (DOF 1948a, 1950, 1972, 1986a). In the 1950s, the state created the National Advisory Commission of Fisheries to undertake the research on fisheries in all its dimensions, as requested by the Ministry of the Navy (in charge of fisheries at that time) or other interested parties (DOF, 1950, 1972). The Commission was integrated by federal agencies, the private sector (organized by fishers, vessel owners, and the industry), and civil society with a legitimate interest in fisheries (DOF, 1950).

Knowledge production is the governing function in which actors (e.g., fishers, industry, researchers) are consistently involved in all fisheries laws. This shows that although the state has the bureaucratic structure to conduct research, it expands its shadow of hierarchy through collaborations with other actors (e.g., fishers, industry, researchers), who are able to conduct research, under the coordination of the state.

\section{Self-governance}

This section explains how the state facilitates self-governance in day to day operations, through two mechanisms, the allocation of fishing rights and the provision of resources.

Allocation of fishing rights. The state has privileged self-governed groups in permit and concession granting. However, this support has decreased over time. The first law of 1925 made it explicit that fishing by inhabitants of coastal populations has preference over other actors who fish to fulfil regional, domestic, and export needs. This law also includes the allocation of TURFs for the collective exploitation of fisheries, which remains in the laws of 1932, 1948, 1950, and 1972. This type of right provides exclusive spatial use of resources to the inhabitants of coastal populations (DOF, 1925, 1932, 1950) and cooperatives (DOF, 1948a, 1972) that work together or independently (DOF, 1972).

The fisheries law of 1948, in addition to TURFs, introduced the policy of granting concessions of reserved (exclusive use) species (of high commercial value) to fishing cooperatives. As expressed by Article 31: 
Art 31. To practise fishing for the exploitation of the species abalone, shrimp, squid, lobster, mullet, oyster, octopus, snook, and totoaba, a concession contract is required, which will be allocated exclusively to fishing cooperatives, authorized and registered under the terms of the cooperative law, and preferably to cooperatives formed by regional fishers that are located close to fisheries for which they request a concession (DOF, 1948a).

This policy remained until 1986. Some differences apply in the allocation of rights with respect to cooperatives' membership and types. The law of 1948 specifies that preference is given to cooperatives formed by regional fishers - located close to the fisheries. The law of 1950 privileges fishing cooperatives formed by regional fishers in at least $60 \%$ of all members; and if allocation of rights had to be limited for species conservation and protection purposes, privileges were given to those cooperatives that demonstrated that at least half of the $60 \%$ of regional fishers were coastal fishers. The law of 1972 includes ejido cooperatives and distinguishes small-scale from industrial cooperatives. Small-scale cooperatives are those integrated by at least $80 \%$ of coastal fishers and residents of coastal municipalities and localities adjacent to inland waters. The law of 1986 includes communal cooperatives in the allocation of concessions. The laws of 1972 and 1986 include concessions for the cultivation of reserved species to coastal, ejido (DOF, 1972, 1986a), and communal cooperatives (DOF, 1986a).

The law of 1992 eliminates all privileges to cooperatives in relation to fishing rights (TURFs and reserved species). Years later, the law of 2007 introduces the preference to inhabitants of coastal populations and indigenous groups in permit and concession granting; however, it does not have a policy to grant TURFs, reserved areas, or species to these groups.

This section shows the power of the state in deciding which self-governed groups (e.g., cooperatives, coastal communities, indigenous groups) to support and the type of support these groups will receive. In addition, the state shows its shadow of hierarchy in influencing the membership of these groups, as Scharpf (1994) suggests. In this particular case, the state conditioned rights allocations to specific groups, according to its interests.

Technical and financial support. After introducing the policy of granting concessions of reserved species to fishing cooperatives (DOF 1948a), the state provided financial support for cooperatives to acquire equipment and infrastructure (DOF, 1948a, 1950, 
1972, 1986a). In addition, the law of 1972 creates an endowment to provide loans to fishing cooperatives for their development, which also included the acquisition of equipment and infrastructure. Moreover, the laws of 1972 and 1986 included technical support (e.g., support in terms of contracts with equipment owners, fishing methods) and capacity building for cooperatives. The law of 1972 also mandates that students from fisheries training centres could be admitted as members of fishing cooperatives to apply their knowledge once the Ministry had carried out a socio-economic study of the cooperatives and of the students. In 1992, the privileges for fishing cooperatives in terms of rights were eliminated. However, technical support is included, but limited to those cooperatives that requested it. In 2007, the law reintegrates the support to self-governed groups (i.e., coastal communities and indigenous groups), by prioritizing the sustainable development of indigenous communities as part of the National Policy for Sustainable Fishing and Aquaculture, and through the development of programmes, incentives, resources, and technology for these groups to improve productivity. It also includes the translation of titles and relevant documents into traditional languages to ensure information is accessible.

The financial and technical support provided by the state to these groups shows the expansion of the shadow of hierarchy through the provision of resources for the functioning of these groups.

\subsubsection{Second Order of Governance: Institution Making}

The state combines the three governance modes in this second order of governance, which include the decision making for the allocation of fishing rights, regulation of fisheries and management tools, and policy design. However, state intervention is dominant and exercised in coordination with federal agencies and lower state levels for specific issues. The engagement of different actors is limited to specific regulations of management tools.

\section{Hierarchical governance}

The state regulates the extraction of fish resources through the allocation of fishing rights and regulation of management tools within the EEZ. This applies to national fleets and foreign fleets operating in waters of national jurisdiction, as well as to national fleets operating in the high seas. In the case of Mexico, it also applies to the following fishing types: commercial, recreational, domestic consumption, scientific, and didactic. Commercial, recreational, and domestic consumption fishing are regulated in all fisheries laws. Scientific fishing was added to the law of 1948 and didactic 
fishing to the law of 1986. The regulation of the quality and sanitation of fishing products was included in the law of 2007.

According to the analysis of the laws, fishing rights are allocated through authorizations, concessions, and permits. In four laws, fishing rights are transferable, which means that holders can cede their rights to others, but only with the approval of the ministry in charge of fisheries (DOF, 1950, 1972, 1992b, 2007a) under some requirements. In addition, transferability did not apply to the concessions of species reserved for the exclusive use of cooperatives (DOF, 1950, 1972), and in the law of 2007 is applicable to concessions, and for permits, only in those cases of death of right holders. For the latter, preference in rights reallocation will be given to family members (DOF, 2007a).

Diverse management tools are included in the fisheries laws for the conservation of species and ecosystems as well as to provide exclusivity to resource users. As shown in Table 3-3, the tools included in all laws are seasonal closures, reserved areas (i.e., farming, exploitation, and repopulation), fish refuges, minimum size and minimum weight, and restrictions of gear types and fishing methods. Some tools are included only in some laws, such as maximum size or weight (DOF, 1925, 1932, 1948a), fishing effort control (e.g., number of fishers, vessels, cooperatives) (DOF, 1932, 1948a, 1950, 1972, 1986a, 1992b), total allowable catch (TAC) (DOF, 1948a, 1972, 1986a, 1992b, 2007a), and restrictions for protected species (DOF, 1925, 1950, 1972, 1992b, 2007a). Tools that account for broader ecosystem considerations are waste control (DOF, 1925), water quality programmes (DOF, 1986a), and areas for restoration, rehabilitation, and conservation of coastal, lagoon, and inland waters (DOF, 2007a). The tools to provide exclusivity to users include TURFs for coastal communities (DOF, 1925, 1932, 1948a, 1950), reserved species for exclusive use of fishing cooperatives (DOF, 1948a, 1950, 1972, 1986a), and reserved species and areas for recreational fishing (DOF, 1972, 1986a, 1992b, 2001d, 2007a). The laws that include more tools are those of 2007 (22), 1992 (18), and 1986 (16). 
Table 3-3. Management tools for the regulation of fisheries in Mexico

\begin{tabular}{|c|c|c|c|c|c|c|c|c|}
\hline 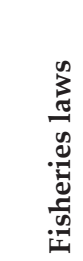 & 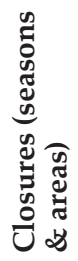 & 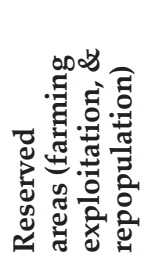 & 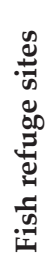 & 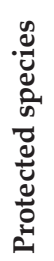 & 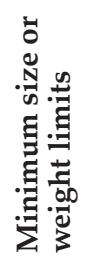 & 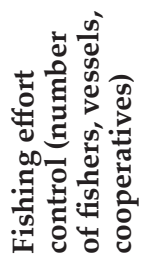 & 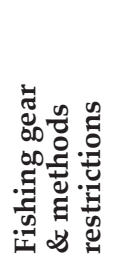 & 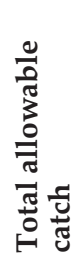 \\
\hline 1925 & • & • & • & • & • & & • & \\
\hline 1932 & • & • & • & & • & • & • & \\
\hline 1942 & • & • & • & & • & • & $\bullet$ & • \\
\hline 1950 & $\bullet$ & • & • & • & • & • & $\bullet$ & \\
\hline 1972 & $\bullet$ & $\bullet$ & • & • & • & $\bullet$ & $\bullet$ & • \\
\hline 1986 & • & • & • & & • & • & • & • \\
\hline 1992 & • & • & • & • & • & • & • & • \\
\hline 2007 & • & • & • & • & $\bullet$ & & • & • \\
\hline
\end{tabular}

Source: Own elaboration based on the eight fisheries laws.

Coordination among federal agencies. Except for the law of 1992, the state includes coordination between different ministries for the development of specific institutions and duties. For example, coordination with the Ministry of Economics for regulating fishing areas, species for cooperatives, TAC (DOF, 1948a), and the percentage of catch to fulfil domestic requirements (DOF, 1950); with the Ministry of Communications and Transportation for the establishment of the number of boats; with the Ministry of Urban Development and Ecology for the establishment of closures (seasonal and area based), areas for production (i.e., post-larvae, larvae, and seeds), measures for conservation, cultivation, or repopulation of fish resources, and for the identification of species at risk (DOF, 1986a); with the Ministry of Hygiene and Sanitation for regulating the quality and sanitation of fish products as well as for traceability systems (DOF, 2007a, 2012e).

Power devolution to lower state levels. The first (1925) and the current (2007) laws include power devolution to lower state levels in relation to fishing rights allocation and fisheries regulation. In the law of 1925, municipalities and local authorities, in the absence of the federation, could issue permits for local waters. Article 10 of the fisheries law of 1925 states:

Art 10. Permits for local fishing within waters within the jurisdiction of a municipality will be granted by the delegates of the Ministry of Agriculture and Development, and in their absence, by the municipal presidents or local authorities (DOF, 1925).

In the law of 2007, provinces can grant recreational fishing permits, regulate and grant permits for sessile species that do not move beyond the coastal waters of the 
corresponding province, and support policy design in alignment with the national policy on fisheries sustainability. In addition, municipalities can design and implement local policies and programmes for fisheries and aquaculture, as well as advise the ministry on methods and measures for the conservation of fishing resources and repopulation of fishing areas. The collaboration between federal, provincial, and municipal agencies is formalized through collaboration agreements. For example, Article 11 of the fisheries law mandates:

Art 11. In order to achieve the objectives of this Law, the Ministry may celebrate contracts or coordination agreements with the governments of coastal provinces, with the participation, where appropriate, of their municipalities, with the aim of assuming the following functions: I. the administration of permits for the realization of sport-recreational fishing; II. the sustainable management of the sessile species that are found in the estuarine lagoon systems and in the territorial waters...; III. administration of fishing in waters that serve as a limit between two provinces, or that pass from one to another...(DOF, 2007a).

\section{Co-governance}

The analysis shows that the state creates the spaces for public, private, and social actors to engage in institution making. However, as shown below, the state does not cede this governing function to other actors participating in this governance mode.

Actors participating in institution making. Four fisheries laws (DOF, 1948, 1950, 1986, 2007) include mechanisms for co-governance through the participation of actors. The law of 1948 mandates consultation with fishing federations to set the maximum volume of exploitation for reserved species to cooperatives. As mentioned before, the law of 1950 creates a National Advisory Commission of Fisheries, to engage private, public, and social actors in providing technical advice under the request of the ministry or any interested party about the issues included in the law (DOF, 1950). The law of 1972 raises the profile of the National Advisory Commission of Fisheries by making it in charge of promoting laws and regulations as well as of elaborating the annual programme for fisheries development. In the law of 1986, this Commission supports the development of fisheries programmes, participates in the definition of objectives, goals, regulations, and development measures within these programmes, and proposes solutions to the problems caused by the exploitation of aquatic flora and fauna (DOF, 1986a). The Commission was not included in the law of 1992, and no other space for non-state actors' participation was created. This does 
not mean that non-state actors did not participate in fisheries governance; it only means that their participation was not regulated by the state. On the contrary, the law of 2007 creates National and Provincial Councils for Fisheries and Aquaculture to support fisheries policy, programmes, and regulations of management tools, and provides advice on resolutions concerning fishing rights. The National Council also includes representatives of the public, private, and social sector. No information on membership for Provincial Councils is included in the law (DOF, 2007a).

\section{Self-governance}

The analysis shows that the state can facilitate self-governance in this order of governance through the legitimization of rights to fish and local institutions. For the latter, only one of the eight laws recognized local institutions. This only case shows the autonomy of the state to cede this governing function to local and other actors.

Legitimization of local institutions and rights. The eight fisheries laws include the right of Mexican citizens to fish for subsistence consumption. This type of fishing does not require a permit, concession, or authorization. It is also exempt from taxation. Five of the laws indicate that this right cannot be deprived by fishing rights granted by the state to citizens and corporations (DOF, 1925, 1932, 1948a, 1950, 2007a).

The law of 2007 is the one law that supports the development of customary rules by users, based on their traditional knowledge, and the creation of community groups to support the administration and conservation of fish resources (DOF, 2007a). For example, Article 38 of the law of 2007 states:

Art 38. [Ordinance Programmes] The authority will support the creation of control mechanisms established by users, based on traditional knowledge on management systems, where they exist, and will promote the creation of community groups to support the administration and conservation of resources according to the principles of the present Law (DOF, 2007a).

Except for this law, the state has not shown a preference for including coastal communities in the development of institutions. It has preferred to involve larger forms of organizations (i.e., federations, confederations) with wider representation of fishers and industry, in institution making. 


\subsubsection{Third Order of Governance: Definition of Overarching Goals}

\section{Hierarchical governance}

The state adopts the hierarchical mode in the third order of governance. Overarching goals, which are the norms guiding fisheries governance, are defined by the Congress with the inputs of the Executive and are included in the fisheries laws. The engagement of non-state actors is not mandated. However, two laws (DOF, 1986, 2007) include mechanisms for non-state actors' contributions to objectives definition for programmes and fisheries management plans. The law of 1986 allows private and social actors to support the development of fisheries programmes, including the definition of objectives, goals, regulations, and development measures for these programmes. For example, Article 62 of the law of 1986 states:

Art 62. The National Advisory Commission of Fishing is an advisory instrument of the Ministry of Fisheries, whose aims are: I. to support the Ministry of Fisheries in the formulation of programmes for the sector; and II. to serve as a mechanism for the participation of public, private, and social sectors to define the objectives and goals of the programmes referred to in the previous fraction I;...(DOF, 1986a).

In addition, the law of 2007 engages different actors, through their participation in the national and provincial councils, in the definition of fishery-specific objectives for management plans. Article 39 of the law of 2007 states:

Art 39. According to the ends and objectives of this law, management plans shall include: I. fishery-management objectives defined by the Fisheries and Aquaculture National Council and the Provincial Councils...

Although actors do not participate in defining overarching goals for fisheries governance, their participation in defining objectives for specific fisheries and programmes, embrace their contributions to larger and overarching goals.

Overarching goals for fisheries governance defined by the state mainly refer to environmental goals, which are combined with economic and social goals. Goals are summarized in Table 3-4. The following trend is observed over time:

- laws of 1925, 1932, 1948, and 1950: environmental/economic goals;

- laws of 1972 and 1986: environmental/social goals;

- law of 1972: environmental/economic goals; and,

- law of 2007: sustainable development. 
The first four fisheries laws refer to goals on species conservation as well as to best development, resource use (DOF, 1925), rational exploitation (DOF, 1925, 1932, 1948a), higher economic yield (DOF, 1932, 1948a), and maximum use (DOF, 1950). The law of 1948 expands its focus on target commercial species to include all species that live in the water. The fisheries laws of 1972 and 1986 also include the conservation of the aquatic flora and fauna of the marine environment. In addition, these two latter laws are the first to incorporate social goals such as equal distribution (DOF, 1972, 1986a) and social benefits (DOF, 1986a). The law of 1992 shifts back to the focus on target commercial species and on fisheries development, mandating the conservation, protection, and exploitation of fish resources for their adequate development and management (DOF, 1992b). The fisheries law of 2007 includes sustainable development as the overarching goal (DOF, 2007a). The goals are summarized in Table 3-4. These goals are meant to guide the other two orders of governance: institution making and day-to-day operations.

As shown in Table 3-4, the goals set by fisheries laws are consistent with Article 27 of the Mexican Constitution, which involves ensuring social benefits (DOF, 1976a), equitable distribution of the public wealth (DOF, 1917), the development of the nation, the livelihoods of rural and urban populations, whilst avoiding the destruction of natural resources (DOF, 1976a), preserving and restoring the ecological equilibrium (DOF, 1987b), and providing the conditions and regulations for an integrated and sustainable rural development to guarantee sufficient food for Mexicans (DOF, 2011b).

Table 3-4. Summary of overarching goals for fisheries governance within the Mexican legal framework

\begin{tabular}{|c|c|c|c|}
\hline Legal framework & Environmental goals & Economic goals & Social goals \\
\hline \multicolumn{4}{|l|}{ Mexican Constitution } \\
\hline Art 1. Reform 2011 & & & $\bullet \bullet$ \\
\hline $\begin{array}{l}\text { Art } 27 \\
\text { Reform } 1976 \\
\text { Reform } 2011\end{array}$ & $\begin{array}{l}\bullet \bullet \\
\bullet \bullet \bullet\end{array}$ & $\bullet \bullet \bullet$ & $\begin{array}{c}\bullet \\
\bullet \\
\bullet \bullet \bullet\end{array}$ \\
\hline \multicolumn{4}{|l|}{ Maritime zone laws } \\
\hline 1967 law & & $\bullet \bullet$ & \\
\hline 1976 law & $\bullet \bullet$ & $\bullet$ & \\
\hline 1986 law & $\bullet \bullet$ & $\ddot{\bullet}$ & \\
\hline \multicolumn{4}{|l|}{ Fisheries laws } \\
\hline 1925 law & $\bullet$ & $\bullet * *$ & \\
\hline 1932 law & $\bullet$ & $\bullet \bullet$ & \\
\hline 1948 law & $\bullet \bullet$ & $\bullet \bullet$ & \\
\hline 1950 law & $\bullet$ & $\bullet$ & \\
\hline 1972 law & $\bullet \bullet$ & $\bullet \bullet$ & $\bullet \bullet$ \\
\hline
\end{tabular}




\begin{tabular}{|l|c|c|c|}
\hline \multicolumn{1}{|c|}{ Legal framework } & Environmental goals & Economic goals & Social goals \\
\hline 1986 law & $\bullet \bullet$ & & \\
\hline 1992 law & $\bullet$ & & \\
\hline 2007 law & $\bullet \bullet \bullet$ & $\bullet \bullet \bullet$ & $\bullet \bullet \bullet$ \\
\hline
\end{tabular}

Source: Own elaboration based on the Mexican legal framework. Environmental goals include target (commercial) species conservation $\bullet$, species (not only commercial) conservation $\bullet$, ecosystem (includes habitats) conservation $\bullet \bullet \bullet$, and sustainable development $\bullet \bullet \bullet$. Economic goals include: resource exploration $\bullet$, use and maximization of use $\bullet \bullet$, economic yield, markets $\bullet \bullet \bullet$, and sustainable development $\bullet \bullet \bullet$. Social goals include social benefits/well-being $\bullet$, equal distribution of benefits $\bullet \bullet$, protection of human-rights $\bullet \bullet \bullet$, and sustainable development $\bullet \bullet \bullet$.

The Mexican Constitution's core objective is the respect and protection of human rights (DOF, 1917) in alignment with international treaties that Mexico is part of (DOF, 2011a). The Mexican Constitution states in its Article 1:

Art 1. In the United Mexican States, all individuals shall be entitled to the human rights granted by this Constitution and the international treaties signed by the Mexican state, as well as the guarantees of the protection of these rights. Such human rights shall not be restricted or suspended, except for the cases and under the conditions established by this Constitution (DOF, 2011b).

This constitutional goal has not permeated into the fisheries laws. However, the human rights-based approach has been suggested and endorsed by the FAO's member states, through the SSF Guidelines, aimed at ensuring the sustainability of smallscale fisheries in the context of food security and poverty eradication (Chuenpagdee \& Jentoft, 2018).

The goals of fisheries laws are also consistent with the maritime fisheries laws, which incorporate the state jurisdiction over marine fish resources. The Law of the Nation's Exclusive Fishing Zone published in 1967 is aimed at increasing the area of state jurisdiction for fishing purposes (see Art 2; DOF, 1967). The Regulatory Law of Paragraph 8 of Article 27 focuses on the conservation of natural resources, preservation of the marine environment, exploration, and exploitation of natural resources for economic activities (see Art 4; DOF, 1976b). The Federal Law of the Sea is aimed at conserving and using living and non-living marine resources, protecting the marine environment, and using oceans for economic purposes (see Art 6; DOF, 1986b). This is exemplified by the following articles of these laws, which respectively state:

Art 2. The United Mexican States establish their exclusive jurisdiction for fishing ends within an area of 12 nautical miles of width $(22,224 \mathrm{~m}) \ldots$ (DOF, 1967). 
Art 4. In the exclusive economic zone, the nation has: I. sovereignty rights for the end goals of exploration, exploitation, conservation, and administration of natural resources, renewable and non-renewable, of the seabed including the subsoil and suprajacent waters; II. exclusive rights and jurisdiction with respect to the establishment and use of artificial islands and infrastructure; III. exclusive jurisdiction with respect to other exploration and economic exploitation activities; IV. jurisdiction with respect to: a) preservation of the marine environment, including control and elimination of pollution; and b) scientific research (DOF, 1976b).

Art 6. The sovereignty of the nation and its sovereignty rights, jurisdiction, and competences within the limits of the respective marine zones, according to this law, will be executed according to the Political Constitution of the United Mexican States, the international law, and national legislation applicable to: II. the regime applicable to living marine resources, including their conservation and use; III. the regime applicable to non-living marine resources, including their conservation and use; IV. economic use of the sea... V. protection and preservation of the marine environment... VI. development of marine scientific research (DOF, 1986b).

Table 3-5 summarizes the institutional setting for the coexistence of governance modes in different orders of governance presented in this section. The 44 changes illustrated by the legal framework demonstrate the capacity of the state to make changes in the governance system, by ceding and revoking governing functions, according to state goals, preferences, and priorities.

Table 3-5. Coexistence of governance modes in Mexican fisheries

\begin{tabular}{|c|c|c|c|c|c|c|c|c|c|c|c|c|}
\hline \multirow{3}{*}{ Legal framework } & \multicolumn{4}{|c|}{ Hierarchical governance } & \multicolumn{5}{|c|}{ Co-governance } & \multicolumn{3}{|c|}{ Self-governance } \\
\hline & 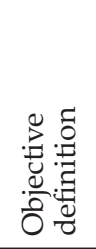 & 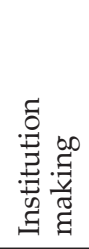 & 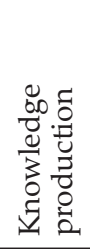 & 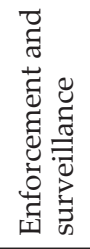 & 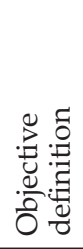 & 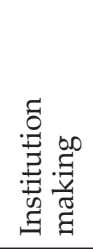 & 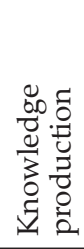 & 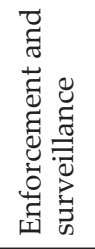 & 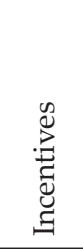 & 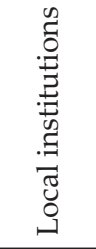 & 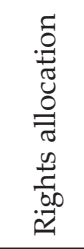 & 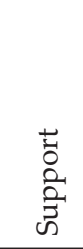 \\
\hline & $\begin{array}{c}3^{\text {rd }} \\
\text { order }\end{array}$ & $\begin{array}{c}2^{\text {nd }} \\
\text { order }\end{array}$ & $\begin{array}{c}1^{\text {st }} \\
\text { order }\end{array}$ & $\begin{array}{c}1^{\text {st }} \\
\text { order }\end{array}$ & $\begin{array}{c}3^{\text {rd }} \\
\text { order }\end{array}$ & $\begin{array}{c}2^{\text {nd }} \\
\text { order }\end{array}$ & $\begin{array}{c}1^{\text {st }} \\
\text { order }\end{array}$ & $\begin{array}{c}1^{\text {st }} \\
\text { order }\end{array}$ & $\begin{array}{c}1^{\text {st }} \\
\text { order }\end{array}$ & $\begin{array}{c}2^{\text {nd }} \\
\text { order }\end{array}$ & $\begin{array}{c}1^{\text {st }} \\
\text { order }\end{array}$ & $\begin{array}{c}1^{\text {st }} \\
\text { order }\end{array}$ \\
\hline $\begin{array}{l}\text { Art. } 27 \\
\text { (Refs 1992, 2001) }\end{array}$ & - & $\bullet$ & & & & & & & & 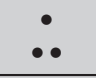 & • & \\
\hline $\begin{array}{l}\text { Art. } 73 \text { XXIX-L } \\
\text { (Ref 2004) }\end{array}$ & $\bullet$ & $\bullet \bullet$ & $\bullet \bullet$ & $\bullet \bullet$ & & $\bullet$ & $\bullet$ & $\bullet$ & $\bullet$ & & & \\
\hline \multicolumn{13}{|l|}{ Maritime laws } \\
\hline 1967 law & $\bullet$ & $\bullet$ & & & & & & & & & & \\
\hline 1976 law & $\bullet$ & $\bullet$ & $\bullet$ & & & & & & & & & \\
\hline 1982 law & $\bullet$ & $\bullet$ & $\bullet$ & & & & & & & & & \\
\hline
\end{tabular}




\begin{tabular}{|c|c|c|c|c|c|c|c|c|c|c|c|c|}
\hline \multirow{3}{*}{ Legal framework } & \multicolumn{4}{|c|}{ Hierarchical governance } & \multicolumn{5}{|c|}{ Co-governance } & \multicolumn{3}{|c|}{ Self-governance } \\
\hline & 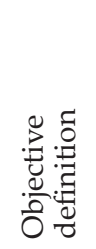 & 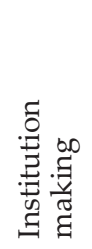 & 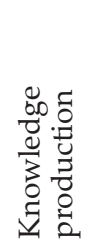 & 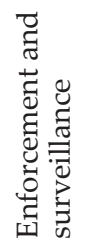 & 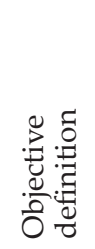 & 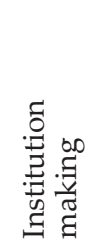 & 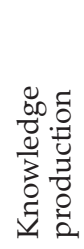 & 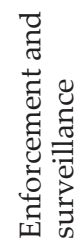 & 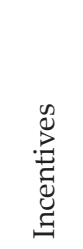 & 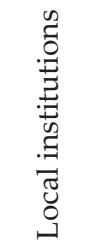 & 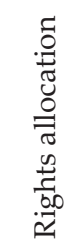 & 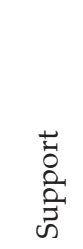 \\
\hline & $\begin{array}{c}3^{\text {rd }} \\
\text { order }\end{array}$ & $\begin{array}{c}2^{\text {nd }} \\
\text { order }\end{array}$ & $\begin{array}{c}1^{\text {st }} \\
\text { order }\end{array}$ & $\begin{array}{c}1^{\text {st }} \\
\text { order }\end{array}$ & $\begin{array}{c}3^{\text {rd }} \\
\text { order }\end{array}$ & $\begin{array}{c}2^{\text {nd }} \\
\text { order }\end{array}$ & $\begin{array}{c}1^{\text {st }} \\
\text { order }\end{array}$ & $\begin{array}{c}1^{\text {st }} \\
\text { order }\end{array}$ & $\begin{array}{c}1^{\text {st }} \\
\text { order }\end{array}$ & $\begin{array}{c}2^{\text {nd }} \\
\text { order }\end{array}$ & $\begin{array}{c}1^{\text {st }} \\
\text { order }\end{array}$ & $\begin{array}{c}1^{\text {st }} \\
\text { order }\end{array}$ \\
\hline \multicolumn{13}{|l|}{ Fisheries laws } \\
\hline 1925 law & $\bullet$ & $\bullet \bullet$ & & $\bullet \bullet$ & & & $\bullet \bullet$ & $\bullet$ & & $\bullet \bullet$ & $\stackrel{\bullet}{\bullet \bullet}$ & \\
\hline 1932 law & $\bullet$ & $\bullet$ & & $\bullet$ & & & & $\bullet$ & & $\bullet \bullet$ & $\bullet \bullet \bullet$ & \\
\hline 1948 law & - & $\bullet$ & & $\bullet$ & & - & $\bullet \bullet$ & & & $\stackrel{\bullet}{\bullet}$ & $\ddot{\bullet}$ & $\bullet$ \\
\hline 1950 law & - & $\bullet$ & $\bullet$ & $\bullet$ & & & $\bullet$ & $\bullet$ & & $\bullet \bullet$ & $\ddot{\bullet}$ & $\bullet$ \\
\hline 1972 law & $\bullet$ & $\bullet$ & $\bullet$ & $\bullet$ & & - & $\bullet$ & & $\bullet$ & $\bullet$ & $\begin{array}{c}\bullet \\
\bullet \bullet\end{array}$ & $\bullet$ \\
\hline 1986 law & - & $\bullet \bullet$ & $\bullet$ & $\bullet$ & & - & $\bullet \bullet$ & & & $\bullet \bullet$ & $\stackrel{\bullet}{\bullet}$ & $\bullet$ \\
\hline 1992 law & $\bullet$ & $\bullet$ & $\bullet$ & $\bullet$ & & & $\bullet$ & & & $\bullet$ & & $\bullet$ \\
\hline 2007 law & - & $\bullet \bullet$ & $\stackrel{\bullet}{\bullet \bullet}$ & $\stackrel{\bullet}{\bullet \bullet}$ & • & $\bullet$ & $\ddot{\bullet}$ & - & $\bullet$ & $\therefore$ & • & $\stackrel{\bullet}{\bullet}$ \\
\hline
\end{tabular}

Source: Own elaboration based on the Mexican Constitution, maritime laws and fisheries laws for the period 1917-2019. Forty-four changes are illustrated in the legal framework. Hierarchical governance includes governing functions: centralised in one agency $\bullet$, coordinated among federal agencies $\bullet \bullet$, and devolved to lower state levels $\bullet \bullet$. Co-governance includes mechanisms for stakeholder's participation $\bullet$ and devolution of governing functions $\bullet \bullet$. Self-governance includes the legitimization of local institutions $\bullet$, the protection of right to fish for subsistence needs $\bullet \bullet$; fishing rights allocation to self-governed groups: preference $\bullet$, allocation of exclusive use for reserved species $\bullet \bullet$, territorial rights allocation $\bullet \bullet \bullet$, support to self-governed groups: financial support $\bullet$, technical support $\bullet \bullet$, programmes and policies $\bullet \bullet \bullet$. The $3 \mathrm{rd}, 2 \mathrm{nd}$, and 1 st refer to orders of governance.

\subsubsection{Actors Engaged and Recognized in the Governing of Fisheries}

Results show the meta-governance power of the state to include and exclude actors from the governing, in different orders of governance, as expressed in the legal framework. The number of actors involved in governing functions increased from 1925 to 1986. In 1992, except for researchers, actors were not formally recognized in governing functions for fisheries. This does not mean that actors did not participate in fisheries governance, it only means that the state did not regulate their participation. The law of 2007 reintegrates the participation of social and private actors in governing functions, due to the amendment of Article 73 section XXXIX-L of the Mexican Constitution to incorporate private and social actors in fisheries matters. 
Citizens, who represent the public interest, were involved only in the first order of governance (enforcement and surveillance) in two laws $(1925,1948)$, and since then have been excluded from fisheries governance. Researchers, who represent actors with technical expertise, became involved in knowledge production in 1948 and their participation continues today. Fishers, who represent social and private sectors, have been incorporated in different formats and orders. For example, right holders were included in most laws (except for the law of 1992) for the governing functions of the first order, such as knowledge production, and enforcement and surveillance. Their participation in the format of federations was upgraded to the second order of governance in 1948, to support the establishment of quotas for fishing cooperatives. The laws of 1972 and 1986 included larger forms of organizations such as confederations and industry chambers (of fisheries and other sectors), which, according to Knill and Tosun (2012), follow a corporatist approach. These organizations are organized in a single, non-competitive, and hierarchical manner with a representational monopoly to exercise control over their supporters; the cooperatives and fish workers. The law of 2007 reintegrates private and social organizations into governing functions in the three orders of governance (objective definition, institution making, enforcement and surveillance, and incentive provision).

The state has the power to include and exclude actors from the governing of fisheries. However, over the years the state has preferred to involve the private and social sectors (in their different organization formats), and leave civil society out from the governing of fisheries. Therefore, civil society does not have the opportunity to formally participate in fishery governance.

The self-governed groups recognized and supported by the state changed over time. Coastal small-scale fishers are recognized in the fisheries laws of 1925, 1932, and 1972. The law of 1932 supported fishers' organizations in order to improve their social and economic conditions. From the law of 1948 to the law of 1986 the preferred form of organization for the allocation of fishing rights was the fishing cooperatives. The law of 1972 added the ejido cooperatives and the law of 1986 the communal cooperatives. The fisheries law of 1992 recognizes cooperatives, but eliminated the privileges in terms of fishing rights and only provided support under request. The law of 2007 recognizes the inhabitants of coastal communities and indigenous groups as preferential receivers of fishing rights, and recognized their capacity to develop local institutions to administer fish resources. Indigenous became a priority for policies and programmes. Over time the state has indirectly influenced the format (i.e., cooperatives), membership (i.e., the percentage of coastal and local fishers), and procedures (i.e., contracts to acquire equipment) of self-governed groups to better suit fisheries governance 
goals and preferences. Self-governed groups have adapted to the different formats in order to access to fishing rights. Some groups were excluded (e.g., cooperatives, small-scale fishers) from the legal framework. All this influence reflects the shadow of hierarchy of the state in self-governance contexts.

\subsection{Discussion}

This chapter shows how the legal framework illustrates the power of the state to create coexisting governance modes. By using the interactive governance theory to frame the analysis of the Mexican case, this chapter shows how the state, created an institutional setting to operate a hybrid system (combined governance modes) in 1925 that continues to date. This hybrid system is characterized by the sole presence of the state in the meta-order; its dominant presence in institution making (fishing rights, policies, regulations); and a greater engagement of actors in day-to-day operations (e.g., knowledge production, enforcement and surveillance). This confirms the absence of purism of fisheries governance modes (Chuenpagdee \& Jentoft, 2018; Kooiman et al., 2005) as well as the presence of non-state actors in the governing of fisheries in lower levels of decision-making (Sen \& Nielsen, 1996), with little influence on policies (Berkes, 2009) and objectives. It is argued that large devolution of power can cause problems of unaccountability, inequalities, or failure to address issues of public interest such as environmental protection (Viet-Thang, 2018). However, to strengthen fisheries governance, greater hybridization in the second and third order is needed.

The analysis of the legal framework also shows the meta-governance power of the state to cede and revoke governing functions from actors. The forty-four changes made to the legal framework illustrate the changes in governing functions performed in different orders, the inclusion and exclusion of actors (e.g., citizens, cooperatives), the creation and operation of multi-actors and self-governed groups (e.g., membership, form of organization), and the transformation of the state bureaucratic system (e.g., concentrating governing functions in one agency, splitting them among different agencies and to its lower governing levels such as provinces). This power of meta-governance allows the state to expand its shadow of hierarchy in the governance system, even in situations where alternative governance modes (i.e. self-governance and co-governance) seem to dominate. This is relevant in the context of fisheries given the heterogeneity of fish populations and fishers. It also helps in times when a rapid reaction is needed (Leavitt, 1951) in situations of risk, for example, fisheries overexploitation. However, it can also lead to centralization, power concentration, and few opportunities for actors to influence (Leavitt, 1951; Shaw, 1981) and act collectively as required for fisheries governance (Steel \& Weber, 2001). 
The analysis shows that the state retains the power of defining the overarching goals for fisheries governance that guide institution making and day to day operations. According to Kooiman \& Jentoft (2009) governors need to be explicit about this dimension of meta-governance. In the Mexican case, overarching goals reflect the public interest, and alignment with other legal instruments (i.e., Mexican Constitution, maritime laws) and binding agreements (i.e., UNCLOS). They combine environmental with economic and social goals. This is consistent with the evolution of overarching goals for fisheries at the global level, from protecting target species (single-species approach) to ensuring healthy oceans (ecosystem approach to fisheries (EAF)), social justice, livelihoods, and employment (Bavinck \& Chuenpagdee, 2005). In the context of fisheries, the integration of these types of goals (environmental, economic, and social) is relevant to sustain fish populations and fishers. As an example, the Sustainable Development Goal (SDG) 14 recognizes that in order to achieve the zero-overfishing target by 2020, economic and social targets need to be in place (e.g., small-scale fishers' access to resources and markets). In recent years, the human rights-based approach (respect for, and protection of, human rights) is recognized as essential to ensure small-scale fisheries' sustainability (Sharma, 2011; Song \& Soliman, 2019; Sowman et al., 2014). In the Mexican case, the protection of human rights is the main objective of the Mexican Constitution (for all Mexicans, not just for small-scale fisheries) but it has not permeated to the fisheries laws. In addition, an outcome-based approach is relevant and needed to understand the impacts of institutional change in fisheries (Schmid, 1987) as well as the effectiveness towards overarching goals, especially in cases like Mexico, where multiple changes are occurring.

Knowledge production, enforcement, and surveillance are the governing functions that the state shares with different actors. The state shows preference for the integration of expertise of researchers, right holders, as well as of the private and social sector (fishers) for knowledge production. This is consistent with the shadow of hierarchy literature, which suggests integration of and delegation to specialized organizations to ensure sufficient expertise is included in decision-making, and to ensure the stability and predictability of policymaking (Héritier \& Lehmkuhl, 2008). The state also integrates non-state actors (i.e., citizens, right holders, and indigenous groups) in enforcement and surveillance activities, which helps expand the spatial coverage of these activities, which is relevant in the context of states with large coasts and multiple fisheries, such as the case of Mexico. The sharing and delegation of these two governing functions are strategic for the state to cope with the high information and enforcement costs associated with inherent characteristics of 
fisheries. These characteristics include species mobility and major uncertainties associated with natural systems, the biological, social, and political factors (Hilborn \& Peterman, 1996), and the challenges of implementing fishing rights in low exclusive CPR (Seijo et al., 2010).

Another important aspect evidenced by the legal framework is the meta-governance power of the state to exclude actors (previously included) from fisheries governance. In the Mexican case, this applies to self-governed groups and citizens. Although the Mexican Constitution takes a strong stand for the well-being of self-governed groups, the state support for these groups has decreased over time. Small-scale fishers and cooperatives, as well as the policies to ensure their access to fishing rights (for fisheries and spaces for collective and exclusive exploitation) have been eliminated from the legal framework. It is important to note that the global trend is going in the opposite direction, especially since states endorsed the Guidelines (FAO, 2015) and the 2030 Agenda for Sustainable Development, which include targets to ensure the access of small-scale fisheries to rights and markets (e.g., SDG 14b). Scholars have raised the attention to the challenges of applying the SSF Guidelines and achieving the SDG 14b target in the context of current institutional frameworks (laws and policies) and are calling for reforms (Landin, 2020; Nakamura \& Hazin, 2020; Said et al., 2020). In the case of Mexican fisheries, a first analysis on the adoption of the SSF Guidelines recommends to recognize the relevant aspects of small-scale fisheries in policies and engage small-scale fishers and civil society in the implementation of these guidelines (Espinosa-Romero et al., 2017).

We note in this analysis the autonomy of the state to change the legal framework in order to change the status quo. However, in the case of Mexico, the state does that by changing the preceding law rather than analysing what has worked or not in the past, from the diverse state interventions and governance approaches. Thus, we observed drops and reuse of different approaches with no order or sequence (decentralization, centralization, management sharing with non-state actors, recentralization, and decentralization). This relates to the "shifting the baseline" concept presented by Pauly (1995) in which he describes how fisheries experts, to evaluate change, use as the baseline the status of fish populations at the start of their careers (rather than in its untouched state). Each generation thus redefines the "baseline", losing the perception of change. Pauly (1995) suggests developing frameworks to add earlier knowledge into present models. This appears to be applicable to fisheries policymakers. For future fisheries laws, this analysis recommends to shift the baseline to the beginning of the fisheries' legal frameworks to learn from past experience. 
This shifting can bring learning from the diversity of mechanisms to to engage the state and other actors into fisheries governance.

\subsection{Concluding Remarks}

This chapter analyses the shadow of hierarchy by investigating How the state uses its legal framework to create coexisting governance modes, using Mexican fisheries as the case study. The application of the interactive governance theory allowed for the analysis of the diverse mechanisms that the Mexican state has employed for the coexistence of governance modes during the period 1917-2019. The case study shows that the state created a hybrid system in 1925 that remains to date. It also shows that the state retains its superior hierarchy in this system to define overarching goals for fisheries governance and define which actors must be engaged in the definition of particular institutions and the corresponding implementation. The historical perspective of this analysis shows that over time, actors can be formally included (e.g., private sectors, researchers) and excluded (e.g., citizens, cooperatives, small-scale fishers) from the governance system. It also shows the power of the state to transform its own bureaucratic operation, for example by centralizing and decentralizing governing functions with provinces and municipalities. The following Chapter deepens on the analysis of the shadow of hierarchy. It goes beyond actors' interaction, to show how the state meta-governs by steering and shaping the general patterns of fishing. Hence, the following chapter uses the legal framework and fisheries regulations to analyse the state regulation of the general cognitive understanding of fishing, the competences, and materials for the practice of fishing, rather than regulating individual actions conducted by public, private, and social actors. 


\section{Chapter 4. The Shadow of Hierarchy in the Governance of Fishing Practices ${ }^{29}$}

\subsection{Introduction}

The transformation of the state intervention in public policies involves changes in the interactions among actors moving beyond the traditional hierarchical participation and control of the state. The shift from the formal governmental order to informal governance dynamics involves the division of competences between different levels of government and other public, private, and social actors (Cairney, 2020, p. 130). This process of delegation leads to the increase of the shadow of hierarchy where the state serves as the ultimate point of reference in the governance of policy fields among actors themselves (Scharpf, 1997). The governing functions performed by the state focuses on the 'coordination of various forms of formal and informal types of public-private interaction' (Pierre, 2000, p. 3). Thus, the central state remains relevant in spite of its limited involvement in the everyday management of policy domains performed by other public, private, and social bodies.

The research on fisheries policies exemplifies this transformation of governance dynamics. To take account of these changes, the prolific literature on fisheries governance developed numerous concepts and approaches to consider a diversity of involved actors (Jentoft \& Chuenpagdee, 2015c; Kooiman et al., 2005), the malleability of their interactions (Baker et al., 2020; Brent et al., 2020), and the idiosyncrasy of institutional, regulatory, and political factors (Baird et al., 2020; Espinoza-Tenorio et al., 2011). Such a multiplicity of factors leads to the emergence of different structures and patterns of fisheries governance, including processes of decentralization (Wever et al., 2012), privatization (Bennett, 2017; Bresnihan, 2019a, 2019b; Haller, 2019), polycentric governance (Mahon et al., 2005), and networks (Zepeda-Domínguez et al., 2019). At the same time, even in the context of emerging bottom-up forms of governance, the state remains as the point of reference in the analysis of different fisheries governance structures, including co-management (Jentoft, 1989; Pomeroy \& Berkes, 1997; Viet-Thang, 2018), self-organization (Anthony \& Campbell, 2011; Mansbridge, 2014; Ostrom, 1990), property regimes of CPRs (Grafton, 2000), and other non-hierarchical polycentric governance settings (Sowman \& Wynberg, 2014). However, in spite of the diversification of governance forms, how the state acts in

\footnotetext{
${ }^{29}$ This chapter was co-authored with Dr Michal Natorski. Affiliation: United Nations University (UNUMerit) and Maastricht University - Maastricht Graduate School of Governance (MGSG).
} 
the shadow of hierarchy in the fisheries field remains understudied. In particular, it remains unclear how the state confronts the dilemma of losing direct everyday command of actors and simultaneously preserving the capacity to influence them indirectly.

To address this gap, this chapter investigates how the state influences the governance of fisheries within an extending shadow of the state hierarchy, i.e., when its influence becomes more indirect given the distribution of competences among different actors, as illustrated in Chapter 3. This chapter argues that to compensate for the weakening of direct influence on actors, the state increases its indirect intervention through the definition of the patterns of fishing practices that constitute the entire fisheries policy domain. It involves displacement from the direct control of individual actions of fishers to the control of general patterns of these actions. The meanings, the competences, and the materials (Shove et al., 2012) required to perform fishing practices constitute the general patterns of these actions. As a result, the state frames cognitive and material parameters to guarantee a regularity of actions without directly commanding actors' actions. Such steering of social practices facilitates indirect coordination of the actors by shaping the general patterns of their individual actions. It creates a framework for regulating the expectations regarding appropriate actions for otherwise autonomous actors.

This argument was investigated in the longitudinal analysis of the evolution of the regulation of fisheries in Mexico. The transformation of the Mexican state in fisheries governance took place against the background of political transformation from authoritarianism through neoliberal reforms to democratization (Baer \& Maloney, 1997; Bennett, 2017; Blecker, 2009; Thorpe \& Aguilar, 2010). The governance of fisheries in Mexico illustrates this apparent contradiction between the diversification of governance forms in the fisheries domain due to the extension and coexistence of different non-hierarchical modes of governance and the endurance of state authority. It shows how the Mexican state governs at the intersection of hierarchical and horizontal modes of governance by increasingly shaping the patterns of fishing practices.

Section 4.2 outlines briefly the analytical approach to understanding the nature of governing through the control of practices. Section 4.3 introduces the empirical materials and research methods employed in this chapter. Section 4.4 presents the evolution of different forms of governing policy resources and an increasing regulation 
of the elements comprising fishing practices. Finally, Section 4.5 discusses the findings and Section 4.6 presents concluding remarks.

\subsection{Analytical Approach}

The approach adopted in this paper departs from the Weberian definition of the state as a 'compulsory political organization with continuous operations as its administrative staff [that] successfully upholds the claim to the monopoly of the legitimate use of physical force in the enforcement of its order' (Weber, 1978). This traditional approach assumes a hierarchical role for the state as it regulates, monitors, and polices society by making and enforcing collective decisions. However, to modify this approach this chapter assumes a more collaborative character of the state and society interactions. According to Jessop (2009, p. 372), the state is defined as 'a distinct ensemble of institutions and organizations whose socially accepted function is to define and enforce collectively binding decisions on a given population in the name of their "common interest" or "general goal"'. This approach suggests a transition from a Weberian conception of a bureaucratic state to a 'postmodern' state involving, among other things, a shift in the state involvement as well as involved power relations in different governance domains.

The nature of the state transforms from uniform hierarchical structures between different actors towards more heterarchical relations comprising simultaneous coexistence of networks, hierarchies, and markets (Richards \& Smith, 2002, p. 36). Following the criteria of the distance and distribution of the responsibilities in relation to other actors in a governed domain, this chapter distinguishes four ideal types of involvement of the state. The state can be involved in a given domain directly or indirectly by delegating some responsibilities and functions to other actors. Similarly, the distribution of these responsibilities and functions can be more concentrated and centralized in one of very few actors or more distributed and decentralized among more actors. Based on these criteria and emerging types of relationships established with other actors, there are four possible models of state involvement in a policy domain (see Table 4-1). Based on these considerations, the more distributed and indirect the involvement of the state is, the greater is its shadow over the locus of the governed domain. 
Table 4-1. Models of the state involvement in a governed domain

\begin{tabular}{|c|c|c|}
\hline State involvement & Direct & Indirect \\
\hline $\begin{array}{l}\text { Concentrated in one type } \\
\text { actor }\end{array}$ & $\begin{array}{l}\text { Direct concentrated } \\
\text { (e.g. one dedicated ministry with } \\
\text { authority) }\end{array}$ & $\begin{array}{l}\text { Indirect concentrated } \\
\text { (e.g. one ministry share authority with } \\
\text { provinces and municipalities) }\end{array}$ \\
\hline $\begin{array}{l}\text { Distributed in various } \\
\text { types of actors }\end{array}$ & $\begin{array}{l}\text { Direct distributed } \\
\text { (e.g. various ministries share authority) }\end{array}$ & $\begin{array}{l}\text { Indirect distributed } \\
\text { (e.g. ministries share authority with other } \\
\text { private or social actors or various non-state } \\
\text { actors share authority) }\end{array}$ \\
\hline
\end{tabular}

Source: Own elaboration.

In the context of the changing nature of the state, the perspective of meta-governance focuses on the engagement of political authorities in the steering of non-hierarchical forms of governance (Jessop, 1997, p. 575). It assumes that the state itself decides about the extension of its shadow in other different governance systems. The notion of meta-governance in the shadow of hierarchy stresses the persistence of hierarchical forms of authority even if other forms of co-governance and self-governance seem to dominate. At the same time, both hierarchical and non-hierarchical forms are interdependent and coexist as 'structurally embedded self-governance' (Jessop, 1997, 2009; Scharpf, 1994). This process involves the distribution of different responsibilities and roles among different state and non-state actors. Therefore, it implies shifts in the nature of the state authority.

The state authority as a legitimate power recognized in the society builds upon the assumption that to promote common goals, the state has the competences to adopt binding rules and norms for a certain collective good as well as the competence to interpret them (Zürn, 2018, pp. 51-53). The state authority is sustained by different tangible and intangible power resources, such as legal rules, bureaucracy, and money, as well as information and expertise (Barnett \& Finnemore, 1999). Different governing functions (see Chapter 3) are performed using different relevant power resources. Each of these resources has inbuilt different mechanisms and associated policy tools influencing other actors. The following four policy resources were used for this analysis: regulatory, organizational, financial, and expertise (based on Hood \& Margetts, 2007; Howlett, 2004; Natorski, 2013). Regulatory resources refer to the state capacity to use legal acts to regulate the scope of lawful and legitimate activities implied such as laws, regulations, licences, and certificates (e.g., fishing rights, permits, and concessions). Organizational resources refer to the bureaucratic and administrative capacities employed through such policy tools as public enterprises, enforcement and surveillance systems (e.g., inspections), service delivery (e.g., commercialization), and infrastructure ownership. Financial resources mean positive and negative material incentives to steer the behaviour of actors with such policy 
tools as fees, fines, grants, loans, and rewards. Finally, expertise resources involve all sources of information and knowledge related to reporting, training, advice, research, education, and publications.

However, in the context of meta-governance dynamics, the relations of authority evolve, yet the resources required to govern a layered governance system remain similar. For example, Jessop (1997, p. 575) distinguished such mechanisms of meta-governance as the definition of governance rules, the organizational knowledge, the arbitration in disputes, the distribution of power resources, or shaping the self-understanding of actors' identities and preferences. Following a similar conception, Pierre and Peters (2020, pp. 95-102) distinguished legal authority, incentives, ideas, requirements, public planning, institution making, and the use of information. The use of such legal, bureaucratic, symbolic, and financial resources creates a general framework for actors' activities rather than steering specific instances of actions. At the same time, power relations evolve from concentrated zero-sum games to more fragmented diffuse positive-sum games. The transition from unitary centralized state control performed by strong, central executives to a more decentralized and fragmented state is observed where steering is performed by segmented executive agencies (Richards \& Smith, 2002, p. 36).

As a result, the shifts in the shadow of hierarchy involve trade-offs between direct and indirect as well as concentrated and distributed forms of control over policy resources. Indirect and distributed forms develop as a proof of the increasing shadow of hierarchy when the state reduces its direct control over power resources. At the same time, however, the state can employ meta-governance legal, bureaucratic, symbolic, and financial resources to compensate for this decreased direct control over resources. In this context, this chapter claims that the state shapes practices in parallel with the increasing shadow of hierarchy. Some authors have already drawn attention to the concept of practices as a meta-governance mechanism to 'secure governmental influence, command, and control within governance' (Whitehead, 2003 , p. 8) yet it remains underdeveloped in the literature. To address this gap, this paper conceptualizes the steering of practices as a meta-governance function performed by the state.

The shaping of practices encompasses simultaneously different symbolic and material dimensions to establish some general parameters of actions instead of focusing on specific actions. The need to regulate cognitive and material aspects emerges from the conceptualization of practices as complex entities. Reckwitz (2002, p. 249) 
defines practice as 'a routinized type of behaviour that consists of several elements, interconnected to one another: forms of bodily activities, forms of mental activities, "things" and their use, a background knowledge in the form of understanding, know-how, states of emotion, and motivational knowledge'. The interconnections of all elements make practices, but they cannot be reduced to the elements. For Schatzki (2002), practice is 'a temporally and spatially dispersed nexus of doings and sayings', yet it also involves more specific ingredients of practical understandings, rules, teleoaffective structures, and general understandings. Shove et al. (2012) developed a more simplified typology of elements of practices. In this account, the three components of practices are key: meanings, competences, and materials. Meanings include symbolic values, ideas, aspirations, and motivations; competences encompass formally accredited and/or intangible capacities, skills, know-how, and techniques; and materials involve artefacts, things, technologies, tangible physical entities, and the stuff of which objects are made (Schatzki, 2002; Shove, 2009; Shove et al., 2012).

Following this conceptualization, the attempts at regulating the practices focus on framing their general cognitive and material patterns. Besides the combination of different cognitive and material elements, practices also require some kind of regularity to distinguish them from individual actions. As stressed by Adler and Pouliot (2011, p. 6), practices are 'patterned actions that are embedded in a particular organized context and, as such, are articulated into specific types of action'. The patterned element of practice means that it 'generally exhibits certain regularities over time and space' and reproduces similar actions embedded with similar meanings (Adler \& Pouliot, 2011, p. 7). As a result, the state defines these patterns of practices to guarantee a regularity of actions without commanding each of them separately. In practice, the state meta-governs by retaining the capacity to define patterns of practices. This is a capacity to influence the naming and codification of the meanings, the competences, and the materials (Shove et al., 2012) required to perform practices. The process of shaping is usually performed in regulatory activity visible in different legislative acts. To regulate practices, the state defines the rules and employs the organizational knowledge underlying any legislative regulatory document. In this way, the state also defines other actors' power resources and preferences. By shaping practices, the state retains its indirect influence on governance actors and also indirectly intermediates in dispute resolutions among actors by creating a framework of reference for their actions. 
This approach was used in this analysis to comprehend social practices to illustrate how the state uses its meta-governance authority to shape fishing practices in Mexico. Our general expectation is that the diversification of the state involvement in the fisheries governance in Mexico will increase the employment of regulatory authority. To compensate for the decrease of direct control, the state will attempt to increase its influence by increasingly shaping the patterns of fishing practices. An apparent withdrawal of the state from direct rule is accompanied by the use of authority to regulate indirectly the interactions taking place in the shadow of hierarchy. To illustrate this argument, this chapter shows an increase of indirect and distributed state involvement in the governance of fisheries in Mexico, suggesting a greater shadow of hierarchy. Furthermore, this chapter shows that to compensate for this process the state increasingly shapes the patterns of fishing practices through broader framing of meanings associated with the fisheries policy in parallel with the increased technical specification of fishing materials as well as the categorization and delimitation of required competences.

\subsection{Methods and Data Sources}

A thematic analysis (Matthews \& Ross, 2010) was used to trace the evolution of the shadow of the state hierarchy in Mexico and the regulation of elements of fishing as a social practice. Thematic analysis is the most common method for working with qualitative data. It allows concepts or issues to be identified and analysed through an interactive process, in which the data are used to refine and find links within these concepts or issues (Matthews \& Ross, 2010). It is a process of segmentation, categorization, and relinking of aspects of data for final interpretation (Grbich, 2007, p. 16).

In the first phase, to trace the evolution of the shadow of hierarchy one of the four models of the involvement of the state was attributed to the four policy resources employed to govern the fisheries domain (see Table 4-1). In the first step, different normative prescriptions mentioned in the legal framework ${ }^{30}$ were attributed to the four types of resources (regulatory, organizational, financial, expertise) discussed above by looking at different policy tools mentioned in the legal framework of fisheries. In the second step, to distinguish four models of the presence of the state, two themes were identified in the empirical material: 1) the direct or indirect involvement of the state, and 2) the concentrated or distributed presence of the state. To distinguish the first theme, the instances of the state federal ministries' presence in

\footnotetext{
30 The legal framework includes the Mexican Constitution and the eight fisheries laws. See Chapter 3, Table 3-1 for reference.
} 
the governance of resources and the presence of empowered actors were codified. The concentration means one actor, while distributed means various actors. In view of these considerations, for example, the article stating that 'the Ministry of Finances, in collaboration with the Navy and Economics Ministries, will be in charge of establishing the rights, quotas, fees, and other legal compensations' (Art 13, DOF, 1948a) is coded as direct distributed involvement in the governance of financial resources. On the other hand, the article stating that the 'permits for local fishing within waters within the jurisdiction of a municipality will be granted by the delegates of the Ministry of Agriculture and Development, and in their absence, by the municipal presidents or harbour captains' (Art 10, DOF, 1925) was coded as indirect concentrated governance of the organizational resources given that it provides a conditional mandate for delegation to local actors forming part of the state administration. Similarly, the article stating that "the National Advisory Commission of Fishing [which involves non-state actors] will help the Ministry of Industry and Commerce and other public agencies (...) in recommending the Federal Executive the promotion of laws and issuance of regulations and disposition promoting fisheries" (Art 20, DOF, 1972) was coded as the indirect distributed governance of regulatory resources given that it diversifies regulatory mandates to numerous actors.

In the second phase, to illustrate the regulation of the patterns of fishing practices, the three elements of social practices were the themes for the coding process: meanings, materials, and competences. The meanings, which refer to the conceptualization and categorization of fishing activity, are framed by overarching goals and aspirations of legislators. They are generally explicit in the general legal framework and defined during the legislative process. For this thematic coding, the following themes were analysed: definition of fishing, fishing types, overarching goals, and aspirational goals of legislators. The sources of data are the eight fisheries laws and the 46 documents derived from the legislative process. The documents from the legislative process include the first draft of the laws (bills), the resolutions of this draft conducted by the technical commissions in charge of fisheries matters within the Congress (i.e., Lower Chamber and Senate), the discussions in Congress plenaries, and the contributions from the Executive.

For materials, the following themes were codified and analysed: vessel types, gear types, technology, landing sites, and artefacts utilized in the practice of fishing. Furthermore, for competences, the themes used were the specifications of how fishing practices can be performed by using the above materials. Therefore, in practice these specifications imply the skills to employ specific fishing materials associated with 
fishing methods as well as to follow the spatial, biological, and temporal limits such as seasons, areas, sizes, and quotas. Competences are frequently implicit in the definition of materials and their limits since they assume that fishermen will have the skills to implement these limits by, for example, distinguishing species or navigating fishing areas. Such competences can also have some explicit definitions, such as requirements included in formal permissions recognizing fishers' qualifications necessary for engaging in fishing practice. Fisheries laws include general information on materials and competences allowed for the extraction of species in waters of state jurisdiction (EEZ); however, their application to specific species is codified in regulations, which implement mandates provided by the general federal laws. Therefore, the data sources for both themes were the eight fisheries laws and the 470 implementing regulations published in the Official Gazette.

The analysed documents cover the period 1917-2019. The starting year indicates the promulgation of the Mexican Constitution in 1917. The documents of the Mexican Constitution, fisheries laws, and implementing regulations were collected from the Official Gazette website (http://dof.gob.mx). The documents of the legislative process were collected from the Lower Chamber and Senate's digital archives. To contextualize this information, this chapter employed historical fisheries policy analysis recorded in academic publications and policy reports (Alcalá-Moya, 2003; Espinoza-Tenorio et al., 2011; Hernández \& Kempton, 2003; Hernández-Fujigaki, 1987; López-Chavarria, 1997; Martínez-Martínez \& González-Laxe, 2016; OECD, 2006; Patrón-Sánchez, 2010; Secretaría de Pesca, 1976, 1994; Vázquez-León, 1998).

\subsection{Results}

First, the empirical data illustrate an increasing shadow of hierarchy in the governance of fisheries in Mexico. Subsection 4.4.1 argues that whilst during the entire period of analysis there was an ample scope of distribution of responsibilities. This process has accelerated during the democratization of the Mexican political regime since the late 1990s, which coincides with both the neoliberal minimal state retraction from the fisheries domain and the consolidation of a more democratic system in Mexico since 2000. Coincidentally, both phases led to the extension of the shadow of hierarchy in fisheries governance. In the second place, the empirical evidence illustrates an increasing extension of the meta-governance power of the state in shaping the patterns of fishing practices in Mexico. Subsection 4.4.2 shows that the expansion of meanings associated with fishing practices as well as the specification of involved materials and required competences have accelerated since the state diversified the forms of governing policy resources. 


\subsubsection{An Evolving Shadow of Hierarchy in Mexico}

The Mexican Constitution establishes that territorial waters and associated natural resources are the property of the nation and the state apparatus (federal government) governs them and concedes exploitation rights of marine fish resources and ecosystems to Mexican citizens or corporations (DOF, 1917). The declaration in the Mexican Constitution of the $200 \mathrm{~nm}$ of exclusive economic zone (EEZ) under state jurisdiction established a similar mandate (DOF, 1976a). Similarly, the political regime as reflected in the ordinary legislative process shows the centralization of legislative initiative and debate in federal organs. Frequently, the presidential administrations embodied the Mexican state given its tenacious presidentialism without balancing control mechanisms (Alcalá-Moya, 2003). This presidentialism emerges from its formal constitutional power as the head of the executive and from its political position of supreme control of political parties' nominations for elective positions, especially during the Partido Revolucionario Institucional (PRI, Institutional Revolutionary Party in English) ${ }^{31}$ domination of Mexican politics (Patrón-Sánchez, 2010). The Mexican presidentialism features in most decisions on productive and extractive economic activities.

In spite of the above conditions, Mexican fisheries governance has gone through many changes over time (Alcalá-Moya, 2003; Bennett, 2017; Espinoza-Tenorio et al., 2011; Hernández \& Kempton, 2003) in which diverse actors have participated (e.g., fishers, middlemen, civil society organizations, state at different levels) (EspinosaRomero et al., 2014; Zepeda-Domínguez et al., 2019; Zetina-Rejón et al., 2020), in parallel with the direct involvement of the state agencies in the domain. Consequently, there is an evolution and expansion of indirect modes of fisheries governance in Mexico in the shadow of hierarchy. Table 4-2 shows that following the legal framework, the domain of fisheries has been placed under different thematic domains (e.g., agriculture, navy, economics). The thematic Ministry of Fisheries existed only from 1982 until 1994, when it was placed in the Ministry of Environment for the presidential term of Ernesto Zedillo, before returning in 2000 to the Ministry of Agriculture. However, in practice, one leading federal ministry in charge of fisheries usually needs to coordinate with other federal agencies in charge of financial, food safety, research, and national defence areas. At the same time, as Table 4-2 illustrates, the legal framework allowed the involvement of other non-state actors in the governance

\footnotetext{
${ }^{31}$ Partido Revolucionario Institucional (PRI). This political party was founded in 1929 and held interrupted power for 71 years, from 1929 to 2000. This party was first called Partido Nacional Revolucionario (National Revolutionary Party), then Partido de la Revolución Mexicana (Party of the Mexican Revolution), and finally PRI since 1946.
} 
of fisheries. Therefore, other private and social actors, and in particular fishers from local communities organized in cooperatives as well as researchers, participated in the governance of this policy field.

Table 4-2. Relevant actors identified in the legal framework for the governance.

\begin{tabular}{|c|c|c|c|c|}
\hline $\begin{array}{l}\text { Fisheries } \\
\text { laws }\end{array}$ & $\begin{array}{l}\text { Ministry in } \\
\text { charge of } \\
\text { fisheries }\end{array}$ & $\begin{array}{l}\text { Other involved } \\
\text { ministries }\end{array}$ & $\begin{array}{l}\text { Decentralized } \\
\text { state units }\end{array}$ & Non-state actors \\
\hline 1925 & $\begin{array}{l}\text { Agriculture \& } \\
\text { Development }\end{array}$ & $\begin{array}{l}\text { Ministry of } \\
\text { Finances }\end{array}$ & $\begin{array}{l}\text { Municipalities } \\
\text { and harbours }\end{array}$ & $\begin{array}{l}\text { Citizens, rights holders, small-scale } \\
\text { fisheries (SSF) and coastal communities }\end{array}$ \\
\hline 1932 & $\begin{array}{l}\text { Agriculture \& } \\
\text { Development, } \\
\text { Navy }\end{array}$ & $\begin{array}{l}\text { Ministry of } \\
\text { Finances }\end{array}$ & & $\begin{array}{l}\text { Rights holders, SSF, coastal } \\
\text { communities, fishing organizations }\end{array}$ \\
\hline 1948 & Navy & $\begin{array}{l}\text { Ministries of } \\
\text { Finances, } \\
\text { Economics }\end{array}$ & & $\begin{array}{l}\text { Federations, right holders, and } \\
\text { researchers, fishing cooperatives }\end{array}$ \\
\hline 1950 & $\begin{array}{l}\text { Navy, Industry \& } \\
\text { Commerce }\end{array}$ & $\begin{array}{l}\text { Ministries of } \\
\text { Finances, } \\
\text { Economics }\end{array}$ & & $\begin{array}{l}\text { Citizens, private sector, fishing } \\
\text { cooperatives, those with a legitimate } \\
\text { interest in fishing, right holders, } \\
\text { researchers }\end{array}$ \\
\hline 1972 & $\begin{array}{l}\text { Industry \& } \\
\text { Commerce, } \\
\text { Fisheries }\end{array}$ & $\begin{array}{l}\text { Ministries of } \\
\text { Finances, } \\
\text { Hydraulic } \\
\text { Resources, } \\
\text { Navy, National } \\
\text { Defence }\end{array}$ & & $\begin{array}{l}\text { Parastatal banks and companies, } \\
\text { National Confederation of } \\
\text { Cooperatives, National Confederation } \\
\text { of Farmers, National Chamber of } \\
\text { the Fishing Industry, right holders, } \\
\text { researchers, cooperatives (fishing, } \\
\text { ejidos and communal) }\end{array}$ \\
\hline 1986 & Fisheries & $\begin{array}{l}\text { Ministries of } \\
\text { Communications } \\
\text { \& Transportation, } \\
\text { Urban } \\
\text { Development \& } \\
\text { Ecology, Commerce } \\
\text { \& Industrial } \\
\text { Development }\end{array}$ & & $\begin{array}{l}\text { Parastatal banks and companies, } \\
\text { National Confederation of } \\
\text { Cooperatives, National Confederation } \\
\text { of Farmers, National Chamber } \\
\text { of the Fishing Industry, National } \\
\text { Confederation of Industry Chambers, } \\
\text { researchers, right holders, other actors } \\
\text { from the public, private, and social } \\
\text { sector could be invited }\end{array}$ \\
\hline 1992 & $\begin{array}{l}\text { Fisheries, } \\
\text { Environment, } \\
\text { Agriculture }\end{array}$ & & & Researchers \\
\hline 2007 & Agriculture & $\begin{array}{l}\text { Ministries of } \\
\text { Environment, } \\
\text { Navy, National } \\
\text { Defence, Agri-food } \\
\text { Health, Safety \& } \\
\text { Quality, National } \\
\text { Council for Science } \\
\text { \& Technology, } \\
\text { Congress }\end{array}$ & $\begin{array}{l}\text { Coastal } \\
\text { provinces and } \\
\text { municipalities }\end{array}$ & $\begin{array}{l}\text { Social and private organizations, } \\
\text { coastal communities, indigenous } \\
\text { groups, researchers, right holders }\end{array}$ \\
\hline
\end{tabular}

Source: Own elaboration based on the eight fisheries laws published in the Official Gazette. 
However, from the perspective of the shadow of hierarchy, the scope and nature of the involvement of these actors evolved over time. The historical overview of the involvement of the state in the governance of fisheries suggests an evolution of the diffusion and distribution of the governance of different policy resources. The summary of the state intervention in the fisheries governance of different regulatory, organizational, financial, and expertise resources illustrates an increasing diversification of coexisting models for each resource as well as a consolidation of indirect distributed forms of governance (see Annex 5-1). Therefore, based on these changes and the background of the general political regime features in Mexico, we distinguish three historical periods: authoritarian state intervention (1917-1985), neoliberal minimal state (1986-2006), and democratic state delegation (2007-2019).

\section{Authoritarian state intervention (1917-1985)}

The first period of authoritarian state intervention (1917-1985) expanded direct and concentrated involvement in the governance of most policy resources, while most of the time other indirect and distributed modes were circumscribed to very narrow issues. This period begins with the promulgation of the Mexican Constitution and takes place mostly during the period of the one-party domination of the PRI in Mexico. During PRI governments, the state regulated fisheries and increased its intervention in the value chain from extraction to commercialization (Vázquez-León, 1998). The Congress based the very first fisheries law in 1925 on an existent presidential regulation (López-Chavarria, 1997) and the presidents promoted during this period another four fisheries laws initiatives. Consequently, the reformed laws and policies reflected the political ideologies and priorities of subsequent presidents (Alcalá-Moya, 2003; Espinoza-Tenorio et al., 2011). Following an authoritarian rule context, Table 4-3 summarizes a usually unproblematic process of approving a general legal framework during most of the debates in the parliament. In most cases, the process consisted of adopting the projects presented by the Executive without any major amendments. During this period, the debates usually emphasized the Constitutional mandate to regulate and reflected a paternalistic approach to the legislation of fisheries. The promoters justified the proposals arguing on the basis of assumed fishers' aspirations about the potential benefits fisheries can bring to Mexican citizens (e.g., employment, food security) as well as the care for vulnerable groups (small-scale fishers, coastal communities) and marine fish resources.

The consultations with fishing organizations and industry in the legislative process featured federal state domination. For example, the Navy Commission of the Senate 
considered the interests and experience of the sector reflected in the feedback of the National Confederation of Cooperatives and the Centre for Fisheries Studies of the Mexican Industries to the 1950 law, yet emphasized the priority of general public interest over other considerations. As recognized in the debate, "the Commission has tried to harmonize the divergent criteria, without compromising, at any time, the public interest - which represents the essential norm of any law, especially in the present case, which refers to the regulation of the exploitation of national wealth, such as fisheries..." (Diario de los Debates, 1949). Similarly, for the law of 1972, even though the Senate organized the Fisheries Commission to consult experts, fishers, industry, and other interested parties, it remains unclear whether they have any influence on the Senate deliberations (Diario de los Debates, 1971). The study conducted on the same occasion by the administrative staff of the Commission of Fisheries Development of the Lower Chamber involved on-site visits to the Mexican coast and direct consultations with fishers. The detected issues of insufficient fisheries infrastructure, ineffective coastal cooperatives, environmental pollution, and the competitiveness of fragmented industrial fisheries competing with foreign fleets (Diario de los Debates, 1972a,b) led to the reinforcement of direct state intervention to reinforce cooperatives through the creation of parastatal enterprises and banks.

Table 4-3. Legislative process for the enactment of fisheries laws (1925-2007)

\begin{tabular}{|c|c|c|c|c|c|c|}
\hline $\begin{array}{l}\text { Fisheries } \\
\text { laws }\end{array}$ & $\begin{array}{l}\text { Presentation } \\
\text { of bills }\end{array}$ & $\begin{array}{l}\text { Resolutions } \\
\text { by the } \\
\text { Commission }\end{array}$ & $\begin{array}{l}\text { Resolutions } \\
\text { discussed in } \\
\text { plenary }\end{array}$ & $\begin{array}{l}\text { Resolutions } \\
\text { by the } \\
\text { Commission }\end{array}$ & $\begin{array}{l}\text { Resolutions } \\
\text { discussed in } \\
\text { plenary }\end{array}$ & $\begin{array}{l}\text { Opinions from } \\
\text { the Executive }\end{array}$ \\
\hline 1925 & $\begin{array}{l}\text { LC - provincial } \\
\text { level }\end{array}$ & $\begin{array}{l}\text { LC Agriculture } \\
\text { \& Development }\end{array}$ & $\begin{array}{l}\text { LC } \\
\text { Amendments } \\
\text { suggested }\end{array}$ & $\begin{array}{l}\text { Senate - } \\
\text { Agriculture \& } \\
\text { Development }\end{array}$ & Senate & No \\
\hline 1932 & Executive & No & No & No & No & No \\
\hline 1948 & Executive & No & No & No & No & No \\
\hline $1950^{*}$ & Executive & Senate - Navy & Senate & $\begin{array}{l}\text { LC - Hunting \& } \\
\text { Fisheries }\end{array}$ & $\mathrm{LC}$ & No \\
\hline $1972^{*}$ & Executive & $\begin{array}{l}\text { Senate - Special } \\
\text { Fisheries }\end{array}$ & Senate & $\begin{array}{l}\text { LC - Fisheries } \\
\text { Development/ } \\
\text { Cooperatives } \\
\text { Development/ } \\
\text { Productivity } \\
\text { of Domestic } \\
\text { Commerce }\end{array}$ & $\begin{array}{l}\text { LC } \\
\text { Amendments } \\
\text { suggested }\end{array}$ & No \\
\hline $1986^{*}$ & $\begin{array}{l}\text { LC - Fisheries } \\
\text { Commission }\end{array}$ & LC - Fisheries & $\mathrm{LC}$ & $\begin{array}{l}\text { Senate - } \\
\text { Fisheries \& } \\
\text { Navy }\end{array}$ & Senate & No \\
\hline $1992 *$ & Executive & LC - Fisheries & $\mathrm{LC}$ & $\begin{array}{l}\text { Senate - } \\
\text { Environment }\end{array}$ & Senate & No \\
\hline $2007^{*}$ & $\begin{array}{l}\text { LC - Fisheries } \\
\text { Commission } \\
\text { LC - provincial } \\
\text { level }\end{array}$ & LC - Fisheries & $\mathrm{LC}$ & $\begin{array}{l}\text { Senate - } \\
\text { Environment }\end{array}$ & Senate & $\begin{array}{l}\text { Yes } \\
\text { Amendments } \\
\text { suggested }\end{array}$ \\
\hline
\end{tabular}

Source: Own elaboration based on legislative process documents found in the Lower Chamber (LC) and Senate archives. 
The fisheries sector developed during this period due to the direct and concentrated state involvement employing considerable regulatory, organizational, financial, and expertise resources through the public investment in infrastructure, industries, and research (see Table 4-4). In the 1940s, the state invested in public transport and electricity infrastructure, which consequently facilitated the transportation of fish products and the improvement of their quality (i.e., the use of ice). The federal administration financially supported the development of the high commercial value fisheries (e.g., abalone, lobster, shrimp, tuna, sardines) and the production of fish flour for meat production (beef, bird, pork), given the international trend of increasing the consumption of meat protein (Hernández-Fujigaki, 1987). From the 1950s to the 1970s, the state developed port infrastructure in different regions (Alcalá-Moya, 2003; Hernández-Fujigaki, 1987; Secretaría de Pesca, 1994) and research programmes for fisheries development (Baja California Peninsula and the south-western coast of Mexico) (Alcalá-Moya, 2003). The decades of the 1970s and the 1980s constituted the peak of state intervention. To support the sector, the administration created parastatal banks for the capitalization of small-scale fishers and the promotion of highly commercial species as well as parastatal enterprises to participate in seafood commercialization. It also created special credit and loan endowment programmes (e.g., the Diez mil lanchas programme) to support vessel repairs, the development of port infrastructure, and the buy-back of the shrimp fleet to transfer it to the cooperatives. Finally, the state administration also promoted research and training initiatives, such as the collaboration with the United States to evaluate the fishing exploitation in the Gulf of Mexico or the creation of the National System of Integrated Fisheries Education for capacity building of fishers (Alcalá-Moya, 2003; Hernández \& Kempton, 2003; Hernández-Fujigaki, 1987; Secretaría de Pesca, 1994).

Nevertheless, the five fisheries laws adopted during this period allowed different actors (municipalities, local authorities, citizens, fishing organizations, the private sector, and researchers) some limited access to the governance of policy resources, yet the central administration as a general rule continued direct and concentrated involvement and other actors' access was always very contested and consequently well delimited in terms of the areas of application. For example, the debate in 1925 focused on the question of which central body would be entitled to establish fees for fishing (the Ministry of Agriculture, the Ministry of Finance, or the Congress) and whether municipalities and local authorities would have the competence of granting local permits (Diario de los Debates, 1924). The most debated issues in the 1972 law referred mainly to clarification of the distribution of prerogatives between the central state and cooperatives as well as parastatal enterprises. It included the question 


\section{of the state responsibilities as regards the commercialization of products as well as its participation in governing bodies (Diario de los Debates, 1971, 1972a, 1972b) .}

Table 4-4. Public investment for industry development (1917-1982)

\begin{tabular}{|c|c|}
\hline Presidents & Public investment \\
\hline $\begin{array}{l}\text { Lázaro Cárdenas } \\
(1934-1940)\end{array}$ & Fishing cooperatives development: The creation of the National Bank for Cooperatives \\
\hline $\begin{array}{l}\text { Miguel Alemán } \\
\text { Valdéz } \\
\text { (1946-1952) }\end{array}$ & $\begin{array}{l}\text { Public infrastructure: Highways, paved roads, electricity, which provided the opportunity to } \\
\text { transport fish products and of the production of ice to maintain the quality of the products. } \\
\text { Industry development: Supported the shrimp fishery in the Gulf of Mexico as well as the } \\
\text { abalone and lobster fishery in the Pacific. Supported the development of the fish flour } \\
\text { industry for exportation and domestic consumption. }\end{array}$ \\
\hline $\begin{array}{l}\text { Adolfo Ruiz- } \\
\text { Cortines } \\
\text { (1952-1958) }\end{array}$ & $\begin{array}{l}\text { Industry development: Provided loans to grow the sardine and anchovy fleet and the } \\
\text { infrastructure (i.e., processing plants) for fish flour production. This was due to the increasing } \\
\text { demand of meat and the increased price of fish flour imported from Chile, which was used to } \\
\text { feed livestock, seabirds, and pigs. } \\
\text { Fishing cooperatives development: The Maritime Progress Programme for the development } \\
\text { of fishing activities through the investment in vessels and infrastructure in the North Pacific } \\
\text { and the Gulf of Mexico. }\end{array}$ \\
\hline $\begin{array}{l}\text { Adolfo López } \\
\text { Mateos } \\
(1958-1964)\end{array}$ & $\begin{array}{l}\text { Jublic infrastructure: Development of the Veracruz Port to support fishing operations in the } \\
\text { Sulf of Mexico. }\end{array}$ \\
\hline $\begin{array}{l}\text { Gustavo Díaz Ordaz } \\
\text { (1964-1970) }\end{array}$ & $\begin{array}{l}\text { Public infrastructure: Ports of Puerto Vallarta, Manzanillo, San Carlos, Yucalpeten y Banco } \\
\text { Playa. } \\
\text { Industry development: Development of the tuna, sardine, and anchovy fisheries in the Pacific } \\
\text { and the shrimp fishery industry in the Gulf of Mexico and Pacific. The state received funding } \\
\text { from the United Nations Development Programme (UNDP) for research projects for fisheries } \\
\text { development in the Baja California Peninsula and the southwest coast of Mexico. } \\
\text { Fishing cooperatives development: Created the National Cooperative Bank. Provision of } \\
\text { equipment to fishers. Infrastructure for aquaculture. }\end{array}$ \\
\hline $\begin{array}{l}\text { Luis Echeverría } \\
\text { (1970-1976) }\end{array}$ & $\begin{array}{l}\text { Public infrastructure: National Fund for the Development of Ports. } \\
\text { Industry development: Development of the tuna, sardine, and anchovy fisheries in the Pacific } \\
\text { and the shrimp fishery industry in the Gulf of Mexico and Pacific. Bought the enterprise } \\
\text { "Ocean Garden" through which the state participates in the commercialization of products. } \\
\text { Fishing cooperatives development: The state bought the shrimp industrial fleet to transfer } \\
\text { it to cooperatives. Created parastatal enterprises, including shipyards enterprises, to build } \\
\text { and repair vessels (e.g., Productos Pesqueros Mexicanos, which integrated } 22 \text { enterprises, } \\
\text { Distribuidora Pesquera Ejidal, Empresa Pesquera de Balsas). Created the National Fund for } \\
\text { Fishing Cooperatives Development, Prevention, and Control of Waters and Development of } \\
\text { the Aquatic Fauna; loans for cooperatives to buy shrimp vessels and for vessel repairs, and to } \\
\text { buy back shrimp vessels. }\end{array}$ \\
\hline $\begin{array}{l}\text { José López Portillo } \\
\text { (1976-1982) }\end{array}$ & $\begin{array}{l}\text { Public infrastructure: Banpesca was created to develop fishing and port infrastructure, } \\
\text { Industry development: Banpesca was used to support highly commercial species (shrimp, } \\
\text { tuna, anchoveta). Created the parastatal enterprises called Fishing Industries of the Northwest } \\
\text { and the National Producer of Nets. } \\
\text { Fishing cooperatives development: Banpesca was used to capitalize small-scale fisheries. Diez } \\
\text { mil lanchas programme to equip fishing cooperatives. Created the endowments Guarantees for } \\
\text { Cooperatives and the Fund for Development and Support of Fisheries. Created the National } \\
\text { System of Integrated Fisheries Education to provide holistic capacity building to fishers. }\end{array}$ \\
\hline
\end{tabular}

Source: Own elaboration based on Alcalá-Moya (2003), Hernández-Fujigaki (1987), Secretaría de Pesca (1976,1994). 


\section{Neoliberal minimal state (1986-2006)}

The second period, labelled here the neoliberal minimal state (1986-2006), displays a gradual process of retreat of the state intervention in the sector and the regulation of the participation of other actors. This period largely overlaps with the democratic transition in Mexico progressively challenging the power monopoly of the PRI. The period was largely influenced by the international neoliberal trends (Altamirano-Jimenez, 2017; Bennett, 2017), the development of national fleets within the EEZ, and the notion of responsible fisheries to ensure effective conservation of marine fish resources (Hernández-Fujigaki, 1987; OECD, 2006). Moreover, the financial crisis in Mexico in 1982 led to changes in political regimes in parallel with the neoliberal reforms. During the debt negotiation agreements (Baer \& Maloney, 1997) with international organizations (the World Bank, the International Monetary Fund), they demanded substitution of the state-driven developmental policies with state-austerity and market-oriented policies to benefit the private sector (Altamirano-Jimenez, 2017; Bennett, 2017). During this period two fisheries laws governed the sector, which, on the one hand, aligned the state rights and duties to the UNCLOS (DOF, 1986), and, on the other hand, liberalized and deregulated the sector (DOF, 1992).

At the beginning of the economic crisis, the state continued its direct concentrated or distributed involvement in the governance of organizational, financial, and expertise policy resources (see Annex 5-1). There was also a tendency to distribute the governance of resources among more central administration bodies rather than to non-state actors. The 1986 law kept the general mechanisms for non-state actor participation in fisheries governance in the National Advisory Commission of Fisheries. However, it also reduced the status of cooperatives, by not distinguishing coastal and industrial cooperatives, and by abolishing the exclusive rights of coastal cooperatives entitled to cultivate species and to have areas for common exploitation. At the same time, cooperatives could join private corporations. By doing so, the state emphasized the importance of private commercial Mexican investment. Besides the legal framework, Mexico revived with the support of international funding (e.g., the Inter-American Development Bank, the World Bank, the International Monetary Fund, other countries such as the Netherlands and France) fisheries projects related to training programmes (e.g., the use and maintenance of vessels and outboard motors, the use of new materials, the manufacture of gear types) and even continued the creation of other parastatal enterprises (e.g., Pesca Corporativa) to support the development of infrastructure for fisheries (Alcalá-Moya, 2003; Secretaría de Pesca, 1994). Furthermore, the administration aspired to continue the collaboration with 
research centres and universities to provide technical support and training to fishers to improve extraction, processing, and markets (Diario de los Debates, 1984, 1985; DOF, 1986a).

However, the 1992 law largely liberalized and deregulated the sector. The law promoted by the President Salinas administration changed radically the approach and concentrated direct state intervention around very few policy resources without further regulating the roles of other actors. Therefore, the state concentrated directly on its regulatory and organizational resources, including the entitlement of fishing rights and the enforcement and surveillance for compliance of the regulation. Fishing rights resolutions and decision-making were based on science, thus the state distributed research responsibilities with INAPESCA, and involved researchers and fishing right holders in the provision of information. At the same time, the state administration withdrew from participation in the governance of financial resources and closed the parastatal bank (Banpesca) and sold parastatal enterprises (Hernández-Fujigaki, 1987; Secretaría de Pesca, 1994). The approach de facto delegated the financial aspects of the development of the sector to weakly controlled private investment initiatives. By including only Mexican citizens and corporations in the new scheme for fishing rights, this approach eliminated special fishing rights for cooperatives, particularly those entitled to reserved species of high commercial value. Cooperatives de facto became a form of corporations and could apply for permits without enjoying any preferences in comparison to other applicants. At the same time, with the exception of the inclusion of private actors in the governance expertise resources as information providers, the 1992 law omitted any regulation on the participation of other actors in more indirect and distributed governance of other policy resources. Similarly, this new approach eliminated any specific mechanisms for non-state actors' participation and they moved to more ad hoc fora. As a result, the non-regulation of many areas relevant for the governance of policy resources created an ample space for interactions among non-state private and social actors organizing themselves without any state intervention. Paradoxically, they developed in the shadow of possible state intervention, without an explicit mandate, but based on the retention of core regulatory and organizational resources under the direct realm of the state.

\section{Democratic state delegation (2007-2019)}

The period of democratic state delegation (2007-2019) features the expansion of state intervention in the fisheries domain in parallel with the distribution of the governing 
roles of policy resources among many public, private, and social actors. The antecedent of this process was the pluralization of the political parties in the Lower House by 1997 and the presidential victory of non-PRI candidate Vincente Fox in 2000, concluding the transition from an authoritarian to a democratic regime (Patrón-Sánchez, 2010). The amendments to the Mexican Constitution in this period privileged indigenous groups in the access and use of natural resources (DOF, 2001c) and entitled the Congress to develop fisheries and aquaculture laws to involve provinces and municipalities, as well as the private and social sectors in fisheries matters (DOF, 2004b). The 2007 fisheries law debates allowed the participation of different political parties and empowered different actors in fisheries governance aimed at guaranteeing more sustainable development of the sector (Altamirano-Jimenez, 2017; Espinoza-Tenorio et al., 2011). Furthermore, Mexico's participation and leadership in the international arena, particularly in the creation of the Code of Conduct for Responsible Fisheries, was acknowledged and used as a reference to integrate sustainable development as the main priority for fisheries (Diario de los Debates, 1992a, 1992b; Secretaría de Pesca, 1994).

The 2007 law expands state intervention in parallel with a more inclusive distribution of roles among public, private, and social actors. In fact, from a historical perspective, it became the most developed and detailed fisheries law ever adopted in Mexico. Therefore, its thematic content analysis (see Table 4-3) shows that besides the traditional direct concentrated governance of regulatory and organizational resources, as refers to the regulations and enforcement and surveillance system, there is a great variety of ways in which the Mexican state administration intervened in the field. Even in these core areas, the governance of regulatory and organizational resources involves many other federal agencies as well as provinces and municipalities. Therefore, for example, the regulation of newly added areas of sanitation and the quality of seafood products involves collaboration with the National Health for Food Safety and Food Quality (SENASICA - Servicio Nacional de Sanidad, Inocuidad y Calidad Agroalimentaria) and the operation of the enforcement and surveillance system with the Navy Ministry.

At the same time, provinces and municipalities at local level are involved in indirect concentrated as well as distributed governance of some policy resources. They received new opportunities to become involved in the governance of fishing activities through collaboration agreements. For example, the possibility that provinces can grant recreational fishing permits, regulate and grant permits for sessile species that do not move beyond one coastal province, support policy design in alignment with the national 
policy on sustainability, as well as advise the ministry on methods and measures for the conservation of fishing resources and repopulation of fishing areas, reflects the indirect concentrated modality of regulatory resources governance. Similarly, in the indirect concentrated governance of organizational resources, the provinces can support enforcement and surveillance, while for the expertise resources they participate in the creation and updating of information systems, and the generation of information for the National Fisheries Charter (NFC). Additionally, both provinces and municipalities can be involved in indirect and distributed frameworks of governance of the same resources. For example, for indirect distributed governance of regulatory resources, the National and Provincial Councils for Fisheries and Aquaculture can support fisheries policy, programmes, and regulations of management tools, as well as provide advice on resolutions on fishing rights. In practice, this entitlement shapes the governance of fisheries resources considering a bottom-up approach. For example, the state administration has adopted 22 fisheries management plans (e.g., species of clams, lobsters, sea urchins, small pelagic, macroalgae, shrimps) since 2012, whereas these documents, with the feedback of non-state actors, include fishery-specific objectives and the description of the species, the extractions, fishing areas, socio-economic indicators, gear types, and fishing methods.

\subsubsection{The Consolidation of the Patterns of Fishing Practices}

This section shows that an increase in the shadow of hierarchy by limiting direct concentrated governance of fisheries policy resources went hand in hand with the shaping of the patterns of fishing practices. In line with our expectations, the analysis of the three above-distinguished periods shows an increasing focus on the definition of the general patterns of fishing practices. It implies a more encompassing definition of meanings and framing in the general legal framework (Mexican Constitution and fisheries laws) in parallel with the increase of regulations to define in greater detail the competences and materials employed in fishing practices (see Figure 4-1). 
Figure 4-1. Regulations of fishing practices during political periods of Mexico 250

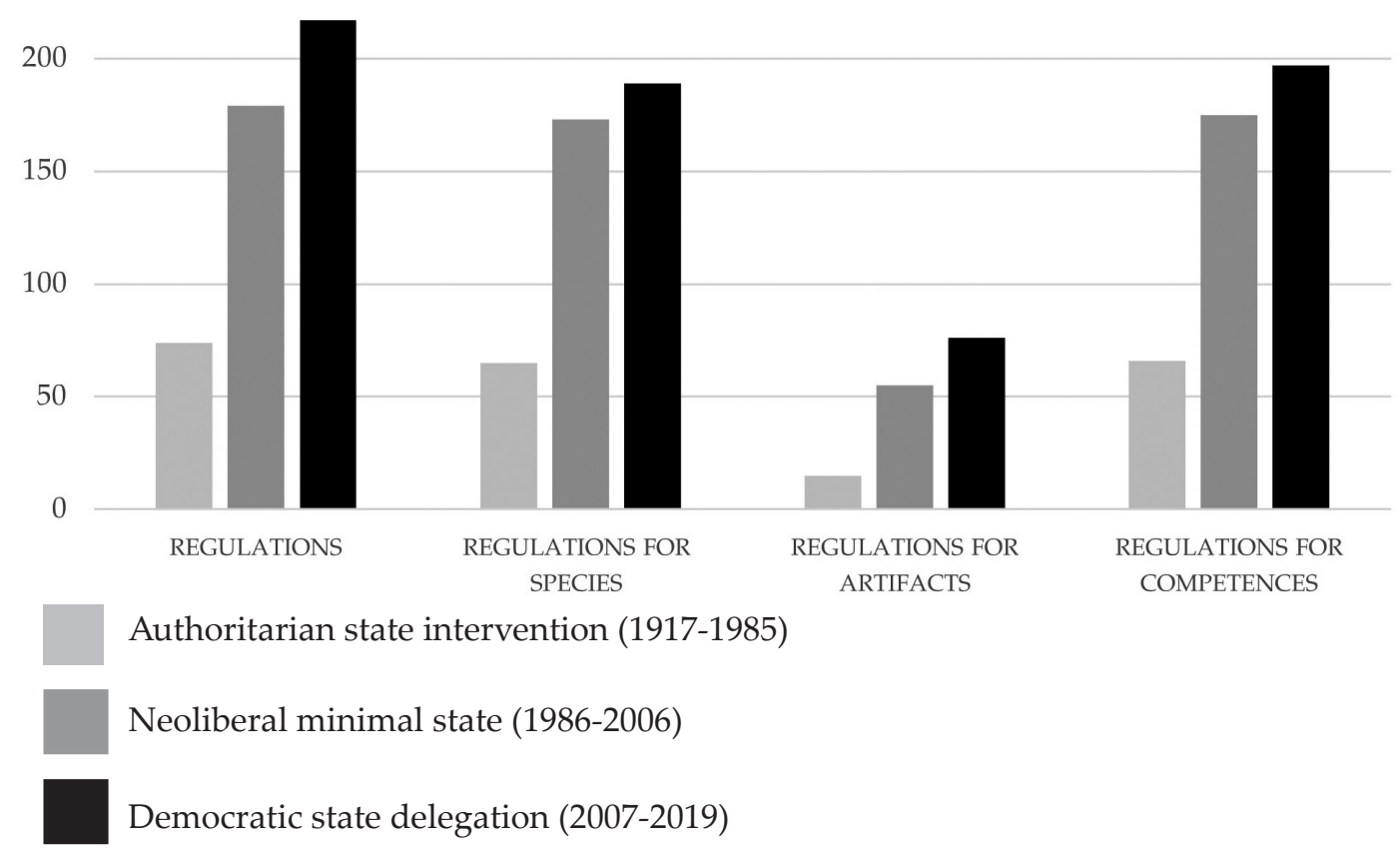

Source: Own elaboration based on the regulations published in the Official Gazette (1917-2019).

\section{Authoritarian state intervention (1917-1985)}

The analysis of the meanings of fishing practice from the perspective of its conceptualization shows an increasing expansion, from a very narrow focus on activities of extraction and cultivation to broader chains of activities associated with the result of the core extraction activity (e.g., transformation, commercialization). Therefore, the definition of fishing in 1925 involved "any activity that is implemented with the purpose of extracting living aquatic animals on the coast or beach; the use of waters and coast for farming aquatic animals; exploitation for industrial or commercial purposes; exploitation of the aquatic flora that serves as food or refuge for fish and other target animals for fishing" (DOF, 1925). The laws approved since 1948 extended this definition of fishing to include mentions of other activities prior and posterior to extraction and cultivation, directly related to fishing. They could include industrialization, marketing, transportation, or transformation of products of extraction. The expansion of the meaning of fishing was accompanied by an expansion of its more general framing and typologies. The definitions of the types of fishing expanded from commercial, recreational, and domestic consumption to include scientific fishing in 1948 (DOF, 1948). In some laws, small-scale fishing practised by coastal communities was distinguished from industrial fishing, a profit-oriented activity (DOF, 1925), with product transformation (DOF, 1932), and practised offshore 
(DOF, 1972). Moreover, the 1932 law also added the variation of the communitarian nature of fishing practice and emphasized its complex features to be performed by self-organized associations of fishers to improve their socio-economic living conditions (DOF, 1932). Such a communitarian meaning of fishing practice continued to be emphasized by the distinctive role of cooperatives in fisheries laws until 1986.

A similar extension of meanings is observed when the goals and ambitions of these activities are discussed in legal documents. The 1917 Mexican Constitution frames the meaning of the use of natural elements, including fisheries, by emphasizing the conservation of public wealth and its equitable distribution. The Constitution's amendment in 1976 signals a much more comprehensive understanding of the social and environmental purposes. The text includes the regulation of the use of these natural elements for social benefits, the improvement of living conditions for rural and urban populations, the collective exploitation and organization in fishing cooperatives, and the prevention of destruction of natural resources as well as the detriment of society. As a result, the constitutional mandate encompasses broader understandings for practices associated with natural elements. In the context of marine waters, the Constitution unilaterally created the EEZ of 200 nautical miles (nm) that same year for exploration, exploitation, conservation, and administration of natural resources, as well as for the preservation of the marine environment, including the control and elimination of pollution (DOF, 1976a).

Following this expansion, the fisheries laws also illustrate the evolution of the meanings of fisheries both to provide more precision and to encompass more associated activities. Therefore, the first four fisheries laws (1925-1950) included environmental goals focused on species conservation (mainly for commercial species) combined with fisheries development and economic goals. The aspirations of legislators were to privilege coastal communities (the cooperatives became the preferred form of organization), develop fisheries, and regulate foreign fleets. In 1972, the environmental goals included broader ecosystem conservation by including all aquatic flora and fauna; economic goals focused on the transformation of fishing resources and the regulation of domestic and foreign markets; and the social dimension of the equitable distribution of the public wealth. The aspiration of legislators was to continue developing fisheries, with a nationalist approach, and with stronger support for fishing cooperatives, particularly coastal cooperatives.

The regulations defining the materials show an increasing codification of this component of fishing practices. Of the 74 regulations published during this period, 65 
apply to species and 15 to fishing artefacts, mainly gear types, for the fishing of specific species (e.g., abalone, lobster, octopus, shrimp, small pelagic species) (see Figure 4-1). Following the regulations of fishing artefacts since the 1920s, the agreements provided the specifications (e.g., size, material, number of hooks) of the allowed (e.g., trawlers, nets, jigs) as well as prohibited (e.g., the use of dynamite and other explosives for the capture of species) artefacts for different regions and species (DOF, 1924a, 1924b). In addition to this, the regulations refer to landing sites, vessel specifications (DOF, 1934), and the requirement for the canning process of small pelagic species (DOF, 1980).

The competences are the most commonly regulated pattern of fishing practices. The analysed regulations did not specify the expectations of specific qualifications about using the materials but regulated in greater detail the methods, which implicitly assumed the skills necessary to perform them. Of the analysed 74 regulations for this period, 66 focused on competences related to specific fisheries by establishing biological, spatial, and temporal limitations. They established minimum and maximum sizes for commercial species (DOF, 1945a), the full protection of species (e.g., totoaba Cynoscion macdonaldi and manatee Trichechus manatus) (DOF, 1974, 1981), reserved species for coastal fishers (DOF, 1937, 1948a, 1948b), reserved species for recreational fishing (DOF, 1972), seasonal closures, and geographic limits for distinguishing areas. Such delimitations include reserved areas for coastal inhabitants (DOF, 1937) and for fishing cooperatives (DOF, 1948a, 1948b), reserved zones for the cultivation of shrimp (DOF, 1974), and fish refuges for single (DOF, 1977) and multiple species (DOF, 1955a). These regulations also included updates for the seasonal openings and closures (DOF, 1955b, 1973).

Similarly, the competences defined in terms of economic and organizational criteria delimited the temporal and spatial access of the subjects entitled to perform fishing practice according to fisheries laws. Initially, based on the type of activity criteria, concessions were granted for industrial fishing, and permits for commercial small-scale and recreational fishing as well as for selling the products. Three types of permits were granted: 1 ) general permits for fishing in waters of federal jurisdiction, 2) local permits for fishing in a specific area, and 3) special permits for species for which conservation was relevant and for recreational fisheries. In 1932, the state added the duration of concessions (up to 15 years). Since 1948, the granting of concessions has depended on the period for investment recovery (if longer than two years), determined by technical studies. In the period 1948-1971 concessions where granted for up to 30 years, and in 1972 the time was reduced to 20 years. Besides the 
economic criteria, the composition of fishing organizations (e.g., the percentage of regional and local fishers) also determined the access to this practice. Different types of fishing cooperatives have been able to benefit since 1948 from the concession of reserved species of high commercial value (e.g., abalone, lobster, shrimps, oysters).

Yet, the nature and typology of concessions and holders substantially diversified in the 1972 law. In addition to existing concessions, the law of 1972 adds the concessions for recreational fishing clubs, for fishing areas, and for the cultivation of non-reserved species. The latter two forms of concessions were established as rights for coastal fishing cooperatives. The cultivation of reserved species was granted to fishing cooperatives (coastal and industrial) and to educational and research centres. Moreover, ejido and communal cooperatives were also distinguished in this law. Concessions and permits for non-reserved species could be issued to Mexican citizens, organized fishers and cooperatives, decentralized agencies, parastatal enterprises, and mercantile corporations constituted according to Mexican laws and requirements. In order to improve the technical competences of fishing cooperatives, this law promoted the incorporation into cooperatives of graduate students from fisheries education centres and also allowed these graduate students to organize in fishing cooperatives when they could not join the existing cooperatives.

\section{Neoliberal minimal state (1986-2006)}

The analysis of the conceptualization of the fishing practice in the two laws adopted during this period (1986 and 1992) shows a reduction in the meanings attributed to fishing practice. At the beginning of this period, fishing still included activities prior and posterior to extraction. The 1986 law included actions of "cultivating, catching biological species that live in the water (totally, partially, temporarily) using an authorized procedure, as well as the activities prior and posterior to extraction". These activities include exploration, transformation, distribution, and commercialization (DOF, 1986a). Didactic fishing was added as a fishing category to be regulated. The subsequent 1992 law (similarly to the 1925 and 1932 laws) reduced the focus to activities conducted in the water, defining fishing as extraction and cultivation of aquatic species while excluding activities prior and posterior to extraction (DOF, 1992b).

Nevertheless, the framing of fishing in broad terms continued, but with shifts in emphasis. On the one hand, the Mexican Constitution expanded the environmental goals to include the preservation and restoration of the ecological equilibrium as part of the public interest (DOF, 1987b). In addition, the endorsement of the UNCLOS 
by coastal states in 1982 significantly influenced the objectives for fishing towards environmental conservation and economic use. The 1986 fisheries law continued to frame the objectives for fishing in environmental and social well-being terms, while the 1992 law framed the objectives in environmental and economic terms focusing on the conservation and rational use of fish resources (DOF, 1992b). The shift of the emphasis from social to economic priorities is also observed in the discourse legitimizing the approval of both legislative reforms. The debates in 1986 framed fishing in socio-economic terms as a source of employment, well-being, regional development, and income. The larger economic context of Mexico and the introduction of neoliberal policies introduced the relevance of private investment and collaboration opportunities among the social, private, and public sectors. Diversification of species extraction and processing as well as domestic and local consumption of low-cost seafood products were also part of the debates (Diario de los Debates 1985a, 1985b, 1986). Subsequently, the debates in 1992 focused mostly on environmental conservation and fishing development with an economic financial and technocratic efficiency approach. The notions of "effectiveness and productivity" justified the claims about the failure of cooperatives and more access to the private sector, and "trade globalization" as an opportunity for market expansion (Diario de los Debates, 1992a, 1992b, 1992c).

In the context of the above meanings attributed to the practice of fishing, the period of the neoliberal minimal state emphasizing deregulation paradoxically registered a significant increase in the regulation of fishing practices. During this period, the administration published 179 regulations, with 173 applying to species and 55 to fishing artefacts. This increase can be associated with the regulation of additional fisheries and the fact that since 1992 regulations have been developed under a specific legal framework created by the Federal Metrology and Normalization Law. The general template for the regulation allowed the inclusion of all technical and material aspects of extraction and products for responsible fishing practices in the Mexican Official Standards (Normas Oficiales Mexicanas (NOMs)) (OECD, 2006). Of the 26 NOMs published in this period, 24 included specific material elements for fishing practices, including sanitation requirements. In addition, the NFC (2000, updated 2004, 2006) was published. The NFC listed specific technologies and materials for the extraction of commercial species. For example, it defines in detail the dimensions of the vessels and gear types that can be used for the extraction of commercial species as well as provides information about their stock status. 
The regulation of technological specification of artefacts used for fishing practices registered significant developments towards more control. In addition to the regulation of gear types for commercial and recreational fishing (DOF, 1995a), specifications for seafood sanitation were included (DOF, 1995a, 1995b). New requirements for smallscale vessels introduced the obligation of proper identification of fishers' activity and equipment by cooperatives (DOF, 1991b). It also included technological innovations, such as the collaborative elaboration with small-scale fishers of new types of nets (i.e., Magdalena I y Suripera) to replace the prohibited traditional nets for the small-scale shrimp fishery. This innovation included Fish Excluder Devices (FEDs) and Turtle Excluder Devices (TEDs) to reduce the negative impact in bays (DOF, 2001b). Similarly, for environmental protection purposes, TEDs were designed and adopted for shrimp trawlers to reduce the impact on the sea turtle population (DOF, 1993a, 1993b, 1996c).

The above-specified developments regarding the materials and technologies used for fishing also involved further development and specification of subjects and skills required to perform fishing practices. Of the 179 regulations published in this period, 175 encompassed an increasing number of biological, spatial, and temporal limitations. Twenty-six NOMs were published in relation to these limitations. The assumption in the texts of regulations is that fishers involved in the fishing practices are competent enough to implement these methods and technologies. The regulations included updates for already regulated fisheries (e.g., mullets, shrimp, small pelagic species) and new regulations for other existing fisheries (e.g., red sea urchins, snails, billfish species) (DOF, 1987a, 1988, 1990, 1994a). Specific regulations established the permanent closure and prohibition of extraction of protected species (e.g., vaquita marina, turtles) (CT-CERN-001-91, NOM-054-ECOL-94). Moreover, regulations involved not only the limitation of size and fishing periods, but also novel elements such as the release of females with eggs and sanitation requirements for domestic consumption, imports, and exports. The process for establishing seasonal and spatial closures was regulated within a NOM (DOF, 1994b). Thus, this period involved an increasing number of regulations concerning seasonal closures for specific areas. Further regulations involved the exclusion of specific types of vessels, such as the exclusion of shrimp trawlers, from shallow waters (0-10 fathoms) and a new system of permits, privileges, and requirements (e.g., areas, species) for recreational fishing (DOF, 1991a, 1994a, 2001a), including the development of NOMs. Finally, technological, spatial, and biological aspects intertwine in adopted regulations as in the case of the regulations for tuna and shrimp fisheries to reduce their negative interaction with the protected species of dolphins and turtles, respectively. Given the international attention to such interactions with protected species, from 1992 
to the end of the period, regulations (published as emergency NOMs) required the recording, release, and reduction of dolphin (DOF, 1992c, 1996a, 1999) and turtle bycatch (DOF, 1993a, 1996b) and the implementation of observers' programmes for monitoring compliance.

Furthermore, the established system of concessions and permits was further expanded, in particular by including associated conditions. For example, the 1992 law established the condition that permits, concessions, and authorizations would be granted following the criteria of the legal ownership of equipment, public interest, and the availability of resources would delimit the area and species. The durability of concessions and permits depended on the investment recovery period. In the case of concessions, their duration was limited to 20 years and resolutions were determined by technical and economic studies. While the 1986 and 1992 laws limited the diversification of cooperative types (fishing cooperatives including ejidos and communal), the 1992 law also eliminated their distinctive treatment for accessing concessions. Permits and concessions for commercial fishing (specific fisheries, including one or more species) could be granted to individuals and corporations. The latter included any type of organization (DOF, 1992b).

\section{Democratic state delegation (2007-2019)}

The practice of fishing further expanded its meaning to new areas in the 2007 law. The definition of this activity became more nuanced and encompassing than in previous periods. This fisheries law included the concepts of fishing and fisheries. Fishing was defined as "the act of extracting, capturing, or collecting, by any method or procedure, biological species or biogenic elements, whose total, partial, or temporary stages of life are the water", and fisheries as "the set of fishing production systems, which encompasses the whole or part of the successive phases of the fishing activity, and which may include the capture, management, and processing of a resource or group of resources, whose means of production, organizational structure, and production relations occur in a defined geographical and temporal scope" (DOF, 2007a). Following general international trends towards sustainable development, fisheries became an element of the promotion of sustainability in Mexico. The integration of sustainable development as an overarching frame for fishing practices is clearly visible during the process of the elaboration of the 2007 fisheries law (Diario de los Debates 2005, 2006a, 2006b). In addition, the overarching goal and 15 specific goals integrate the three dimensions of sustainability (environmental, social, and economic dimensions of fisheries), but with special emphasis on environmental protection 
of resources and ecosystems, the livelihoods of fishers, and the preferential access to fishing for coastal communities and indigenous groups (DOF, 2007a). Legislators perceived Mexico as an international point of reference for fishing and emphasized the relevance of the modernization of the sector in harmony with the environment. Fishing was perceived as an activity with the potential to eradicate poverty and ensure food security. Human rights (healthy environment, access to health services), the recognition of indigenous groups' rights, and the democratization of fisheries (i.e., participation of municipalities, provinces, the social and the private sectors) (Diario de los Debates, 2005, 2006a, 2006b) were key elements of fishing practices in legislators' discourses and became codified in the Constitutional amendments that framed the 2007 fisheries law (DOF, 2001c, 2004b).

The regulation of materials continued under the 2007 law with the provision of new and updated specifications on materials. During this period, the administration published in total 217 regulations, 189 applicable to species and 76 to artefacts used for extraction (see Figure 4-1). Most regulations updated and provided further specifications for gear types to be used in regulated fisheries. Regulations also introduced new requirements for existing (e.g., corvina gulfina, groupers, sharks) (DOF, 2006b, 2007b) and for emerging fisheries (e.g., sea cucumber, geoduck) (DOF, 2015c, 2018d). Thirteen NOMs were updated (e.g., clams, Caribbean lobster, small pelagic, shrimps, tuna) and 15 NOMs (e.g., snails, sharks and rays, groupers) and 22 management plans were created and published with detailed specifications on materials for fishing practices. Prohibited artefacts with respective fishing methods were integrated into a NOM (DOF, 2015e). The technological standardization was the most important development during this period. For example, the universalization of technological equipment included in particular the incorporation of a vessel monitoring system (VMS) for the industrial fleets (groupers, shrimps, sharks, small pelagic species, tuna fisheries) (DOF, 2015d), an automatic identification system for the small-scale fleets (DOF, 2013a), and the introduction of a NOM with the technical standards for the use of TEDs by the trawler fleets (DOF, 2007c). In addition, a digital strategy to modernize services, knowledge, and information systems was established as part of the Executive's strategy on transparency (DOF, 2018a, 2018b). Further regulations to address international environmental concerns were published, such as the regulation of gear types for elasmobranchs (shark and rays) (DOF, 2006b) and curvina golfina to reduce the interaction with protected species (i.e., totoaba and vaquita marina) (DOF, 2007b). The NFC was updated to specify gear types, vessels, and stock status for commercial fisheries (DOF, 2000, 2012a, 2018c). 
Of the 217 regulations, 197 apply to competences related to biological, spatial, and temporal specification for fishing practices. The regulation of competences includes updates of seasonal closures and NOMs. New regulations establish quotas for fisheries (e.g., curvina gulfina, bluefin tuna, sea cucumber), new NOMs for existing (e.g., groupers, sharks, swimming crabs, pole and line tuna) and emerging fisheries (e.g., geoduck), as well as specifications to reduce the interaction of fisheries with protected species (yellow turtle in the Pacific, curvina golfina with totoaba and vaquita marina) (DOF, 2005, 2015a, 2016), and the closures of overexploited species (i.e., queen conch) and of species of international concern (white shark) (DOF, 2012c, 2015b). The NOMs and management plans detailed the information on the competences (e.g., fishing methods and operations, areas) (DOF, 2014a, 2014b, 2014c). In order to reduce the impacts on marine ecosystems and species, the cultivation of pearls and shrimps in marine waters was regulated (DOF, 2013b, 2014f). In addition, the process for establishing fish refuges was regulated through NOM-049 (DOF, 2014e), and consequently 23 regulations were published to establish and renew fish refuges in 15 sites (e.g., DOF, 2012b, 2017). Due to the inclusion of food safety and quality in the law of 2007, regulations were published on the specifications for seafood product safety and quality (DOF, 2011, 2012f, 2012g) and to require the origin labelling of shrimp species for the use of producers and consumers (DOF, 2014d). In addition to the regulations developed by the state, the law of 2007 recognizes the customary regulations developed by inhabitants of coastal communities for the practice of fishing based on their traditional knowledge (DOF, 2007a).

The system of concessions and permits was established based on the law of 1992 . Permits and concessions for species, groups of species, or areas are granted for up to five and 20 years, respectively. They are granted to individuals and corporations, based on the investment, public interest, conditions of equity, and availability of fish resources. In those cases when resources are overexploited or in recovery status, the ministry in charge of fisheries has to follow the requirements specified in the NFC. The fishing equipment under permits and concessions has to be registered in the National Maritime Public Registry. For concessions, the law specifies that applicants have to demonstrate technical, administrative, and financial capacity as well as compliance with the NOMs and regulations, and the generation of social and economic benefits for the region. The ministry in charge of fisheries has to inform the Provincial Councils about concession applications, for the councils to provide advice for concession resolutions. Preference for permit and concession granting is given to the inhabitants of coastal communities and to indigenous groups. When concessions or permits affect ecosystems in which the indigenous groups live, the ministry in charge of fisheries has to collect the opinion of such groups. 


\subsection{Discussion}

This chapter shows how the state shapes the patterns of fishing practices as a way to control this policy domain in view of an increasing tendency for more indirect and distributed forms of governing policy resources.

In the particular case of Mexico, there are different shades of grey when looking at the shadow of hierarchy from the perspective of the involvement of the state and other actors in the governing of policy resources (see Annex 4-1). The greys imply direct and indirect state intervention as well as different degrees of distribution of duties and resources among federal, provincial and local agencies, as well as private and social actors. The participation of these actors was explicit and regulated in fisheries laws in the first (authoritarian state delegation) and third (democratic state delegation) political periods. However, this does not mean that during the second period (neoliberal minimal state) the actors were excluded from the governance of the field, but it could be interpreted that their participation is simply not regulated and controlled by the state. The changes in the shades of grey show the state capacity and meta-governance power to retain, delegate, and recover direct power in different areas of intervention at any time, as already observed in Chapter 3.

In addition, the analysis of Mexican fisheries using the social practices theory, illustrates that beyond the explicit regulation of the boundaries of actors' participation in fisheries governance, the shadow of hierarchy is also explained by the employment of the state meta-governance power for the codification of the patterns of fishing practices. The state retains this power to define the cognitive meaning, materials, and competences for fishing practices, and it is through the increasing exercise of this power that the state continues influencing actors, including those involved in non-hierarchical forms of governance (e.g., coastal communities, indigenous groups). Over the last 100 years, the increasing regulatory activity of the Mexican state has been observed not only in the number of regulations for fishing practices, but also in the number of regulated fisheries, the level of specification, the regulatory instruments (NOMs, management plans), and the thematic areas (extraction, impacts on the ecosystem, food safety and sanitation). This shows that despite the changes in the political periods (authoritarian state delegation, neoliberal minimal state, democratic state delegation) and actors' intervention in governance, the state retains in different more or less direct forms its presence and hierarchy in fisheries governance. 
The analysis of fisheries regulations shows the multiple ways of conducting the fishing practices, as they incorporate different species, sites, and fishers. In the case of Mexico, the changes in meanings within the political periods went in parallel with the expanded regulation of requirements for fishing rights applicants (i.e., cooperatives, citizens, corporations), the type of materials (e.g., species, gear types, vessels), and competences (e.g., size limits, seasonal closures). During the late authoritarian state intervention and the neoliberal minimal state periods, greater attention and specificity were given to the regulation of these aspects for the main commercial fisheries. However, a broader coverage of species was addressed through the publication of the NFC, which includes an inventory of commercial species as well as authorized materials and competences in broad terms. This trend continued in the subsequent period (democratic state delegation) with the elaboration of management plans, the creation and updating of NOMs for main commercial fisheries, and the updating of the NFC. In this last period, the number of regulations for additional aspects of fishing practices increased, such as the case of fish refuges, food safety and sanitation measures, and the use of technology for monitoring fishing operations.

The analysis of fishing as a social practice also shows that the state incorporates international requirements into the regulation of Mexican fisheries to prevent negative market implications. This was evidenced particularly in the last two political periods (e.g., the use of TEDs, the use of technology for the monitoring of vessel operations, the regulation of interactions of fisheries with protected species). This shows that the state bridges global best practices with the regulation of practices at local scales. However, the state retains its autonomy on what is and what is not incorporated into regulations. For example, during the neoliberal minimal state period, the state did not incorporate market-driven tools such as the Individual Transferable Quotas (ITQs), which were largely applied in this period in other parts of the world (Pinkerton \& Davis, 2015; Young et al., 2018). The Mexican Constitution, which does not allow the transferability of rights, as this is a power for the state, not for individuals and corporations (DOF, 1917), disabled the application of these solutions. In addition, during the last period (democratic state delegation) the state continued the regulation of fisheries based on a single-species approach, although the ecosystem approach to fisheries (EAF) (Pikitch et al., 2004) is largely suggested for fisheries sustainability and there are elements of the Mexican regulations (e.g., bycatch regulation, fish refuges, quotas) and the NFC (e.g., associated species with fisheries and environmental phenomena impacting fisheries) adapting this approach. 
This chapter contributes to the literature on the shadow of hierarchy in fisheries governance, previously investigated by Viet-Tang (2018), to illustrate the resources provided by the state for the functioning of co-governed fisheries. It builds on Chapter 3 (institutional setting for the coexistence of governance modes), to show how the state uses the legal framework and regulations as a meta-governance power to govern policy resources with public, private, and social actors, as well as to codify the general patterns of fishing practices. Although it is difficult to explain causality within these mutually constitutive elements of the shadow of hierarchy, the Mexican case shows that they can occur in parallel to establish the boundaries and indirectly influence actors' participation in governance systems of any mode (e.g., co-governance, self-governance). All coastal states have been provided with this regulatory power through the UNCLOS and national legal frameworks. Thus, the case of Mexico illustrates the autonomy of the coastal state to employ it to metagovern fisheries, according to its capacities and interests. Further research efforts are needed to understand how the state assesses the performance of such diverse regulations as well as how the state integrates the heterogeneity of marine resources into regulations, which, in addition to actors, constitute another key element of the marine governance system.

\subsection{Concluding Remarks}

This chapter shows how the state uses the legal framework and regulations to shape policy resources and the patterns of fishing practices. The case of Mexico shows the increasing tendency for indirect and distributed forms of policy resources and the expanded codification of fishing practices (i.e., meanings, materials, and competences). Although it is difficult to show causality within these two elements of the shadow of hierarchy, the Mexican case shows that they occur in parallel for the state to remain present and to indirectly influence actors' participation in governance systems of any mode (e.g., co-governance, self-governance). Despite the changes in political periods, public, private, and social actors interact and participate in marine fisheries governance under the shadow of the hierarchy, and therefore under indirect state control given that their individual activities are fashioned within a broad framework of patterns of fishing practices codified by the state. To deepen the research on the shadow of hierarchy in fisheries governance, the next chapter explains how the state assesses the performance of regulations as well as how it integrates the characteristics of different types of marine fish resources in the regulation process in order to pursue the sustainability of fisheries. 
Annex 4-1. The historical variety of the state involvement in Mexican fisheries governance. DC means direct and concentrated resources; one ministry has the authority and resources. DD means direct and distributed resources; various ministries share authority and resources. IC means indirect concentrated; one ministry shares authority and resources with provinces and municipalities. ID means indirect and distributed authority and resources; ministries share authority and resources with private and social actors. Darker colours of grey indicate greater shadow of state hierarchy.

\begin{tabular}{|c|c|c|c|c|}
\hline $\begin{array}{l}\text { Fisheries } \\
\text { laws }\end{array}$ & Regulation & Organization & Financial & Expertise \\
\hline \multirow[t]{3}{*}{1925} & $\begin{array}{l}\text { DC: Regulations and } \\
\text { fishing rights }\end{array}$ & $\begin{array}{l}\text { DC: Enforcement and } \\
\text { surveillance }\end{array}$ & $\begin{array}{l}\text { DD: The establishment } \\
\text { of fees with the Ministry } \\
\text { of Finances }\end{array}$ & $\begin{array}{l}\text { ID: Catch registration } \\
\text { by fishers shared with } \\
\text { government agencies } \\
\text { and inspectors }\end{array}$ \\
\hline & $\begin{array}{l}\text { IC: Municipalities } \\
\text { and local authorities } \\
\text { grant permits and } \\
\text { concessions for local } \\
\text { waters }\end{array}$ & $\begin{array}{l}\text { IC: Enforcement and } \\
\text { surveillance shared } \\
\text { with municipalities and } \\
\text { local authorities }\end{array}$ & & \\
\hline & & $\begin{array}{l}\text { ID: Enforcement and } \\
\text { surveillance - Citizens } \\
\text { report misdemeanours } \\
\text { for } 25 \% \text { of the fines; } \\
\text { concession holders } \\
\text { pay a guarantee for } \\
\text { the compliance of } \\
\text { regulations and share } \\
\text { the enforcement costs }\end{array}$ & & \\
\hline \multirow[t]{2}{*}{1932} & $\begin{array}{l}\text { DC: Regulations and } \\
\text { fishing rights }\end{array}$ & $\begin{array}{l}\text { DC: Enforcement and } \\
\text { surveillance }\end{array}$ & $\begin{array}{l}\text { DD. The establishment } \\
\text { of fees with the Ministry } \\
\text { of Finances }\end{array}$ & \\
\hline & & $\begin{array}{l}\text { ID: Concession holders } \\
\text { guarantee financially } \\
\text { the compliance of } \\
\text { regulations and share } \\
\text { the enforcement costs }\end{array}$ & & \\
\hline \multirow[t]{3}{*}{1948} & $\begin{array}{l}\text { DC: Regulations and } \\
\text { fishing rights }\end{array}$ & $\begin{array}{l}\text { DC: Enforcement and } \\
\text { surveillance }\end{array}$ & $\begin{array}{l}\text { DC: Financial support } \\
\text { for cooperatives to } \\
\text { acquire equipment and } \\
\text { infrastructure }\end{array}$ & $\begin{array}{l}\text { ID: Permits for scientific } \\
\text { fishing to conduct } \\
\text { research; applicants } \\
\text { provide information for } \\
\text { concessions resolutions }\end{array}$ \\
\hline & $\begin{array}{l}\text { DD: Coordination } \\
\text { with the Ministry } \\
\text { of Economics for } \\
\text { regulating fishing areas, } \\
\text { reserved species for } \\
\text { cooperatives, and total } \\
\text { allowable catch (TAC) }\end{array}$ & & $\begin{array}{l}\text { DD: The establishment } \\
\text { of fees with the Ministry } \\
\text { of Finances }\end{array}$ & \\
\hline & $\begin{array}{l}\text { ID: Consultation with } \\
\text { fishing federations } \\
\text { to set the maximum } \\
\text { volume for reserved } \\
\text { species to cooperatives }\end{array}$ & & & \\
\hline \multirow[t]{2}{*}{1950} & $\begin{array}{l}\text { DC: Regulations and } \\
\text { fishing rights }\end{array}$ & $\begin{array}{l}\text { DC: Enforcement and } \\
\text { surveillance }\end{array}$ & $\begin{array}{l}\text { DC: Financial support } \\
\text { for cooperatives to } \\
\text { acquire equipment and } \\
\text { infrastructure }\end{array}$ & $\begin{array}{l}\text { DC: The creation of } \\
\text { the National Fisheries } \\
\text { Registry }\end{array}$ \\
\hline & $\begin{array}{l}\text { DD: Coordination } \\
\text { with the Ministry } \\
\text { of Economics for } \\
\text { establishing the catch } \\
\text { limits to fulfil domestic } \\
\text { requirements }\end{array}$ & & $\begin{array}{l}\text { DD: The establishment } \\
\text { of fees with the Ministry } \\
\text { of Finances }\end{array}$ & $\begin{array}{l}\text { ID: The National } \\
\text { Advisory Commission } \\
\text { of Fisheries to } \\
\text { undertake research; } \\
\text { permits for scientific } \\
\text { fishing to conduct } \\
\text { research; applicants } \\
\text { provide information for } \\
\text { concessions resolutions }\end{array}$ \\
\hline
\end{tabular}




\begin{tabular}{|c|c|c|c|c|}
\hline $\begin{array}{l}\text { Fisheries } \\
\text { laws }\end{array}$ & Regulation & Organization & Financial & Expertise \\
\hline \multirow[t]{2}{*}{1972} & $\begin{array}{l}\text { DC: Regulations and } \\
\text { fishing rights }\end{array}$ & $\begin{array}{l}\text { DC: Enforcement and } \\
\text { surveillance; } \\
\text { exploitation and } \\
\text { commercialization } \\
\text { through the } \\
\text { cooperatives and } \\
\text { parastatal enterprises; } \\
\text { Ministerial support for } \\
\text { cooperatives to acquire } \\
\text { equipment }\end{array}$ & $\begin{array}{l}\text { DC: Financial support } \\
\text { for cooperatives to } \\
\text { acquire equipment and } \\
\text { infrastructure }\end{array}$ & $\begin{array}{l}\text { DC: National Fisheries } \\
\text { Registry and the } \\
\text { National Fisheries } \\
\text { Inventory; INAPESCA } \\
\text { conducts research; } \\
\text { technical support } \\
\text { (fishing methods) and } \\
\text { capacity building for } \\
\text { cooperatives }\end{array}$ \\
\hline & $\begin{array}{l}\text { ID: The National } \\
\text { Advisory Commission } \\
\text { of Fisheries promotes } \\
\text { laws and regulations } \\
\text { and elaborates the } \\
\text { annual programme for } \\
\text { fisheries development }\end{array}$ & $\begin{array}{l}\text { DD: The establishment } \\
\text { of franchises for } \\
\text { fisheries and related } \\
\text { industries with the } \\
\text { Ministry of Finances; } \\
\text { The coordination with } \\
\text { the Navy Ministry } \\
\text { for enforcement and } \\
\text { surveillance }\end{array}$ & $\begin{array}{l}\text { DD: The establishment } \\
\text { of fees with the Ministry } \\
\text { of Finances; the Fund } \\
\text { for the Development of } \\
\text { Fishing Cooperatives } \\
\text { for the provision of } \\
\text { loans operated by a } \\
\text { committee integrated } \\
\text { by mainly by the public } \\
\text { sector, with minority } \\
\text { representation of the } \\
\text { sectoral confederations }\end{array}$ & $\begin{array}{l}\text { ID: Authorizations and } \\
\text { permits for scientific } \\
\text { fishing to conduct } \\
\text { research; applicants } \\
\text { provide information for } \\
\text { concessions resolutions; } \\
\text { The National Advisory } \\
\text { Commission of } \\
\text { Fisheries conducts } \\
\text { research on at the } \\
\text { request of the Ministry } \\
\text { or other interested } \\
\text { parties }\end{array}$ \\
\hline \multirow[t]{3}{*}{1986} & $\begin{array}{l}\text { DC: Regulations and } \\
\text { fishing rights }\end{array}$ & $\begin{array}{l}\text { DC: Enforcement and } \\
\text { surveillance }\end{array}$ & $\begin{array}{l}\text { DC: Financial support } \\
\text { for cooperatives to } \\
\text { acquire equipment and } \\
\text { infrastructure }\end{array}$ & $\begin{array}{l}\text { DC: The National } \\
\text { Fisheries Charter (NFC) } \\
\text { with the inventory of } \\
\text { all commercial fisheries; } \\
\text { technical support } \\
\text { (fishing methods) and } \\
\text { capacity building for } \\
\text { cooperatives }\end{array}$ \\
\hline & $\begin{array}{l}\text { DD: Coordination } \\
\text { with the Ministry of } \\
\text { Communications and } \\
\text { Transportation for the } \\
\text { establishment of the } \\
\text { allowed number of } \\
\text { boats; with the Ministry } \\
\text { of Urban Development } \\
\text { and Ecology for } \\
\text { the establishment } \\
\text { of closures and fish } \\
\text { resources management }\end{array}$ & $\begin{array}{l}\text { DD: The auctions } \\
\text { for fishing products } \\
\text { and sub-products in } \\
\text { coordination with the } \\
\text { Ministry of Commerce } \\
\text { and Industry } \\
\text { Development }\end{array}$ & & $\begin{array}{l}\text { DD: The INAPESCA } \\
\text { as a deconcentrated } \\
\text { independent body; The } \\
\text { coordination with the } \\
\text { National Council for } \\
\text { Science and Technology } \\
\text { for research }\end{array}$ \\
\hline & $\begin{array}{l}\text { ID: The National } \\
\text { Advisory Commission } \\
\text { of Fisheries supports } \\
\text { the development of } \\
\text { fisheries programmes } \\
\text { and solutions for } \\
\text { exploitation of aquatic } \\
\text { flora and fauna }\end{array}$ & & & $\begin{array}{l}\text { ID: Permits for scientific } \\
\text { fishing to conduct } \\
\text { research; applicants } \\
\text { provide information for } \\
\text { concessions resolutions }\end{array}$ \\
\hline 1992 & $\begin{array}{l}\text { DC: Regulations, and } \\
\text { fishing rights }\end{array}$ & $\begin{array}{l}\text { DC: Enforcement and } \\
\text { surveillance }\end{array}$ & & $\begin{array}{l}\text { DD: INAPESCA } \\
\text { conducts the research }\end{array}$ \\
\hline
\end{tabular}




\begin{tabular}{|c|c|c|c|c|}
\hline $\begin{array}{l}\text { Fisheries } \\
\text { laws }\end{array}$ & Regulation & Organization & Financial & Expertise \\
\hline & & & & $\begin{array}{l}\text { ID: Permits for scientific } \\
\text { fishing to conduct } \\
\text { research; applicants } \\
\text { provide information for } \\
\text { concessions resolutions; } \\
\text { catch registration by } \\
\text { fishers shared with } \\
\text { government agencies } \\
\text { and inspectors; fishers } \\
\text { participate in research } \\
\text { studies }\end{array}$ \\
\hline \multirow[t]{3}{*}{2007} & $\begin{array}{l}\text { DC: Regulation } \\
\text { and fishing rights. } \\
\text { Preference is given to } \\
\text { inhabitants of coastal } \\
\text { communities and } \\
\text { indigenous groups }\end{array}$ & $\begin{array}{l}\text { DC: Enforcement and } \\
\text { surveillance }\end{array}$ & $\begin{array}{l}\text { DD: The development } \\
\text { of incentives, resources } \\
\text { and technology to } \\
\text { support indigenous } \\
\text { groups to improve their } \\
\text { productivity }\end{array}$ & $\begin{array}{l}\text { DD: Science production } \\
\text { through INAPESCA } \\
\text { (deconcentrated } \\
\text { agency); the } \\
\text { elaboration of the } \\
\text { NFC in collaboration } \\
\text { with Ministry of } \\
\text { Environment; The } \\
\text { development of } \\
\text { programmes and } \\
\text { technology to support } \\
\text { indigenous groups }\end{array}$ \\
\hline & $\begin{array}{l}\text { DD: Collaboration } \\
\text { with the Ministry } \\
\text { of Environment for } \\
\text { the conservation of } \\
\text { protected areas and } \\
\text { species; measures } \\
\text { for the quality and } \\
\text { sanitation of fish } \\
\text { products as well as for } \\
\text { traceability systems } \\
\text { with the Ministry of } \\
\text { Hygiene and Sanitation. }\end{array}$ & $\begin{array}{l}\text { DD: The operation } \\
\text { of enforcement and } \\
\text { surveillance with the } \\
\text { Navy Ministry; the } \\
\text { traceability system and } \\
\text { the monitoring and } \\
\text { enforcement of live, } \\
\text { fresh or frozen products } \\
\text { transportation with the } \\
\text { Ministry of Hygiene } \\
\text { and Sanitation }\end{array}$ & $\begin{array}{l}\text { ID: The creation of } \\
\text { a Fund for Fisheries } \\
\text { Development (for } \\
\text { fishers, science, } \\
\text { technology) operated } \\
\text { by a mixed committee } \\
\text { integrating the public, } \\
\text { private and social } \\
\text { sectors; the recognition } \\
\text { and awarding of } \\
\text { best practices in } \\
\text { collaboration with the } \\
\text { Congress, INAPESCA, } \\
\text { private and social } \\
\text { organizations }\end{array}$ & $\begin{array}{l}\text { IC: Provinces and } \\
\text { municipalities } \\
\text { participate in the } \\
\text { creation and update of } \\
\text { information systems } \\
\text { and for NFC }\end{array}$ \\
\hline & $\begin{array}{l}\text { IC: Provinces can grant } \\
\text { recreational fishing } \\
\text { permits; regulate sessile } \\
\text { species; support policy } \\
\text { design in alignment } \\
\text { with the national policy } \\
\text { on sustainability; } \\
\text { municipalities can } \\
\text { design and implement } \\
\text { local policies } \\
\text { and programmes } \\
\text { for fisheries and } \\
\text { aquaculture; advise the } \\
\text { ministry on methods } \\
\text { and measures for } \\
\text { the conservation of } \\
\text { fishing resources and } \\
\text { repopulation of fishing } \\
\text { areas }\end{array}$ & $\begin{array}{l}\text { IC: Provinces and } \\
\text { municipalities } \\
\text { can participate in } \\
\text { enforcement and } \\
\text { surveillance }\end{array}$ & & $\begin{array}{l}\text { ID: The National } \\
\text { Network for fisheries } \\
\text { research with } \\
\text { universities and } \\
\text { researchers; researchers } \\
\text { and users contribute to } \\
\text { the NFC, the National } \\
\text { Program of Scientific } \\
\text { and Technological } \\
\text { Research for Fisheries } \\
\text { and Aquaculture, } \\
\text { as well as research } \\
\text { projects; permits for } \\
\text { scientific fishing to } \\
\text { conduct research; } \\
\text { applicants provide } \\
\text { information for } \\
\text { concessions resolutions; } \\
\text { right holders provide } \\
\text { information }\end{array}$ \\
\hline
\end{tabular}


Chapter 4. The Shadow of Hierarchy in the Governance of Fishing Practices

\begin{tabular}{|c|c|c|c|c|}
\hline $\begin{array}{c}\text { Fisheries } \\
\text { laws }\end{array}$ & Regulation & Organization & Financial & Expertise \\
\hline & $\begin{array}{l}\text { ID: National and } \\
\text { provincial councils } \\
\text { support fisheries } \\
\text { policy, programmes, } \\
\text { regulations of } \\
\text { management tools, } \\
\text { and resolutions of } \\
\text { fishing rights; the state } \\
\text { recognizes customary } \\
\text { rules developed by } \\
\text { users; the recognition } \\
\text { of community groups } \\
\text { to support the } \\
\text { administration and } \\
\text { conservation of fish } \\
\text { resources }\end{array}$ & $\begin{array}{l}\text { ID: Users and } \\
\text { indigenous groups } \\
\text { can participate in the } \\
\text { Integrated Programme } \\
\text { for Enforcement } \\
\text { and Surveillance } \\
\text { for Fisheries and } \\
\text { Aquaculture }\end{array}$ & & \\
\hline
\end{tabular}

Source: Own elaboration based on Mexican fisheries laws. 


\section{Chapter 5. The Shadow of Hierarchy in the Governance of Fisheries Sustainability ${ }^{32}$}

\subsection{Introduction}

This chapter investigates the shadow of hierarchy by illustrating how the state ensures desirable outcomes (i.e., fisheries sustainability) from marine fisheries governance systems. According to public policy literature, the state is the meta-governor actor that defines the boundaries and indirectly influences governance modes to serve the public and third parties' interests such as environmental protection or sustainability (Jessop, 1997, p. 505; Scharpf, 1997, p. 202). Although policies developed within the context of alternative governance modes can be effective in terms of the involved actors' interests, the capacity for these actors to contribute to overarching goals at large, such as fisheries sustainability, is due to the fact that they perform in the shadow of hierarchy (Scharpf, 1997, p. 205). This chapter uses Mexican fisheries as a case study and the impact institutional theory (Schmid, 1987) to explain how the state creates the institutional settings to ensure fisheries sustainability.

Sustainability has been the overarching goal (desired outcome) for fisheries governance over the last few decades, due to the increasing overexploitation of fish marine resources $(\mathrm{FAO}, 2020)^{33}$, the mandates of United Nations Convention on the Law of the Sea (UNCLOS), and the endorsement of other international agreements that commit to this goal (e.g., the FAO Code of Conduct for Responsible Fisheries). By 1982, when the UNCLOS was endorsed, fisheries sustainability referred only to target commercial species (UN, 1982). Over time, sustainability has integrated broader dimensions, accounting for the social, economic, and governance aspects of fisheries (Caddy \& Seijo, 2005; FAO, 1995; FAO 2015).

To achieve fisheries sustainability, the state, beyond regulating actors' participation, it creates institutions (fishing rights and regulations) with enforcement systems to sanction those that violate them (Cochrane, 2018, p. 8). These institutions have to account for the inherent characteristics of different types of marine fish resources associated to their mobility and uncertainties of abundance and distribution over space and time (Hilborn \& Peterman, 1996). Under the state-based institutions, actors interact within different governance modes, and often create complementary rules

\footnotetext{
${ }^{32}$ This chapter was co-authored with Prof. Dr. Juan Carlos Seijo. Marist University of Merida.

${ }^{33}$ Overfished stocks increased from $10 \%$ in 1974 to $34 \%$ in 2017, particularly in developing countries (FAO, 2020).
} 
and mechanisms to those of the state to engage in fisheries governance and sustainability. For example, private and social actors implement market-based mechanisms (e.g., ecolabelling, certification processes, and fishery improvement projects (FIPs)), which are bounded by national regulations and entail auditing and verification systems to ensure compliance that contribute to the enforcement systems of the state (Cochrane, 2018). This chapter explains how the state pursues sustainability, by defining institutional settings for different resources, which frame and bound private and social actors' organization and rules, to be performed under its shadow of hierarchy.

\subsection{Analytical Approach}

The situation, structure, performance (SSP) approach (Schmid, 1987, pp. 5-23) is used to investigate how the state defines institutional settings for different resource types to purse fisheries sustainability. Different types of resources possess different characteristics, associated to their mobility and uncertainties of abundance and distribution. These characteristics entail high exclusion ${ }^{34}$ (Schmid, 1987), information (Hilborn \& Peterman 1996), and enforcement costs (Anderson \& Seijo, 2010) for the governing of marine fisheries. Then, in order to pursue fisheries sustainability, the state regulates the extraction of different resource types, based on such characteristics, to guarantee the regularity of actions performed by actors, without directly controlling individual actors and actions. In this way, as shown it in Chapter 4, the state creates the framework for appropriate actions for autonomous actors. By regulating the extraction of resource types as well as the boundaries of actors' participation in governance (as shown in Chapter 3) the state pursues overarching goals of public interest, indirectly influences actors' behaviour, and shares the costs associated to the governing of fisheries.

The SSP approach is anchored in the institutional impact theory derived from neoinstitutional economics (Schmid, 1987, pp. 5-23) to understand the performance of institutions applied to a specific context. In this particular study, this approach is used to investigate the corresponding performance of institutional settings designed for different types of resources. Within the institutional setting, the SSP approach allows to investigate the state regulations, and the informal rules and mechanisms developed and performed by non-state actors under the shadow of hierarchy. For example, the SSP approach was applied by Seijo (1993) to explain the institutional setting for the Mexican lobster fishery (Panulirus argus), which involved state allocation of territorial

\footnotetext{
${ }^{34}$ The high cost of excluding unauthorized fishers from exploiting the resource. It means that the use of an existing fish stock is difficult to limit only to those who have the right to fish (Schmid, 1987, 2004).
} 
use rights in fisheries (TURFs), and a community-based system inbuilt of individual transferable grounds. In order to facilitate the understanding of how the state ensures fisheries sustainability as the performance of institutional settings for different type of resources, the analysis of the three elements (i.e., situation, structure, performance) of this approach is key.

Situation refers to the inherent attributes of the individuals, community, or goods to be used or harvest. In the fisheries context, situation refers to fish resources types. Caddy and Seijo (2005) and Seijo et al. (2010) suggest three types of resources according to species mobility: sedentary (shared stocks that migrate through, or occur in, more than one exclusive economic zone (EEZ)), and highly migratory (species moving in the high seas). This research incorporates a fourth type of resource, mobile resources within an $E E Z$, as a new category given the relevance of this type of resources in coastal states with wide littorals. ${ }^{35}$ Fleet types are part of the situation element. Fleet types include small-scale and industrial fleets. A small-scale fleet is characterized by multiple users, multi-specific fisheries, as well as diverse gear types, organizational systems, and markets (Salas et al., 2007, 2015; Seijo et al., 2010). An industrial fleet is represented by high investment, intensive use of technology, high levels of organization, and political power in regulatory and management matters (Altamirano-Jimenez, 2017; Bennett, 2017). These fleets interact for some fisheries to harvest different components of the population structure, also called 'sequential fisheries $^{\prime 36}$ (e.g., shrimp, red groupers).

Structure refers to fishing rights and rules, which influence the opportunities of users and their power to have access to resource use. Fishing rights require to be clearly specified, exclusive, transferable, and effectively enforced for the optimal allocation of fish resources, (Randall, 1981; Schmid, 1987; Scott, 1955; Seijo et al., 1998). Rules refer to formal (i.e., state regulations) and informal (e.g., community- or industry-based) institutions for specific fisheries (i.e., input and output controls) and governance aspects (e.g., monitoring, and enforcement). As shown in Table 5-1, for each type of resources, different institutions are adequate to mitigate the effects of high exclusion, information, and enforcement costs associated with marine fisheries

\footnotetext{
${ }^{35}$ Countries with the longest coastlines: 1. Canada, 2. Norway, 3. Indonesia, 4. Russia, 5. the Philippines, 6. Japan, 7. Australia, 8. the United States, 9. Antarctica, 10. New Zealand, 11. China, 12. Greece, 13. the United Kingdom, 14. Mexico (World Atlas, 2018).

${ }^{36}$ Sequential fisheries. Two fleets of spatially segregated fisheries (e.g., coastal artisanal and industrial) affect different age components of the population structure of one or more species (e.g., shrimps in Willmann \& Garcia, 1985). Thus, sequential competition between different resource users is expected.
} 
(Caddy \& Seijo, 2005; Seijo, 2005; Seijo et al., 2010). This chapter include state regulations and informal or customary rules developed by private and social actors to contribute to fisheries sustainability.

Table 5-1. Institutional setting for different resource types to cope with high exclusion, information, monitoring and enforcement costs

\begin{tabular}{|c|c|c|c|}
\hline Resource type & Exclusion costs & Information costs & Enforcement costs \\
\hline $\begin{array}{l}\text { Sedentary: } \\
\text { Low mobility resources } \\
\text { such as invertebrates } \\
\text { (bivalves) }\end{array}$ & $\begin{array}{l}\text { Individually Transferable } \\
\text { Quotas (ITQs) } \\
\text { Individual transferable grounds } \\
\text { or leases among community } \\
\text { members (for small-scale } \\
\text { fisheries) }\end{array}$ & $\begin{array}{l}\text { Share among those deriving } \\
\text { rent and the state }\end{array}$ & $\begin{array}{l}\text { Self-policing } \\
\text { Community-managed } \\
\text { monitoring control and } \\
\text { surveillance (MSC) } \\
\text { Co-management }\end{array}$ \\
\hline $\begin{array}{l}\text { Mobile: } \\
\text { Resources that move } \\
\text { within the exclusive } \\
\text { economic zone (EEZ) } \\
\text { of a nation }\end{array}$ & $\begin{array}{l}\text { Limited entry } \\
\text { Allocation of shared total } \\
\text { allowable catches (TAC) } \\
\text { ITQs }\end{array}$ & Stakeholder cooperation & Stakeholder cooperation \\
\hline $\begin{array}{l}\text { Straddling stocks: } \\
\text { Resources that move } \\
\text { in waters of multiple } \\
\text { neighbour nations } \\
\text { EEZs }\end{array}$ & $\begin{array}{l}\text { Limited entry agreed bilaterally } \\
\text { or multilaterally, allocation of } \\
\text { shared TACs }\end{array}$ & $\begin{array}{l}\text { Bilateral/multilateral } \\
\text { cooperation (binding } \\
\text { and non-binding) and } \\
\text { standardized data collection } \\
\text { and stock assessments }\end{array}$ & $\begin{array}{l}\text { Bilateral/multilateral } \\
\text { cooperation, harmonised } \\
\text { regulations }\end{array}$ \\
\hline $\begin{array}{l}\text { Highly migratory } \\
\text { (high seas) } \\
\text { Resources that move } \\
\text { beyond the EEZs }\end{array}$ & $\begin{array}{l}\text { Harvest quotas, negotiated } \\
\text { allocations and entry rules } \\
\text { established by the Commission } \\
\text { Members of the commission } \\
\text { arrange negotiations on } \\
\text { resource allocations, and } \\
\text { establish harvest rules for the } \\
\text { fishery }\end{array}$ & $\begin{array}{l}\text { Data collection and stock } \\
\text { assessment organized by the } \\
\text { Commission }\end{array}$ & $\begin{array}{l}\text { Shared costs proportional } \\
\text { to annual harvest by } \\
\text { individual countries }\end{array}$ \\
\hline
\end{tabular}

Source: Adapted from Caddy and Seijo (2005) and Seijo et al. (2010).

Performance is the outcome of applying institutions (structure component) to specific context (situation component-resource types). Fisheries sustainability is the outcome investigated in this chapter. In 1982, the UNCLOS recognized the maximum sustainable yield (MSY) as the target reference point for marine fisheries within the EEZ and high seas. This performance measure represents the largest yield that can be taken from a species' stock to maintain the population size at the point of maximum growth, allowing the population to continue (Caddy \& Mahon, 1995, p. 8). Subsequent developments in the theory of fisheries management suggest that MSY is a risky reference point for fisheries, given the uncertainties of marine stocks and environmental changes, as well as the potential cutbacks in fishing efforts in response to sharp drops in ecosystem productivity, for which the industry is often not prepared (Caddy \& Seijo, 2005). However, MSY continues to be the most known and used reference point by coastal states to reach fisheries sustainability. 
Certification ${ }^{37}$ and ecolabelling ${ }^{38}$ schemes have created standards for sustainable fishing (e.g., Marine Stewardship Council (MSC), Friends of the Sea) that incorporate broader measures of sustainability (e.g., ecosystem impacts, management effectiveness). These standards are aligned to binding agreements (e.g., UNCLOS, United Nations Agreement for the Implementation of the Provisions of the United Nations Convention on the Law of the Sea of 10 December 1982 relating to the Conservation and Management of Straddling Fish Stocks and Highly Migratory Fish Stocks (UN Fish Stocks Agreement)), and non-binding ones (e.g., the Code of Conduct for Responsible Fisheries). In addition, the standards are generally based on the Guidelines for the ecolabelling of fish and fishery products from marine capture fisheries (FAO guidelines for ecolabelling) (FAO, 2009), developed by FAO at the request of coastal states, to set the minimum substantive requirements for fisheries sustainability ${ }^{39}$ in response to the increased use of labelling and traceability of fishery products in international trade. The biggest ecolabelling scheme for marine fisheries is the MSC (Cochrane, 2018), ${ }^{40}$ whose fisheries standard is used by states, producers, and industry to assess fisheries and make improvements towards sustainability (MSC, 2019).

Both, MSY and indicators of the MSC fisheries standard are used in this chapter to explain the institutional performance of fisheries sustainability. Schmid (1987) suggests an emphasis on substantive performance, meaning by that the distributional effects of institutions. These effects are not included in this analysis, because they are not yet incorporated into performance measures of sustainable fishing. Distributional effects, however, are being addressed by different scholars to understand the performance of different property rights such as individual transferable quotas (ITQs) (Brinson \& Thunberg, 2016), territorial use rights in fisheries (TURFs) (Villanueva-Poot et al., 2019; Villanueva-Poot et al., 2017), and annual catch entitlements (Clay et al., 2014).

The three elements of the SSP approach allow to analyse the state development of institutions for different resource types and corresponding performance. They also

\footnotetext{
${ }^{37}$ Certification refers to the procedure by which a third party gives written or equivalent assurance that a product, process, or service conforms to specified requirements (FAO, 2009, p. 4).

${ }^{38}$ Ecolabelling schemes entitle a fishery product to bear a distinctive logo or statement, which certifies that the fish is harvested in compliance with conservation and sustainability standards (FAO, 2009, p. 5). 39 The FAO guidelines on ecolabelling set the minimum substantive requirements for fisheries sustainability within three categories: the management system, the status of the stock, and the impacts of the fishery on the ecosystem (FAO, 2009).

${ }^{40}$ At the end of 2019 it reported 361 certified fisheries (15\% of the global marine catch) and 109 fisheries in assessment (MSC, 2019).
} 
allow for the analysis of the voluntary efforts of private and social actors, to understand how other realities take place in the context of the extraction of resources that are under public trust according to national legal frameworks and the UNCLOS.

\subsection{Methods and Data Sources}

This chapter uses a case study approach and the thematic analysis (Matthews \& Ross, 2010) method to explain the shadow of hierarchy, particularly to address the question How does the state defines institutional settings for fisheries sustainability?.

Mexican fisheries are the case study selected to address the research question given the central position of the state, the participation of non-state actors in the governing (e.g., Zepeda-Domínguez et al., 2020) of the four resource types under analysis (sedentary, mobile within the EEZ, straddling, and highly migratory), and the focus of the state in fisheries sustainability as the overarching goal for fisheries governance (DOF, 2007a).

The thematic analysis is used to analyse the three elements of the SSP approach. This is the most common method for working with qualitative data. It allows to identify and analyse concepts or issues through an in teractive process, and data are used to refine and find the links within these concepts or issues (Matthews \& Ross, 2010). This method was applied to two data sources: 1) the National Fisheries Charter (NFC) and 2) third-party assessments conducted for FIPs and certified fisheries using the MSC fisheries standard.

The NFC is an official document developed by the Mexican state, which includes the inventory of commercial species, information on fishing rights, the applicable regulations, and the stock status (fisheries performance) based on assessments conducted by the state. From the six publications of the NFC (DOF, 2000, 2004a, 2006a, 2010, 2012a, 2018c), the ones selected for this analysis were those publications from every six years (2000, 2006a, 2012a, 2018c). For comparison purposes, this analysis includes the twelve fisheries, which involve 31 species, that were consistently reported in the four publications. For the situation or context component the subthemes were the resource types (i.e., sedentary, mobile, straddling, and highly migratory) and fleet types (i.e., small-scale, industrial, or sequential). For the institutional structure the subthemes were fishing rights as well as domestic regulations, input and output controls, applicable to resource types and fleets. Input regulations include fishing licence limits, seasonal and area closures, gear types, species excluding devices, among others. Output regulations include total allowable quotas (TACs), individual 
catch quotas, minimum and maximum size limits, prohibition of harvesting berried or gravid females, etc grounds (Jentoft, 1989). For straddling stocks and highly migratory species, this analysis includes the international arrangements that are applicable to Mexico and are adopted in domestic regulations. The subtheme for performance was the stock status, based on the MSY reference point reported in the NFC. ${ }^{41}$

Some species reported different exploitation status in different sites. The overexploited species category in this study includes those ones that are reported as overexploited in one or more areas of its geographic distribution within the EEZ of Mexico. The information from the NFC was triangulated with the information included in fisheries regulations for selected species. Themes and subthemes used in this chapter are summarized in Table 5-2.

Third-party assessments conducted for FIPs and MSC certification processes have used the MSC fisheries standard to evaluate performance. This standard has been applied in Mexico to the four resource types included in this analysis (see Fernández-Rivera et al., 2018). By December 2019, third-party assessments were conducted in Mexico for 22 FIPs and four MSC certification processes, which account for 33 species. Assessments against the MSC fisheries standard include 28 indicators of stock health, ecosystem impacts, and management effectiveness. The description of these indicators is public and can be found on the MSC website. ${ }^{42}$ The standard uses a scoring and traffic light system for the assessment of indicators. Scores of 80 or above (green colour) indicate that the requirements for that indicator are met. The assessments of indicators for the 33 species are also public on the fisheriesprogress. org and MSC websites. Assessments have been conducted by third parties, including Conformity Assessment Bodies (CABs) (i.e., MRAG Americas, SCS), civil society organizations (e.g., Comunidad y Biodiversidad, Pronatura Noroeste, and Ocean Outcomes), and consultants (i.e., Intertek Fisheries Certification, Pesca Responsable y Comercio Justo). In this analysis, the subthemes for the context component were resource type (i.e., sedentary, mobile, straddling, and highly migratory) and fleet types

\footnotetext{
${ }^{41}$ The NFC explains that when the ratios of current biomass/biomass at MSY or current fishing mortality rate/fishing mortality rate at MSY are equal to 1 , the stock is at its maximum sustainable use (green) and fishing effort cannot be increased (no more permits, fishing gear, vessels); at greater than 1 the stock has potential for development (green with dots), meaning that fishing effort can be increased according to the technical advice of the National Research Institute for Fisheries and Aquaculture (from now on INAPESCA); at lower than 1 the stock is overexploited and management measures need to be applied for population recovery, and fishing effort cannot be increased (DOF, 2018), based on reference points and the traffic light approach suggested by Caddy (2002).

${ }_{42}$ https://www.msc.org/docs/default-source/default-document-library/for-business/program-documents/ fisheries-program-documents/msc-fisheries-standard-v2-01.pdf?sfvrsn=8ecb3272_11.
} 
(i.e., small-scale, industrial, or sequential). For the institutional structure, the subthemes were those indicators related to fishing rights and fisheries regulations, as well as the formal and customary (those defined by communities or industry) rules for objectives definition, information collection, and enforcement systems. For the performance component, the subthemes were the outcome indicators of the MSC fisheries standard that include the status of target commercial species (MSY or point of recruitment impairment $\left.(\mathrm{RI})^{43}\right)$; the status of primary and secondary associated species; endangered, threatened, and protected species (ETP species); the status of habitats and ecosystems; as well as the compliance with regulations. The latter is not reported as an outcome indicator in the MSC fisheries standard; however, information is available in third-party assessments. Themes and subthemes are summarized in Table 5-2.

\footnotetext{
${ }^{43}$ When the new generation is not sufficient for replacing the old. The point of reference for RI is $20 \%$ of the initial biomass (Bo) or 50\% of the biomass at MSY (Bmsy) (MSC, 2018).
} 
Table 5-2. Themes and subthemes for the codification of information collected from the National Fisheries Charter (NFC) and third-party assessments (2000-2019)

\begin{tabular}{|c|c|}
\hline NFC & Third-party assessments \\
\hline Theme: Situation & \\
\hline $\begin{array}{l}\text { Resource type: sedentary, mobile } \\
\text { within the EEZ, straddling, highly }\end{array}$ & Resource type: sedentary, mobile within the EEZ, straddling, highly migratory species \\
\hline
\end{tabular}

migratory species

Fleet type: small-scale, industrial, Fleet type: small-scale, industrial, sequential

sequential

Theme: Structure

Fishing rights: permit, concessions

Fisheries regulations: input and

Fishing rights: permit concessions

output controls applied by resource

and fleet types. Reference points

Fisheries regulations: A robust and precautionary harvest strategy (design, evaluation, monitoring, review) and well-defined harvest control rules are in place (design and application, robustness and uncertainty, and evaluation)

Primary species and secondary species management strategy. There is a strategy (in place, evaluated, implemented) to maintain or not to hinder the rebuilding of species, regularly reviews and implementation of measures, as appropriate, to minimise the mortality of unwanted catch

Endangered, threatened and protected (ETP) species management strategy. There are precautionary management strategies (in place, evaluated, implemented) that meet national and international requirements, and the Unit of Assessment (UoA) not hinder the recovery of species

Habitats and ecosystem management strategies. There is a strategy (in place, evaluated and implemented) to ensure the UoA does not pose a risk of serious or irreversible harm to habitats, ecosystem structure, and function

Long-term objectives. The management policy has clear objectives to guide decisionmaking that are consistent with the MSC fisheries standard, and incorporates the precautionary approach

Fishery-specific objectives. The fishery-specific management system has clear objectives designed to achieve the outcomes

Target stocks information. Relevant information is available to support the harvest strategy (i.e., range of information, monitoring, comprehensiveness)

Primary and secondary species information. Information is adequate to determine the risk posed by the UoA and the effectiveness of the management strategy

ETP species information. Information is relevant to support the management of the UoA on ETP species. Assessment of impacts, management strategy

Habitats information. Information is adequate to determine the risk posed to the habitat by the UoA and the effectiveness of the strategy to manage impacts on habitats. Information quality, assessment of impacts, and monitoring

Ecosystem information. Adequate knowledge of impacts on the ecosystem. Information quality, assessment of impacts, understanding the components functions, information relevance, monitoring

Enforcement. Monitoring, control, and surveillance mechanisms to ensure management measures are enforced and complied with. Implementation and sanctions

Theme: Performance

Stock health: Maximum sustainable yield (MSY), above MSY (overexploited), below MSY (with potential of development)

Stock health: Stocks fluctuating around MSY or low probability of recruitment overfishing (below the point of recruitment impairment (RI). For key low trophic levels, the stock is at a level which has a low probability of serious ecosystem impacts. Where the stock is reduced, evidence of stock rebuilding within a specified timeframe

Primary species outcome. The UoA maintains these species above the PRI, and does not hinder recovery and rebuilding of these species if they are below the PRI

Secondary species outcome. The UoA aims to maintain these species above biologically limits and does not hinder recovery if these species are below the limit.

ETP species outcome. The UoA meets national and international requirements for protection of ETP species. The UoA does not hinder recovery of ETP species.

Habitat and ecosystem outcome. The UoA does not cause serious or irreversible harm to habitats and key elements of ecosystem structure and function 
The two sources of data (NFC and third-party assessments) supported the triangulation of information as well as the understanding of state regulations and the underlying rules developed by private and social efforts, fashioned under the shadow of hierarchy, to achieve fisheries sustainability.

\subsection{Results}

The application of the SSF approach was useful to investigate the shadow of hierarchy by analysing how the state defines the institutional setting for fisheries sustainability. Results show that the state defines fishing rights and regulations for the different types of fisheries. Except for sedentary species and two lobster fisheries (meta-populations, straddling species), most fishing rights granted for Mexican fisheries are not exclusive and are difficult to enforce because they are granted for large areas. In addition, the state regulates fisheries mainly through five types of management tools, although the fisheries law includes 22. These five management tools correspond to input controls (i.e., gear types, seasonal closures, no-take areas), and output controls (i.e., size limits, TACs). From the 31 species analysed in this study, ten species are reported as overexploitated during the period of 2000-2018, from which, six species have not shown signs of recovery.

The FIPs and MSC certification processes implemented by private and social actors are nested within the institutional setting developed by the state. In some cases, particularly in small-scale fisheries, implementers of FIPs and certification have developed complementary rules and mechanisms for objectives definition, management tools application, data collection, and enforcement. Particularly for non-regulated fisheries or in areas where the state is absent, this contribution is relevant for fisheries sustainability. In terms of performance, the requirements of the MSC standard are greater not only because they integrate broader dimensions of fisheries sustainability, but also because they require greater evidence. From the studied species, 55\% of the species reported to meet (scores in green, 80 and above) the requirements for outcome indicators of target species, $58 \%$ of primary species, $52 \%$ of secondary species, $55 \%$ of ETP species, $61 \%$ of habitat, and $39 \%$ of ecosystems.

The results of the analysis are presented below. Section 5.4.1 presents the analysis derived from state assessments and Section 5.4.2 the analysis derived from thirdparty assessment. 


\subsubsection{State Assessments}

The analysis of state assessments for the 31 commercial fish species reported in the four editions of the NFC (2000, 2006a, 2012a, 2018c) presents the following findings.

\section{Fisheries situation}

Of the 31 species, $10 \%$ are sedentary, 32\% mobile within the Mexican EEZ, 55\% straddling, and 3\% highly migratory stocks. Mobile species within the EEZ (the addition of resource type included in this analysis) are native species (e.g., red grouper - Epinephelus morio) and cosmopolitan species with local populations (e.g., common octopus - Octopus vulgaris). In addition, $52 \%$ of the species are caught by a smallscale fleet, $3 \%$ by an industrial fleet, and $45 \%$ are sequential fisheries, extracted by the two fleets. The composition of species in this analysis, which were those consistently included in the four publications of the NFC (DOF 2000, 2006a, 2012a, 2018c), shows: i) the dominance of small-scale fisheries, which are generally characterized by complexity and heterogeneity (multiple users, gear types, and target species) (Salas et al., 2007; Seijo et al., 2010), and ii) the presence of shared stocks (straddling and highly migratory) for which domestic institutional settings are based on international agreements negotiated with other coastal states extracting these stocks.

\section{Structure}

Fishing rights. The state through the Executive branch grants the fishing rights. According to the Mexican Constitution, the state cannot transfer the property of marine resources and waters to citizens or corporations, only their use (DOF, 1917). Since 1992, the state has granted fishing rights through permits and concessions issued per vessel, fishing effort unit, specific species, groups of species, or areas (DOF, 1992b). Commercial fishing permits are issued for two to five years and concessions for five to 20 years (DOF, 2007a). Concessions are issued in those cases when the investment for fishing is high and requires longer periods for its recovery. The granting of concessions and permits is subject to the public interest, the abundance and availability of the natural stocks, equity principles, and the use of the best scientific information available (DOF, 2007a). Permits and concessions specify fishing gears, seasons, landing sites, and applicable management tools. Permits and concessions, in some cases, allocate exclusive exploitation areas, which constitute another form of right called territorial use rights in fisheries (TURFs). In addition to permits and concessions, the law of 2007 allows for the granting of quotas - an additional type of right for fisheries. 
Permits are granted for all 31 species included in this analysis, and therefore for the four resource types. Concessions are only granted for six species, which are under state jurisdiction: sedentary (turban star shell - Megastrea turbanica, turban snails Megastrea undosa) and mobile species within the EEZ (four-eyed octopus - Octopus maya, common octopus - Octopus vulgaris, yellowleg shrimp - Farfantepenaeus californiensis, and Pacific white shrimp - Litopeneaus vannamei). Individual quotas are only recorded for two sedentary species of snails (turban star shell-Megastrea turbanica and turban snail-Megastrea undosa), which were first assigned to vessel (DOF, 2000) and later to fishing grounds (DOF, 2006a). As shown in Figure 5-1, fishing rights (i.e., permits, concessions, individual quotas) that are site-specific (i.e., TURFs, Campeche Bank, Chinchorro Bank, Cozumel Bank), even if they include one or multiple species, are more exclusive and less costly to enforce than those rights granted for large areas. Fishing rights (i.e., permits, concessions) for large areas (e.g., Gulf of Mexico, Pacific) are granted for mobile species (within the EEZ, straddling, and highly migratory species). These types of rights are the least exclusive and enforceable rights when granted for multiple species. This applies for example to the fishing rights granted for the finfish fishery, which permits are granted for large areas and allow the fishing of multiple species. As shown in Figure 5-1, fishing rights granted by the state, for most species included in this analysis, fall under a low exclusivity and low enforceability spectrum.

Figure 5-1. Types of fishing rights in Mexico

\begin{tabular}{|c|c|}
\hline \multicolumn{2}{|c|}{ High enforceability (specific areas) } \\
\hline $\begin{array}{l}\text { Single fishery, exclusivity, enforceability } \\
\text { Permits and concessions for } \\
\text { - Sedentary species. Queen conch (Chinchorro } \\
\text { Bank, Cozumel Bank) } \\
\text { - Mobile species within the EEZ. Shrimps (Upper } \\
\text { GoC, GoT) }\end{array}$ & $\begin{array}{l}\text { Multiple fisheries, exclusivity, high enforceability } \\
\text { Concessions for } \\
\text { - Sedentary species. Multi-species with fishing } \\
\text { quotas allocated to fishing grounds (i.e., turban } \\
\text { snails) (occidental coast of Baja California }\end{array}$ \\
\hline ingle fishery & -Multiple fisheries \\
\hline $\begin{array}{l}\text { Single fishery, low exclusivity, low enforceability } \\
\text { Permits and concessions for } \\
\text { - Mobile species within the EEZ. Octopus and } \\
\text { swimming crabs (GoM) } \\
\text { - Straddling stocks: Sharks (GoM and Caribbean) } \\
\text { - Highly migratory stocks: Tuna (Atlantic, Pacific) }\end{array}$ & $\begin{array}{l}\text { Multiple fisheries, low exclusivity, low enforceability } \\
\text { Permits for } \\
\text { - Mobile species within the EEZ and straddling stocks. } \\
\text { Species grouped within the finish fishery (e.g., } \\
\text { groupers, mullets, snappers, snooks) (GoM, Pacific) }\end{array}$ \\
\hline
\end{tabular}

Source: Own elaboration based on the National Fisheries Charter (NFC) (DOF 2000,2006, 2012, 2018). GoC refers to Gulf of California, GoT to Gulf of Tehuantepec, GoM to Gulf of Mexico. See Figure 5-2 for geographical reference. 
Figure 5-2. Map of the Mexican EEZ, coastal provinces, and relevant fishing sites. The doted area corresponds to the EEZ, where the Mexican state has jurisdiction.

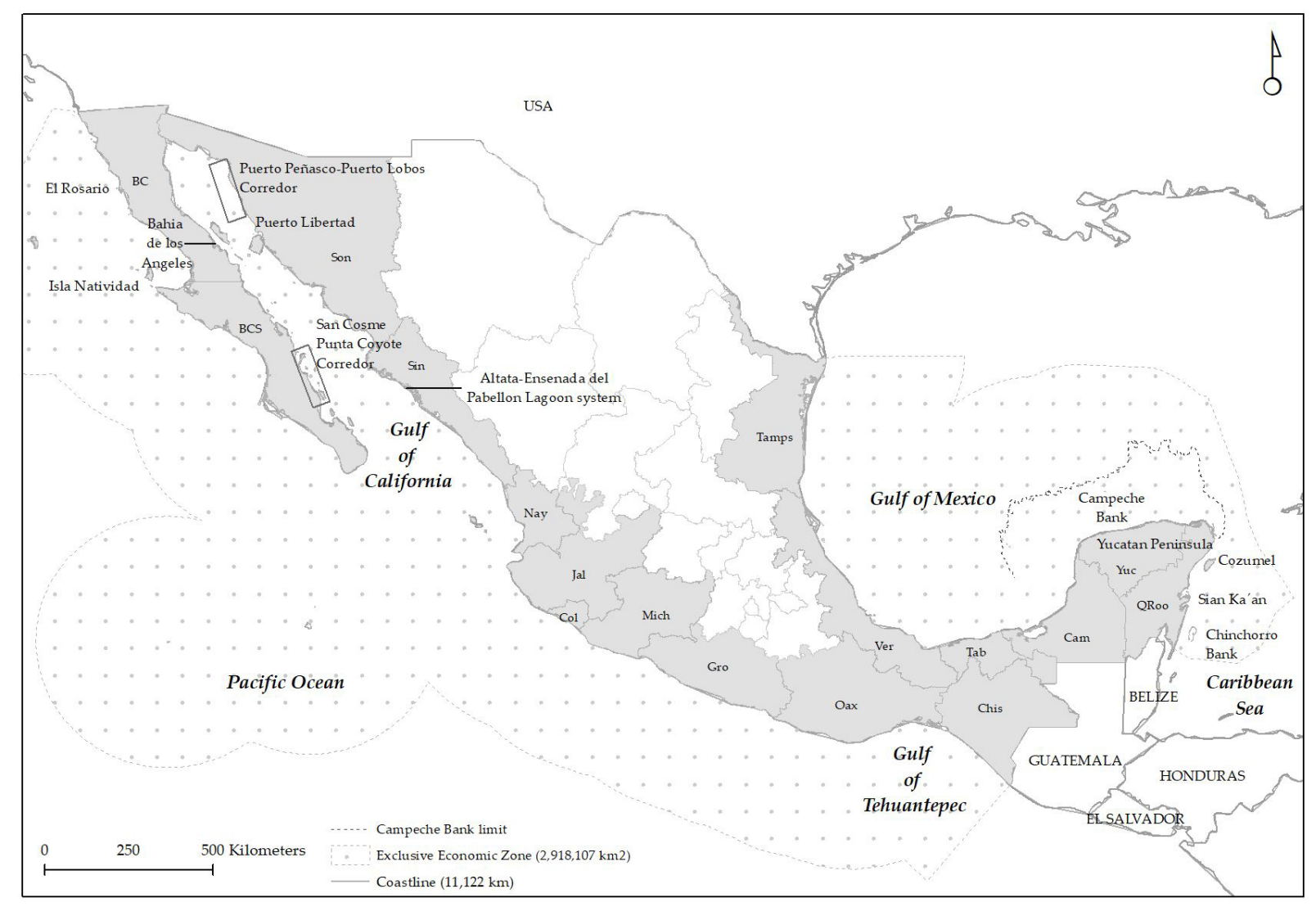

Fisheries regulations. Through fisheries regulations, the state applies management tools as policy mixes ${ }^{44}$ rather than as single tools. Of the 22 management tools included in the fisheries law (DOF, 2007a), the state applies a set of five in most fisheries: gear-type restrictions (100\% of the species), seasonal closures (65\%), TACs $(26 \%)$, no-take areas (55\%), and size limits (48\%). Gear types, seasonal closures, and no-take areas are input controls and are applied to all resource types and to both fleets (smallscale and industrial). TACs and size limits are output controls; TACs are applied to all types of resources in different time periods, and size limits are not applied only to highly migratory species (i.e., tuna fishery). It is important to note that the NFC reports that the state is conducting research to implement this tool in the tuna fishery. A set of prohibited fishing methods and techniques apply to both fleets (e.g., the use of nets and trawlers in estuaries and lagoons, the use of toxic substances for fishing purposes) (DOF, 2015e). The state reported additional tools for small-scale fisheries that include a quota for domestic consumption for the three species of mullets, as well as the prohibition of harvesting berried or gravid females, applied to the species

\footnotetext{
${ }^{44}$ Governance tools that, one way or another, involve the utilization of state resources, or their conscious limitation, in order to achieve policy goals. They are the 'tools of government', the mechanisms and techniques used to implement or give effect to public policies (Salamon, 2002).
} 
of lobster and swimming crabs. The state also reported additional tools applicable to the industrial fleet to meet international requirements, which include: i) the use of turtle excluder devices (TEDs) for shrimp vessels (DOF, 1993a, 1996c) to meet international market requirements for the exports to United States; ii) the use of fish excluder devices (FEDs) for the shrimp vessels, iii) bycatch limits, vessel storage limits, and the implementation of observer programs, to comply with international arrangements set by the Inter American Tropical Tuna Commission (IATTC) and the Agreement on the International Dolphin Conservation Programme (AIDCP) (DOF, 1992c, DOF, 1999); and (iv) the use of vessel monitoring systems (VMS) for all industrial fleets to meet the requirements of the IATTC and the International Commission for the Conservation of Atlantic Tunas (ICCAT), to contribute to the International Plan of Action to Prevent, Deter, and Eliminate Illegal, Unreported, and Unregulated Fishing (IPOA-IUU) (DOF, 2015d).

In summary, the analysis of institutional settings shows that: i) fishing rights for mobile species (within the Mexican EEZ, straddling, and highly migratory stocks) have low exclusivity and high costs of enforcement; ii) five management tools are applied to all species (sedentary and mobile), iii) the trend in regulations is to update management tools, rather than to adopt new ones, iv) regulations for highly migratory species adopt international rules negotiated within the RFMOs (i.e., IATTC, ICCAT), and v) the regulations for the industrial fleet (i.e., shrimp trawlers, tuna purse seine) are shaped by institutional arrangements made within other layers of governance (i.e., RFMOs, market requirements, international agreements). The institutional setting shows the state regulatory power to shape fishing practices for different types of resources, as well as its boundaries and influence by other layers of governance for specific resource types (i.e., highly migratory species) and fleets.

\section{Performance}

The Mexican state uses the MSY reference point as the measure of species sustainability. It is important to note, as mentioned in Section 5.2, that this reference point may not be the most adequate given the risks and uncertainties associated to marine species, and the lack of attention to broader dimensions of sustainability (e.g., impacts on ecosystems, governance system). In the case of Mexico, the state has started to list, in the NFC, the species associated and interacting with commercial fisheries as well as the environmental stressors on fisheries. This information is useful for integrating broader dimensions of fisheries sustainability in assessments. For example, by incorporating, when applicable, the impacts of El Niño, La Niña, and ocean 
acidification (DOF, 2018c) on fisheries in assessments, which according to the NFC, represent environmental factors that affect most Mexican fisheries.

According to the fisheries assessments developed by the state, in 2000, $74 \%$ of the species were reported to be at MSY, 3\% with potential for development, and 23\% overexploited (DOF, 2000). By 2018, 81\% of the species were reported at MSY and $19 \%$ overexploited (DOF, 2018c). From the 31 studied species, ten species were reported as overexploited during the period 2000-2018. These overexploited species correspond to three different resource types: sedentary (queen conch - Lobatus gigas), mobile within the EEZ (shrimps - Farfantepenaeus californiensis and Litopeneaus vannamei, groupers - Epinephelus morio and Mycteroperca bonaci), and straddling species (mullets - Mugil cephalus and Mugil curema, snappers - Lutjanus campechanus, Lutjanus buccanella, and Lutjanus vivanus). Six of these species (i.e., queen conch, groupers, and snappers) continue in this status. For the three species of snappers, the state did not report any change in regulations or implementation of remedial action strategies to recover the stocks.

Table 5-3. Species reported as overexploited in the NFC (2000-2018).

\begin{tabular}{|c|c|c|c|}
\hline NFC 2000 & NFC 2006 & NFC 2012 & NFC 2018 \\
\hline $\begin{array}{l}\text { Queen conch fishery } \\
\text { (Lobatus gigas) }\end{array}$ & $\begin{array}{l}\text { Queen conch fishery } \\
\text { (Lobatus gigas) }\end{array}$ & $\begin{array}{l}\text { Queen conch fishery } \\
\text { (Lobatus gigas) }\end{array}$ & $\begin{array}{l}\text { Queen conch fishery } \\
\text { (Lobatus gigas) }\end{array}$ \\
\hline $\begin{array}{l}\text { Grouper fishery } \\
\text { (Epinephelus morio, } \\
\text { Mycteroperca bonaci) }\end{array}$ & $\begin{array}{l}\text { Grouper fishery } \\
\text { (Epinephelus morio, } \\
\text { Mycteroperca bonaci) }\end{array}$ & $\begin{array}{l}\text { Grouper fishery } \\
\text { (Epinephelus morio, } \\
\text { Mycteroperca bonaci) }\end{array}$ & $\begin{array}{l}\text { Grouper fishery } \\
\text { (Epinephelus morio, } \\
\text { Mycteroperca bonaci) }\end{array}$ \\
\hline $\begin{array}{l}\text { Shrimp fishery } \\
\text { (Farfantepenaeus } \\
\text { californiensis and Litopeneaus } \\
\text { vannamei) }\end{array}$ & $\begin{array}{l}\text { Shrimp fishery } \\
\text { (Farfantepenaeus } \\
\text { californiensis and Litopeneaus } \\
\text { vannamei) }\end{array}$ & $\begin{array}{l}\text { Snapper fishery (Lutjanus } \\
\text { campechanus, Lutjanus } \\
\text { buccanella, Lutjanus vivanus) }\end{array}$ & $\begin{array}{l}\text { Snapper fishery (Lutjanus } \\
\text { campechanus, Lutjanus } \\
\text { buccanella, Lutjanus vivanus) }\end{array}$ \\
\hline $\begin{array}{l}\text { Mullet fishery } \\
\text { (Mugil cephalus and Mugil } \\
\text { curema) }\end{array}$ & $\begin{array}{l}\text { Mullet fishery } \\
\text { (Mugil cephalus) } \\
\text { Snapper fishery (Lutjanus } \\
\text { campechanus, Lutjanus } \\
\text { buccanella, Lutjanus vivanus) }\end{array}$ & & \\
\hline
\end{tabular}

Source: DOF $(2000,2006,2012,2018)$.

The analysis of species that overcame overexploitation during the reported period is summarized as follows. The shrimp species reported overexploitation in 2000 the Gulf of Tehuantepec, Nayarit, Sonora, Sinaloa, and the occidental coast of Baja California Sur in 2000, and reported recovery (to be at MSY) in 2012 (DOF, 2000, 2012a, 2018c). Institutional change was observed in this fishery. For example, the state published the annual seasonal closures, the development of a new gear type (Magdalena and Suripera I) (DOF, 2001b), the integration of TEDs (DOF, 1993a, 1996b, 2007a), and the publication of the official standard that establishes gear types, vessels, and 
outboard motor requirements, fishing effort controls (prohibited areas, schedule for operations, and duration of fishing lances in the water), the use of FEDs and TEDs, and of the VMS for the industrial fleet (DOF, 2013c). In the case of the mullet species, the flathead great mullet (Mugil cephalus) reported overexploitation in the Pacific in 2000 and in the Veracruz coast in 2006 (DOF, 2006a) and recovery (at MSY) in 2018 (DOF, 2018c); the white mullet (Mugil curema) reported overexploitation in 2000 (DOF, 2000) in the Pacific and recovery in 2006 (DOF, 2006a). Since the species were reported as overexploited, the state updated the seasonal closure for the Veracruz and Tamaulipas coasts (DOF, 2003), published a management plan for these sites (DOF, 2014g), and updated the standard to include outboard motors specifications and prohibited gear types and fishing methods, forbid fish cleaning at sea to avoid pollution, and establish the quotas for domestic consumption (DOF, 2015f).

The analysis of species that continue to be reported as overexploited is summarized as follows. The queen conch (Lobatus gigas) is a sedentary species, for which the state has granted permits for specific sites and implemented management tools such as size limits, requirements for gear and fishing methods, TACs, and no-takes (e.g., MPAs). In some areas, the state implemented permanent closures (e.g., Yucatan) or moratoriums applicable for some years (e.g., Cozumel bank and Chinchorro bank) until the stock shows recovery status. Despite the regulatory efforts, the fisheries continue overexploited in the Yucatan and Quintana Roo coasts, because this type of high value species, which barely moves, is highly vulnerable to fishers' overexploitation and possible illegal fishing. The grouper fishery, which is a long-lived territorial species with mobility during reproduction aggregations within the Mexican EEZ, reports overexploitation despite the regulations established by the state and their corresponding updates. The NFC also reports that the Cuban fleet still participates in this fishery with a catch quota. According to the Mexican fisheries law (Article 62) and UNCLOS (Article 62), coastal states should only allow foreign vessels to participate in domestic fisheries exploitation in those cases when catch surpluses exist, and are not extracted by the national fleet. This is not the case. Finally, the snapper fishery, which is a straddling stock shared with the USA, reports overexploitation, except for the coastal province of Tabasco, where it is assumed that the fishing effort is below MSY for the species sub-stock. Despite the signs of overexploitation, no institutional change has been observed for remedial actions to recover the fish stock since 2000.

The lack of signs of recovery for the six overexploited species confirms what Caddy and Seijo (2005) suggest; once fisheries surpass MSY, species recovery can be slow or 
difficult to reach. Recovery also becomes less likely in those cases where no remedial or recovery actions are taken.

\subsubsection{Third-party Assessments}

The analysis of the third-party assessments using the MSC standard for sustainable fishing, involves 22 FIPs and four MSC certification processes that include 33 commercial species. A wide range of public, private, and social actors participate in FIPs and MSC certifications, including governments, industry, small-scale fisheries organizations, buyers, academia, and civil society organizations as shown in Annex 5-2. The state participates in 11 of the 22 FIPs and the four MSC certification processes. This does not mean that in such processes where the state does not participate actively, the state is not present. The state continues operating in the shadow of hierarchy through the definition of formal institutions for fisheries, as shown in Chapters 3 and 4, which bounds actors' participation in the use and governing of marine resources. The analysis illustrates the following findings.

\section{Situation}

Of the 33 species assessed by third parties, $61 \%$ are under state jurisdiction ( $9 \%$ are sedentary, 52\% mobile within the Mexican EEZ) and the reminding species correspond to straddling (33\%) and highly migratory stocks (6\%). From the total, $52 \%$ of the species are extracted by a small-scale fleet, $27 \%$ by an industrial fleet, and $21 \%$ are sequential fisheries extracted by both fleets. The species assessed by third parties include the most important fisheries in Mexico in terms of value and volume (e.g., shrimps, sardines, tunas) according to state statistical information (CONAPESCA, 2017). Moreover, FIPs and certified fisheries are concentrated in the most productive region of Mexico, namely the northern Pacific, which includes the Gulf of California ( $82 \%$ of the species). Fewer cases are available for the Gulf of Mexico and the Caribbean (18\%) and no cases for the South Pacific. This situation reflects that FIPs and certification processes, by being market-based mechanisms, are implemented in commercial fisheries and areas of interest for private and social actors. The state, however, covers a wider range of fisheries and geographies due to its area of jurisdiction, basically covering the whole Mexican coast and all fleet types.

\section{Structure}

As mentioned above, the MSC fisheries standard assesses broader dimensions of institutional structure: fishing rights, regulations, definition of objectives, information ga- 
thering, and enforcement. The analysis of these dimensions is included in this chapter to investigate how voluntary efforts by private and social actors are performed within the shadow of hierarchy and how they contribute to fisheries sustainability.

The analysis of FIPs and MSC certified fisheries shows that FIPs, particularly for small-scale fisheries, are designed and implemented for specific sites and specific fleets, reflecting non-state actors' geographies (where the species are extracted or bought) rather than species' geographic distribution. Therefore, more than one FIP is available for specific species or fisheries. For example, clam species are distributed in the Gulf of California (see Figure 5-2 for geographic reference) and two FIPs are developed for two different sites: Puerto Libertad, Sonora and Lagoon system of Altata-Ensenada del Pabellon, Sinaloa. This situation applies to eight species, which show to have different FIPs for different sites (chocolate clam - Megapitaria squalida, ocean whitefish - Caulolatilus princeps, swimming crab - Callinectes bellicosus, Pacific blue shrimp - Litopenaeus stylirostris, brown shrimp - Farfantepenaeus californiensis, thread herring - Opisthonema libertate, yellow amberjack - Seriola lalandi, blue crab - Callinectes sapidus). Certified fisheries, on the other hand, do consider species distribution, but assessments and action plans are designed for particular fleets. For example, two certification processes are in place for the small pelagics fishery, one for the purse seine fleet of Sonora and the other for the fleet operating in Sinaloa and Nayarit coasts. The state, on the contrary, regulates at the level of fishery including corresponding fleets. This situation reveals the relevance of state regulation at the level of fisheries; the state develops the rules for fisheries and corresponding fleets, that serve as a point of departure for private and social actors to develop sophisticated systems to purse sustainability for specific fleets and sites.

Fishing rights. Non-state actors performing FIPs and certified fisheries require to have fishing rights granted by the state. The types of rights granted in Mexico are summarized in Figure 5-1. Non-state actors require to comply and support the enforcement of rights and corresponding regulations. The three sedentary species included this analysis are extracted through permits that are fishery and site-specific. Except for small pelagic species, the species of fish (seven mobile species within the Mexican EEZ and three straddling stocks) are extracted with finfish permits (multispecies) for large areas, which are the least exclusive and enforceable rights. The mobile species of octopus, swimming crabs, squids, small pelagic species and tunas - which include mobile species within the Mexican EEZ, straddling, and highly migratory - are extracted through fishery-specific permits granted to large areas, which represent also challenge for exclusivity and enforcement. On the contrary the two species of 
lobster, which are meta-populations moving across EEZs - spiny lobster (Panulirus argus) in the Caribbean and red rock lobster (Panulirus interruptus) in the Pacific are harvested through the site-specific concessions (TURFs) granted to cooperatives. The concessions for spiny lobster are specific to this fishery whilst the concession for the red rock lobster include diverse species (i.e., abalone, lobster, sea cucumber, and snails). Users who have TURFs have established effective enforceable systems, which also benefit other species extracted in the same areas. For example, the cooperatives extracting ocean whitefish (Caulolatilus princeps) in Isla Natividad and El Rosario, have finfish permits for large areas. However, these cooperatives also have concessions with TURFs for multiple-species species (i.e., abalone, lobster, sea cucumber, and snails), for the same area. Thus, users benefit from this spatial overlap, as their enforcement systems apply for both types of rights. Users have developed additional layers to their fishing rights to make them more exclusive and enforceable. For example, the cooperatives extracting the Caribbean lobster, divided the space granted within the concession, among the members of the cooperative. This institutional setting was analysed by Seijo (1993) to demonstrate the complementarity of management schemes developed by the state and communities to make rights more exclusive and enforceable.

Fisheries regulations. Although the fisheries law (DOF, 2007a) and the MSC standard (MSC, 2019) recognize traditional management and customary rules, FIPs and certification processes rely mainly on state regulation.

The MSC fisheries standard requires the application of management tools for the sustainable use of target species as well as to reduce the impacts of the fishery on associated species (primary, secondary, and ETP species), habitats, and ecosystems (structure and functioning). FIPs and MSC processes reported the application of the same five management tools reported by the state, to address the additional dimensions. All the species included in this analysis reported gear type restrictions, 85\% no-take areas (fish refuges and MPAs), 70\% seasonal closures, 55\% size limits, and $21 \%$ TACs. The specifications of gear types, seasonal closures, no-take areas, and TACs apply to all resource types. Size limits are not yet defined for the highly migratory species of tuna; however, as mentioned before the state is conducting research to determine the size limits (DOF, 2018c). Restrictions on gear types and no-take areas are reported as the main tools to address the MSC fisheries standard requirements related to the impacts on associated species (primary, secondary, and ETP), habitats, and ecosystems. The state in collaboration with the industrial fleet implements additional tools to comply with international arrangements (i.e., RFMOs), 
such as the observer programmes, bycatch restrictions, and the VMS, which in fact support the fulfilment of requirements established by the MSC fisheries standard to improve performance.

Five FIPs for small scale fisheries reported the implementation of customary rules that complement the institutional setting developed by the state. These customary rules include the distribution of the TAC for clams allocated to fishing grounds (by the state) among the cooperatives in Puerto Libertad, a permanent closure of the chocolate clam (Megapitaria squalida) in Sinaloa, no-take areas for ocean whitefish fishery (Caulolatilus princeps) in Isla Natividad and El Rosario, and limits on fishing effort, prohibition of chlorine and other substances, a fish refuge, and a bank rotating harvest for the octopus fishery (Octopus bimaculatus and Octopus hubbsorum) in the north Pacific. FIP implementers tend to request the state to legitimise these customary rules (seasonal closure, no-take area, limits to fishing effort, prohibition of chlorine, and the bank rotation) through the formalization in the form of regulations. This shows that non-state actors are capable of, and in some cases do, implement complementary tools to those established by the state.

The MSC fisheries standard requires evidence not only on design and implementation of harvest strategies ${ }^{45}$ and control rules, but also on their evaluation and monitoring, to reach effectiveness and responsiveness to stock status. Only when this evidence is available a fishery meets the requirements (score green, 80 and above). Of the total number of species, $18 \%$ show this evidence for harvest strategies, $8 \%$ for harvest control rules, $52 \%$ for strategies for reducing impact on primary species, $42 \%$ on secondary species, $55 \%$ on ETP species, $55 \%$ on habitat management, and $21 \%$ on ecosystem structure and functioning. Most species show evidence on implementation; however, less evidence is available for demonstrating effectiveness and responsiveness to stock status. Three resource types (i.e., sedentary, straddling, and highly migratory stocks) presented cases that fulfilled these indicators.

Fisheries objectives. The state defined fisheries sustainability as the main overarching goal for fisheries governance in the fisheries law of 2007. In this law, the state allowed the participation of non-state actors in defining fishery-specific objectives through the provincial councils and fisheries management plans (DOF, 2007a).

\footnotetext{
${ }^{45}$ Management strategies are represented by one policy/management tool, or a mix of tools, adopted for a fishery. They include management objectives and are responsive to stock and ecosystem state (MSC, 2018).
} 
Long-term objectives, for the MSC fisheries standard, are associated with the legal framework. The requirements are reached for most species (82\%), suggesting that the legal framework for Mexican fisheries has clear objectives, incorporates the precautionary approach, and is consistent with the MSC fisheries standard. Fisheryspecific objectives, on the other hand, required to be set and effectively implemented for the specific FIP or certification unit of assessment, in order to reach the outcomes (i.e., stock health, least impact on the ecosystem, and effective management). A small set of species (18\%) fulfil fishery-specific objectives requirements, because objectives are established in official management plans that are published and effectively implemented. In one case only, which is the red rock lobster fishery (Panulirus interruptus), the fishery has no official management plan, but fulfils the requirements because its objectives and management system are aligned with the existing information in the fisheries law and the annual research plan of INAPESCA's regional office. Other species did not reach the requirements because the state established the objectives on the scale of the fishery not for specific sites, or because communities defined fishery-specific objectives in local management plans that are not yet in legitimized by the state and published in official documents. For this latter point, ambiguity in auditing processes is observed, because some fisheries (e.g., the lobster case) meet the MSC fisheries standard requirements through the definition of specific management objectives by locals in alignment to those defined by the state in the legal framework (i.e., long term objectives), and for others this does not apply to meet the requirements. Although the MSC standard requires specific objectives for FIPs and certification processes, the state needs to keep its work and objective definition at the level of the fishery or population stock to ensure sustainability. Under these objectives, implementers of FIPs and MSC can develop site or fleet specific objectives to contribute to state larger objectives.

Information. The fisheries law and the MSC fisheries standard recognize tradition$\mathrm{al}$ and other types of knowledge for the development of institutions for fisheries. However, the standard pays attention to information quality, monitoring, and comprehensiveness. In addition, it requires that information collection addresses the impacts of the fishery and responds to management strategies implementation. Less than half of the assessed species reached the information requirements for harvest strategies $(21 \%)$, primary species $(48 \%)$, secondary species $(39 \%)$, ETP species $(30 \%)$, habitat $(42 \%)$, and ecosystems $(27 \%)$. For well-managed and data-limited fisheries, the MSC fisheries standard allows the use of the Risk-Based Framework (RBF), which uses information from workshops and existing data for the development of management strategies. The RBF was applied to five species (ocean whitefish - Cau- 
lolatilus princeps, arched swimming crab - Callinectes arcuatus, yellowtail amberjack Seriola lalandi, Caribbean spiny lobster - Panulirus argus, and giant squid - Dosidicus gigas) and recommended for three species (red octopus - Octopus maya, common octopus - Octopus vulgaris, and swimming crab-Callinectes bellicosus).

The assessments report that the state (INAPESCA), in collaboration with the industry, monitors species with high commercial value and extracted by industrial fleets report (e.g., blue shrimp - Litopenaeus stylirostris, Pacific sardine - Sardinops sagax, thread herring - Opisthonema libertate, tuna - Katsuwonus pelamis and Thunnus albacares). In addition, the tuna fishery (i.e., Katsuwonus pelamis, Thunnus albacares) assessment shows that the state shares information production, stock assessments, and the corresponding costs with other states extracting these resources, through the IATTC and its regional scientific and enforcement programme. Small-scale fisheries, on the contrary, reported the implementation of voluntary community-based monitoring to fulfil the MSC fisheries standard requirements (e.g., the clams - Dosinia ponderosa and Megapitaria squalida, Verill's two-spot octopus - Octopus hubbsorum, Hubb's octopus - Octopus bimaculatus).

This is consistent with the findings of Chapter 3, which show that in the shadow of hierarchy, information production is a governing function that the state shares with non-state actors. In addition, it shows the power of the state to decide which fisheries to monitor and which fisheries can be monitored by other actors.

Enforcement. FIPs and certification processes also rely on state enforcement. Only $9 \%$ of the species met the requirements of the MSC fisheries standard, which requires monitoring, control, and surveillance mechanisms to ensure management measures are complied with. The standard requests for evidence on implementation, application of sanctions, and compliance. The assessments indicate that the state administration (in particular in the Comisión Nacional de Acuacultura y Pesca CONAPESCA) has insufficient staff, a lack of sanctions, and a lack of consistency in the application of sanctions when enforcing regulations (e.g., quotas, size limits, the use of chlorine). However, industry and community engagement, market pressures, and international binding arrangements contribute to improve enforcement activities. For example, the industrial fleet engages with the observer programmes and the VMS systems to meet the MSC standard requirements. For one species of swimming crab (Callinectes bellicosus), a buyer is in charge of monitoring the compliance of fishers with legal practices (e.g., permits, authorized fishing gear, and regulations). For the spiny lobster (Panulirus argus), regulations and sustainable practices were integrated into the cooperative by-laws to be enforced effectively; fishers display a high 
level of compliance and shared responsibility in enforcement activities. Actors have also put pressure on the state for intervention. For example, the market pressure by the United States for the adoption of a comprehensive enforcement programme for the Pacific blue shrimp fishery (Litopenaeus stylirostris) made the Mexican state implement an annual certification, which covers $100 \%$ of the fleet and implies random inspections in port and at sea. For the tuna fishery, enforcement activities (i.e., observer program, VMS) are subject to international binding arrangements negotiated by states participating in the fishery within the IATTC, particularly to comply with the regional scientific and enforcement programme. States members of this RFMO are responsible to ensure the implementation of measures and for the resulting violations of those measures by state's vessels.

As shown in Chapter 3, the state, through its legal framework, provides the mechanisms for non-state actors to participate in enforcement activities. Given the lack of capacity of the Mexican state to enforce fishing rights and regulations for the diversity of resources, the engagement of non-state actors is an alternative to cope with the high enforcement costs associated with Mexican fisheries.

\section{Performance}

The species that reached the MSC fisheries standard requirements for all outcome indicators (target species, primary species, secondary species, ETP species, habitat, and ecosystems) are the lobster fisheries (Panulirus argus and Panulirus interruptus), which are granted exclusive and enforceable fishing rights.

The MSC fisheries standard accounts for the likelihood of the stock to be below the point of RI or around MSY, and when the stock surpasses these reference points, the standard requires evidence of stock rebuilding within a specified time. Of the total, $55 \%$ of the species met the MSC fisheries standard requirements for ensuring the health of the stock. These species are highly likely to be below the point of RI or are fluctuating around MSY, according to the stock assessments conducted by the state or the assessments by third parties using the RBF framework. The species that did not meet this requirement (45\%) are those that lack stock assessments (mainly for the species within the finfish fishery) or have obsolete assessments conducted by the state. For example, the stock assessments for some shrimp fisheries were 13 years old, thus these fisheries did not meet the requirements. Four species (12\%) show signs of overexploitation or decline in particular areas (chocolate clam-Megapitaria squalida, groupers - Epinephelus morio and Mycteroperca bonaci, and blue shrimp - 
Litopenaeus stylirostris). The overexploited species are sedentary and mobile species within the Mexican EEZ, which are under the Mexican state jurisdiction. It is important to note that, except for the shrimp fishery, the assessments indicate the lack of stock rebuilding strategies or stock recovery trends. For the shrimp species, the assessment indicates that the state defined measures to rebuild the fishery, based on limits on fishing effort; however, there is no evidence yet of improvements in the status of the stock. In relation to other outcome indicators, $58 \%$ of the species reached the requirements for primary species, $52 \%$ for secondary species, $55 \%$ for ETP species, $61 \%$ for habitat, and 39\% for ecosystems. The use of selective gear and the establishment of no-take areas helped meet the requirements of these outcome indicators.

In terms of compliance, the assessment reported diverse forms of non-compliance or illegal fishing in different resource types. This includes: i) the presence of illegal fishers (clam fishery Dosinia ponderosa, Megapitaria aurantiaca, and Megapitaria squal$i d a$ ) and vessels (swimming crab-Callinectes bellicosus in the Puerto Peñasco-Punta San Cosme corridor, blue crab - Callinectes sapidus in Campeche); ii) the catch of undersized organisms (swimming crab - Callinectes bellicosus in Baja California, black grouper - Mycteroperca bonaci, and red grouper - Epinephelus morio in the Yucatan shelf); iii) the exceeding of the allowed percentage of undersized organisms (Pacific sardine - Sardinops sagax and thread herring - Opisthonema libertate in the Gulf of California); iv) the unreported catch; v) the extraction during seasonal closures (blue shrimp - Litopenaeus stylirostris on the north-west Pacific coast); vi) the retention of protected species (e.g., Mobula japonica by the thread herring fishery - Opisthonema libertate in the Nayarit section of the fishery); vii) the use of prohibited substances during fishing operations (e.g., the use of chlorine by illegal divers for red octopus - Octopus maya); and viii) exceeding the total allowed quotas (common octopus - Octopus vulgaris in the Yucatan shelf).

\subsection{Discussion}

This chapter applies the SSP approach to Mexican fisheries to explain how the state develops the institutional setting for the sustainability of different types of marine fish resources. The chapter also analyses how the private and social efforts towards sustainability are performed under the shadow of hierarchy. The main findings are discussed in terms of the three components of the SSP approach.

Fisheries situation. The analysis covers four types of fish resources to enable the investigation of institutional settings and corresponding performance. The inclusion 
of the resource type mobile species within the EEZ as part of this analysis allows the representation of mobile species under the coastal state jurisdiction (within the EEZ). This type of resource accounted for endemic species (e.g., red octopus-Octopus maya), local populations of native species (e.g., red grouper - Epinephelus morio) and local populations of cosmopolitan species (widely distributed in different oceans) (e.g., common octopus - Octopus vulgaris). Although industrial fisheries were present in the analysis ( $3 \%$ in NFC, $27 \%$ in third-party assessments), most fisheries in this analysis were reported as small-scale (52\% of the NFC and third-party assessments), and in some cases sequential fisheries ( $45 \%$ in NFC and $21 \%$ in thirdparty assessment). The composition of studied species also indicates the presence of shared resources (straddling and highly migratory stocks) with other states (58\% in state assessments, and $38 \%$ in third-party assessments). This is important to note because the governing of these resources is beyond the coastal state jurisdiction; it requires coordination and definition of institutional arrangements among coastal states extracting such resources.

The species information recorded from the NFC, accounts for fisheries distribution and the state jurisdiction, including a wide range of species and geographical areas. On the contrary, species information for MSC certification processes is presented by fleet, and for FIPs by site. More than one FIP was available for eight species and more than one MSC certification for the small pelagics fishery. In addition, FIPs and certification processes concentrate on commercial species and productive areas. Therefore, they do not cover the whole coast. The state, thus, plays an important role as a meta-governor to ensure the regulation of fisheries and coordination among private and social efforts, to ensure sustainability.

Structure. The state, through the fisheries law, established the fishing rights and management tools to regulate fisheries. Fishing rights granted for sedentary species (clams and snails) and two straddling meta-populations (lobster fisheries) are permits and concessions with TURFs (site-specific exploitation areas), which are exclusive and enforceable. The fishing rights for mobile species (including those species moving within the Mexican EEZ, straddling, and highly migratory stocks) are granted for large areas, which makes them less exclusive and enforceable. Furthermore, fish species are generally grouped within the finfish fishery. Thus, the rights granted for the finfish fishery are allocated for multiple species and large areas, which imply less exclusivity and higher costs of enforcement. Beyond the state allocation of fishing rights, users demonstrate to build complementary systems to make fishing rights more enforceable and exclusive. For example, for one of the sedentary spe- 
cies (snails), TURFs are complemented with individual quotas for fishing grounds, which provide additional exclusivity and enforceability.

In terms of management tools, the state demonstrates the application of five of them (gear types, size limits, seasonal closures, no-take areas, and TACs) to all resource types. This is consistent with the work of Salas et al., (2007) on management tools for fisheries in Latin America and the Caribbean, in which the same management tools were reported to be the most frequent across different countries in the region. The use of these management tools supports the fulfilment of the MSC fisheries standard requirements for FIPs and MSC certification processes, which intention includes broader dimensions of sustainability, to ensure the health of the stock, the least impact on the ecosystem, and effective management.

Private and social actors that are part of FIPs and certification processes, are bounded by the state regulation of management tools. As for fishing rights, these actors develop customary rules based on traditional knowledge to address the management of non-regulated fisheries and to complement the management of already regulated fisheries. The Mexican fisheries law and the MSC fisheries standard acknowledge these customary rules. However, third-party assessments show a preference for state regulation. Auditors score better the process-based indicators (i.e., management strategies and objectives) of fisheries that rely on state regulation than those of fisheries that rely solely on customary rules, under the argument that the latter are not yet official or included in management plans. Therefore, private and social actors that develop customary rules tend to request the state the legitimization and formalization of those rules in official agreements in order to meet the requirements, improve their scores, and receive state support.

Regulations for highly-migratory species (i.e., tuna fishery) and for the industrial fleet (i.e., tuna, groupers, shrimp) show to be bounded by other layers of governance, including the corresponding resolutions of RFMOs (e.g., IATTC), international binding (e.g., UNCLOS) and non-binding agreements (e.g., IPOA-IUU) as well as the market requirements.

The analysis of FIPs and certification processes shows that private and social actors support the creation of fishery specific objectives, monitoring, and enforcement systems. The participation of non-state actors (market, fishing organizations, communities) in monitoring and enforcement systems is relevant in the case of Mexico, as most FIPs and certification processes reported the lack of capacity of the state to sustain 
data collection and regulations enforcement. In addition, FIPs and MSC certification processes require extensive information to fulfil the evidence-based requirements of the MSC fisheries standard, which are too costly for a single actor to absorb. These information requirements can only be met through collective action efforts.

Overall, as presented in Chapter 3, the state creates mechanisms for non-state actor's participation in these governing functions (e.g., institution making, information production, enforcement). However, the state plays a key role at coordinating and harmonizing efforts at a meta-governance order, and with other layers of governance (i.e. RFMOs). It should be pointed out that non-state actors, also play a key role at sharing the costs of data collection and enforcement for the regulations on target species, associated species, habitats, and ecosystems.

Performance. At the international level, MSY continues to be the most widely used target reference point for fisheries (e.g., Sustainable Development Goals, SDG 14), despite the risks associated with surpassing this reference point (Caddy \& Seijo, 2005). These risks are exemplified in the Mexican case, where ten species were reported as overexploited in the last two decades and six of them (queen conch, groupers, and snappers) have not shown signs of recovery. In addition, MSY is not a suitable reference point for all species. It should not be applied to fluctuating stocks (e.g., small pelagic species), whose abundance, stock fluctuations and spatial distribution are explained by environmental factors (Lluch-Belda et al., 1986; Lluch-Cota et al., 1999). Their fluctuations do not allow a single equilibrium point. No MSY in a fluctuating stock fishery is possible given its inherent dynamic fluctuations over time (Anderson \& Seijo, 2010). More conservative reference points are suggested, such as the Maximum Economic Yield (MEY), in which resource rent is maximized, while involving lower exploitation rates and higher biomass levels. However, the employment of more conservative reference points involves less direct employment in the fishery. Only Australian fisheries are already testing this target point and have incorporated economic efficiency as the primary fisheries management objective (see Fisheries Management Act of 1991) to recover stocks and eliminate overcapacity (e.g., northern prawn fishery) (Dichmont et al., 2008; Dichmont, et al., 2010). It is important to note that for the fisheries already performing at MSY, it will be challenging to incorporate more conservative reference points, because implementation requires, in some cases, a substantial reduction of fishing effort (fleets, catch quotas, etc) and less direct employment (Dichmont et al., 2008; Dichmont, et al., 2010). This is the case of Mexico, where $81 \%$ of the species are reported at MSY (DOF, 2018). 
In addition, fisheries policy scholars suggest accounting for broader dimensions of sustainability than just the target commercial species (Fletcher et al., 2010; Garcia et al., 2003). These dimensions include environmental factors associated to the fisheries such as climate change (Anderson \& Seijo, 2010) and ocean acidification (Punt et al. 2014, Seijo et al., 2016, Seijo \& Villanueva, 2018), impacts on associated species, habitats and ecosystem integrity, as well as the distribution of resource rents needed for sustaining the fishery over time (Caddy \& Seijo, 2005). International actors involved in the development of ecolabelling and certification mechanisms (e.g. FAO, MSC, among others) have incorporated some of these dimensions into guidelines (i.e., FAO's ecolabelling guidelines) and international standards for sustainable fishing (e.g., MSC). In the case of Mexico, actors involved in FIPs and MSC certifications are applying these standards and therefore, integrating broader dimensions of sustainability (e.g., impacts on associated species, habitats, and ecosystems) to the governing and assessment of fisheries. Because standards are evidence based, actors involved in FIPs and MSC certifications, to meet the requirements of the MSC fisheries standard, generate the required information on those additional dimensions of sustainability, often in collaboration with the state. In addition, evidence shows the testing of methods for data-poor fisheries, such as the RBF. This is relevant for species that have not been assessed by the state and for fisheries that lack information on the impacts on other species as well as on habitats and ecosystems to improve management and outcomes. A recent global analysis points out that fisheries in FIPs show a higher likelihood of management improvement and overfishing reduction than those fisheries without FIPs (Cannon et al., 2018). However, it is important to note the scale on which FIPs and MSC certifications operate in; FIPs often focus on specific areas and MSC certifications on specific fleets. Therefore, except for sedentary species and meta-populations (i.e. lobster fisheries), these efforts prove to be insufficient to ensure a good performance of a fishery as a whole. Thus, the state plays a key role at overseeing the status and regulation of fisheries and fleets within its jurisdiction, considering the spatial distribution of resources, and the institutional arrangement beyond the scope of its jurisdiction. FIPs and certification processes represent a reference for the state to leverage the incorporation of broader dimensions of fisheries sustainability in the management and assessments of other fisheries and sites.

Although the SSP approach emphasizes the integration of the distributional effects (Schmid, 1987) of institutions for measuring performance, this dimension is not yet incorporated into state-based and third-party assessments. Therefore, it represents a key element to integrate to the governing of fisheries sustainability. Different scho- 
lars have conducted research on the distributional effects of different fishing rights allocations, such as ITQs (Abayomi \& Yandle, 2012; Brinson \& Thunberg, 2016; Hamon et al., 2009), annual catch entitlements (Clay et al., 2014), TACs allocated by producer organizations (Bellanger et al., 2016), and TURFs (Villanueva-Poot et al., 2019; Villanueva-Poot et al., 2017). The analyses of TURFs were conducted for the spiny lobster (Panulirus argus) fishery in Punta Allen and for the multi-specific fishery in the northern part of Yucatan (Villanueva-Poot et al., 2019; Villanueva-Poot et al., 2017). Results of these analysis show that TURFs (collective and individual), present the lowest inequality levels compare to other fishing rights, which means that fishing revenues and resource rents are spread more equally among resource users (i.e., fishers). These fisheries and types of rights (TURFs) are included in the present analysis, showing good performance in terms of stock, associated species, habitats and ecosystems, as well as of regulations compliance. They are applied to sedentary species and lobster fisheries and represent an opportunity to be expanded to these resource types.

This study only includes third-party assessments using the MSC standard for sustainable fishing applied to Mexican fisheries. However, there are additional standards adopted by Mexican fisheries such as the Seafood Watch Programme of Monterey Bay Aquarium and Fairtrade (Fernández-Rivera et al., 2018; Zepeda-Domínguez et al., 2019), which are not included. The assessments with the MSC fisheries standard were chosen because they include the four resource types investigated in this analysis. The Monterey Bay Aquarium standard has been applied mainly to marine fisheries whose products are exported to the United States. The Fairtrade standard has only been adopted in two Mexican fisheries (shrimp in Sinaloa and finfish fishery in El Rosario), which have been assessed with the MSC standard and thus included in the present analysis.

Overall, this analysis shows how private and social actors participate in the development of customary rules for fishing rights and management tools, as well as in the assessment, monitoring and enforcement of fisheries. The state can replicate and scale the experiences of FIPs and certification in other fisheries and sites. This study recommends that the Mexican state increases the exclusivity and enforceability of fishing rights by establishing TURFs where appropriate (e.g., sedentary species) and by formalizing the customary rules created by private and social actors. It also recommends to integrate non-state actors in the assessment, monitoring and enforcement, especially in areas where the state does not have the capacity to govern fisheries and where other actors are ready to become competent partners. The formalization 
of customary rules and the integration of private and social actors in management duties are particularly relevant for mobile species where achieving sustainability represents a greater challenge due to the nature of fishing rights (granted for large areas, and in some cases for multiple species) and the need for the application and enforcement of management tools. This study also suggests the development of remedial actions for overexploited fisheries that currently lacks them, in order to pursue recovery. Finally, this study recommends the integration of broader dimensions of fisheries sustainability beyond the MSY reference point, such as environmental factors affecting fisheries (e.g., climate change and ocean acidification), impacts on associated species, habitats and ecosystem integrity, as well as the distribution of resource rents among fishing fleets and fishers.

This research investigates the shadow of hierarchy in the context of a single coastal state, i.e., Mexico. It therefore focuses on domestic institutional settings for different types of resources to pursue sustainability, including state regulations and customary rules developed by non-state actors, which are performed in the shadow of the state. Another approach is to investigate the shadow of hierarchy in greater layers of governance. This research gap can be addressed by analysing the institutional settings developed and endorsed at supranational level, including those binding and non-binding agreements of FAO, UN, RFMOs, and other regional bodies (e.g., the European Union). This type of analysis will contribute to the understanding of state indirect influence in regional and international policies as well as their corresponding performance on distributional effects and on the status of shared species, such as the case of straddling stocks and highly migratory species.

\subsection{Concluding Remarks}

The SSP approach was useful to understand how the coastal state establishes institutional settings for ensuring fisheries sustainability. This approach allowed for the understanding of diverse institutional settings established for different resource types and the corresponding performance towards sustainability. In addition, it shows how collective efforts of private and social actors are implemented under the shadow of hierarchy of state regulation.

The analysis of institutional settings shows that the TURFs granted by the state for small-scale sedentary fisheries and for straddling meta-populations of lobster show higher exclusivity and lower enforcement costs than other types of rights. These fisheries show good performance in stock status, associated species, habitats, and ecosystems. However, this type of right is not applied and applicable to all resource types. Mobile species represent a greater challenge for the allocation of fishing rights 
and for fisheries sustainability. In the Mexican case, the state grants fishing rights for large areas, which provide less exclusivity for users and high enforcement costs. In terms of fisheries regulations, this analysis shows the extension of state authority in the regulation of domestic fisheries, and the use of a small set of five management tools for all resource types in order to pursue sustainability. In addition, it shows the boundaries of state regulation and influence by other layers of governance (i.e., RFMOs, international binding and non-binding agreements, market requirements), particularly for highly migratory species and the industrial fleet.

The analysis of performance show that, whilst MSY continues to be the most common measure of performance for fisheries sustainability, broader dimensions are already incorporated to management and assessments through the implementation of the standards for sustainable fishing, such as the MSC fisheries standard. Measures of distributional effects, which are suggested by the SSP approach, are still lacking.

The collective efforts of FIPs and MSC certification processes, rather than limiting state intervention, are bounded by the state allocation of fishing rights and regulation of fisheries. In some cases, actors develop customary rules, undertake the data gathering, implement enforcement systems, and participate in voluntary auditing and verification systems, to improve the governing system, which often lead to better fishery performance. Although private and social efforts are generally site- or fleet-specific, they provide information on good practices that can be expanded to broader scales, under the indirect influence of the state, which remains present under the shadow of its hierarchy. 


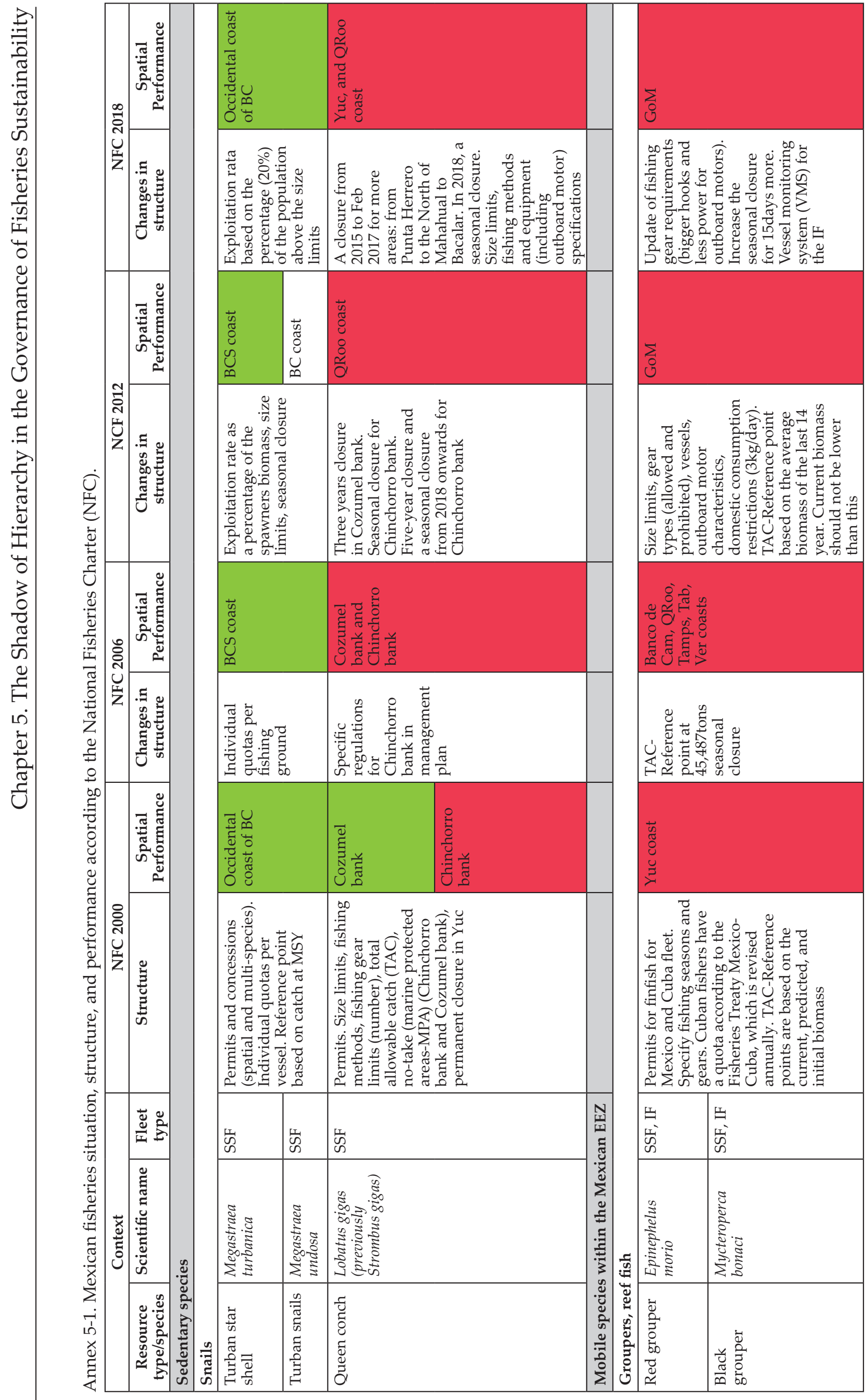




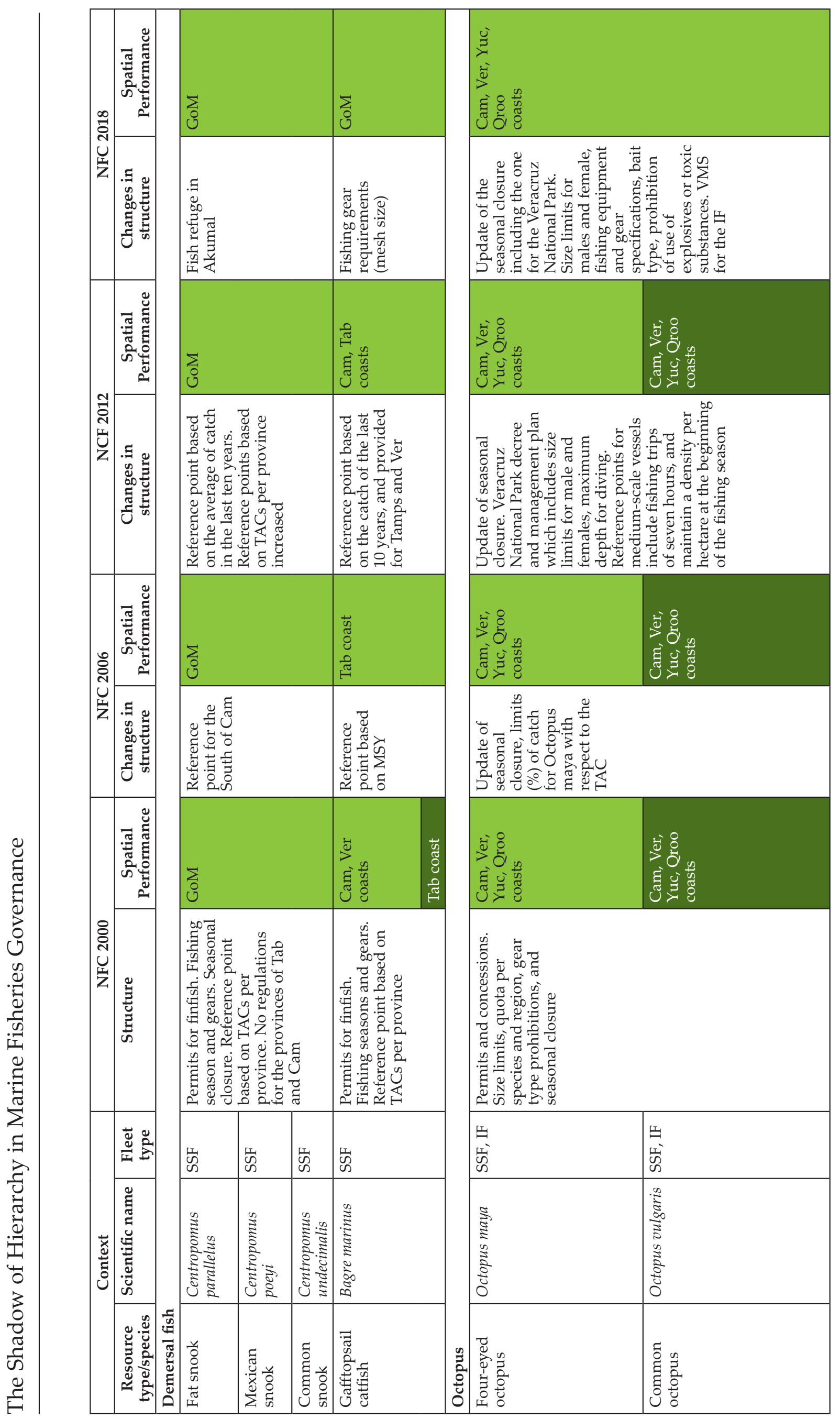




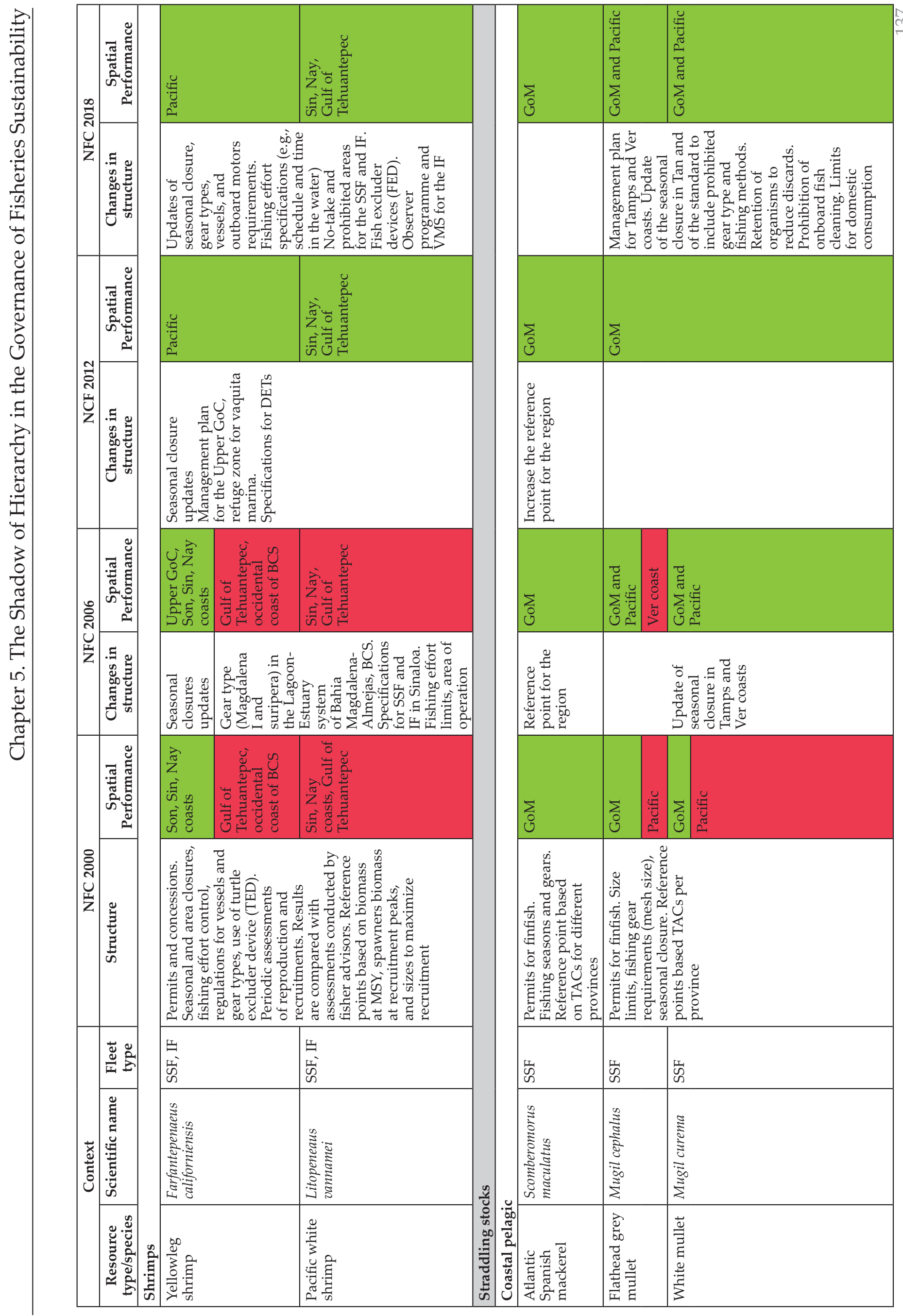




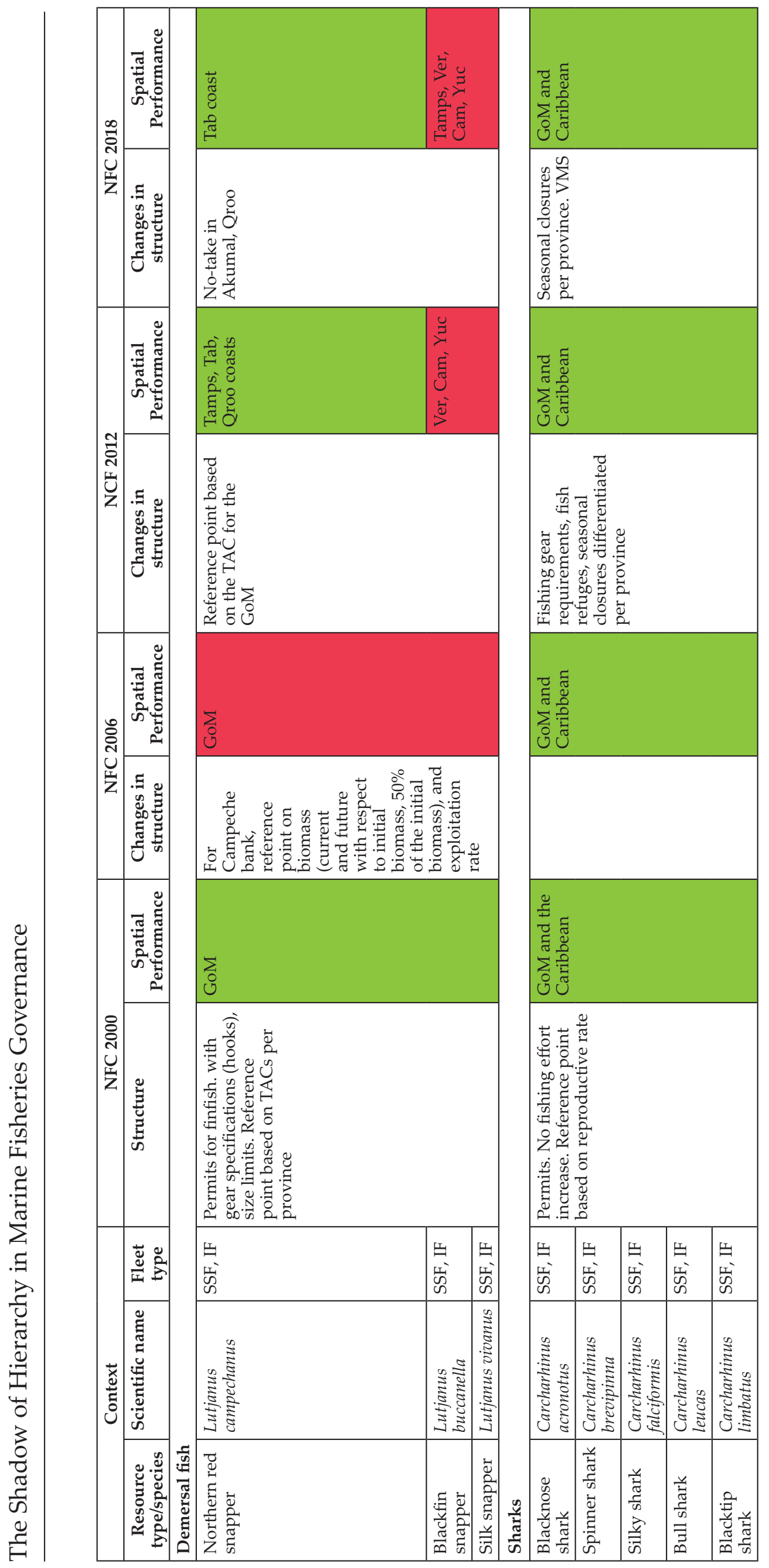




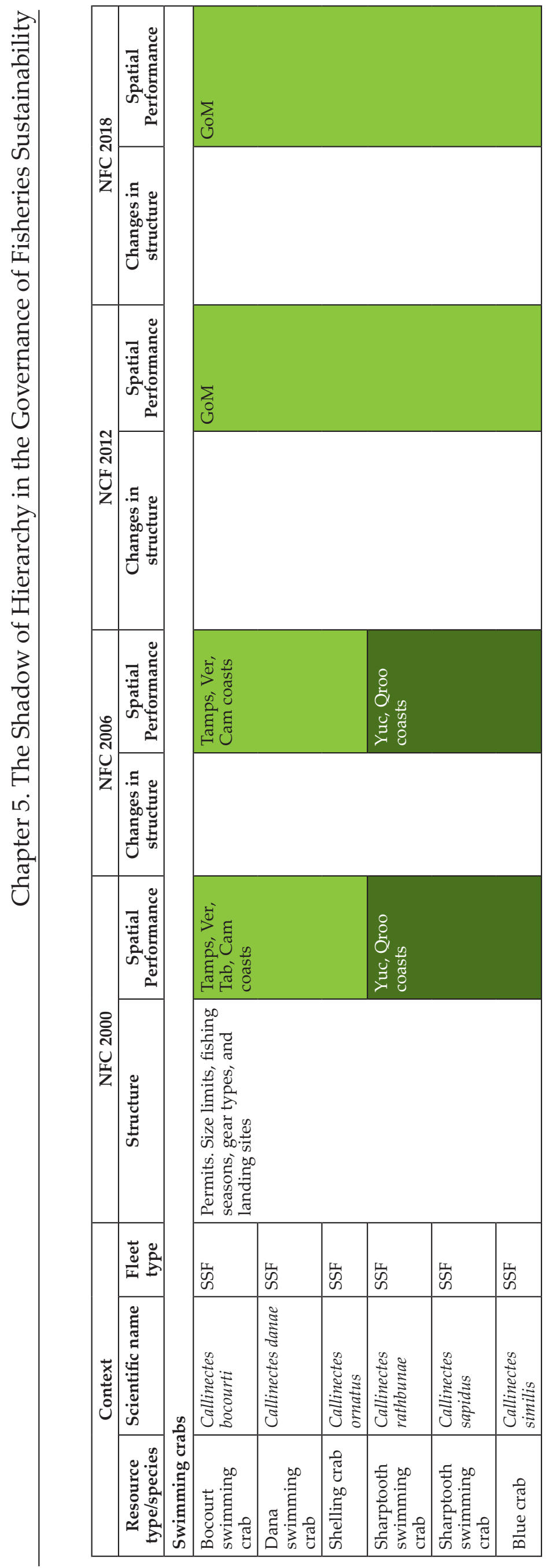




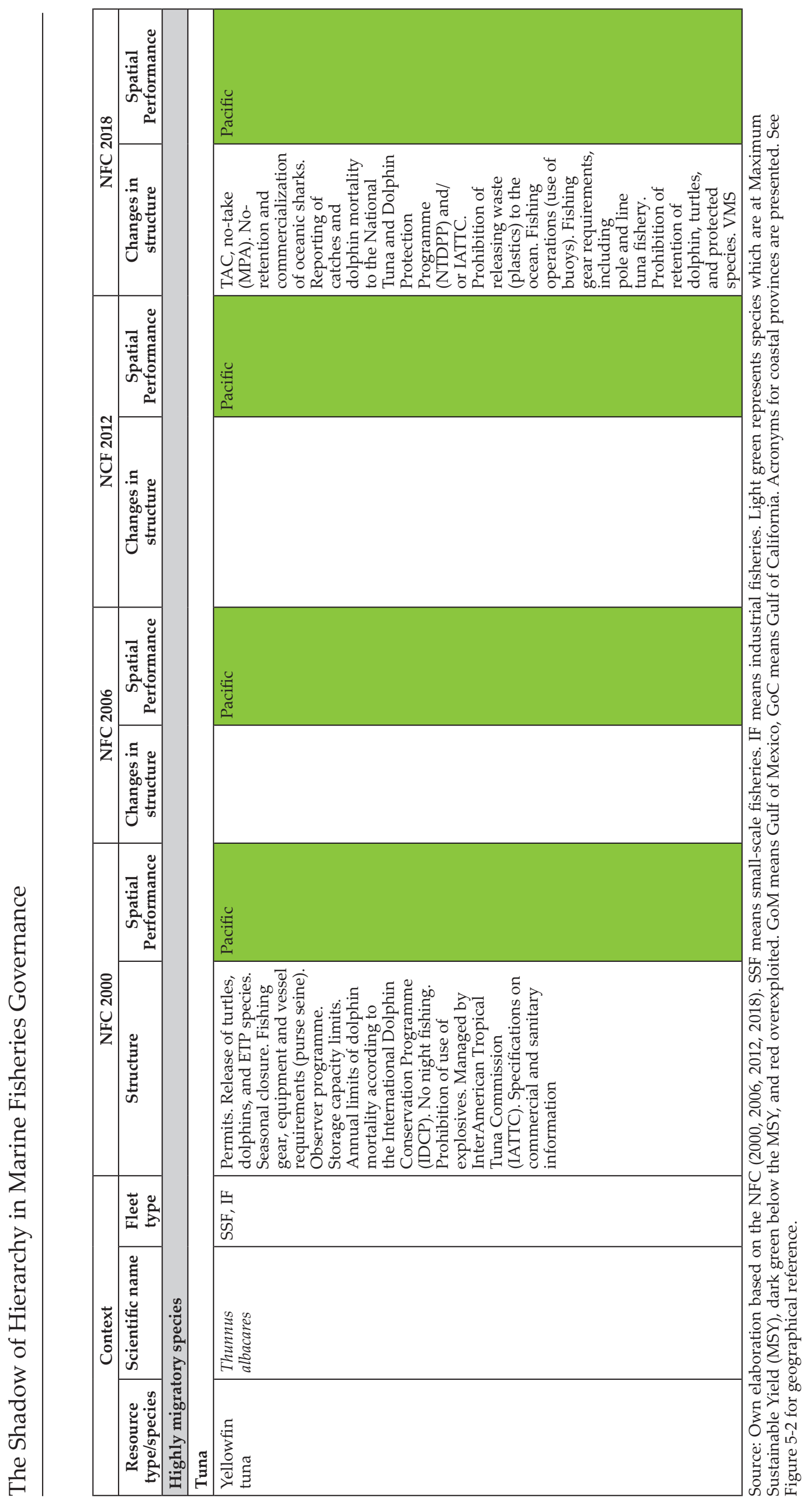




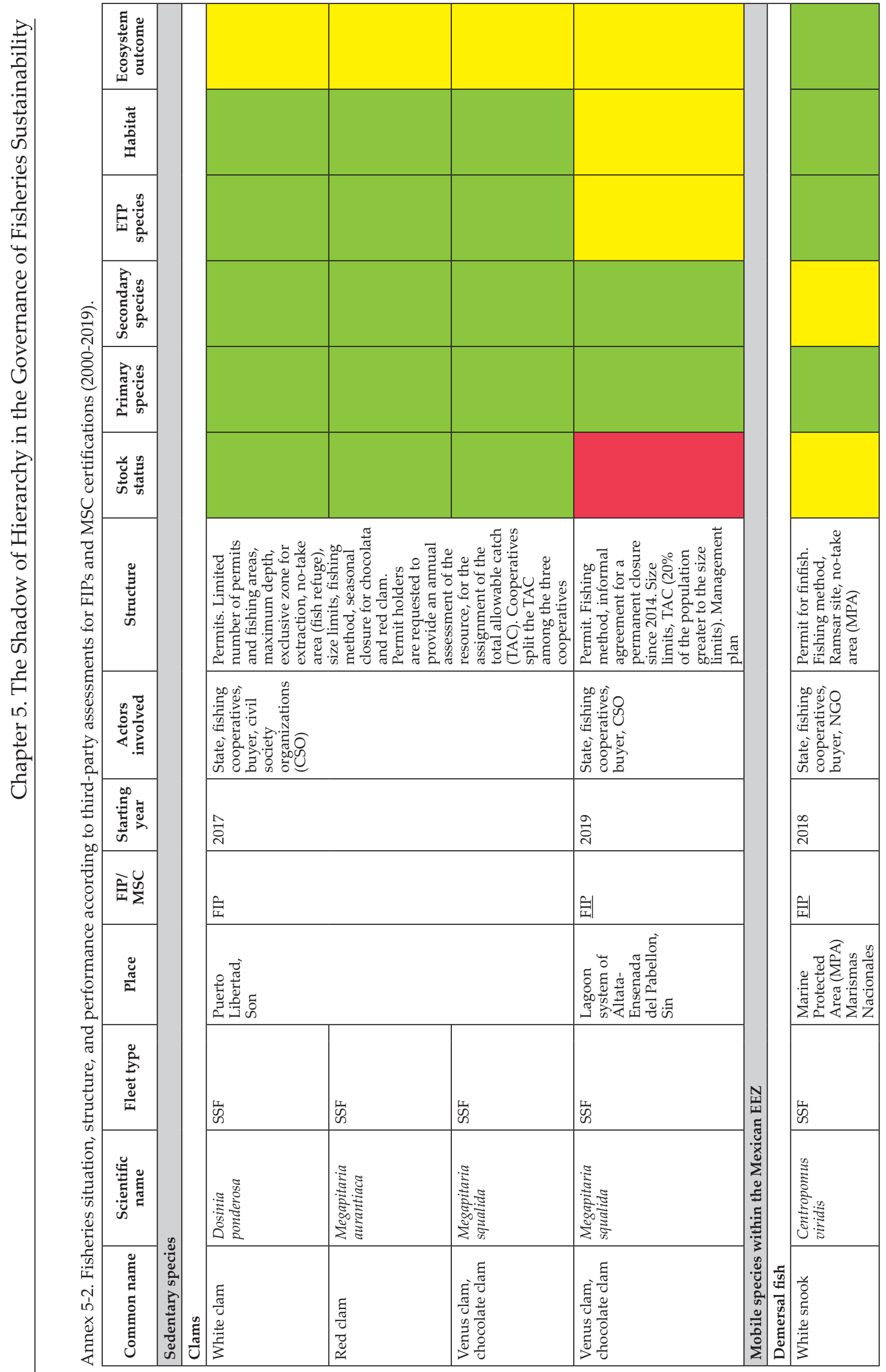




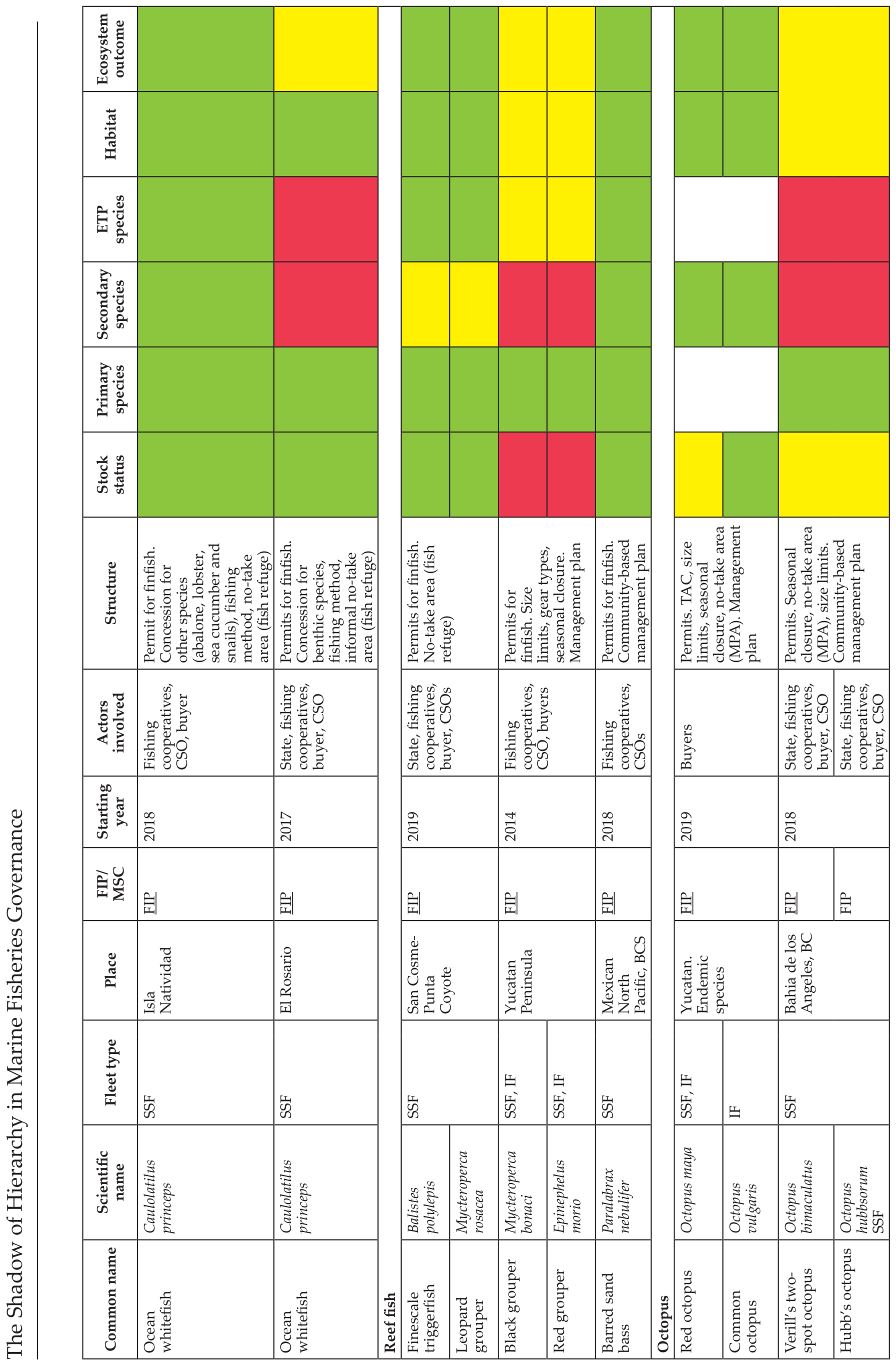




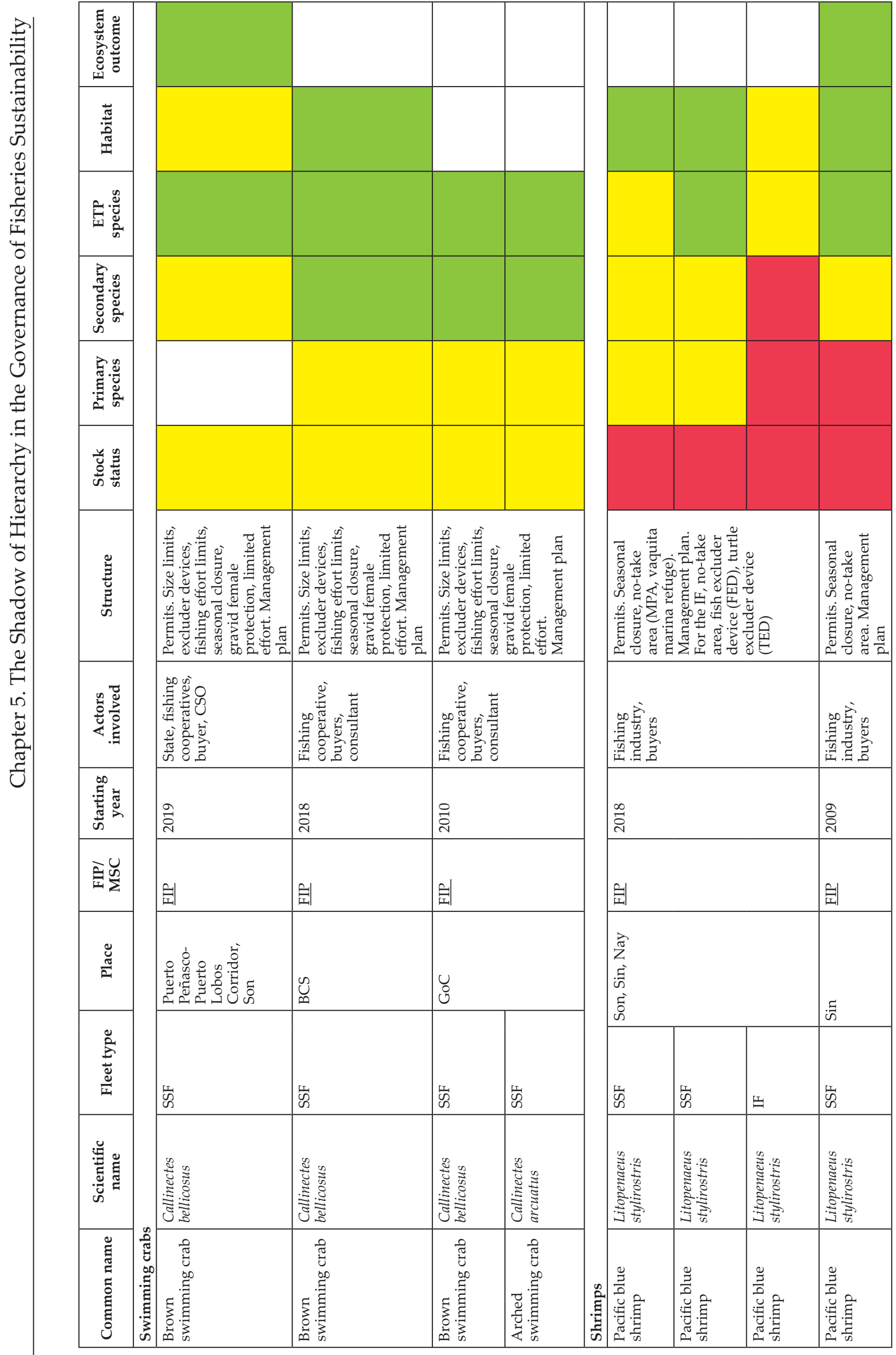




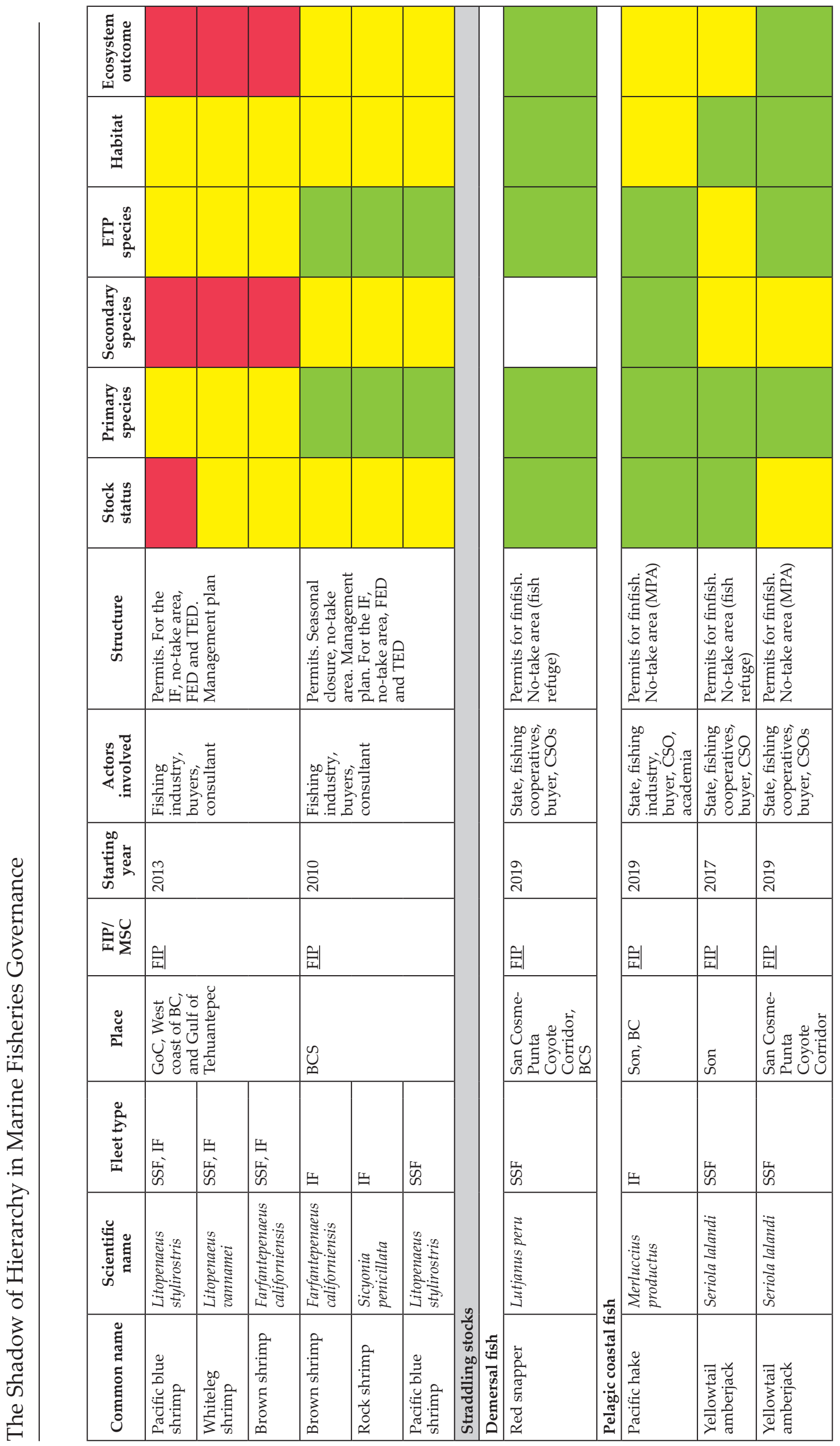




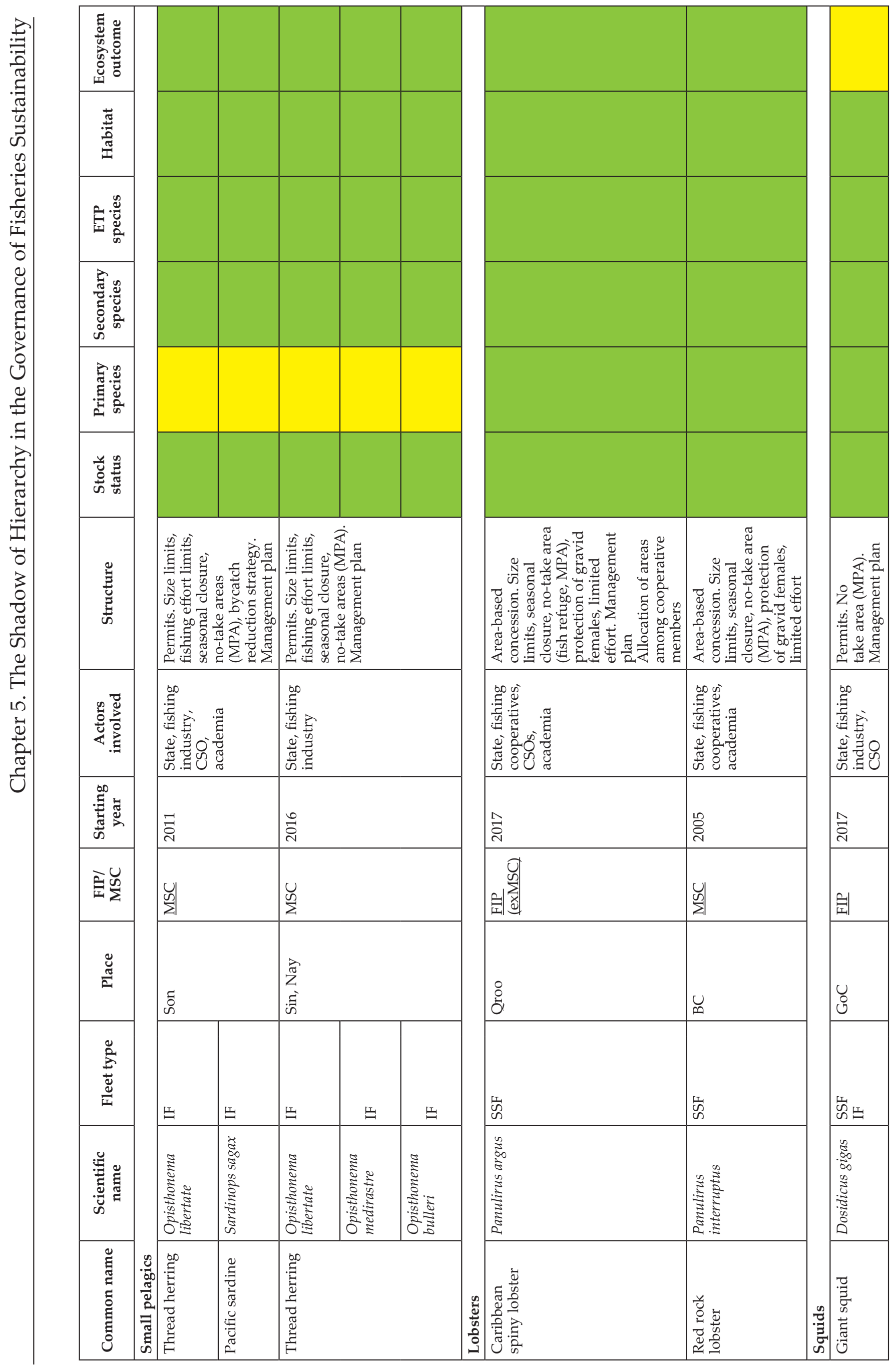




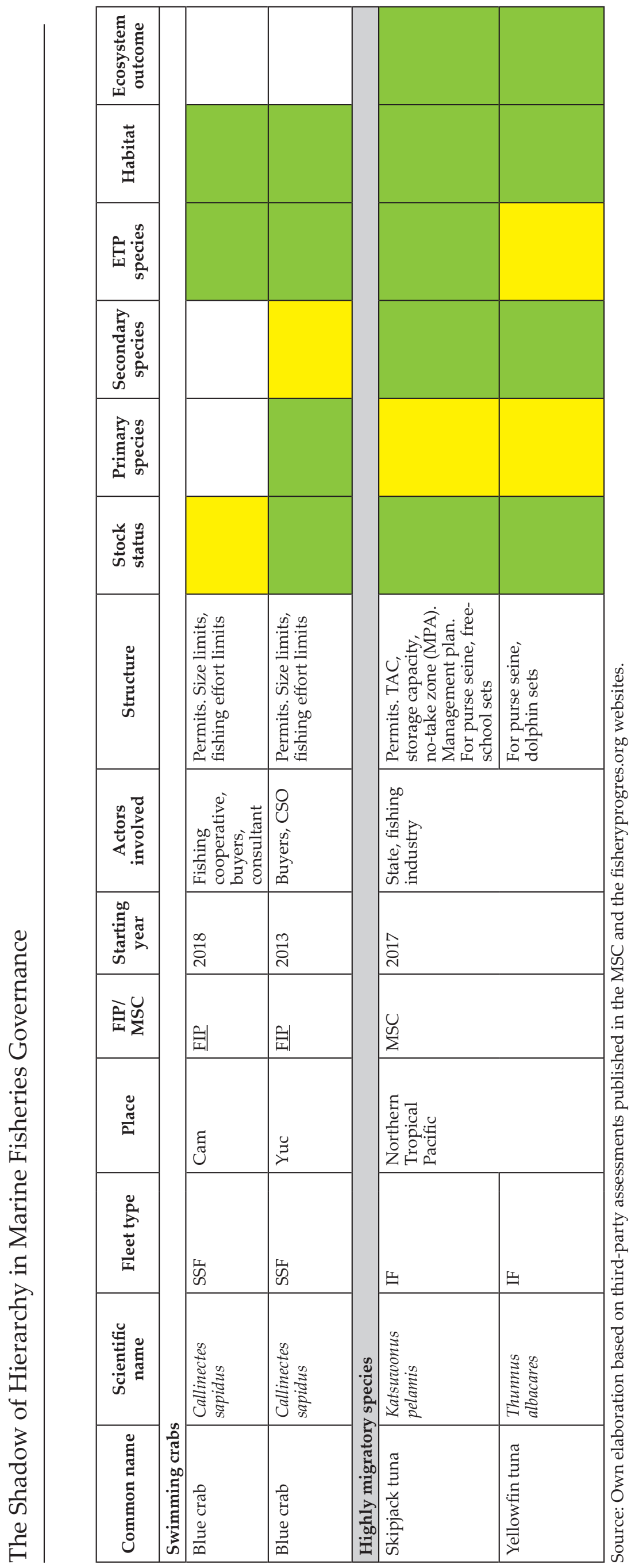




\section{Chapter 6. Conclusions}

This study contributes to the research on the shadow of hierarchy in marine fisheries governance. The shadow of hierarchy refers to the state use of non-traditional hierarchal forms to indirectly influence governance, even when non-hierarchical modes (i.e., self-governance, co-governance) seem to dominate. As shown in this research, the application of this non-traditional hierarchical forms is due to the meta-governance power of the state and its power resources. This research contributes to the study of meta-governance functions performed by the state to indirectly influence the governance of marine fisheries. Particularly, it focuses on three functions, which are: i) the creation of coexisting governance modes; ii) the steering and definition of the general patterns of fishing; and iii) the creation of the institutional setting for ensuring fisheries sustainability. The application of three theoretical approaches, the empirical research using Mexican fisheries as the case study, and the integration of different data sources (i.e., existing literature, legal frameworks, documents of legislative processes for the enactment of fisheries laws, fisheries regulations, historical policy reports, and fisheries assessments) provided a holistic understanding of the overarching research question How is the shadow of hierarchy performed by the state in marine fisheries governance?

Section 6.1 presents a synthesis of the findings with respect to the research question and sub-questions addressed in the literature review and the empirical research. Section 6.2 reflects on the complementarity of a multidisciplinary theoretical approach. Section 6.3 outlines the research contributions and further research. Section 6.4 reflects on the policy relevance and implications of this research. Finally, section 6.5 presents concluding remarks.

\subsection{Synthesis of Findings}

The analysis of existing literature of fisheries governance and common-pool resources (CPR), presented in Chapter 2, used the three governance modes (i.e., hierarchical, co-governance, and self-governance) of interactive governance theory (Kooiman, 2003) to investigate the following questions: What are the governance modes and what are the governing functions of the state? To address these questions, this Chapter identified in existing literature the functions the state performs in the three governance modes to identify those meta-governance functions performed in the shadow of hierarchy. Consequently, this research identified the determinants influencing the emergence of governance modes and the reported performance of such modes. 
This analysis shows shadow of hierarchy in the three governance modes. Existing literature generally presents the analysis of governance modes as if they were independent (e.g., Jentoft, 2005) or in transition from one to another (e.g., Chuenpagdee \& Jentoft, 2018). Although existing literature acknowledges that in practice these governance modes co-exist and are hybrid, it lacks the analysis and understanding of this coexistence and furthermore their embeddedness in larger systems. When looking at the three governance modes as part of one system, the position of the state as a meta-governor and its shadow of hierarchy in the governance system are evident. For example, the state shows authority to meta-govern when deciding the situations to exercise direct control over actors and fisheries, and the situations to share power with private and social actors to govern certain aspects of marine fisheries. Through different degrees of power delegation, alternative governance modes (i.e. co-governance and self-governance) formally coexist and benefit from state available resources (e.g., financial support, conflict resolution and enforcement mechanisms). Other meta-governance functions identified in the literature review include the integration of the public interest in fisheries objectives (e.g., sustainability), the establishment of linkages of governance modes among at different scales (local, provincial, national), and the assessments of institutional impact over different areas and resources.

The analysis of determinants influencing the emergence of governance modes also shows the indirect influence of the state. For example, the state through the mobilization of resources and relational capacity supports or hinders the emergence or coexistence of governance modes (see Chuenpagdee \& Jentoft, 2018). Another example is the legitimization of local institutions and fishing rights provision in self-governed contexts. Finally, the analysis of reported performance of governance modes shows that no one size fits all. Different governance modes and institutions prove to be suitable for different type of marine fish resources types and situations (e.g., types of fishing fleets participating in the fishery). Therefore, this research recommends the state to design coexisting governance modes and institutions for different resources types, which can be coordinated by the state in an extended shadow of hierarchy, to reduce the risk of overexploitation that continues increasing in marine fisheries.

Chapters 3, 4, and 5 presented the analysis of three meta-governance functions of the state using Mexican fisheries as the case study. The analysis of these meta-governing functions shows how the state confronts the dilemma of losing the direct control of actors in non-hierarchical modes of governance, while preserving its capacity to influence them, in the shadow of hierarchy. 
Meta-governance function: creation of coexisting governance modes. Chapter 3 presented the empirical analysis of this meta-governance function using interactive governance theory (Kooiman, 2003, Kooiman et al., 2005, 2008). Specifically, this chapter used two dimensions of this theory to frame the analysis of the Mexican fisheries' legal framework: governance modes (i.e., hierarchical, co-governance, and self-governance) and governance orders (i.e., $1^{\text {st }}$ order/day to day management, $2^{\text {nd }}$ order/ institution making, $3^{\text {rd }}$ order/objective definition). These two dimensions allowed to investigate which actors become state partners for the governing of fisheries as well as how the state interacts with and distributes governing functions among public, private, and social actors at different orders of governance.

The analysis of the legal framework of Mexican fisheries, using the two dimensions of interactive governance theory, illustrates the shadow of hierarchy in the creation of coexisting governance modes since 1925. The case study shows that the state employs different mechanisms for the participation of non-state actors in the governing of fisheries, at different orders of governance. From 1917 to 2019, 44 changes were made to the Mexican legal framework to involve private and social actors in the governing of fisheries, mainly at the level of day-to-day operations $\left(1^{\text {st }}\right.$ order of governance), on specific cases at the institutional level ( $2^{\text {nd }}$ order of governance), and not at all at the level of objectives definition and agenda setting for the whole governance system ( $3^{\text {rd }}$ order of governance). This is consistent with Bell and Hindmoor (2009), who argue that the state retains the power to define policy problems, objectives, and agendas. In addition, the number of changes in the legal framework confirms that the state has the option of delegating functions at multiple levels of governance, while retaining the option of recentralizing them (Peters \& Pierce, 2004). Moreover, the analysis shows the flexibility of the state to choose and change the mechanisms through which it expands its indirect influence in governance modes. For example, the state at first provided self-governed groups (e.g., coastal fishers, communities, and cooperatives) with fishing rights for the common exploitation of marine resources. Currently, the state chooses to support these groups through the legitimization of local institutions and the preference to coastal communities in the granting of fishing rights. Finally, the analysis shows that state chooses which actors to partner or not to partner with. In the Mexican case, right holders (individuals, organizations, and corporations) and researchers are the preferred partners for the constitution of co-existing and alternative governance modes. Other actors such as citizens (who represent the public interest) and small-scale fishers were considered part of the governing system in the early years of the legal framework. However, they were excluded in 1972 and 1986 fisheries laws, respectively. 
Meta-governance function: The steering and definition of the general patters of fishing. Chapter 4 presented the empirical analysis of this meta-governance function using social practices theory (Shove et al., 2012). The elements of social practices (meanings, materials, and competences) were used to frame the analysis of the Mexican legal framework and fisheries regulations to explain how the state uses its regulatory power to steer the general patterns of fishing.

The social practices theory (Shove et al., 2012) allowed to illustrate the increasing regulation of the patterns (meanings, materials, and competences) of fishing. This regulatory power is provided to the coastal state by the United Nations Convention on the Law of the Sea (UNCLOS) and national fisheries legal frameworks. In the Mexican case, this process occurs in parallel with an increasing tendency for more indirect and distributed forms of governing policy resources (i.e., regulatory, organizational, financial, expertise). For the last hundred years, the increasing regulation of the patterns of fishing practices has been aligned with an increasing number of regulations and regulated fisheries, levels of specification, regulatory instruments, and thematic areas. This has occurred despite the political changes Mexico went through over the last hundred years (i.e., authoritarian state intervention, neoliberal minimal state, and democratic state delegation). The analysis also shows that the state does retain this power to define the cognitive meaning, materials, and competences for the practice of fishing to influence actors, in an indirect form, including those involved in practising non-hierarchical forms of governance. In addition, the state shows the autonomy of the state to adopt different paradigms, materials, and competences, even those suggested by international trends and guidelines for the regulation of fisheries, sites, and fleets.

Meta-governance function: Creation of the institutional setting to ensure fisheries sustainability. Chapter 5 presented the empirical analysis of this meta-governance function, using the situation, structure, performance (SSP) approach of the institutional impact theory (Schmid, 1987). This theoretical approach was applied to the analysis of institutional settings (property rights and regulations) established for different type of resources, including those of private and social actors, and the corresponding performance of such institutional settings.

The SSP approach allowed for the understanding of the shadow of hierarchy in the institutional settings established for different marine fish resources (i.e., sedentary, mobile with the EEZ, straddling, and highly migratory stocks) and the corresponding performance. The analysis shows that state institutions (i.e., regulations) for 
sedentary species are more exclusive and feasible to enforce than those developed for mobile species, which provide less exclusivity to users and high enforcement costs, which represent a greater challenge for achieving sustainability. The institutional analysis demonstrates the extension of the shadow of hierarchy within territorial waters and the EEZ, its boundaries, and the influence of additional layers of governance at supranational level for shared stocks (i.e., highly migratory) and the industrial fleet (e.g., shrimp, tuna, groupers). The analysis of performance shows that in 2000, $74 \%$ of the species were reported to be at MSY, $3 \%$ with potential for development, and $23 \%$ overexploited (DOF, 2000). By 2018, 81\% of the species were reported at MSY and 19\% overexploited (DOF, 2018c). From the 31 studied species, ten species were reported as overexploited during the period 2000-2018, which correspond to three different resource types (i.e., sedentary, mobile within the EEZ, and straddling stocks). Six species are still reported as overexploited, and for three species the state did not report any change in regulations or implementation of remedial action strategies to recover the stocks.

The analysis of private and social efforts (FIPs and MSC certifications) towards fisheries sustainability illustrates the shadow of hierarchy. In these cases, the state develops the long-term and overarching objectives for fisheries governance as well as the regulations for specific fisheries. Non-state actors involved in FIPs and MSC often develop complementary institutions and contribute to the definition of objectives for specific species and sites. In addition, these actors lead day to day operations (i.e., monitoring, enforcement), and in assessments, they include broader considerations of fisheries sustainability (e.g., impact to the ecosystem). In those fisheries assessed with the MSC standard, private and social actors commit to make improvements around three principles of fisheries sustainability (i.e., health of the target population, the least impact to the ecosystem, and a robust governance system), to participate in third-party assessments, and to have the information of improvements and assessments public. Those FIPs and certification processes that engage state and non-state actors prove to have different feedback loops between information gathering and analysis, objectives, management strategies, and enforcement, which not only meets the MSC fisheries standard requirements but also improves fisheries governance. This analysis shows the complementarity of actions among state and non-state actors, and the performance of governance within the shadow of hierarchy of state regulation. 


\subsection{The Complementarity of Theoretical Approaches}

The three theories (i.e., interactive governance, social practices, and institutional impact) applied in this research offered different and complementary approaches for the study of the shadow of hierarchy. This complementarity is explained below and illustrated in Figure 6-1.

Interactive governance theory allowed to investigate the shadow of hierarchy from the point of view of interactions between public, private, and social actors. It assumes governance as composed by the governing system, the governed system, and the interactions among both systems. By focusing on the governing system, it allowed to investigate how the state defines institutions (i.e., legal framework) that guide such interactions for the governing of marine fisheries. Specifically, how the state shares governing functions with other actors in different modes and at different orders. It also allowed to investigate the coexistence of diverse governance modes. Through the use interactive governance theory, the analysis shows the shadow of hierarchy at different orders and modes of governance. For example, in the Mexican case, the state defines the overarching goals (third order) and regulates fisheries (second order). In addition, the state devolves power to engage other actors in defining institutions for specific fisheries (second order) and in the day to day operations (first order). As theorized by Kooiman et al. (2008), interactive governance can also be applied to different scales (i.e., local, regional, global). This was evidenced in the analysis of existing literature, which included case studies at the different scales, and this theoretical approach allowed for the analysis of all cases for the identification of meta-governance functions of the state.

Social practices theory (Shove et al., 2012) was used to investigate how the state steers and defines the general patters of fishing. This theory has not been applied to fisheries before. By analysing the three elements of social practices - meanings, materials, and competences, in the fisheries domain, this theoretical approach illustrated the meta-governance power of the state and its indirect and significant influence in fisheries governance. Even in times when the democratization of fisheries occurred, and the state acknowledged and regulated the participation of non-state actors in the governing of fisheries. The analysis of the legal framework and fisheries regulations with the social practices approach complemented the analysis conducted with the interactive governance theory. For example, the latter illustrated that the state retains the definition of overarching goals for fisheries governance and dominates the institution making. Then, the analysis conducted with the social practices 
theory allowed for the understanding of underlying motivations and aspirations (meanings) of the state behind the overarching goals established in the laws, as well as the exercise of the institution making through implementing regulations (materials and competences) to influence governance. However, these approaches differ in the sense that social practices theory does not focus on actors and their interactions. It assumes actors are the carriers of practices (Reckwitz, 2000, p. 250), and practices are the outcome of the interactions of three elements - meanings, materials, and competences - over time and space. Then, practices change and evolve, when one or more of these elements change. The analysis of fishing as a social practice showed how the state, despite the sharing of governing functions with non-state actors, retains the power of defining the cognitive meaning, materials, and competences for fishing practices. Through the increasing exercise of this power, it influences and shapes the behaviour of the collective, including those actors involved in non-hierarchical forms of governance.

The SSP approach of institutional impact theory added two elements to this research, the analysis of institutions for different resource types, and the analysis of performance towards fisheries sustainability. This theoretical approach focuses on a different stage of the policy process, institutional performance. For the SSP approach, performance is the outcome of institutions (structure) applied to a context (situation). Thus, institutions have different outcomes depending on the context to which they are applied. The situation element of the SSP approach allowed for accounting different marine resource types, due to their mobility and associated uncertainties. This is relevant to note in the context of marine fisheries because it brings an additional layer to governance, in addition to actors' interactions, given the spatial dynamics of marine resources. Thus, the situation component allowed to analyse the institutional setting (fishing rights and rules) applicable for different resource types. The analysis of the institutional setting included not only the fishing rights and rules developed by the state (here, those applicable to different resource types), but also those rules emerging from private and social actors who implement voluntary efforts towards sustainability, in the shadow of hierarchy. The SSP approach rather than deepening on the institutions guiding the interactions of actors (as in interactive governance), it focuses on the institutions guiding the extraction of different resource types. Finally, the performance component, allowed to prove that institutions (fishing rights and rules) have different outcomes depending on the resource types. 
Figure 6-1. Complementarity and interrelations among the three theories (i.e., interactive governance, social practices, and institutional impact) and their key elements.

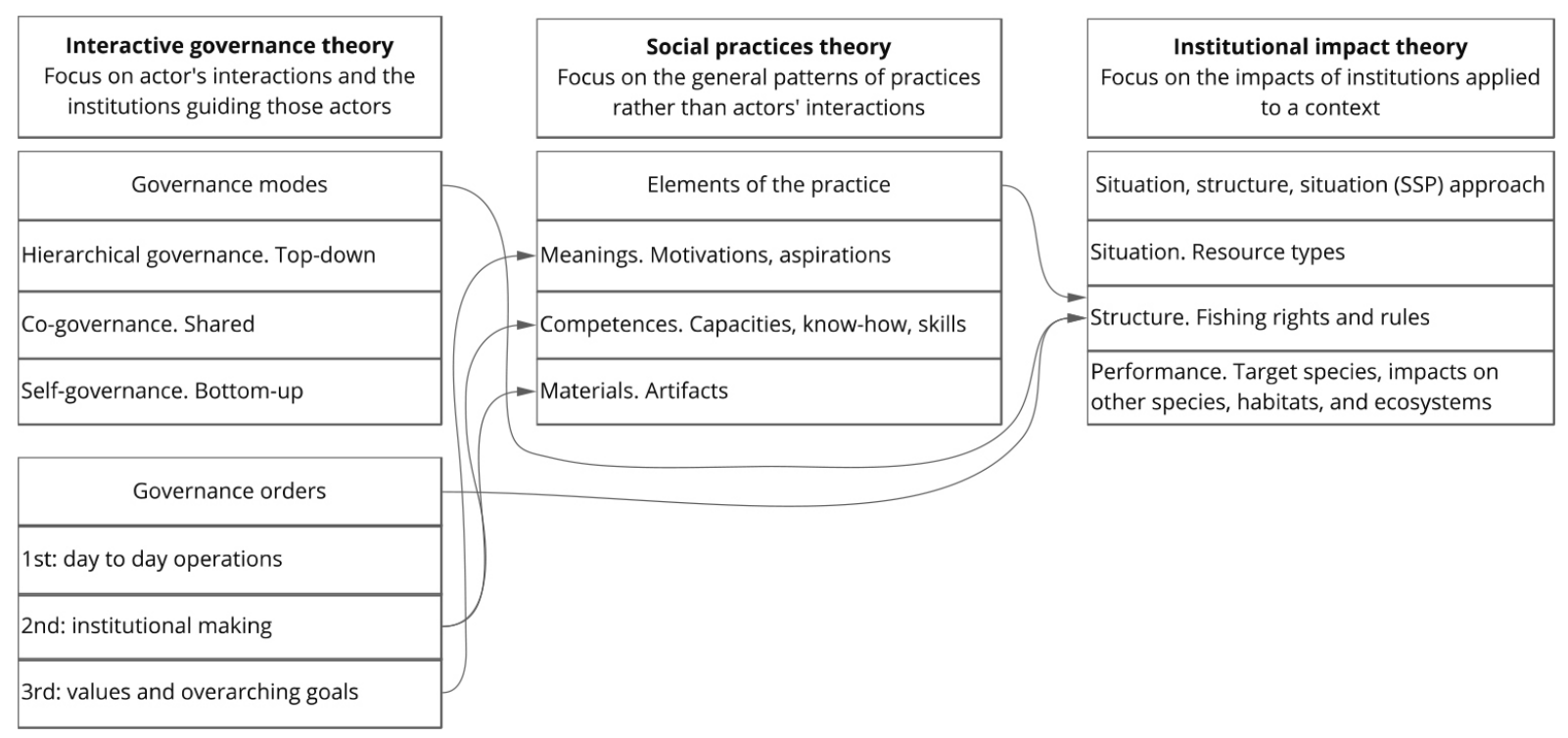

\subsection{Research Contributions}

This research contributes to fisheries governance literature. The shadow of hierarchy in fisheries governance was first investigated by Viet-Thang (2018) to illustrate the state provision of resources (e.g., financial, legal, conflict resolution support) to influence co-governed fisheries. This research builds on this emerging literature on the shadow of hierarchy in marine fisheries, by investigating in depth three additional meta-governance functions of the coastal state. It also presents the application of different theoretical approaches to analyse the meta-governance functions. Two of the theoretical approaches (i.e., interactive governance and the SSP approach) have been applied to fisheries governance before. However, their application generally focuses on particular governance modes, the transition from one governance to another (e.g., Chuenpagdee \& Jentoft, 2018), or the institutional setting for a particular resource type (e.g., Seijo, 1993). In this research, these theoretical approaches (i.e., interactive governance and the SSP approach) are applied to analyse meta-governance functions of the state in coexisting governance modes and for different resource types. The social practices theory had not been applied to the field of fisheries governance and prove to be suitable for the investigation of the significant influence of the state in steering and defining the general patterns of fishing.

The Mexican case illustrates how the coastal state uses its regulatory power for the exercise these three meta-governance functions that indirectly influences governance systems. This power is applicable to the coastal state in fisheries over territorial wa- 
ters and EEZs for the regulation of marine living resources, the conservation of the marine environment, and for conducting research, as mandated by the UNCLOS. In general, 'how' coastal states perform these meta-governance functions is a decision for each state to make, as illustrated in the Mexican case. It is important to note that the meta-governance functions explored in this research, are only investigated in the context of a coastal state. Their application to supranational levels of governance, for example in the context of regional fisheries management organizations (RFMOs) and the European Union, requires further investigation. In these contexts, participating states undertake joint stock assessments, and negotiate international agreements that are translated into national policies. In such cases, rather than one state deciding what is allowed, who can be engaged, and to what extent, these decisions are part of inter-state negotiations.

The analysis of the Mexican fisheries allowed to investigate the institutions for different types of resources in which the coastal state has jurisdiction (full or partial). Generally, marine resources are categorized as three types: sedentary, straddling (shared stocks, moving between EEZs), and highly migratory species (Caddy and Seijo, 2005; Seijo et al., 2010). This research adds another type of resource, mobile within the EEZ, which represent those mobile species relevant for coastal states with long shorelines. The addition of this type of resource allowed for the analysis of the institutional setting developed for endemic species and local populations of native and cosmopolitan populations. The results of this analysis show that this type of resource represents a greater challenge for achieving sustainability, than those sedentary species, due to the mobility of such resources, and the low exclusivity and enforceability fishing rights provide. This represents the case of Mexico, where the state grants fishing rights for large areas and often for multiple species moving within the EEZ. The regulation of management tools (i.e., gear types, seasonal closures, size limits restrictions, no-take areas, among others) for these species is essential in order to avert the overexploitation of fisheries.

The approach used for this research (i.e., meta-governance functions and theories applied) can be used as a reference to expand research on the shadow of hierarchy for other common-pool resources (CPRs) governance, such as forests and water irrigations systems, which share common characteristics with fisheries, such as state regulation, high exclusion costs, and the coexistence of hierarchical and non-hierarchical forms of governance. 


\subsection{Policy Relevance and Implications}

Research on the shadow of hierarchy helps in understanding the state superior hierarchy as well as its autonomy to shape and indirectly influence fisheries governance. This is relevant, especially in times when opportunities and problems emerge and a rapid response and coordination are needed (Leavitt, 1951), due to the complexity and heterogeneity of marine fisheries in terms of the dynamics of fish populations and fishers. However, it can limit the collective action and autonomy of non-state actors to influence policy (Leavitt, 1951; Shaw, 1981). The Mexican case shows that through its regulatory power the state decides (limits or expands), according to its preferences and goals, on the possibility of other actors to participate in the governing of fisheries.

The global marine and fisheries policies suggest the integration of actors (e.g., small-scale fishers, value chains, civil society organizations) in pursuing fisheries and ocean sustainability (e.g., the 2030 Agenda for Sustainable Development; FAO's Small-scale Fisheries Guidelines). However, as illustrated in this research, the state is the meta-governance actor with the power to formally engage public, private, and social actors in the governing of fisheries. Some actors can be excluded if the state does not see their potential to participate. In the Mexican case, for example, the state excluded citizens from the governance system, who is the sector that can represent the public interest (i.e., the conservation of national wealth) and counterbalance those private interests (i.e. exploitation). With the introduction of neoliberal policies in the 1980s, small-scale fisheries and cooperatives were also left out of the legal framework. Although the legal framework has elements to support coastal communities, where small-scale fisheries and cooperatives concentrate, the support in terms of access to fishing rights has significantly decreased over time. For this particular sector, international fisheries policies, such as the SSF Guidelines (FAO, 2015) and the Agenda 2030 for Sustainable Development are raising the attention and calling the states for action to secure these rights and the sustainability of small-scale fisheries (Chuenpagdee \& Jentoft, 2018; FAO, 2015).

The Mexican case confirms that non-state actors are mainly engaged in day-to-day operations such as knowledge production and enforcement, while the state retains its superior hierarchy for policy making and the definition of objectives. This is consistent with Berkes (2009) and Sen and Nielsen (1996), whose research suggests that non-state actors contribute to lower levels of decision-making in fisheries governance, with little influence on policy formulation. In order to increase governance, 
non-state actors should be involved in the three orders of governance suggested by Kooiman (2003) (definition of objectives, institution making, and day-to-day operations). This can be beneficial for the state in the pursue of sustainability, especially when the state lacks the resources and non-state actors have the capacity and are ready to become competent partners.

Knowledge production is the governing function in which the Mexican state captured wider participation of actors, including experts (academia), private and social actors. This is consistent with the shadow of hierarchy literature, which suggests delegation of power and the integration of specialized organizations to ensure sufficient expertise in decision-making as well as stability and predictability of policymaking (Héritier \& Lehmkuhl, 2008). The involvement of actors in this governing function also increases the likelihood of covering the high information costs associated with marine species given their mobility and uncertainties associated with their abundance and distribution over space and time.

Sustainability is the desired outcome for fisheries governance at the global level (FAO, 1995a, 1995b, 2015). The Sustainable Development Goals (SDGs) of the 2030 Agenda for Sustainable Development include goals and targets for oceans and marine fisheries (i.e., SDG 14 life below water), which refer to fisheries sustainability and the end of overfishing by 2020. However, the latest report of the FAO shows evidence of the continuity of stock depletion. Overfished stocks increased from $10 \%$ in 1974 to $34 \%$ in 2017, particularly in developing countries (FAO, 2020). Coastal states thus need to rethink fisheries governance and their mechanisms to reach fisheries sustainability goals.

The maximum sustainable yield (MSY) is the reference point, mandated by the UNCLOS, most used for the conservation of fish populations and for fisheries sustainability. However, its particular focus on target fish populations proves to be insufficient for sustaining fisheries. Surpassing the MSY can cause fisheries collapse, and in this situation significant fishing efforts cuts will need to be applied, and the recovery of fisheries may take long or not occur (Caddy and Seijo, 2005). In the Mexican case, from the 31 studied species, 10 surpassed the MSY in the period 2000-2018 (queen conch - Lobatus gigas, shrimps - Farfantepenaeus californiensis and Litopeneaus vannamei, groupers - Epinephelus morio and Mycteroperca bonaci), mullets - Mugil cephalus and Mugil curema, snappers - Lutjanus campechanus, Lutjanus buccanella, and Lutjanus vivanus) and six of them have not been recovered. It is important to note that for seven species the state limited the fishing effort and updated management tools. 
However, for three species (i.e. snapper fishery), the state did not publish or update regulations to implement remedial or recovery actions.

More conservative reference points have been suggested, such as the Maximum Economic Yield (MEY), in which economic net returns are maximized, involving lower exploitation rates and higher biomass levels. This reference point involves less direct employment in the fishery, and catch quota reductions. Only Australian fisheries are already testing the MEY and have incorporated economic efficiency as the primary management objective in its Fisheries Management Act to recover stocks and eliminate overcapacity (e.g., northern prawn fishery) (Dichmont et al., 2008; Dichmont, Pascoe, Kompas, Punt, \& Deng, 2010). However, for states where most fisheries are already performing at MSY, such as the Mexican case, it will be challenging to incorporate more conservative reference points, as implementation would require a substantial decrease of fishing effort (fleets, quotas, etc).

In addition, fisheries policy scholars have suggested accounting for broader dimensions of sustainability than just the target commercial species (Fletcher et al., 2010; Garcia et al., 2003). These dimensions include environmental factors associated to the fisheries (climate change) (Anderson \& Seijo, 2010), impacts on associated species to the fishery, habitats and ecosystem integrity, as well as the distribution of resource rents needed for sustaining the fishery over time (Caddy \& Seijo, 2005). International actors (e.g. FAO, MSC, among others) have developed guidelines and standards that incorporate some of these dimensions and international standards for sustainable fishing. As pointed out by Cochrane (2018), these guidelines and standards are aligned to international binding (e.g., UNCLOS) and non-binding agreements (e.g., FAO's Code of Conduct for Responsible Fisheries). As shown in Mexican fisheries and in other countries, non-state actors implement these standards in the shadow of hierarchy, as they require and are conducted under state regulations. This research recommends the state to use these efforts, as a reference, to leverage and scale the incorporation of broader dimensions of sustainability as well as to share the costs of governing marine resources.

This study reflects the autonomy of the state to change the legal framework to indirectly influence fisheries governance. In the particular case of Mexico, it is noted that the state changes the legal framework to change the status quo, which for policy makers is represented in the current law. This research recommends to account for earlier knowledge to learn from the application of different approaches of state intervention incorporated in fisheries laws. In the Mexican case, the state discards and 
reuses different approaches with no order or sequence (e.g., decentralization, centralization, integration of non-state actors, recentralization, and decentralization). This situation recalls the "shifting the baseline" concept of Pauly (1995), which describes how fisheries experts, to evaluate change, use as the baseline the status of fish populations at the start of their careers, rather than in its untouched state. Each generation thus redefines the "baselines", losing the perception of change and its impacts. Pauly (1995) suggests the development of frameworks to add earlier knowledge into present models. The Mexican case shows that the shifting the baseline concept is applicable to fisheries policy making. This research argues that including earlier knowledge will allow to learn from past experience to better shape the governance of fisheries. In the case of Mexico, the state has applied different approaches of state intervention with important lessons learned on which actors to involve and to which governing functions, in order to improve fisheries policies in the present context.

The Mexican state, through the fisheries laws, has involved public, private, and social actors in the governing of fisheries since 1925. This distribution of power, occurs in parallel with the increasing regulation of the general patterns of practices, despite changes in political regimes. This regulation of general patterns has focused on defining the meanings of fishing as well as regulating fishing rights and a set of five management tools (i.e., gear types and fishing methods, minimum sizes, no-take areas, seasonal closures, and total allowable catches (TAC)). Over the last two decades, regulations have refered mostly to updates rather than the adoption of novel management approaches and tools. This study recommends that the Mexican state increases the exclusivity and enforceability of fishing rights through the establishment of TURFs where appropriate (e.g., sedentary species) and the formalization of the customary rules created by private and social actors.

Non-state actors are currently participating in the governing of fisheries in some coastal areas. This is evidenced by the increasing implementation of FIPs and MSC certification processes, in which non-state actors develop customary rules that complement those of the state to lead data collection, enforcement systems and fisheries assessments. These efforts represent a point of reference for the state to scale best practices in fisheries and areas where conservation efforts are needed, or where the state does not have the capacity to govern fisheries and non-state actors are ready to become competent partners. In addition, these efforts serve as a reference for incorporating broader dimensions of sustainability. This is relevant, if considering the records of species overexploitation, non-recovery of stocks, and the lack of remedial actions for some Mexican fisheries, as mentioned before. In addition, the overarching goals for 
fisheries governance established in the laws have historically accounted for environmental, social, and economic dimensions.

This research is timely and relevant. In 2018, the president of Mexico, proposed the creation of a new fisheries law within the 2018-2024 Plan for the Nation (MORENA, 2018). This research provides a historical analysis with elements to inform the state in the design of a new law that contributes to the consolidation of an inclusive governance system, the inclusion of broader dimensions of fisheries sustainability, and the recovery of overexploited species. Preliminary results of this research, particularly those of Chapter 3, were presented to the Commission of Agriculture, Livestock, Fisheries, and Rural Development of the Senate to contribute to the law initiative. In addition, given the wide range of public documents collected for this research (i.e., legal framework, fisheries regulations, documents for the enactment of fisheries law, fisheries assessments), a repository of the collected documents is being established by Comunidad y Biodiversidad, A. C. for the consultation of public and private organizations and individuals that study and work in the public policy arena for marine fisheries.

\subsection{Further Research}

This research illustrates how the coastal state expands and retracts its shadow of hierarchy to indirectly influence fisheries governance, according to its priorities and capacities. Further research can focus on comparing the variation of the shadow of hierarchy among different coastal states, and its variation in relation to overarching goals, performance, or power resources. In terms of performance, this research accounts for fisheries sustainability dimensions (e.g., MSY, impacts on the ecosystem, governance system). However, the SSP approach suggests accounting for the distributional effects of institutions (Schmid, 1987). Future research can explore the relation between the expansion of the shadow of hierarchy and distributional effects of policy decisions in marine fisheries. This will allow to understand state indirect influence on the rent and profit distribution derived by different resource users in coastal areas, resulting from different alternative policies and institutions applied to fisheries targeting different types of fish species.

The conception of state in this research is tightly linked to the concept of sovereignty and the capacity of the state to control its own boundaries against the outside world (Scharpf, 1997). Thus, this study investigated the shadow of hierarchy, considering the autonomy of the coastal state within its jurisdiction, and therefore using domestic regulations for marine fisheries in the analysis. Further research can focus on 
how the shadow of hierarchy is performed at supranational fisheries governance. This includes shared fish stocks (straddling and highly migratory), which involve joint stock assessment efforts and bargaining negotiations among different states for the extraction of ocean living and non-living resources. Another approach is to investigate how the shadow of hierarchy is bounded by supranational layers of governance, particularly by international binding and non-binding instruments or regional bodies such as the RFMOs or the European Union.

Finally, other meta-governance functions that are not included in this research require further investigation. Additional meta-governance functions include how the state accounts for the large uncertainties associated with marine fish resources, how it mitigates the risks associated with these uncertainties (Viet-Thang, 2018), and how the state ensures democracy (i.e., ensuring compliance with democratic practices and norms) and accountability (i.e., clear lines of responsibility) (Bell \& Hindmoor, 2009, p. 47).

\subsection{Concluding Remarks}

This research investigates the shadow of hierarchy in marine fisheries governance, through the analysis of the meta-governance functions using different theoretical approaches. The Mexican case illustrates how the coastal state meta-governs, using its legal and regulatory power to select actors and shape their action boundaries, steer and define the cognitive practice of fishing, and account for different types of marine fisheries to pursue fisheries sustainability. Although the state is immersed into new governance modes, the exercise of this meta-governance power allows the state to preserve its capacity to indirectly influence governance systems, in order to compensate for losing day-to-day command and control in fisheries governance. State intervention is thus not limited by alternative governance modes, but rather is performed in non-traditional hierarchical forms, in the shadow of hierarchy. 


\section{References}

Abayomi, K., \& Yandle, T. (2012). Using Conditional Lorenz Curves to Examine Consolidation in New Zealand Commercial Fishing. Marine Resource Economics, 27(4), 303-321.

Adler, E., \& Pouliot, V. (2011). International practices: introduction and framework. In E. Adler \& V. Pouliot (Eds.), International pracices Cambridge: Cambridge University Press.1-35p.

Afflerbach, J. C., Lester, S. E., Dougherty, D. T., \& Poon, S. E. (2014). A global survey of "TURF-reserves", Territorial Use Rights for Fisheries coupled with marine reserves. Global Ecology and Conservation, 2: 97-106.

Alcalá-Moya, G. (2003). Políticas pesqueras en México (1946-2000). Contradicciones y aciertos en la planificación de la pesca nacional. El Colegio de México, Centro de Investigación Científica y de Educación Superior de Ensenada, El Colegio de Michoacán.

Altamirano-Jimenez, I. (2017). “The sea is our bread": Interrupting green neoliberalism in Mexico. Marine Policy, 80:28-34.

Anderson, L. G., \& Seijo, J. C. (2010). Bioeconomics of Fisheries Management. New Jersey: Wiley-Blackwell. 305p.

Anthony, D. L., \& Campbell, J. L. (2011). States, social capital, and cooperation: looking back on Governing the Commons. International Journal of the Commons, 5(2):284-302.

Baer, W., \& Maloney, W. (1997). Neoliberalism and income distribution in Latin America. World Development, 25(3), 311-327.

Baird, I. G., Manorom, K., Phenow, A., \& Gaja-Svasti, S. (2020). Opening the Gates of the Pak Mun Dam: Fish Migrations, Domestic Water Supply, Irrigation Projects and Politics. Water Alternatives-an Interdisciplinary Journal on Water Politics and Development, 13(1), 141-159.

Baker, S., Ayala-Orozco, B., \& García-Frapolli, E. (2020). Hybrid, public, and private environmental governance: the case of sustainable coastal zone management in Quintana Roo, Mexico. International Journal of Sustainable Development $\mathcal{E}$ World Ecology, 27(7), 625-637.

Barkin, J. S., DeSombre, E. R., Ishii, A., \& Sakaguchi, I. (2018). Domestic sources of international fisheries diplomacy: A framework for analysis. Marine Policy, 94, 256-263.

Barnett, M., \& Finnemore, M. (1999). The Politics, Power, and Pathologies of International Organizations. International Organization, 53(4), 699-732. 
Bavinck, M., \& Chuenpagdee, R. (2005). Current Principles. In Kooiman J., Bavinck M., Jentoft S., \& Pullin R. (Eds.), Fish for Life: Interactive Governance for Fisheries. Amsterdam: Amsterdam University Press. 245-264p.

Bavinck, M., Chuenpagdee R., Diallo M., Van der Heijden P., Kooiman J., Mahon R., \& Williams S. (2005a): Interactive fisheries governance: a guide to better practice. Delft (Neth- erlands): Eburon.

Bavinck, M., Chuenpagdee, R., Degnbol, P., Pascual-Fernández J.J. (2005b). Challenges and Concerns Revisited. In Kooiman J., Bavinck M., Jentoft S., \& Pullin R. (Eds.), Fish for Life: Interactive Governance for Fisheries. Amsterdam: Amsterdam University Press. 303-324p.

Bell, S., \& Hindmoor, A. (2009). Rethinking governance: the centrality of the state in modern society. Port Melbourne, Vic: Cambridge University Press.

Bellanger, M., Macher, C., \& Guyader, O. (2016). A new approach to determine the distributional effects of quota management in fisheries. Fisheries Research, 181, 116-126.

Bennett, A. (2017). The influence of neoliberalization on the success and failure of fishing cooperatives in contemporary small-scale fishing communities: A case study from Yucatan, Mexico. Marine Policy, 80, 96-106.

Berkes, F. (2002). Cross-scale institutional linkages: Perspectives from the bottom up. In E. Ostrom, T. Dietz, D. N., P. Stern, S. Stonich, \& E. U. Weber (Eds.), The drama of the commons. Washington, D.C.: National Academy Press. 293-322p.

Berkes, F. (2009). Evolution of co-management: Role of knowledge generation, bridging organizations and social learning. Journal of Environmental Management, 90(5), 1692-1702.

Berkes, F., \& Nayak, P. K. (2018). Role of communities in fisheries management: “one would first need to imagine it". Maritime Studies, 17(3), 241-251.

Blecker, R. A. (2009). External Shocks, Structural Change, and Economic Growth in Mexico, 1979-2007. World Development, 37(7), 1274-1284.

Botello, M., Villaseñor, R., \& Mezo, S. (2010). Programa de ordenamiento pesquero ribereño. México: Comisión Nacional de Acuacultura y Pesca (CONAPESCA), Secretaría de Agricultura, Ganadería, Desarrollo Rural, Pesca y Alimentación. Bowen, G. (2009). Document Analysis as a Qualitative Research Method. Qualitative Research Journal, 9(2), 27-40.

Brent, Z. W., Barbesgaard, M., \& Pedersen, C. (2020). The Blue Fix: What's driving blue growth? Sustainability Science, 15(1), 31-43.

Bresnihan, P. (2019a). Revisiting neoliberalism in the oceans: Governmentality and the biopolitics of 'improvement' in the Irish and European fisheries. Environment and Planning a-Economy and Space, 51(1), 156-177. 
Bresnihan, P. (2019b). The (Slow) Tragedy of Improvement: Neoliberalism, Fisheries Management \& the Institutional Commons. World Development, 120, 210-220.

Brinson, A. A., \& Thunberg, E. M. (2016). Performance of federally managed catch share fisheries in the United States. Fisheries Research, 179, 213-223.

Bromley, D. W. (1991). Testing for common verus private property: Comment Journal of Environmental Economics and Management, 21(1), 92-96.

Caddy, J. F., \& Mahon, R. (1995). Reference points for fisheries management. FAO Fisheries Technical Paper. No. 347. FAO. 1995. 83p.

Caddy, J. F., \& Seijo, J. C. (2005). This Is More Difficult than We Thought! The Responsibility of Scientists, Managers and Stakeholders to Mitigate the Unsustainability of Marine Fisheries. Philosophical Transactions: Biological Sciences, 360(1453), 59-75.

Cairney, P. (2020). Understadning public policy. Theories and issues. London: Red Global Press. 327p.

Cannon, J., Sousa, P., Katara, I., Veiga, P., Spear, B., Beveridge, D., \& Van Holt, T. (2018). Fishery improvement projects: Performance over the past decade. $M a$ rine Policy, 97, 179-187.

Cavaleri-Gerhardinger, L., de Castro, F., \& Simão-Seixas, C. (2015). Scaling-up smallscale fisheries governability through marine protected areas in Southern Brazil. In S. Jentoft \& R. Chuenpagdee (Eds.), Interactive Governance for Small-Scale Fisheries. MARE Publication Series. Springer, Cham. 339-357p.

Chuenpagdee, R., Degnbol, P., Bavinck, M., Jentoft, S., Johnson, D., Pullin, R., \& Williams, S. (2005). Challenges and Concerns in Capture Fisheries and Aquaculture. In Kooiman J., Bavinck M., Jentoft S., \& Pullin R. (Eds.), Fish for Life: Interactive Governance for Fisheries. Amsterdam: Amsterdam University Press. 25-37p.

Chuenpagdee, R., \& Jentoft, S. (2007). Step zero for fisheries co-management: What precedes implementation. Marine Policy, 31(6), 657-668.

Chuenpagdee, R., \& Jentoft, S. (2015). Exploring Challenges in Small-Scale Fisheries. In J. Svein \& R. Chuenpagdee (Eds.), Interactive Governance for Small-Scale Fisheries: Global Reflections. MARE Publication Series. Springer, Cham. 3-16p.

Chuenpagdee, R., \& Jentoft, S. (2018). Transforming the governance of small-scale fisheries. Maritime Studies, 17(1), 101-115.

Clay, P. M., Kitts, A., \& Pinto da Silva, P. (2014). Measuring the social and economic performance of catch share programs: Definition of metrics and application to the U.S. Northeast Region groundfish fishery. Marine Policy, 44, 27-36.

Cochrane, K. L. (2002). A fishery manager's guidebook. Management measures and their application. FAO Fisheries Technical Paper No. 424. FAO 2002. 231p. 
Cochrane, K. L. (2018). Eco-labelling and eco-certification of fisheries. In J. C. Seijo \& J. Sutinen (Eds.), Advances in Fisheries Bioeconomics. Theory and Policy. Routledge. Taylor and Fracis Group. 114-136p.

CONAPESCA. (2017). Anuario Estadístico de Acuacultura y Pesca. México: CONAPESCA.

Corbin., S. A. L. a. J. (1998). Basics of Qualitative Research: Grounded Theory Procedures and Techniques. 2nd Edition. Thousand Oaks, CA: Sage Publications .

Cox, M., Villamayor-Tomas, S., \& Arnold, G. (2016). Design principles in commons science: A response to "Ostrom, Hardin and the commons" (Araral). Environmental Science \& Policy, 61, 238-242.

Cuéllar-Lugo, M. B., Asiain-Hoyos, A., Juárez-Sánchez, J. P., Reta-Mendiola, J. L., \& Gallardo-López, F. (2018). Evolución normativa e institucional de la acuacultura en México. Acuacultura, Sociedad y Desarrollo, 15(4), 541-564.

Cullis-Suzuki, S., \& Pauly, D. (2010). Failing the high seas: A global evaluation of regional fisheries management organizations. Marine Policy, 34(5), 1036-1042.

Cullis-Suzuki, S., \& Pauly, D. (2016). Global evaluation of high seas fishery managment. In D. Pauly \& D. Zeller (Eds.), Global Atlas of Marine Fisheries. A critical appraisal of catches and ecosystem impacts. 76-85p.

Delaney, A. E. (2015). Japanese fishing cooperative associations: Governance in an era of consolidation. In S. Jentoft \& R. Chuenpagdee (Eds.), Interactive Governance for Small-Scale Fisheries. Springer International Publishing. 263-280p.

Diario de los Debates. (1924). Proyecto de Ley de Pesca. México. Cámara de Diputados. 18-36p.

Diario de los Debates. (1949). Proyecto de Ley de Pesca de los Estados Unidos Mexicanos. México. Cámara de Senadores. 2-16p.

Diario de los Debates. (1971). Iniciativa de la Ley Federal para el Fomento de la Pesca. México. Cámara de Senadores. 7-19p.

Diario de los Debates. (1972a). Dictamen de Primera Lectura de la Ley Federal para el Fomento de la Pesca. México. Cámara de Diputados. 3-32p.

Diario de los Debates. (1972b). Dictamen a Discusión de Ley Federal para el Fomento de la Pesca. México. Cámara de Diputados. 1-85p.

Diario de los Debates. (1984). Iniciativa de Ley Federal de Pesca México. México. Cámara de Diputados. 45-74p.

Diario de los Debates. (1985). Dictamen con Proyecto de Decreto Ley Federal de Pesca. México. Cámara de Diputados. 183-210p.

Diario de los Debates. (1986). Dictamen de Segunda Lectura Ley Federal de Pesca México. Cámara de Senadores. 3-27p. 
Diario de los Debates. (1992a). Iniciativa de Ley de Pesca. México. Cámara de Diputados. 23p.

Diario de los Debates. (1992b). Dictamen de Primera Lectura del proyecto de la Ley de Pesca. México. Cámara de Diputados. 18-32p.

Diario de los Debates. (1992c). Dictamen de Primera Lectura Ley de Pesca. México. Cámara de Senadores. 19p.

Diario de los Debates. (2005). Dictamen a la minuta con Proyecto de Decreto que expide la Ley General de Pesca y Acuaucltura Sustentables. México. Cámara de Senadores. 454-492p.

Diario de los Debates. (2006a). Dictamen con Proyecto de Secreto por el que se expide la Ley General de Pesca y Acuacultura Sustentables. México. Cámara de Diputados. 289-352p.

Diario de los Debates. (2006b). Dictamen con Proyecto de Decreto que expide la Ley General de Pesca y Acucultura Sustentables. Cámara de Diputados. 127-192p.

Dichmont, C., Deng, A., Punt, A. E., Ellis, N., Venables, W.N., Kompas, T., Ye, Y., Zhou, S. and Bishop, J. (2008). Beyond biological performance measures in management strategy evaluation: Bringing in economics and the effects of trawling on the benthos. Fisheries Research, 94(3), 238-250.

Dichmont, C., Pascoe, S., Kompas, T., Punt, A., \& Deng, R. (2010). On implementing maximum economic yield in commercial fisheries. Proceedings of the National Academy of Sciences of the United States of America, 107(1), 16-21.

DOF. (1917). Constitución Política de los Estados Unidos Mexicanos que reforma la de 05 de febrero de 1857. Secretaría de Gobernación. 297p.

DOF. (1924a). Acuerdo fijando las disposiciones reglamentarias a que se sujetará la explotación de productos de pesca en aguas marítimas territoriales del Pacífico. Secretaría de Agricultura y Fomento. 2p.

DOF. (1924b). Acuerdo fijando las disposiciones reglamentarias a que se sujetara la pesca y explotación de peces en aguas territoriales e islas adyacentes de la costa occidental de la Baja California. Secretaría de Agricultura y Fomento. 2p.

DOF. (1925). Ley de Pesca. Secretaría de Agricultura y Fomento. 8p.

DOF. (1932). Ley de Pesca. Secretaría de Agricultura y Fomento. 5p.

DOF. (1934). Acuerdo que reglamenta las operaciones de pesca utilizando barcos y redes "purse-seiners". Secretaría de Agricultura y Fomento. 2p.

DOF. (1937). Acuerdo que declara zona dedicada al uso exclusivo de los pescadores ribereños, para el buceo de abulón, el litoral occidental de la Baja California. Departamento Forestal de Caza y Pesca. 2p.

DOF. (1945a). Acuerdo que fija las tallas mínimas para diversas especies de pesca. Secretaría de Marina. 2p. 
DOF. (1945b). Decreto que reforma el párrafo V del artículo 27 Constitucional.

DOF. (1948a). Ley de Pesca, Secretaría de Marina. 7p.

DOF. (1948b). Acuerdo que reserva a las cooperativas de producción pesquera domiciliadas en Sonora y Baja California, la pesca de Cabrilla y Corvina en aguas del Golfo de California. Secretaría de Marina. 2p.

DOF. (1950). Ley de Pesca de los Estados Unidos Mexicanos, Secretaría de Marina. $16 \mathrm{p}$.

DOF. (1952). Decreto que reforma varios artículos de la Ley de Pesca en Vigor. Secretaría de Marina. 3p.

DOF. (1955a). Acuerdo que establece veda y fija zona de refugio para todas las especies en el Golfo de California. Dirección General de Pesca e Industrias Conexas. $1 \mathrm{p}$.

DOF. (1955b). Acuerdo que establece vedas y reglamenta la pesca de las especies conocidas con los nombres de totoaba y cabaicucho y tiburones establece normas para la pesca del tiburón en el Golfo de California. Secretaría de Marina. $2 \mathrm{p}$.

DOF. (1960). Decreto que reforma los párrafos cuerto, quiento, sexto y séptimo, fracción I del artículo 27 y los artículos 42 y 43 de la Constitución de los Estados Unidos Mexicanos. Secretaría de Gobernación. 2p.

DOF. (1967). Ley sobre la Zona Exclusiva de Pesca de la Nación. Presidencia de la República. 1p.

DOF. (1972). Ley Federal para el Fomento de la Pesca. Secretaría de Industria y Comercio. 12p.

DOF. (1973). Acuerdo que establece la veda de la tortuga marina para las especies del litoral del Golfo de México y mar Caribe, del 12 de julio al 31 de agosto de 1973 y del 1o. de mayo al 31 de agosto para los años siguientes. Secretaría de Industria y Comercio. 1p.

DOF. (1974). Acuerdo que determina como zona de reserva para el cultivo de camaron la Laguna de Terminos del Estado de Campeche. Secretaría de Industria y Comercio. 1p.

DOF. (1976a). Decreto por el que se adiciona el artículo 27 de la Constitución Política de los Estados Unidos Mexicanos, para establecer una zona económica exclusiva situada fuera del mar territorial.

DOF. (1976b). Ley Reglamentaria del Párrafo Octavo del Artículo 27 Constitucional, relativo a la zona económica exclusiva. Presidencia de la República. 2p.

DOF. (1977). Acuerdo que establece como zona de refugio y de veda, para la protección de la tortuga lora marina, Lepidochelys kempi, la comprendida en la Playa Rancho Nuevo, Municipio de Villa Aldama, Tamaulipas. 34-35. 
DOF. (1980). Norma Oficial Mexicana NOM-F-179-1980, Sardinas y pescados análogos enlatados. Secretaría de Patrimonio y Fomento Industrial. 6p.

DOF. (1986a). Ley Federal de Pesca. Secretaría de Pesca. 19p.

DOF. (1986b). Ley Federal del Mar. Presidencia de la República. 11p.

DOF. (1987a). Acuerdo que establece veda para la pesca del erizo rojo (Strongylocentrotus franciscanus), en la costa Oeste de Baja California. Secretaría de Pesca. $2 \mathrm{p}$.

DOF. (1987b). Decreto por el que se reforma el párrafo tercero del artículo 27; y se adiciona una fracción XXIX-G al artículo 73 de la Constitución Política de los Estados Unidos Mexicanos.

DOF. (1988). Acuerdo que establece veda permanente para las especies de caracol blanco (Strombus gigas), lanceta (Strombus costatus), tomburro (Xancus sp), chirita (Busycom sp) y chactel (Pleuroploca gigantea), en aguas litorales del Estado de Yucatán. Secretaría de Pesca. 2p.

DOF. (1990). Acuerdo que establece veda para las especies de caracol blanco (Strombus gigas), lanceta (Strombus costatus), tomburro (Xancus sp), chirita (Busycom sp) y chactel (Pleuroploca gigantea), en aguas litorales del Estado de Quintana Roo. Secretaría de Pesca. 2p.

DOF. (1991a). Acuerdo por el que se establece un esquema de regulación para la pesca deportivo recreativa. Secretaría de Pesca. 3p.

DOF. (1991b). Acuerdo por el que se establecen medidas para la identificación y control de pescadores cooperativistas y embarcaciones menores de diez toneladas brutas de registro autorizadas para la pesca comercial de camarón en sistemas lagunarios-estuarinos y bahías ubicados en los litorales del Océano Pacífico, Golfo de California y Golfo de México. Secretaría de Pesca.

DOF. (1992a). Decreto por el que se reforma el artículo 27 de la Constitución Política de los Estados Unidos Mexicanos. 3p.

DOF. (1992b). Ley de Pesca. Secretaría de Pesca. 7p.

DOF. (1992c). Norma Oficial Mexicana NOMEM-001-PESC-1992, por la que se establece la tasa máxima de captura incidental de delfines durante las operaciones de pesca de túnidos con redes de cerco en el Océano Pacífico Oriental. Secretaría de Pesca. $2 p$.

DOF. (1993a). Norma Oficial Mexicana NOMEM-002-PESC-1993, Por la que se establece el uso obligatorio de dispositivos excluidores de tortugas marinas en el Golfo de México y Mar Caribe mexicanos. Norma de Emergencia. Secretaría de Pesca. 1p.

DOF. (1993b). Norma Oficial Mexicana NOMEM-008-PESC-1993, Por la que se establece el uso obligatorio de dispositivos excluidores de tortugas marinas en las 
redes de arrastre camaroneras durante las operaciones de pesca comercial de camaron en el Golfo de Mexico y Mar Caribe. Secretaría de Pesca. 2p.

DOF. (1994a). Norma Oficial Mexicana NOMEM-01-PESC-1994, para regular el aprovechamiento de las especies que son objeto de la pesca deportiva- recreativa, en aguas de jurisdicción federal. Secretaría de Medio Ambiente, Recursos Naturales y Pesca. 3p.

DOF. (1994b). Norma Oficial Mexicana NOM-009-PESC-1993, que establece el procedimiento para determinar las epocas y zonas de veda para la captura de las diferentes especies de la flora y fauna; acuaticas en aguas de jurisdiccion federal de los Estados Unidos Mexicanos. Secretaría de Medio Ambiente, Recursos Naturales y Pesca. 2p.

DOF. (1995a). Norma Oficial Mexicana NOM-027-SSA1-1993. Bienes y Servicios. Productos de la pesca. Pescados frescos refrigerados y congelados. Especificaciones sanitarias. Secretaría de Salud. 6p.

DOF. (1995b). Norma Oficial Mexicana NOM-029-SSA1-1993. Bienes y servicios. Productos de la Pesca frescos y congelados. Especificaciones sanitarias. Secretaría de Salud. 9p.

DOF. (1995c). Norma Oficial Mexicana NOM-016-PESC-1994, Para regular la peca de lisa y liseta o lebrancha en aguas de jurisdicción federal del Golfo de México y Mar Caribe, así como del Océano Pacífico, incluyendo el Golfo de California. Secretaría de Medio Ambiente, Recursos Naturales y Pesca. 2p.

DOF. (1996a). Aviso por el que se establece la tasa maxima de captura incidental de delfines durante las operaciones de pesca de túnidos con redes de cerco en el Océano Pacífico Oriental. Secretaría de Medio Ambiente, Recursos Naturales y Pesca. 2p.

DOF. (1996b). Norma Oficial Mexicana NOM-EM-001-PESC-1996, Por la que se establece el uso obligatorio de dispositivos excluidores de tortugas marinas en las redes de arrastre durante las operaciones de pesca de camarón en el Océano Pacifico, incluyendo el Golfo de California. Secretaría de Medio Ambiente, Recursos Naturales y Pesca. 10p.

DOF. (1996c). Norma Oficial Mexicana NOM-EM-002-PESC-1996, Por la que se establece el uso obligatorio de dispositivos excluidores de tortugas marinas en las redes de arrastre durante las operaciones de pesca de camarón en el Oceáno Pacífico, incluyendo el Golfo de California. Secretaría de Medio Ambiente, Recursos Naturales y Pesca. 10p.

DOF. (1999). Aviso por el que se establece la tasa maxima de captura incidental de delfines durante las operaciones de pesca de túnidos con redes de cerco en el Océano Pacífico Oriental. Secretaría de Medio Ambiente, Recursos Naturales y Pesca. 2p. 
DOF. (2000). Acuerdo por el que se aprueba la Carta Nacional Pesquera. Secretaría de Medio Ambiente, Recursos Naturales y Pesca. 358p.

DOF. (2001a). Acuerdo por el que se dan a conocer los formatos de Permiso Individual de Pesca Deportivo-Recreativa y de Permiso de Pesca Deportivo-Recreativa para Embarcaciones. Secretaría de Agricultura, Ganadería, Desarrollo Rural, Pesca y Alimentación. 1p.

DOF. (2001b). Aviso por el que se da a conocer la autorización para utilizar las redes Magdalena I y Suripera, como equipos de pesca para la captura de camarón en el Sistema Lagunar Estuarino Bahía Magdalena-Almejas, ubicado en el Estado de Baja California Sur. Secretaría de Agricultura, Ganadería, Desarrollo Rural, Pesca y Alimentación. 3p.

DOF. (2001c). Decreto por el que se aprueba el diverso por el que se adicionan un segundo y tercer párrafos al artículo 1o., se reforma el artículo 2o., se deroga el párrafo primero del artículo 4o.; y se adicionan un sexto párrafo al artículo 18, y un último párrafo a la fracción tercera del artículo 115 de la Constitución Política de los Estados Unidos Mexicanos. Secretaría de Gobernación. 4p.

DOF. (2001d). Decreto por el que se reforma el artículo 13 de la Ley de Pesca. Secretaría de Agricultura, Ganadería, Desarrollo Rural, Pesca y Alimentación. 16p.

DOF. (2003). Aviso por el que se modifica el primer periodo de veda para la captura de lisa (Mugil cephalus), en las aguas de jurisdicción federal del Golfo de México correspondiente al litoral del Estado de Tamaulipas y en la zona Norte del Estado de Veracruz, en la zona delimitada desde el río Tuxpan y la laguna de Tampamachoco, hasta el río Pánuco, establecida en el artículo segundo fracción XIV del diverso publicado el 16 marzo de 1994 . Secretaría de Agricultura, Ganadería, Desarrollo Rural, Pesca y Alimentación. 2p.

DOF. (2004a). Acuerdo mediante el cual se aprueba la actualización de la Carta Nacional Pesquera y su anexo. Secretaría de Agricultura, Ganadería, Desarrollo Rural, Pesca y Alimentación. 439p.

DOF. (2004b). Decreto por el que se aprueba el diverso que adiciona una fracción XXIX-L al artículo 73 de la Constitución Política de los Estados Unidos Mexicanos. Secretaría de Gobernación. 1p.

DOF. (2005). Acuerdo por el que se establece veda de curvina golfina Cynoscion othonopterus en las aguas de Jurisdiccion Federal tanto marinas como estuarinas de la Reserva de la Biosfera Alto Golfo de California y Delta del Rio Colorado. Secretaría de Agricultura, Desarrollo Rural, Pesca y Alimentación. 1p.

DOF. (2006a). Acuerdo mediante el cual se publica la actualización de la Carta Nacional Pesquera. Secretaría de Agricultura, Ganadería, Desarrollo Rural, Pesca y Alimentación. 149p. 
DOF. (2006b). Norma Oficial Mexicana NOM-029-PESC-2006, Pesca responsable de tiburón y especies afines. Especificaciones para su aprovechamiento. Secretaría de Agricultura, Ganadería, Desarrollo Rural, Pesca y Alimentación. 41p. DOF. (2007a). Decreto por el que se expide la Ley General de Pesca y Acuacultura Sustentables. Secretaría de Agricultura, Ganadería, Desarrollo Rural, Pesca y Alimentación. 36p.

DOF. (2007b). Norma Oficial Mexicana NOM-063-PESC-2005 Pesca responsable de curvina golfina Cynoscion othonopterus en aguas de jurisdiccion federal del Alto Golfo de California y Delta del Rio Colorado Especificaciones para su aprovechamiento. Secretaría de Agricultura, Ganadería, Desarrollo Rural, Pesca y Alimentación. 6p.

DOF. (2007c). Norma Oficial Mexicana NOM-061-PESCA-2006, Especificaciones técnicas de los excluidores de tortugas marinas utilizados por la flota de arrastre camaronera en aguas de jurisdicción federal de los Estados Unidos Mexicanos. Secretaría de Agricultura, Ganadería, Desarrollo Rural, Pesca y Alimentación. 7p.

DOF. (2010). Acuerdo mediante el cual se da a conocar la actualización de la Carta Nacional Pesquera. Secretaría de Agricultura, Ganadería, Desarrollo Rural, Pesca y Alimentación. 319p.

DOF. (2011a). Decreto por el que se adiciona la denominación del Capítulo I del Título Primero y reforma diversos artículos de la Constitución Política de los Estados Unidos Mexicanos. Secretaría de Gobernación. 5p.

DOF. (2011b). Decreto por el que se adiciona un párrafo tercero al artículo 4o. recorriéndose en el orden los subsecuentes y un segundo párrafo a la fracción $X X$ del artículo 27 ambos de la Constitución Política de los Estados Unidos Mexicanos. Secretaría de Gobernación. 2p.

DOF. (2012a). Acuerdo por el que se da a conocer la Carta Nacional Pesquera. Secretaría de Agricultura, Ganadería, Desarrollo Rural, Pesca y Alimentación. 236p.

DOF. (2012b). Acuerdo por el que se establece una red de zonas de refugio pesquero en aguas marinas de jurisdiccion federal ubicadas en el area de Sian Kaan dentro de la Bahia Espiritu Santo en el Estado de Quintana Roo. Secretaría de Agricultura, Ganadería, Desarrollo Rural, Pesca y Alimentación.

DOF. (2012c). Acuerdo por el que se modifica el similar que da a conocer el establecimiento de periodos de veda para la pesca comercial de caracol rosado o blanco Strombus gigas en aguas de jurisdiccion federal correspondientes al litoral del Estado de Quintana Roo publicado el 13 de febrero de 2009. Secretaría de Agricultura, Ganadería, Desarrollo Rural, Pesca y Alimentación. 2p. 
DOF. (2012d). Decreto por el que se reforman los artículos 4, 8 y 29 de la Ley General de Pesca y Acuacultura Sustentables. Secretaría de Agricultura, Ganadería, Desarrollo Rural, Pesca y Alimentación. 1p.

DOF. (2012e). Decreto por el que se reforman y adicionan diversas disposiciones de la Ley General de Pesca y Acuacultura Sustentables. Secretaría de Agricultura, Ganadería, Desarrollo Rural, Pesca y Alimentación. 6p.

DOF. (2012f). Norma Oficial Mexicana NOM-242-SSA1-2009, Productos y servicios. Productos de la pesca frescos, refrigerados, congelados y procesados. Especificaciones sanitarias y métodos de prueba. Secretaría de Salud. 120p.

DOF. (2012g). Modificación de los numerales 3.1, 4.2, 6.13.3, 7.1.1.1.2, 7.1.5.2.3, 7.1.7, 7.1.10 y eliminación del Apéndice normativo A de la Norma Oficial Mexicana NOM-242-SSA1-2009, Productos y servicios. Productos de la pesca frescos, refrigerados, congelados y procesados. Especificaciones sanitarias y métodos de prueba. Secretaría de Salud. 3p.

DOF. (2013a). Acuerdo que establece los criterios para la asignación e instalación de un dispositivo transmisor en las embarcaciones menores de trescientas unidades de arqueo bruto y de más de siete metros de eslora. Secretaría de Agricultura, Ganadería, Desarrollo Rural, Pesca y Alimentación.

DOF. (2013b). Norma Oficial Mexicana NOM-058-SAG/PESC/SEMARNAT-2013, Para regular el cultivo de las ostras perleras: madreperla (Pinctada mazatlanica), concha nacar (Pteria sterna), madreperla del Atlántico (Pinctada imbricata) y la ostra perlera alada del Atlántico (Pteria colymbus) en aguas marinas de jurisdicción federal de los Estados Unidos Mexicanos. Secretaría de Agricultura, Ganadería, Desarrollo Rural, Pesca y Alimentación. 9p.

DOF. (2013c). Norma Oficial Mexicana NOM-002-SAG/PESC-2013, Para ordenar el aprovechamiento de las especies de camarón en aguas de jurisdicción fderal de los Estados Unidos Mexicanos. Secretaría de Agricultura, Ganadería, Desarrollo Rural, Pesca y Alimentación. 41p.

DOF. (2014a). Acuerdo por el que se da a conocer el Plan de Manejo Pesquero de Jaiba (Callinectes spp) de Sinaloa y Sonora. Secretaría de Agricultura, Ganadería, Desarrollo Rural, Pesca y Alimentación. 32p.

DOF. (2014b). Acuerdo por el que se da a conocer el Plan de Manejo Pesquero de pulpo (O. Maya y O. Vulgaris) del Golfo de México y Mar Caribe. Secretaría de Agricultura, Ganadería, Desarrollo Rural, Pesca y Alimentación. 39p.

DOF. (2014c). Acuerdo por el que se da a conocer el Plan de Manejo Pesquero para la langosta espinosa (Panulirus argus) de la Península de Yucatán. Secretaría de Agricultura, Ganadería, Desarrollo Rural, Pesca y Alimentación. 52p. 
DOF. (2014d). Norma Oficial Mexicana NOM-047-SAG/PESC-2014 Para la identificacion del origen de camarones cultivados de aguas marinas y de esteros marismas y bahias. Secretaría de Agricultura, Ganadería, Desarrollo Rural, Pesca y Alimentación. 5p.

DOF. (2014e). Norma Oficial Mexicana NOM-049-SAG/PESC-2014 Que determina el procedimiento para establecer zonas de refugio para los recursos pesqueros en aguas de jurisdiccion federal de los Estados Unidos Mexicanos. Secretaría de Agricultura, Ganadería, Desarrollo Rural, Pesca y Alimentación. 10p.

DOF. (2014f). Norma Oficial Mexicana NOM-074-SAG/PESC-2014, para regular el uso de sistemas de exclusión de fauna acuática (SEFA) en unidades de producción acuícola para el cultivo de camarón en el Estado de Sinaloa. Secretaría de Agricultura, Ganadería, Desarrollo Rural, Pesca y Alimentación. 9p.

DOF. (2014g). Acuerdo por el que se da a conocer el Plan de Manejo Pesquero de Lisa (Mugil cephalus) y Lebrancha (Mugil curema), en las costas de Tamaulipas y Veracruz. Secretaría de Agricultura, Ganadería, Desarrollo Rural, Pesca y Alimentación. 52p.

DOF. (2015a). Acuerdo por el que se establece una zona de refugio pesquero y medidas para reducir la posible interacción de la pesca con tortugas marinas en la Costa Occidental de Baja California Sur. Secretaría de Agricultura, Ganadería, Desarrollo Rural, Pesca y Alimentación. 10p.

DOF. (2015b). Acuerdo por el que se modifica el similar que da a conocer el establecimiento de periodos de veda para la pesca comercial de caracol rosado o blanco Strombus gigas en aguas de jurisdiccion federal correspondientes al litoral del Estado de Quintana Roo publicado el 13 de febrero de 2009. Secretaría de Agricultura, Ganadería, Desarrollo Rural, Pesca y Alimentación. 2p.

DOF. (2015c). Norma Oficial Mexicana NOM-014-SAG/PESC-2015 Especificaciones para regular el aprovechamiento de almeja generosa panopea generosa y panopea globosa en aguas de jurisdiccion federal del litoral del Oceano Pacífico y Golfo de California. Secretaría de Agricultura, Ganadería, Desarrollo Rural, Pesca y Alimentación. 5p.

DOF. (2015d). Norma Oficial Mexicana NOM-062-SAG/PESC-2014 Para la utilización del Sistema de Localización y Monitoreo Satelital de Embarcaciones Pesqueras. Secretaría de Agricultura, Ganadería, Desarrollo Rural, Pesca y Alimentación. 13p.

DOF. (2015e). Norma Oficial Mexicana NOM-064-SAG/PESC/SEMARNAT-2013 Sobre sistemas métodos y técnicas de captura prohibidos en la pesca en aguas de jurisdicción federal de los Estados Unidos Mexicanos. Secretaría de Agricultura, Ganadería, Desarrollo Rural, Pesca y Alimentación. 8p. 
DOF. (2015f). Norma Oficial Mexicana NOM-016-SAG/PESC-2014 Para regular la pesca de lisa y liseta en aguas de jurisdicción federal del Golfo de México y Mar Caribe, así como del Océano Pacífico, incluyendo el Golfo de California. Secretaría de Agricultura, Ganadería, Desarrollo Rural, Pesca y Alimentación. $8 \mathrm{p}$.

DOF. (2016). Acuerdo por el que establece la zona de refugio pesquero y nuevas medidas para reducir la posible interacción de la pesca con tortugas marinas en la costa occidental de Baja California Sur. Secretaría de Agricultura, Ganadería, Desarrollo Rural, Pesca y Alimentación. 16p.

DOF. (2017). Acuerdo por el que se establece una Zona de Refugio Pesquero Total Temporal en aguas marinas de jurisdicción federal de Puerto Libertad, Municipio de Pitiquito en el Estado de Sonora. Secretaría de Agricultura, Ganadería, Desarrollo Rural, Pesca y Alimentación. 3p.

DOF. (2018a). Acuerdo por el que se da a conocer el Formato de Guía de Pesca para amparar el transporte de productos pesqueros. Secretaría de Agricultura, Ganadería, Desarrollo Rural, Pesca y Alimentación. 2p.

DOF. (2018b). Acuerdo por el que se da a conocer el formato digital FF-CONAPESCA-01-042-S: Bitácora de la pesquería de tiburón flota de mediana altura en el Golfo de México y Mar Caribe. Secretaría de Agricultura, Ganadería, Desarrollo Rural, Pesca y Alimentación. 11p.

DOF. (2018c). Acuerdo por el que se da a conocer la actualización de la Carta Nacional Pesquera. Secretaría de Agricultura, Ganadería, Desarrollo Rural, Pesca y Alimentación. 268p.

DOF. (2018d). Acuerdo por el que se modifica el Aviso por el que se da a conocer el establecimiento de épocas y zonas de veda para la pesca de diferentes especies de la fauna acuática en aguas de jurisdicción federal de los Estados Unidos Mexicanos, publicado el 16 de marzo de 1994, para establecer la cuota de aprovechamiento de pepino de mar café (Isostichopus badionotus) en las aguas marinas de jurisdicción federal colindantes con el Estado de Yucatán en el año 2018. Secretaría de Agricultura, Ganadería, Desarrollo Rural, Pesca y Alimentación. 3p.

DOF. (2018e). Decreto por el que se reforman diversas disposiciones de la Ley General de Pesca y Acuacultura Sustentables. Secretaría de Agricultura, Ganadería, Desarrollo Rural, Pesca y Alimentación. 1p.

Epstein, G., Nenadovic, M., \& Boustany, A. (2014). Into the deep blue sea: Commons theory and international governance of Atlantic Bluefin Tuna. International Journal of the Commons, 8(2), 277-303. 
Espinosa-Romero, M. J., Chan, K., McDaniels, T., \& Dalmer, D. M. (2011). Structuring decision-making for ecosystem-based management. Marine Policy, 35(5), 575-583.

Espinosa-Romero, M. J., Rodriguez, L. F., Weaver, A. H., Villanueva-Aznar, C., \& Torre, J. (2014). The changing role of NGOs in Mexican small-scale fisheries: From environmental conservation to multi-scale governance. Marine Policy, 50, 290-299.

Espinosa-Romero, M. J., Torre, J., Zepeda, J. A., Solana, F., \& Fulton, S. (2017). Civil Society Contributions to the Implementation of the Small-Scale Fisheries Guidelines in Mexico. In S. Jentoft, R. Chuenpagdee, M. J. Barragán Paladines, \& N. Franz (Eds.), The Small-Scale Fisheries Guidelines: Global Implementation. MARE Publication Series. Springer, Cham. 423-449p.

Espinoza-Tenorio, A., Espejel, I., Wolff, M., \& Zepeda-Domínguez, J. A. (2011). Contextual factors influencing sustainable fisheries in Mexico. Marine Policy, 35(3), 343-350.

FAO. (1995a). Agreement to promote compliance with international conservation and management measures by fishing vessels on the high seas. 9.

FAO. (1995b). Code of Conduct for Responsible Fisheries. FAO. 49p.

FAO. (2009). Guidelines for the ecolabelling of fish and fishery products from marine capture fisheries. FAO. 108p.

FAO. (2015). Voluntary guidelines for securing sustainable small-scale fisheries in the context of food security and poverty eradication. Rome. 34p.

FAO. (2020). The State of World Fisheries and Aquaculture 2020. Sustainability in Action. Rome. 224p.

Fernández-Rivera, F. J., Rocha-Tejeda, L., Cuevas-Gomez, G. A., Gastelum-Nava, E., Sánchez-Cota, J. B., Goldman, N., \& Espinosa-Romero, M. J. (2018). Criterios internacionales de sustentabilidad pesquera: ¿Dónde estamos y qué necesitamos para mejorar? Ciencia Pesquera, 26(2), 65-68.

Fleischman, F. D., Ban, N. C., Evans, L. S., Epstein, G., Garcia-Lopez, G., \& Villamayor-Tomas, S. (2014). Governing large-scale social-ecological systems: Lessons from five cases. International Journal of the Commons, 8(2), 428-456.

Fletcher, W. J., Shaw, J., Metcalf, S. J., \& Gaughan, D. J. (2010). An Ecosystem Based Fisheries Management framework: the efficient, regional-level planning tool for management agencies. Marine Policy, 34(6), 1226-1238.

Garcia, S. M., Rice, J., \& Charles, A. (2014a). Governance of marine fisheries and biodiversity conservation: A history. In S. M. Garcia, J. Rice, \& A. Charles (Eds.), Governance of Marine Fisheries and Biodiversity Conservation. John Wiley \& Son, Ltd. 
Garcia, S. M., Rice, J., \& Charles, A. (2014b). Governance of marine fisheries and biodiversity conservation: Convergence or coevolution? Governance of Marine Fisheries and Biodiversity Conservation. John Wiley \& Son, Ltd. 18-36p.

Garcia, S. M., Rice, J., \& Charles, A. (2014c). Governance of Marine Fisheries and Biodiversity Conservation: Interaction and Coevolution: John Wiley \& Son, Ltd.

Garcia, S. M., Zerbi, A., Aliaume, C., Do Chi, T., \& Lasserre, G. (2003). The ecosystem approach to fisheries. Issues, terminology, principles, institutional foundations, implementation and outlook. Rome.

Gordon, H. S. (1954). The Economic Theory of a Common-Property Resource: The Fishery. Journal of Political Economy, 62(2), 124-142.

Grafton, R. Q. (2000). Governance of the commons: A role for the state? Land Economics, 76(4), 504-517.

Grbich, C. (2007). Qualitative data analysis: An introduction. London: SAGE Publications.

Gutierrez, N. L., Hilborn, R., \& Defeo, O. (2011). Leadership, social capital and incentives promote successful fisheries. Nature, 470(7334), 386-389.

Haas, B., Haward, M., McGee, J., \& Fleming, A. (2020). Explicit targets and cooperation: regional fisheries management organizations and the sustainable development goals. International Environmental Agreements-Politics Law and Economics, 13p.

Haber, S., Klein, H. S., Maurer, N., \& Middlebrook, K. J. (2008). Mexico Since 1980: Cambridge University Press.

Haller, T. (2019). The Different Meanings of Land in the Age of Neoliberalism: Theoretical Reflections on Commons and Resilience Grabbing from a Social Anthropological Perspective. Land, 8(7), 22104.

Hamon, K. G., Thébaud, O., Frusher, S., \& Little, R. L. (2009). A retrospective analysis of the effects of adopting individual transferable quotas in the Tasmanian red rock lobster, Jasus edwardsii, fishery. Aquat. Living Resour., 22(4), 549-558.

Hardin, G. (1968). The Tragedy of the Commons. Science, 162(3859): 1243-1248.

Héritier, A., \& Lehmkuhl, D. (2008). Introduction: The Shadow of Hierarchy and New Modes of Governance. Journal of Public Policy, 28(1), 1-17.

Hernández, A., \& Kempton, W. (2003). Changes in fisheries management in Mexico: Effects of increasing scientific input and public participation. Ocean $\mathcal{E}$ Coastal Management(46), 507-526.

Hernández-Fujigaki, G. (1987). La pesca a través de los informes presidenciales 18251986. Secretaría de Pesca. 30p.

Hilborn, R. M., \& Peterman, R. M. (1996). The development of scientific advice with incomplete information in the context of the precautionary approach Precau- 
tionary approach to fisheries. Part 2: scientific papers. FAO Fisheries Technical Paper. Rome: FAO. 210p.

Hill, M. (2009). The Public Policy Process: Pearson Education.

Hood, C., \& Margetts, H. (2007). The Tools of Government in the Digital Age. London: Red Globe Press.

Howlett, M. (2004). Beyond good and evil in policy implementation: Instruments mixes, implementation styles, and second generation. Theories of policy instruments choice. Policy and Society, 23(2), 1-17.

Huber, E., Lange, M., Leibfried, S., Levy, J. D., Nullmeier, F., \& Stephens, J. D. (2015). Introduction. Transformations of the State. Oxford University Press. 1-32p.

Hurley, M., \& Manel, C. (2015). Coordination, development and governance of Senegal small-scale fisheries. In S. Jentoft \& R. Chuenpagdee (Eds.), Interactive governance for small-scale fisheres: Global reflections. 49-670p.

INEGI. (2010). Datos Estadisticos de los Estados Unidos Mexicanos.

Jentoft, S. (1989). Fisheries co-management: Delegating government responsibility to fishermen's organizations. Marine Policy, 13(2), 137-154.

Jentoft, S. (2004). Public-private management in European fisheries. Samudra, 34:1416.

Jentoft, S. (2005a). Fisheries co-management as empowerment. Marine Policy, 29(1), $1-7$.

Jentoft, S. (2005b). Introduction Part III. In Kooiman J., Bavinck M., Jentoft S., \& Pullin R. (Eds.), Fish for Life: Interactive Governance for Fisheries. Amsterdam: Amsterdam University Press. 147-152p.

Jentoft, S., \& Chuenpagdee, R. (2015a). Assessing governability of small-scale fisheries. In S. Jentoft \& R. Chuenpagdee (Eds.), Interactive Governance for Small-Scale Fisheries. MARE Publication Series. Springer, Cham. 17-35p.

Jentoft, S., \& Chuenpagdee, R. (2015b). Enhancing the governability of small-scale fisheries through interactive governance. In S. Jentoft \& R. Chuenpagdee (Eds.), Interactive Governance for Small-Scale Fisheries. MARE Publication Series. Springer, Cham. 727-747p.

Jentoft, S., \& Chuenpagdee, R. (2015c). Interactive Governance for Small-Scale Fisheries. Global Reflections. MARE Publication Series. Springer, Cham. 858p.

Jentoft, S., Kooiman, J., \& Chuenpagdee, R. (2005). National Institutions. In Kooiman J., Bavinck M., Jentoft S., \& Pullin R. (Eds.), Fish for Life: Interactive Governance for Fisheries. Amsterdam: Amsterdam University Press. 173-196p.

Jentoft, S., \& McCay, B. (1995). User participation in fisheries management. Lessons drawn for international experiencies Marine Policy, 19(3), 227-246. 
Jentoft, S., McCay, B. J., \& Wilson, D. C. (1998). Social theory and fisheries co-management. Marine Policy, 22(4-5), 423-436.

Jessop, B. (1997). Capitalism and its future: remarks on regulation, government and governance. Review of International Political Economy, 4(3), 561-581.

Jessop, B. (2009). The state and power. In S. R. \& M. Haugaard (Eds.), The SAGE Handbook of Power. London: Sage Publications. 367-382p.

Johnson, D., Bavinck, M., \& Veitayaki, J. (2005). Fish Capture. In Kooiman J., Bavinck M., Jentoft S., \& Pullin R. (Eds.), Fish for Life: Interactive Governance for Fisheries. Amsterdam: Amsterdam University Press. 71-92p.

Knill, C., \& Tosun, J. (2012). Public Policy. A New Introduction. Palgrave Macmillan. $331 \mathrm{p}$.

Kooiman, J. (1993). Modern Governance: New Government-Society Interactions. SAGE Publishing. 288p.

Kooiman, J. (2003). Governing as Governance: Sage Publications Ltd.

Kooiman, J. (2005). Introduction Fish for Life. In Kooiman J., Bavinck M., Jentoft S., \& Pullin R. (Eds.), Fish for Life: Interactive Governance for Fisheries. Amsterdam: Amsterdam University Press. 241-244p.

Kooiman, J., \& Bavinck, M. (2005). The Governance Perspective. In Kooiman J., Bavinck M., Jentoft S., \& Pullin R. (Eds.), Fish for Life: Interactive Governance for Fisheries. Amsterdam: Amsterdam University Press. 11-24p.

Kooiman, J., \& Chuenpagdee, R. (2005). Governance and Governability. In Kooiman J., Bavinck M., Jentoft S., \& Pullin R. (Eds.), Fish for Life: Interactive Governance for Fisheries. Amsterdam: Amsterdam University Press. 325-350p.

Kooiman, J., Bavinck, M., Jentoft, S., \& Pullin, R. (2005). Fish for Life. Interactive Governance for Fisheries. Amsterdam University Press. 432p.

Kooiman, J., Bavinck, M., Chuenpagdee, R., Mahon, R., \& Pullin, R. (2008). Interactive governance and governability. Journal of Transdisciplinary Environmental Studies, 7(1), 1-11.

Kooiman, J. \& Jentoft, S. (2009). Meta-governance: Values, norms, and principles, and the making of hard choices. Public Administration 87(4), 818-836.

Landin, S. A. (2020). Social Economy as the Means to Help Achieve the Targets of Sustainable Development Goal 14. Sustainability, 12(11), 1-15p.

Leavitt, H. J. (1951). Some effects of Communication Patterns on Group Performance. Journal of Abnormal and Social Psychology (46), 38-50.

Lim, C. P., Matsuda, Y., \& Shigemi, Y. (1995). Co-managment in marine fisheries. The Japanese experience Coastal Management, 23(3), 195-221.

Lister, M. \& Marsh, D. 2006. Conclusion. In Hay, C., Lister, M., \& Marsh, D. (Eds), The State. Theories and Issues. Macmillan international, Red Globe Press. 310p. 
Lluch-Belda, D., Magallon, B. F. J., \& Schwartzlose, R. A. (1986). Large fluctuations in the sardine fishery in the Gulf of California: possible causes. California Cooperative Oceanic Fisheries Investigations Reports(27), 136-140.

Lluch-Cota, S. E., Lluch-Cota, D., Lluch-Belda, D., Nevarez-Martínez, M. O., Pares-Sierra, A., \& Hernández-Vázquez, S. (1999). Variability of sardine catch as related to enrichement, concentration, and retention processes in the central Gulf of California. California Cooperation Oceanic Fishery Investigation Report (40), 185-190.

López-Chavarria, J. L. (1997). Derecho pesquero. McGraw-HILL.

Mahon, R., Bavinck, M., \& Roy, R. N. (2005). Governance in Action. In Kooiman J., Bavinck M., Jentoft S., \& Pullin R. (Eds.), Fish for Life: Interactive Governance for Fisheries. Amsterdam: Amsterdam University Press. 351-374p.

Mansbridge, J. (2014). The role of the state in governing the commons. Environmental Science E Policy 36, 8-10.

Martínez-Martínez, S. T., \& González-Laxe, F. (2016). La construcción de la política pesquera en México. Una mirada desde el campo geográfico. Atlantic Review of Economics 2nd Volume 27.

Matthews, B., \& Ross, L. (2010). Research methods. A practical guide for the social sciences. University of Birmingham. Pearson Education Limited. 474p.

Monnereau, I., \& McConney, P. (2015). Governability of small-scale lobster fisheries in the wider Caribbean. In S. Jentoft \& R. Chuenpagdee (Eds.), Interactive governance for small-scale fisheries. Global reflections: Springer International Publishing. 223-241p.

Moran, M., \& Wright, M. (1991). The market and the state. Studies of interdependence: London: MacMillan.

MORENA. (2018). Proyecto de Nación 2018-2024. México. 415p.

MSC. (2019). Working together for thriving oceans. The MSC Annual Report 20182019. 25p.

Nakamura, J., \& Hazin, F. (2020). Assessing the Brazilian federal fisheries law and policy in light of the Voluntary Guidelines for Securing Sustainable Smallscale fisheries. Marine Policy(113), 103798.

Natorski, M. (2013). Reforms in the judiciary of Ukraine: domestic practices and the EU's policy instruments. East European Politics, 29(3), 257-272.

Nava-Escudero, C. (2016). Artículo 27. El artículo 27 en materia de aguas. Exégesis constitucional. Introducción histórica, comentarios y trayectoria del artículado Derechos del pueblo mexicano: Mexico a través de sus constituciones. Edición conmemorativa centenario de la Constitución de 1917. Ciudad de México: Miguel Ángel Porrua. 
O'Leary, Z. (2014). The essential guide to doing your research project (2nd Edition ed.): SAGE Publications, Inc.

OECD. (2006). Agricultural and Fisheries Policies in Mexico. Recent achievements, continuing the reform agenda. 332p.

Osborne, S. P. (2010). Introduction.The (New) Public Governance: a suitable case for treatment? In S. P. Osborne (Ed.), The New Public Governance? Emerging perspectives on theory and practice of public governance. London and New York: Routledge. Taylor \& Francis Group. 1-16p.

Ostrom, E. (1990). Governing the commons. The evolution of institutions for collective action.: Cambridge University Press.

Ostrom, E. (2009). A General Framework for Analyzing Sustainability of Social-Ecological Systems. Science, 325(5939), 419-422.

Ostrom, E. (2010). Beyond Markets and States: Polycentric Governance of Complex Economic Systems. American Economic Review, 100(3), 641-672.

Ostrom, E., Gardner, R., \& Walker, J. (2006). Rules, games, and common-pool resources The University of Michigan Press.

Parise, A. (2017). Ownership Paradigms in American Civil Law Jurisdictions. Manifestations of the Shifts in the Legislation of Louisiana, Chile and Argentina (16th-20th Centuries). Brill I Nijhoff.

Pascual-Fernández, J. J., Frangoudes, K., \& Williams, S. (2005). Local Institutions. Interactive Governance for Fisheries. In Kooiman J., Bavinck M., Jentoft S., \& Pullin R. (Eds.), Fish for Life: Interactive Governance for Fisheries. Amsterdam: Amsterdam University Press. 153-172p.

Pascual-Fernández, J. J., Jentoft, S., Kooiman, J., \& Trinidad, A. (2005). Institutional Linkages. Interactive Governance for Fisheries. In Kooiman J., Bavinck M., Jentoft S., \& Pullin R. (Eds.), Fish for Life: Interactive Governance for Fisheries. Amsterdam: Amsterdam University Press. 217-238p.

Patrón-Sánchez, F. (2010). Legislative politics in Mexico: Changing Lanes from Authoritarianism to Democracy. LAP, Lambert Academic Publishing. 246p.

Pauly, D. (1995). Anecdotes and the shifting baseline syndrome of fisheries. Trends in Ecology \& Evolution, 10(10), 430.

Pérez-Nieto Castro, L. (2012). Introducción al estudio del derecho. Oxford. 7a edición.

Peters, B. G. (2010). Governing in the shadows. SFB Governance Lecture Series. No. 3. DFG Research Center (SFB) 700, Berlin. March 2010.

Peters, B. G., \& Pierce, G. J. (2004). Multi-level Governance. A Faustian Bargain Bache, I. Flinders, M.: Oxford.

Pictou, S. (2018). The origins and politics, campaigns and demands by the international fisher peoples' movement: an Indigenous perspective. Third World Quarterly, 39(7), 1411-1420. 
Pierre, J. (2000). Introduction: Understanding governance. In J. Pierre (Ed.), Debating governance: authority, steering, and governance (pp. 1-10). New York: Oxford University Press.

Pierre, J., \& Peters, B. G. (2020). Governance, Politics and the State (2nd Edition ed.). London: Red Global Press.

Pierson. (2004). The Modern State (2nd. Edition ed.). New York: Routledge. Taylor \& Francis Group.

Pinkerton, E. (1989). Co-operative Management of Local Fisheries. University of British Columbia Press.

Pinkerton, E., \& Davis, R. (2015). Neoliberalism and the politics of enclosure un North American small-scale fisheries. Marine Policy 61, 303-312.

Pikitch, E. K. Santora, C., Babcock, E.A., Bakun, A., Bonfil, R., Conover, D.O., Dayton, P., Doukakis, P., Fluharty, D., Heneman, B., Heneman, B., Houde, E.D., Link, J., Livingston, P. A., Mangel, M., McAllister, M.K., Pope, J., \& Sainsbury, K.J. Policy Forum Ecology, 346-347.

Pomeroy, R. S., \& Berkes, F. (1997). Two to tango: The role of government in fisheries co-management. Marine Policy, 21(5), 465-480.

Poteete, A., Janssen, M., \& Ostrom, E. (2010). Collective action, the Commons, and Multiple Methods in Practice. Princeton University Press. 565p.

Punt, A. E., Poljak, D., Dalton, M. G., Foy, R. J. 2014. Evaluating the impact of ocean acidification on fishery yields and profits: The example of red king crab in Bristol Bay. Ecological Modelling (285): 39-53.

Rabasa, E. O. (2007). Comentarios al artículo 27 Constitucional en materia de aguas La Constitución y el Medio Ambiente. México: Instituto de Investigaciones Jurídicas de la UNAM. 227-263p.

Randall, A. (1981). Resource economics: an economic approach to natural resources and environmental policy. Grid Publishing Inc.

Raymond Duncan, W. (1963). The Mexican Constitution of 1917: Its Political and Social Background.

Reckwitz, A. (2002). Toward a theroy of social practices: a development in cultural theorizing. European Journal of Social Theory, 5(2), 243-263.

Rhodes, R. A. W. (2012). Waves of governance. In D. Levi-Faur (Ed.), The Oxford Handbook of Governance: Oxford University Press.

Richards, D., \& Smith, M. (2002). Governance and public policy in the United Kingdom. Oxford: Oxford University Press.

Risse, T. (2015). Limited Statehood: A Critical Perspective. In S. Leibfried, E. Huber, M. Lange, J. D. Levy, F. Nullmeier, \& J. D. Stephens (Eds.), The Oxford Handbook of Transformations of the State. Oxford University Press. 152-168p. 
Said, A., Pascual-Fernández, J., Iglésias Amorim, V. I., Autzen, M. H., Hegland, T. J., Pita, C., Ferretti, J., \& Penca, J. (2020). Small-scale fisheries access to fishing opportunities in the European Union: Is the Common Fisheries Policy the right step to SDG14b? Marine Policy, 118, 1044009.

Salas, S., Chuenpagdee, R., Seijo, J. C., \& Charles, A. (2007). Challenges in the assessment and management of small-scale fisheries in Latin America and the Caribbean. Fisheries Research, 87(1), 5-16.

Salas, S., Fraga, J., Euan, J., \& Chuenpagdee, R. (2015). Common ground, uncommon vision: The importance of cooperation for small-scale fisheries governance. In S. Jentoft \& R. Chuenpagdee (Eds.), Interactive Governance for Small-Scale Fisheries: Springer International Publishing. 477-493p.

Sánchez, C., \& Roelants, B. (2011). Capital and the Debt Trap: Learning from Cooperatives in the Global Crisis. Palgrave Macmillan UK. 284p.

Scharpf, F. (1994). Games real actors could play: positive and negative coordination in embedded negotiations. Journal of Theoretical Politics, 6(1), 27-53.

Scharpf, F. (1997). Games Real Actors Play: Actor-Centered Institutionalism in Policy Research. Boulder/CO/Oxford: Westview Press. 335p.

Schatzki, T. (2002). The site of the social: A philosophical account of the constitution of social life and change: Pennsylvania State University Press.

Schmid, A. A. (1987). Property, power and public choice. An inquiry into law and economics (2nd ed.): Praeger Publishers. 332p.

Scholtens, J. (2016). The elusive quest for access and collective action: North Sri Lankan fishers' thwarted struggles against a foreign trawler fleet. International Journal of the Commons, 10(2), 929-952.

Scholtens, J., \& Bavinck, M. (2018). Transforming conflicts from the bottom-up? Reflections on civil society efforts to empower marginalized fishers in postwar Sri Lanka. Ecology and Society, 23(3), 13.

Schuhbauer, A., Chuenpagdee, R., Cheung, W. W. L., Greer, K., \& Sumaila, U. R. (2017). How subsidies affect the economic viability of small-scale fisheries. Marine Policy, 82, 114-121.

Scott, A. (1955). The Fishery: The Objectives of Sole Ownership. Journal of Political Economy, 63(2), 116-124.

Secretaría de Pesca. (1976). Plan Nacional de Desarrollo Pesquero 1977-1982. 15p.

Secretaría de Pesca. (1994). El sector pesquero en México 1988-1994. 36p.

Seijo, J. C. (1993). Individual transferable grounds in a community managed artisanal fishery. Marine Resource Economics, 8:78-81.

Seijo, J. C. (2005). A simple framework for proactive management to mitigate unsustainability of fisheries: Estimating risks of exceeding limit reference points of 
bio-ecologic, economic, and social indicators. In J. Swan \& D. Gréboval (Eds.), Overcoming factors of unsustainability and overexploitation in fisheries: selected papers on issues and approaches. International Workshop on the Implementation of the International Fisheries Instruments and Factors of Unsustainability and Overexploitation in Fisheries. Siem Reap, Cambodia, 13-16 September 2004. FAO Fisheries Report . No. 782. Rome, FAO. 235-248p.

Seijo, J. C., Charles, A., Chuenpagdee, R., \& Salas, S. (2010). Toward the sustainability for coastal fisheries of Latin America and the Caribbean: effective governance and healthy ecosystems. In S. Salas, R. Chuenpagdee, A. Charles, \& J. C. Seijo (Eds.), Coastal fisheries of Latin America and hte Caribbean. FAO Fisheries Technical Paper. Rome, FAO. 399-417p.

Seijo, J. C., Defeo, O., \& Salas, S. (1998). Fisheries bioeconomics. Theory, modelling and management. FAO Fisheries Technical Paper. No. 368. Rome, FAO 1998. 108p.

Seijo, J.C., \& Villanueva, R. (2018). Bioeconomics of ocean acidification. In: Seijo, J.C. and J.G. Sutinen (eds.). Advances in Fisheries Bioeconomics: Theory and Policy. Routledge, Taylor and Francis. 58-76p.

Seijo, J.C., R. Villanueva, \& A. Charles. (2016). Bioeconomics of ocean acidification effects on fisheries targeting calcifier species: A decision theory approach. Fisheries Research, 176, 1-14.

Sen, S., \& Nielsen, J. R. (1996). Fisheries co-management: A comparative analysis. Marine Policy, 20(5), 405-418.

Sharma, C. (2011). Securing economic, social, and cultural rights of small-scale and artisanal fishworkers and fishing communities. MAST 2(10), 41-61.

Shaw, M. E. (1954). Group strucutre and the behavior of individuals in small groups. Journal of Psycology (38):139-149.

Shove, E. (2009). Everyday practice and the production and consumption of time. In E. Shove, F. Trentmann, \& R. Wilk (Eds.), Time, consumption and everyday life: Practice, materiality, and culture. Oxford: Berg. 17-35p.

Shove, E., Pantzar, M., \& Watson, M. (2012). The dynamics of social practices. Everyday life and how it changes: SAGE Publications. 206p.

Simon, H. A. (1957). Models of Man: Social and Rational. New York: Wiley.

Song, A. M., \& Soliman, A. (2019). Situating human rights in the context of fishing rights - Contributions and contradictions. Marine Policy (103), 19-26.

Sosa-Cordero, E., Liceaga-Correa, M. L. A., \& Seijo, J. C. (2008). The Punta Allen lobster fishery: Current status and recent trends. In R. Townsend, R. Shotton, \& H. Uchida (Eds.), Case studies in fisheries self-governance. FAO Fisheries Technical Paper No. 504. Rome, FAO. 2008. 451p. 
Sowman, M. (2015). Governability challenges facing small-scale fishers living adjacent to marine protected areas in South Africa. In S. Jentoft \& R. Chuenpagdee (Eds.), Interactive Governance for Small-Scale Fisheries Springer International Publishing. 359-377p.

Sowman, M., Sunde, J., Raemaekers, S., \& Schultz, O. (2014). Fishing for equality: Policy for poverty alleviation for South Africa's small-scale fisheries. Marine Policy (46), 31-42.

Sowman, M., \& Wynberg, R. (2014). Governance, equity and sustainability in Sub-saharan Africa: An introduction to the discourse. In M. Sowman \& R. Wynberg (Eds.), Governance for justice and environmetnal sustainability. New York: Routledge. 368p.

Steel, B. S. \& E. Weber. (2001). Ecosystem management: A framework for comprehensive ecosystem management. Environmental management 26(1), 1-12.

Suárez de Vivero, J. L., Rodriguez-Mateos, J. C., \& Florido del Corral, D. (2005). International Institutions. In Kooiman J., Bavinck M., Jentoft S., \& Pullin R. (Eds.), Fish for Life: Interactive Governance for Fisheries. Amsterdam: Amsterdam University Press. 197-216p.

Sumaila, U. R., Ebrahim, N., Schuhbauer, A., Skerritt, D., Li, Y., Kim, H. S., ... Pauly, D. (2019). Updated estimates and analysis of global fisheries subsidies. Marine Policy, 109, 103695.

Sumaila, U. R., \& Schuhbauer, A. (2018). A simple application of bioeconomics to fisheries subsidies. In J. C. Seijo \& J. G. Sutinen (Eds.), Advances in fisheries bioeconomics: Theory and policy. Routledge, Taylor and Francis. 99-113p.

Sumaila, U. R., Skerritt, D., Schuhbauer, A., Ebrahim, N., Li, Y., Kim, H. S., .. Pauly, D. (2019). A global dataset on subsidies to the fisheries sector. Data in Brief, 27,7 .

Symes, D. (1997). Fisheries management: in search of good governance. Fisheries Research, 32(2), 107-114.

Thorpe, A., \& Aguilar, A. (2010). Los modelos económicos de utilización de recursos naturales en Latinoamérica. Ensayos de Economía, 36, 23p.

Towsend, R., \& Shotton, R. (2008). Fisheries self-governance: new directions in fisheries management. In R. Townsend, R. Shotton, \& H. Uchida (Eds.), Case studies in fisheries self-governance. FAO Fisheries Technical Paper No. 504. Rome, FAO. 2008. 451p.

UN. (1982). United Nations Convention on the Law of the Sea. United Nations. 202p. UN. (1995). Agreement for the implementation of the United Nations Convention on the Law of the Sea of 10 December 1982 relating to the conservation and management of straddling fish stocks and highly migratory fish stocks. United Nations. 304p. 
UNAM. (2002). Enciclopedia Jurídica Mexicana. Instituto de Investigaciones Jurídicas de la Universidad Nacional Autónoma de México. Editorial Porrúa. 521p. Vázquez-León, C. (1998). Administración pesquera y desarrollo sustentable en México. Comercio Exterior(48), 995-1001.

Viet-Thang, H. (2018). Rethinking Fisheries Governance. The Role of States and Meta-Governance. Palgrave Macmillan published by Springer Nature. 221p.

Villanueva, R., Lara, O. H., Seijo, J. C., Palomo, L., \& Duarte, J. A. (2019). Distributional performance of two different rights-based managed small-scale lobster fisheries: Individual and collective territorial use rights regimes. Ocean $\mathcal{E}$ Coastal Management, 178, 104804.

Villanueva-Poot, R., Seijo, J. C., Headley, M., Arce, A. M., \& Sosa-Cordero, E. (2017). Distributional performance of a territorial use rights and co-managed smallscale fishery. Fisheries Research (194), 135-145.

Wamukota, A. W., Cinner, J. E., \& McClanahan, T. R. (2012). Co-management of coral reef fisheries: A critical evaluation of the literature. Marine Policy, 36(2), 481-488.

Weber, M. (1978). Economy and Society: An outline of interperatative sociology. Ed by Roth W. and Wittich C. University of California Press. Berkely, Los, Angeles, California. 640p.

Wever, L., Glaser, M., Gorris, P., \& Ferrol-Schulte, D. (2012). Decentralization and participation in integrated coastal management: Policy lessons from Brazil and Indonesia. Ocean \& Coastal Management, 66, 63-72.

Whitehead, M. (2003). In the shadow of hierarchy: Meta-governance, policy reform and urban regeneration in the West Midlands. Area, 35(1), 6-14.

Willman, R. S. \& Garcia, S. (1985). A bioeconomic model of sequential artisanal fisheries for tropical shrimp (with a case study of Surinam shrimp fisheries). FAO Fish. Tech. Pap 270, 1-49.

Wilson, D. C., Ahmed, M., Siar, S. V., \& Kanagaratnam, U. (2006). Cross-scale linkages and adaptive management: Fisheries co-management in Asia. Marine Policy, 30(5), 523-533.

Wilson, D. C., Nielsen, J. R., \& Degnbol, P. (2004). The fisheries co-management experience: Accomplishments, challenges, and prospects. Policy Sciences, 37(1), 95-99.

Yin, R. (2009). Case Study Research: Design and Methods. Fourth Edition,Vol. 5.

Young, O. R., Webster, D. G., Cox, M. E., Raakjær, J., Blaxekjær, L. Ø., Einarsson, N., ... Wilson, R. S. (2018). Moving beyond panaceas in fisheries governance. Proceedings of the National Academy of Sciences 115 (36), 9065-9073. 
Zepeda-Domínguez, J. A., Vergara-Rodarte, M. A., Gomez, A., Espinosa-Romero, M. J., Espinoza-Tenorio, A., \& Lopez-Lopez, D. A. (2019). Beneficio de las ecoetiquetas en pesquerías en vías de desarrollo. In G. Ponce-Díaz \& F. GonzálezLaxe (Eds.), Gobernanza pesquera: México y España. Instituto Politécnico Nacional. 163-180p.

Zepeda-Domínguez, J. A., Zetina-Rejón, M. J., Arreguín-Sánchez, F., \& DelMonte-Luna, P. (2019). Sistemas socioecológicos pesqueros del noroeste de México. In G. Ponce-Díaz \& F. González-Laxe (Eds.), Gobernanza pesquera: México y España. Instituto Politécnico Nacional. 69-92p.

Zetina-Rejón, M. J., Zepeda-Domínguez, J. A., Rodríguez-Fuentes, M., \& Fumero-Andreu, C. M. (2020). Stakeholder diversity correlates with governance network performance in two artisanal fisheries in Northwest Mexico. Ocean $\mathcal{E}$ Coastal Management, 196, 105313.

Zürn, M. (2018). Contested Global Governance. Global Policy, 9(1), 138-145. 


\section{Summary in English}

This research focuses on the shadow of hierarchy in marine fisheries governance. Particularly, it investigates how the coastal state implements its meta-governance power to indirectly influence fisheries governance in non-traditional hierarchical forms. By using the case of Mexican fisheries and applying three theoretical approaches (i.e., interactive governance, self-governance, institutional impact), it explains the exercise of three meta-governance functions: i) the creation of coexisting governance modes; ii) the steering and shaping of the patterns of fishing as a social practice; and iii) the creation of institutional settings to ensure fisheries sustainability.

This research is developed in six chapters. Chapter 1 introduces the topic, research questions, analytical approach, the case study, and methods, as well as the internal validity, the boundaries, and outline of this research.

Chapter 2 presents the literature review with a focus on the presence and meta-governance power of the state in marine fisheries governance. It uses the interactive governance theory to identify: i) the governing functions of the state in three governance modes (i.e., hierarchical, co-governance, self-governance) and those functions that reflect the shadow of hierarchy (i.e., indirect influence of the state), ii) the determinants that influence the emergence of governance modes, and iii) the corresponding performance. The analysis of chapter 2 shows the presence of the state and its superior hierarchy in the governance system, its adaptation and indirect influence in alternative governance modes (i.e., co-governance and self-governance), as well as the suitability of these modes for different types of fish resources.

Chapter 3 investigates the shadow of hierarchy by looking at how the state uses the law to create coexisting governance modes. It applies the interactive governance theory to frame the interactions and distribution of governing functions between the state and non-state actors in different modes (i.e., hierarchical, co-governance, self-governance) and orders (i.e., day to day operations, institutional making, objectives definition). It analyses the legal framework of Mexican fisheries for the period 1917-2019, which includes the Mexican Constitution, maritime laws, and fisheries laws with their corresponding amendments. The results of this analysis show how the state employs different mechanisms to involve private and social actors in the governing of fisheries, mainly at the level of operations, and for the production of knowledge and science. It also shows that the state retains the power of decentralizing and recentralizing functions as well as of choosing which actors to partner or not to partner with for the governing of fisheries. 
Chapter 4 investigates the shadow of hierarchy by looking at how the state uses its regulatory power to steer and define the patterns of fishing practices as a mean to indirectly influence fisheries governance. It uses social practices theory to frame the analysis of how the state defines the symbolic and material dimensions of fishing to establish the general parameters of actions, rather than focusing on specific actions or actors. In addition to the legal framework, this chapter includes the analysis of the legislative process for the enactment of the fisheries laws (i.e., bills, resolutions, legislators' discourses) and fisheries regulations for three political periods in Mexico: i) authoritarian state intervention (1917-1985), ii) neoliberal minimal state (1986-2006), and iii) democratic state delegation (2007-2019). The results of this analysis show that in Mexico, an increasing regulation of the patterns of fishing practices occurs in parallel with an increasing tendency for more indirect and distributed forms of governing policy resources, during the three political periods. It also shows that the state retains this power to define the cognitive meaning, materials, and competences for the practice of fishing to influence actors, including those practising non-hierarchical forms of governance. Finally, it shows the autonomy of the state to adopt different paradigms, including those promoted by international actors, to improve the governing of fisheries.

Chapter 5 addresses the shadow of hierarchy by looking at how the state defines institutional settings for different resource types to ensure sustainability. It uses the situation, structure, performance (SSP) approach of the institutional impact theory to analyse institutions applied to different resource types and the corresponding performance. This approach frames the analysis of Mexican fisheries regulations and assessments conducted by the state and third-parties for Fishery Improvement Projects (FIPs) and certified fisheries by the Marine Stewardship Council (MSC). Results show that institutions, established by the state, for sedentary species are exclusive and feasible to enforce. However, institutions developed for mobile species provide low exclusivity to users and involve high enforcement costs, which represent a greater challenge for achieving sustainability. The analysis of performance shows that in 2000,74\% of the species were reported to be at Maximum Sustainable Yield (MSY), 3\% with potential for development, and 23\% overexploited. By 2018, 81\% of the species were reported at MSY and 19\% overexploited. In addition, from the 31 studied species, ten species were reported as overexploited during the period 20002018, and six species continue in this status. The analysis of third-party assessments for FIPs and MSC certifications shows that non-state actors participate in defining objectives for specific fisheries, rulemaking, and day to day operations (i.e., monitoring, enforcement, assessments). In addition, they include broader dimensions 
of fisheries sustainability (e.g., impact to the ecosystem) beyond the MSY reference point. However, these efforts take place in the shadow of hierarchy, under the state institutional schemes.

Chapter 6 presents the synthesis of findings from the literature review and the three empirical chapters as well as the complementarity of the theoretical approaches used in this research. In addition, it includes further areas of investigation, the academic contribution, as well as the policy relevance and implications of this research.

In summary, this research illustrates how the coastal state expands and retracts its shadow in fisheries governance, according to its priorities and capacities. Although the state is immersed into diverse governance modes, the state remains present and preserves its capacity to indirectly influence governance, in order to compensate for losing day-to-day command and control. Specifically, by shaping actors' boundaries within the governance system, the cognitive practice of fishing, and the institutional setting for different resource types to ensure fisheries sustainability. State intervention is thus not limited by alternative governance modes; but rather performed through non-traditional hierarchical forms, in the shadow of hierarchy. 


\section{Resumen en Español}

La presente investigación se enfoca a la sombra de la jerarquía en la gobernanza de las pesquerías marinas. Particularmente, investiga como el estado costero implementa su poder de meta-gobernanza, en formas no-tradicionales pero jerárquicas, para influir indirectamente en la gobernanza de las pesquerías. Usando el caso de México y aplicando tres enfoques teóricos (i.e., gobernanza interactiva, practicas sociales, e impacto institucional), explica la implementación de tres funciones de meta-gobernanza del estado: i) creación de la coexistencia de modos de gobernanza, ii) dirección y definición de los patrones de la pesca como una práctica social, iii) establecimiento de marcos institucionales para asegurar la sostenibilidad de las pesquerías.

Esta investigación está desarrollada en seis capítulos. El Capítulo 1 introduce el tema, las preguntas de investigación, el enfoque teórico, el estudio de caso, los métodos, así como la validez interna, los límites, y contenido de la investigación.

El Capítulo 2 presenta la revisión de la literatura enfocándose a la presencia y poder de meta-gobernanza del estado en las pesquerías marinas. Este capítulo aplica la teoría de la gobernanza interactiva para identificar: i) las funciones del estado en tres modos de gobernanza (i.e., jerárquico, co-gobernanza, auto-gobernanza) e identificar aquellas funciones que reflejan la sombra de la jerarquía, ii) los determinantes que influencian el surgimiento de los tres modos de gobernanza, y iii) el desempeño de los modos de gobernanza. El análisis del Capítulo 2 muestra la presencia y jerarquía superior del estado en la gobernanza, su influencia indirecta y adaptación en modos alternativos de gobernanza (i.e., auto-organización y co-gobernanza), así como la pertinencia de los modos de gobernanza para diferentes tipos de recursos pesqueros.

El Capítulo 3 investiga la sombra de la jerarquía a través del uso de la ley para crear un sistema de coexistencia de modos de gobernanza. Este capítulo aplica el enfoque teórico de la gobernanza interactiva para analizar las interacciones y distribución de funciones del estado con los actores no estatales en diferentes modos de gobernanza (i.e., jerárquico, co-gobernanza, auto-gobernanza) y a diferentes niveles (i.e., operaciones, establecimiento de instituciones, y definición de objetivos). El Capítulo 3 analiza el marco legal de la gobernanza de las pesquerías mexicanas para el periodo 1917-2019, el cual incluye la Constitución Mexicana, las leyes marítimas, y las leyes de pesca con sus correspondientes reformas. Los resultados del análisis presentan 
cómo el estado aplica diferentes mecanismos para integrar a los actores privados y sociales en el gobierno de las pesquerías, principalmente a nivel operativo, particularmente para la producción de conocimiento y ciencia. Este capítulo también demuestra como el estado retiene el poder de descentralizar y centralizar las funciones de gobierno, así como de elegir qué actores serán sus colaboradores y qué actores no lo serán, para gobernar las pesquerías.

El Capítulo 4 investiga la sombra de la jerarquía a través del poder del estado para dirigir y definir los patrones de la pesca para influir indirectamente la gobernanza de las pesquerías. Este capítulo aplica el marco teórico de las prácticas sociales para analizar las dimensiones simbólicas y materiales que el estado usa para establecer los parámetros generales de acción, en lugar de enfocarse a gobernar acciones o actores específicos. El Capítulo 4 analiza, además del marco legal, el proceso legislativo para la promulgación de las leyes de pesca (i.e., iniciativas, resoluciones, discursos de los legisladores) y las regulaciones pesqueras para tres periodos políticos en México: i) intervención autoritaria del estado (1917-1985), ii) estado minimalista neoliberal (1986-2005), y iii) delegación democrática del estado (2007-2019). Los resultados del análisis demuestran un incremento de las regulaciones para establecer los patrones de las prácticas de pesca, el cual, en el caso de México, ocurre paralelamente con un incremento de recursos de política indirectos y distribuidos por el estado entre los actores no-estatales, durante los tres periodos analizados. Asimismo, el estado retiene el poder de definir el significado cognitivo, los materiales y las competencias para la práctica de la pesca para influir en los diferentes actores, incluso a aquellos que practican formas de gobernanza no jerárquicas. Finalmente, el estado mantiene su autonomía para adoptar diferentes paradigmas, incluyendo aquellos promovidos por actores internacionales para mejorar la gobernanza de las pesquerías.

El Capítulo 5 explora la sombra de la jerarquía a través del poder del estado para definir el marco institucional para garantizar la sostenibilidad pesquera. Este Capítulo aplica la teoría del impacto institucional, particularmente el enfoque de situación, estructura y desempeño, para el análisis de instituciones aplicables a diferentes tipos de recursos pesqueros y su desempeño correspondiente. Este capítulo analiza las regulaciones pesqueras y las evaluaciones realizadas por el estado y por terceras partes para los proyectos de mejora pesquera (Fishery Improvement Projects-FIPs en inglés) y las pesquerías certificadas por el Marine Stewardship Council (MSC). Los resultados del análisis demuestran que las instituciones formales desarrolladas por el estado para especies sedentarias ofrecen exclusividad a los usuarios y son más factibles de vigilar. Sin embargo, las instituciones establecidas para especies móvi- 
les proveen menor exclusividad a los usuarios y altos costos de vigilancia, lo cual representa un mayor reto para alcanzar la sostenibilidad pesquera. El análisis de desempeño demuestra que, en el año 2000, 74\% de las especies estudiadas se reportaron en el Máximo Rendimiento Sostenible (MRS), 23\% sobreexplotadas, y 3\% con potencial de desarrollo. Para el año 2018, 81\% de las especies se reportaron en MRS y $19 \%$ sobreexplotadas. Asimismo, diez de las 31 especies estudiadas reportaron estado de sobreexplotación durante el periodo 2000-2018, de las cuales seis continúan en este estado. El análisis de las evaluaciones realizadas por terceras partes para los FIPs y pesquerías certificadas ilustra la participación de actores no-estatales en la definición de objetivos para pesquerías específicas, desarrollo de instituciones, y operación cotidiana (i.e., monitoreo, vigilancia, evaluaciones). Asimismo, estos actores demuestran la inclusión de dimensiones más amplias de la sustentabilidad pesquera (i.e., impactos al ecosistema) más allá del uso del MRS como punto de referencia. Sin embargo, estos esfuerzos continúan realizándose en la sombra de la jerarquía, bajo los esquemas institucionales formales del estado.

El Capítulo 6 presenta una síntesis de los resultados y conclusiones de la revisión de la literatura y los tres capítulos empíricos, así como una reflexión sobre la complementariedad de los enfoques teóricos utilizados para responder las preguntas de investigación. Asimismo, este capítulo incluye las potenciales áreas de investigación, la contribución académica, y la relevancia e implicaciones políticas de esta investigación.

En resumen, esta investigación ilustra como el estado costero expande y reduce la sombra de su jerarquía en la gobernanza pesquera, de acuerdo a sus prioridades y capacidades. Aún cuando el estado se encuentra inmerso en diversos modos de gobernanza, el estado se mantiene presente y preserva su capacidad de influir indirectamente el sistema de gobernanza, para compensar su perdida de control cotidiana. Esto lo logra estableciendo los límites de acción de los diferentes actores, definiendo la práctica cognitiva de la pesca, y creando los enfoques institucionales para diferentes recursos pesqueros marinos con la finalidad de lograr la sostenibilidad. Por lo tanto, la intervención del estado no está limitada por los diferentes modos de gobernanza, sino que está aplicada en una forma no tradicional jerárquica, en la sombra de la jerarquía. 


\section{Biography of the Author}

María José Espinosa-Romero was born on November $8^{\text {th }}$, 1979 in Mexico. She holds a bachelor degree on Natural Resources Management from the Marist University in Merida, Mexico (1997-2002), and a Master in Science on Resource Management and Environmental Studies from the University of British Columbia in Vancouver, Canada (2008-2010).

Since her initial studies, María José has been working with fisheries and for coastal communities. In 1999, she co-founded the non-profit organization the Youth Environmental Network of Yucatan (RAJY) to support coastal communities and youth participation in sustainable development initiatives, where she acted as the Executive Director for two years (2003-2005). In 2006, she joined the National Commission for Aquaculture and Fisheries of the Mexican government to work for the fisheries regulations department (2006-2008). Since 2010, María José has worked for Comunidad y Biodiversidad, A. C. (COBI) where she currently directs the fisheries and conservation programmes.

To strengthen her professional experience, María José has conducted international training on relevant topics for fisheries, such as institutional analysis and political economy at the Elinor and Vincent Ostrom's Workshop in Bloomington, United States; conflicts over fisheries at the Boğaziçi University in Istanbul, Turkey; and environmental practices at the Socio-economic and Environmental Research Institute in Penang, Malaysia. María José is a member of the Too Big To Ignore (TBTI), a global network for small-scale fisheries research. In addition, her research on fisheries governance, management, and modelling, has been published in international academic journals including Ecological Modelling, Marine Policy, and the MARE series of Springer.

In 2015, María José joined the advisory board of Causa Natura (causanatura.org), a Mexican non-profit organization that promotes transparent, and participatory policies for the governance of natural resources. In 2019, she joined the Stakeholder Advisory Council of the Marine Stewardship Council (msc.org), a non-profit organization leader on ecolabelling and certification schemes for fisheries sustainability.

In 2016, María José she started the Dual Career Training Programme to obtain a PhD in Governance and Policy Analysis (GPAC ${ }^{2}$ ) at the United Nations University and the Graduate School of Governance of Maastricht University (UNU-Merit/MGSoG) to conduct research on the state and its shadow of hierarchy in marine fisheries governance. 


\section{UNU-MERIT/MGSoG Dissertation Series}

2021

\section{Lorena Rivera León}

Unveiling the Determinants of Scientific Productivity in Middle-Income Countries:

An Economics of Science Perspective UNU-MERIT/MGSoG Dissertation

Series № 256

\section{Racky Balde}

Essays on Informal versus formal Economy Choices

UNU-MERIT/MGSoG Dissertation

Series № 255

\section{Caio Torres Mazzi}

Learning, Capabilities and Governance in Global Value Chains

UNU-MERIT/MGSoG Dissertation

Series № 254

\section{Giulia Rossello}

Social Transformations and Labour Market Entry

An Investigation into University Systems in Emerging Economies

UNU-MERIT/MGSoG Dissertation

Series № 253

2020

\section{Rose Camille Vincent}

Essays in Public Economics

Multi-Layer Tax Structure and

Implications

UNU-MERIT/MGSoG Dissertation

Series № 252

\section{Emmanuel Mensah}

Structural change in developing countries: patterns, causes, and consequences UNU-MERIT/MGSoG Dissertation

Series № 251

\section{Ornsaran Manuamorn}

Governance of International Adaptation Finance for Local Climate Change Adaptation: An Analysis of Adaptation Fund Projects

UNU-MERIT/MGSoG Dissertation Series № 250

\section{Gillian McFarland}

Doing policy in Further Education An exploration of the enactment of the GCSE resits policy in Further Education colleges in England UNU-MERIT/MGSoG Dissertation Series № 249

\section{Omar Rodriguez Torres}

Essays on Entrepreneurship in Colombia UNU-MERIT/MGSoG Dissertation Series № 248

\section{Elaine Lebon-McGregor}

International Organizations and Global Migration Governance

UNU-MERIT/MGSoG Dissertation Series № 247

\author{
Janyl Moldalieva \\ Playing the 'Game'of Transparency and \\ Accountability in Kyrgyzstan's Resource \\ Governance \\ UNU-MERIT/MGSoG Dissertation \\ Series № 246
}




\section{Kaleab Kebede Haile}

Essays on Rural Household Decision-

Making under Climate Risk

UNU-MERIT/MGSoG Dissertation

Series № 245

Nora Jasmin Ragab

Diaspora Mobilisation in a Conflict Setting

UNU-MERIT/MGSoG Dissertation

Series № 244

\section{Mary Kaltenberg}

From Micro to Macro: Essays on

Technological Change and Income

Divergence

UNU-MERIT/MGSoG Dissertation

Series № 243

\section{Ayla E. Bonfiglio}

Student migrant, refugee or both?

Exploring Refugee Agency and Mobility through Tertiary Education in Kenya, South Africa and Uganda

UNU-MERIT/MGSoG Dissertation

Series № 242

\section{Danilo Sartorello Spinola}

Cycles, Economic Structures and External Constraints.

A Structuralist study on the causes of economic volatility in Latin America

UNU-MERIT/MGSoG Dissertation

Series № 241

2019

\section{Jemal Adem}

Livelihood Vulnerability to Shocks,

Behaviour and Investment in Education:

Essays in Behavioural Development

Economics

UNU-MERIT/MGSoG Dissertation

Series № 240

\section{Davina Osei}

Corrupt or corrupted networks?

An empirical enquiry

UNU-MERIT/MGSoG Dissertation

Series № 239

\section{Patima Chongcharoentanawat}

Beyond Static Inequality

Public policies and economic mobility in

Thailand

UNU-MERIT/MGSoG Dissertation

Series № 238

\section{Charlotte Guillard}

Rethinking economic growth

and structural change.

The role of boundaries and linkages between industries

UNU-MERIT/MGSoG Dissertation

Series № 237

\section{Nicolas Echarti}

Employment Effects or Vocational

Rehabilitation in Germany:

A quantitative analysis

UNU-MERIT/MGSoG Dissertation

Series № 236

\section{Shellie E. Solomon}

Neighborhoods Matter:

Crime, collective efficacy and foreclosures

in Miami

UNU-MERIT/MGSoG Dissertation

Series № 235

\section{Michał Kazimierczak}

Regional Innovation and Entrepreneurship

Patents, trade marks, entry and entrants'

growth in European manufacturing

industries

UNU-MERIT/MGSoG Dissertation

Series № 234 


\section{Fernanda Soares}

The Influence of Within School and Across

Schools' Collaborative Practices on Student

Learning and Teaching Outcomes in West

Africa

UNU-MERIT/MGSoG Dissertation

Series № 233

\section{Mira Bierbaum}

New Mindsets to Innovate Activation

UNU-MERIT/MGSoG Dissertation

Series № 232

\section{Norman Dytianquin}

Technology in the Asian Miracle and Crisis Debates: Applications of and Insights from the Field of Influence Approach to InputOutput Analysis

UNU-MERIT/MGSoG Dissertation

Series № 231

\section{Nga Le}

The implications of health insurance for the labour market and patient satisfaction with medical care in Vietnam

UNU-MERIT/MGSoG Dissertation

Series № 230

\section{Jinhyuck Park}

Intellectual Property right protection and cross-border RED investments by

multinational enterprises

UNU-MERIT/MGSoG Dissertation

Series № 229

\section{Richard de Groot}

Show me the Money:

Essays on the Impact of Cash Transfers on Child Nutrition and the Role of Intra-

Household Dynamics

UNU-MERIT/MGSoG Dissertation

Series № 228

\section{Catie Lott}

Diamonds are a Women's Best Friend

Broadening Measures of Women's Access

to Formal Political Decision-Making

UNU-MERIT/MGSoG Dissertation

Series № 227

\section{Ana Cristina Calderon Ramirez \\ Public Management Reforms \\ Three stories about public procurement agencification in Latin America \\ UNU-MERIT/MGSoG Dissertation \\ Series № 226}

\section{Camilo Nicanor Carrillo Purin}

Teachers' in-service training and student achievement:

The effect of in-service training of Peruvian teachers on student achievement

UNU-MERIT/MGSoG Dissertation

Series № 225

\section{Hugo Confraria}

Developing scientific capacity in the Global South

UNU-MERIT/MGSoG Dissertation

Series № 224

\author{
Alison Cathles \\ Educational Pathways and Skills: \\ Past, Present, and Future \\ UNU-MERIT/MGSoG Dissertation \\ Series № 223
}

\section{Ibrahima Sory Kaba}

Aggregate Fluctuations and Development: Essays on Macroeconomic Volatility and

Economic Growth

UNU-MERIT/MGSoG Dissertation

Series № 222 


\section{Charlotte Keijser}

Firm Participation, Learning and

Innovation in Heterogenous Value Chains

of IT-enabled Services

UNU-MERIT/MGSoG Dissertation

Series № 221

\section{Salih Çevikarslan}

Innovation Strategies and Their

Implications for Technological Change and Market Outcomes:

An Evolutionary Multi-Agent Based

Modelling Approach

UNU-MERIT/MGSoG Dissertation

Series № 220

\section{Wondimagegn Mesfin Tesfaye}

Essays on the Impacts of Climate-Smart

Agricultural Innovations on Household

Welfare

UNU-MERIT/MGSoG Dissertation

Series № 219

\section{Tatevik Poghosyan}

How Board Networks Affect Firm

Performance and Innovation Incentives in

Transition Economies: The Case of

Armenia

UNU-MERIT/MGSoG Dissertation

Series № 218

\section{Arip Muttaqien}

Essays on Inequality and Polarization: Empirical Studies in Developing Asia UNU-MERIT/MGSoG Dissertation

Series № 217

\section{8}

\section{Katrin Marchand}

Essays on Forced Migration and Labour

Market Participation in Developing

Countries

UNU-MERIT/MGSoG Dissertation

Series № 216
Ortrun Merkle

The Myth of Gender Neutral Power:

Corruption and Gender Norms

UNU-MERIT/MGSoG Dissertation

Series № 215

\section{Biljana Meshkovska}

Life after Trafficking:

(re)integration processes of women that have been trafficked for the purpose of sexual exploitation in Europe

UNU-MERIT/MGSoG Dissertation

Series № 214

\section{Vincenzo Vinci}

The Relevance of Institutions and People's

Preferences for Social Protection

UNU-MERIT/MGSoG Dissertation

Series № 213

\section{Silke Heuser}

The Effectiveness of Environmental Policies on Reducing Deforestation in the Brazilian Amazon

UNU-MERIT/MGSoG Dissertation

Series № 212

\section{Jennifer Waidler}

Social Assistance and Remittances and

Their Role in the Fight Against Poverty

UNU-MERIT/MGSoG Dissertation

Series № 211

\section{Choolwe Muzyamba}

The role of community mobilization in the promotion of maternal health of women living with HIV in Zambia UNU-MERIT/MGSoG Dissertation

Series № 210 
Juan Carlos A. Castillo Sánchez

Assessing the Role of the Export Sector in

Mexican Economic Development,1965-

2014

UNU-MERIT/MGSoG Dissertation

Series № 209

Tareq Abuelhaj

Food Security Policy Impact Analysis: The

Econometrics of Cash and Food Assistance

Cost Effectiveness

UNU-MERIT/MGSoG Dissertation

Series № 208

Marta Férnandez de Arroyabe Arranz

Essays on MEAS and Innovation

UNU-MERIT/MGSoG Dissertation

Series № 207

\section{Clotilde Mahé}

Essays on Migration and Occupational

Choice

UNU-MERIT/MGSoG Dissertation

Series № 206

\section{Simone Sasso}

Talent on the move. Essays on Human

Capital, Graduate Mobility and Economic

Development

UNU-MERIT/MGSoG Dissertation

Series № 205

\section{Khaled Walid Rajab}

Strategic Planning under Fragility

UNU-MERIT/MGSoG Dissertation

Series № 204

\section{Mutinta Hambayi Nseluke}

A Tall Order: Improving Child Linear

Growth

UNU-MERIT/MGSoG Dissertation

Series № 203
Elvis Korku Avenyo

Innovations and Firm Performance

in sub-Saharan Africa: Empirical Analyses

UNU-MERIT/MGSoG Dissertation

Series № 202

\section{Ni Zhen}

Employment Dynamics, Firm Performance and Innovation Persistence in the Context of Differentiated Innovation Types:

Evidence from Luxembourg

UNU-MERIT/MGSoG Dissertation

Series № 201

\section{Caroline Wehner}

Too Scared to Achieve: The Relation

Between Neuroticism, Conscientiousness

and Socioeconomic Outcomes

UNU-MERIT/MGSoG Dissertation

Series № 200

\section{Stefania Innocenti}

On Institutional Persistence

UNU-MERIT/MGSoG Dissertation

Series № 199

\section{Hassen Abda Wako}

Economic Globalization, Institutions and

Development: Essays on Aid, Foreign

Direct Investment and Trade

UNU-MERIT/MGSoG Dissertation

Series № 198

2017

Hans-Erik Edsand

Winds of Change

UNU-MERIT/MGSoG Dissertation

Series № 197

\section{Ana Patricia Silva Vara}

Redressing the Gender Gap

UNU-MERIT/MGSoG Dissertation

Series № 196 


\section{Andrés Iván Mideros Mora}

Essays on the Economic Effects of Noncontributory Social Protection

UNU-MERIT/MGSoG Dissertation

Series № 195

Tobias Broich

New Actors in the Global Economy

UNU-MERIT/MGSoG Dissertation

Series № 194

\section{Bernard Nikaj}

From No-government to E-government UNU-MERIT/MGSoG Dissertation Series № 193

\section{Ali Safarnejad}

Prioritizing the HIV Response

UNU-MERIT/MGSoG Dissertation

Series № 192

\section{Clovis Freire}

Diversification and Structural Economic

Dynamics

UNU-MERIT/MGSoG Dissertation

Series № 191

\section{Michael Verba}

Innovation and Knowledge Dynamics:

Essays on the Knowledge Economy

UNU-MERIT/MGSoG Dissertation

Series № 190

\section{Pui Hang Wong}

The Hearts and Minds in Conflict and

Peace: The Economics of

Counterinsurgency and the Psychology of

Reconstruction

UNU-MERIT/MGSoG Dissertation

Series № 189

\section{Brenda Yamba}

Schooling Despite All Odds: Evidence from Lesotho on Female Child Carers who Stayed in School

UNU-MERIT/MGSoG Dissertation

Series № 188

\section{Sheng Zhong}

Moving towards An Energy Efficient

Future: Essays on Energy Efficiency,

Technology and Development

UNU-MERIT/MGSoG Dissertation

Series № 187

\section{Julieta Marotta}

Access to Justice and Legal Empowerment of Victims of Domestic Violence through Legal Organizations in the City of Buenos Aires: A Qualitative Empirical Legal Study UNU-MERIT/MGSoG Dissertation Series, № 186

\section{Andrea Franco-Correa}

On the Measurement of Multidimensional Poverty as a Policy Tool: Empirical Applications to Chile, Colombia, Ecuador and Peru

UNU-MERIT/MGSoG Dissertation

Series, № 185

2016

\section{Yesuf Awel}

Insurance for Growth: Empirical Essays on Insurance Demand and Impacts in Africa UNU-MERIT Dissertation Series, № 108

\section{Tigist Mekonnen Melesse}

Grow More Food using Fewer Resources: Agricultural Technology Adoption and Innovation Practices for Inclusive and Sustainable Development UNU-MERIT Dissertation Series, № 107 


\section{Eleni Yitbarek}

Getting Ahead or left Behind? Essays on Poverty Dynamics and Social Mobility in Africa

UNU-MERIT Dissertation Series, № 106

\section{Thuy Dieu Nguyen}

Firm-Level Theory and Evidence of

Corruption

UNU-MERIT Dissertation Series, № 105

\section{Raquel Tsukada Lehman}

Essays on Household Production with

Labor-Saving Technology

UNU-MERIT Dissertation Series, № 104

\section{Eva Barteková}

Multi-Problem Challenges for a Renewable Future: Empirical Studies on Competitive Disadvantages from Electricity Price Differentials and Mineral Supply Risk in an Open Economy UNU-MERIT Dissertation Series, № 103

\section{Jocelyn Olivari}

Entrepreneurial Traits and Innovation: Evidence from Chile UNU-MERIT Dissertation Series, № 102

\section{Muhammad Shafique}

Essays on the role of knowledge, $R \mathcal{E} D$, and Technology-based Firms in the Evolution of Socio-techno-economic System UNU-MERIT Dissertation Series, № 101

\section{Serdar Türkeli \\ Governance of Innovation Policy: \\ Empirical Studies on Applied Political \\ Economy by Multi-Methods Analysis \\ UNU-MERIT Dissertation Series, № 100}

\section{Ayokunu Adedokun}

Pathways to Sustainable Peace building in Divided Societies: Lessons and Experiences from Mozambique

MGSoG Dissertation Series, № 75

\section{Luiz Rothier Bautzer}

Organizing Concurrent Engineering through ICT Platforms

Blueprinting Product Lifecycle

Management Platforms across Disciplinary Agencies

MGSoG Dissertation Series, № 74

\section{Natalia Popova}

Migration in the Periphery of the European Union:

Determinants of Successful and Sustainable Labour Market Integration of Return Migrants in Albania, Egypt, Moldova and Tunisia

MGSoG Dissertations Series, № 73

\section{Richard A. Martina}

Uncertainty and Resource Constraint in the Small Island Developing States:

Essays in Entrepreneurial Cognition

MGSoG Dissertations Series, № 72

\section{Cécile Cherrier}

The Expansion of Basic Social Protection in Low-income Countries:

An Analysis of Foreign Aid Actors' Role in the Emergence of Social Transfers in SubSaharan Africa MGSoG Dissertations series, № 71 


\section{Paul Caldron}

The Tacit Bargain in Short-Term Medical Missions: Why U.S. physicians go and what it costs

MGSoG Dissertation Series, № 70

\section{Mahmut Kobal}

Customs \& Excellence: A Comparative

Approach on Administrative and

Regulatory Compliance Perspectives of the

EU-Turkey Customs Union

MGSoG Dissertation Series, № 69

\section{Craig Loschmann}

Essays on Conflict-related Migration and

Development in the Case of Afghanistan

MGSoG Dissertations Series, № 68

\section{Andrea Milan}

Rural Livelihoods, Location and Vulnerable Environments: Approaches to Migration in Mountain areas of Latin America

MGSoG Dissertation Series, № 67

\section{Farida Lada}

On Guarding the Welfare of Clinical Trial Subjects While Promoting Novel Drug Innovation

A Game Theoretical Approach

MGSoG Dissertation Series, № 66

2015

\section{Hibret Belete Maemir}

Dissecting Aggregate Productivity:

International Integration and Growth with Heterogeneous Firms

UNU-MERIT Dissertation Series, № 96

\section{Giorgio Triulzi}

Looking for the Right Path: Technology

Dynamics, Inventive Strategies and

Catching-up in the Semiconductor

Industry

UNU-MERIT Dissertation Series, № 95

\section{Abdul Baseer Qazi}

Knowledge flows and networks in the ICT sector: The case of Pakistan

UNU-MERIT Dissertation Series, № 94

\section{Ajay Thutupalli}

Technology Paradigm Shifts in

Agriculture: Drivers of Sustainability and Catch up

UNU-MERIT Dissertation Series, № 93

\section{Eduardo Urias}

Improving access to HIVIAIDS treatment in Brazil: When are Compulsory Licenses

effective in Price Negotiations?

UNU-MERIT Dissertation Series, № 92

\section{Francesca Guadagno}

Why have so few Countries Industrialised?

UNU-MERIT Dissertation Series, № 91

\section{Daniel Opolot}

The Evolution of Beliefs and Strategic

Behaviour

UNU-MERIT Dissertation Series, № 90

\author{
Alejandro Lavopa \\ Structural Transformation and Economic \\ Development: Can Development Traps be \\ Avoided \\ UNU-MERIT Dissertation Series, № 89
}

\section{Jinjin Zhao}

Urban water management reform: The Case of China

UNU-MERIT Dissertation Series, № 88

\section{Simona Vezzoli}

Borders, Independence and Post-colonial Ties: the Role of the State in Caribbean Migration

MGSoG Dissertation Series, № 65 


\section{Silvia Consuelo Gómez Soler}

Civil Conflict and Education: How Does

Exposure to Civil Conflict Affect Human

Capital Accumulation? Evidence from

Standardized Exit Exams in Colombia

MGSoG Dissertation Series, № 64

\section{Paula Nagler}

Occupational Choice in the Developing

World

MGSoG Dissertation Series, № 63

\section{Jasmin Kientzel}

Determinants of Professional Commitment

to Environmental Sustainability

MGSoG Dissertation Series, № 62

\section{Mehmet Güney Celbiş}

Regional Policies: Convergence, Trade, and the Allocation of Public Capital

MGSoG Dissertation Series, № 61

\section{Florian Henning}

Living Up to Standard: Interoperability Governance and Standards Adoption in Government Information Networks MGSoG Dissertation Series, № 60

\section{Niels P. Groen}

The Never-Ending Project

Understanding E-Government Project

Escalation

MGSoG Dissertation Series, № 59

\section{Derek Copp}

Teacher-Based Reactivity to Provincial

Large-scale Assessment in Canada

MGSoG Dissertation Series, № 58

\section{Michaella Vanore}

Family-Member Migration and the Psychosocial Health Outcomes of Children in Moldova and Georgia

MGSoG Dissertation Series, № 57

\section{Sonja Fransen}

The Economic and Social Effects of Remittances and Return Migration in Conflict-Affected Areas: The Case of Burundi

MGSoG Dissertation Series, № 56

\section{Ibrahim Khalil Conteh}

The Impact of Floods on Primary School

Education in Zambia

MGSoG Dissertation Series, № 55

\section{Richard Bluhm}

Growth Dynamics and Development Essays in Applied Econometrics and Political Economy

MGSoG Dissertation Series, № 54

\section{Nevena P. Zhelyazkova}

Work-Family Reconciliation and Use of Parental Leave in Luxembourg: Empirical Analysis of Administrative Records MGSoG Dissertation Series, № 53

\section{4}

\section{Dirk Crass}

The Impact of Brands on Innovation and Firm Performance: Empirical Evidence from Germany UNU-MERIT Dissertation Series, № 87

\section{Samyukta Bhupatiraju}

The Geographic Dimensions of Growth and Development

UNU-MERIT Dissertation Series, № 86

\section{François Lafond}

The Evolution of Knowledge Systems

UNU-MERIT Dissertation Series, № 85 


\section{Annalisa Primi}

Promoting Innovation in Latin America:

What Countries Have Learned (and What

They Have Not) in Designing and

Implementing Innovation and Intellectual

Property Policies

UNU-MERIT Dissertation Series, № 84

\section{Fatoumata Lamarana Diallo}

Evaluation of Meal and Deworming

Programs for Primary Schools in Rural

Senegal

UNU-MERIT Dissertation Series, № 83

\section{Sachin Kumar Badkas}

Metachoice and Metadata: Innovating with Environmental Policy Analysis in Europe MGSoG Dissertation Series, № 52

Irina S. Burlacu

An Evaluation of Tax-Benefit Systems Impact on the Welfare of Frontier Worker: The Case of Luxembourg and Belgium MGSoG Dissertation Series, № 51

\section{Özge Bilgili}

Simultaneity in Transnational Migration

Research: Links Between Migrants' Host

and Home Country Orientation

MGSoG Dissertation Series, № 50

\section{Yulia Privalova Krieger}

Reshaping the Big Agenda: Transnational Politics and Domestic Resistance Financial crisis and social protection reform in Bosnia and Herzegovina

MGSoG Dissertation Series, № 49

\section{Marieke van Houte}

Moving Back or Moving Forward? Return migration after Conflict

MGSoG Dissertation Series, № 48

\section{Oxana Slobozhan}

Global Governance in the Management of Natural Resources: The Case of the Extractive Industries Transparency Initiative (EITI)

MGSoG Dissertation Series, № 47

\section{Luis Bernardo Mejia Guinand}

The Changing Role of the Central Planning Offices in Latin America: A Comparative Historical Analysis Perspective (19502013)

MGSoG Dissertation Series, № 46

\section{Cheng Boon Ong}

Ethnic Segregation in Housing, Schools and Neighbourhoods in the Netherlands

MGSoG Dissertation Series, № 45

\section{Luciana V. Cingolani}

Bureaucracies for Development: Oxymoron or Reality? Studies on State Capacity in Challenging Governance Contexts

MGSoG Dissertation Series, № 44

\section{Carlos Cadena Gaitán}

Green Politics in Latin American Cities Sustainable Transport Agendas MGSoG Dissertation Series, № 43

\section{Katie Kuschminder}

Female Return Migration and Reintegration Strategies in Ethiopia

MGSoG Dissertation Series, № 42

\section{Metka Hercog}

Highly-Skilled Migration and New

Destination Countries

MGSoG Dissertation Series, № 41

\section{Margaret Agaba Rugadya}

Can Remittances Influence the Tenure and Quality of Housing in Uganda?

MGSoG Dissertation Series, № 40 


\section{Ilire Agimi}

New Governance Under Limited Statehood:

The Case of Local Government Reform in

Kosovo

MGSoG Dissertation Series, № 39

2013

Anant Kamath

Information Sharing through Informal

Interaction in Low-Tech Clusters

UNU-MERIT Dissertation Series, № 82

\section{Flavia Pereira de Carvalho}

What we talk about when we talk about

Brazilian Multinationals: An Investigation on Brazilian FDI, Economic Structure, Innovation and the Relationship between them

UNU-MERIT Dissertation Series, № 81

\section{Jun Hou}

Complementarity in Innovation and

Development: A Cross-country

Comparison

UNU-MERIT Dissertation Series, № 80

\section{Rufin Baghana}

Impacts of Government Incentives to RED, Innovation and Productivity:

A Microeconometric Analysis of the

Québec Case

UNU-MERIT Dissertation Series, № 79

\section{Lilia I. Stubrin}

High-Tech Activities in Emerging

Countries: A Network perspective on the

Argentinean Biotech Activity

UNU-MERIT/MGSoG Dissertation

Series, № 78

\section{Kristine Farla}

Empirical Studies on Institutions, Policies and Economic Development

MGSoG Dissertation Series, № 38

\section{Marina Petrovic}

Social Assistance and Activation in the Pursuit of Happiness: Shedding New Light on Old Policy Solutions to Social Exclusion MGSoG Dissertation Series, № 37

\section{Laura Torvinen}

Assessing Governance Assessments: The Case of Mozambique: Governance Assessments in the Context of Aid Effectiveness Discourse

MGSoG Dissertation Series, № 36

\section{Biniam Egu Bedasso}

Institutional Change in the Long Shadow of Elite: Essays on Institutions, Human Capital and Ethnicity in Developing Countries

MGSoG Dissertation Series, № 35

\section{Sepideh Yousefzadeh Faal Deghati}

Childhoods Embargoed: Constructing and Reconstructing Multidimensional Child Poverty in Iran 1984-2009

MGSoG Dissertation Series, № 34

\section{Robert Bauchmüller}

Investing in Early Childhood Care and Education: The Impact of Quality on Inequality

MGSoG Dissertation Series, № 33

\section{Martin Rehm}

Unified Yet Separated: Empirical Study on the Impact of Hierarchical Positions within Communities of Learning

MGSoG Dissertation Series, № 32

2012
Abdul Waheed
Innovation Determinants and Innovation as a Determinant: Evidence from
Developing Countries
UNU-MERIT Dissertation Series, № 77 


\section{Bilal Mirza}

Energy Poverty and Rural Energy Markets in Pakistan

UNU-MERIT Dissertation Series, № 76

\section{Benjamin Engelstätter}

Enterprise Software and Video Games: An

Empirical Analysis

UNU-MERIT Dissertation Series, № 75

\section{Fulvia Farinelli}

Natural Resources, Innovation and Export Growth: The Wine Industry in Chili and Argentina

UNU-MERIT Dissertation Series

\section{Rodolfo Lauterbach}

Innovation in Manufacturing: From

Product Variety and Labor Productivity

Growth to Economic Development in Chile UNU-MERIT Dissertation Series

\section{Kirsten Wiebe}

Quantitative Assessment of Sustainable Development and Growth in Sub-Saharan Africa

UNU-MERIT Dissertation Series, № 74

Julio Miguel Rosa

Organizational Strategies, Firms'

Performance and Spatial Spillovers: The

Canadian Case in Research and

Development.

UNU-MERIT Dissertation Series, № 73

\section{Johannes Wilhelmus Marie Boels}

Joseph Schumpeter, Honderd Jaar

Economische Ontwikkeling: Een

Historisch-theoretische Beschouwing.

UNU-MERIT Dissertation Series

\section{Dorcas Mbuvi}

Utility Reforms and Performance of the Urban Water Sector in Africa

MGSoG Dissertation Series, № 31

\section{Lina Salanauskaite}

Distributional Impacts of Public Policies:

Essays in Ex-Ante and Ex-Post Evaluation

MGSoG Dissertation Series, № 30

\section{Esther Schüring}

To Condition or not - is that the Question? An Analysis of the Effectiveness of Ex-Ante and Ex-Post Conditionality in Social Cash Transfer Programs

MGSoG Dissertation Series, № 29

\section{Joe Abah}

Strong Organisations in Weak States: Atypical Public Sector Performance in Dysfunctional Environments

MGSoG Dissertation Series, № 28

\section{Zina Samih Nimeh}

Social Citizenship Rights: Inequality and Exclusion

MGSoG Dissertation Series, № 27

\section{1}

\section{Daniel Vertesy}

Interrupted Innovation: Emerging

Economies in the Structure of the Global Aerospace Industry

UNU-MERIT Dissertation Series, № 72

\section{Tina Saebi}

Successfully Managing Alliance Portfolios: An Alliance Capability View

UNU-MERIT Dissertation Series, № 71 


\section{Nora Engel}

Tuberculosis in India: A Case of Innovation and Control

UNU-MERIT/MGSoG Dissertation

Series, № 70

\section{Evans Mupela}

Connectivity and growth in Sub-Saharan

Africa: The Role of Communication

Satellites

UNU-MERIT Dissertation Series, № 69

\section{Nantawan Kwanjai}

Cross Cultural Intelligence amid Intricate

Cultural Webs: A Tale of the

UnDutchables in the Land of 1002 Smiles

UNU-MERIT Dissertation Series, № 68

\section{Lina Sonne}

Innovation in Finance to Finance

Innovation: Supporting Pro-poor

Entrepreneur-based Innovation

UNU-MERIT Dissertation Series, № 67

\section{Lenka Eisenhamerová}

Legitimacy of 'Humanitarian Military

Intervention'

MGSoG Dissertation Series, № 26

\section{Sonila Tomini}

Informal Payments for Health Care

Services in Albania

MGSoG Dissertation Series, № 25

\section{Jinjing Li}

Dynamic Microsimulation in Public Policy

Evaluation

MGSoG Dissertation Series, № 24

\section{Aziz Atamanov}

Rural Nonfarm Employment and International Migration as Alternatives to Agricultural Employment: The Case of Kyrgyzstan

MGSoG Dissertation Series, № 23

\section{Frieda Vandeninden}

Poverty Alleviation: Aid and Social

Pensions

MGSoG Dissertation Series, № 22

\section{Juliana Nyasha Tirivayi}

The Welfare Effects of Integrating AIDS

Treatment with Food Transfers: Evidence from Zambia

MGSoG Dissertation Series, № 21

\section{Agnieska Ewa Sowa}

Who's Left Behind? Social Dimensions of Health Transition and Utilization of Medical Care in Poland

MGSoG Dissertation Series, № 20

\section{Emmanaouil Sfakianakis}

The Role of Private Actors in the Provision of Public Goods with Applications to Infrastructure and Financial Stability MGSoG Dissertation Series, № 19

\section{Siu Hing Lo}

White Collars Green Sleeves: An Interorganizational Comparison of Determinants of Energy-Related Behaviors among Office Workers

MGSoG Dissertation Series, № 18

\section{Treena $\mathbf{W u}$}

Constraints to Human Capital Investment in Developing Countries:

Using the Asian Financial Crisis in Indonesia as a Natural Experiment MGSoG Dissertation Series, № 17 


\section{Henry Espinoza Peña}

Impact Evaluation of a Job-Training

Programme for Disadvantaged Youths:

The Case of Projoven

MGSoG Dissertation Series, № 16

2010

\section{Fernando Santiago}

Human Resources Management Practices and Learning for Innovation in Developing Countries: Pharmaceutical Firms in Mexico

UNU-MERIT Dissertation Series, № 66

\section{Zakaria Babutsidze}

Essays on Economies with Heterogeneous Interacting Consumers

UNU-MERIT Dissertation Series, № 65

\section{Bertha Vallejo}

Learning and Innovation Under Changing Market Conditions: The Auto Parts

Industry in Mexico

UNU-MERIT Dissertation Series, № 64

\section{Donatus Ayitey}

Technical Change, Competitiveness and Poverty Reduction: A Study of the Ghanaian Apparel Industry

UNU-MERIT Dissertation Series, № 63

\section{Sergey Filippov}

Multinational Subsidiary Evolution:

Corporate Change in New EU Member

States

UNU-MERIT Dissertation Series, № 62

\section{Asel Doranova}

Technology Transfer and Learning under the Kyoto Regime: Exploring the Technological Impact of CDM Projects in Developing Countries UNU-MERIT Dissertation Series, № 61

\section{Florian Tomini}

Between Family and Friend:

Understanding the Interdependency of

Private Transfers

MGSoG Dissertation Series, № 15

\section{Michał Polalowski}

The Institutional Transformation of Social Policy in East Central Europe: Poland and Hungary in Comparative and Historical Perspective

MGSoG Dissertation Series, № 14

\section{Maha Ahmed}

Defining, Measuring and Addressing Vulnerability: The Case of Post Conflict

Environments

MGSoG Dissertation Series, № 13

\section{Pascal Beckers}

Local Space and Economic Success: The Role of Spatial Segregation of Migrants in the Netherlands

MGSoG Dissertation Series, № 12

\section{Victor Cebotari}

Conflicting Demands in Ethnically Diverse Societies: Ethno political Contention and Identity Values in Europe

MGSoG Dissertation Series, № 11

\section{Dennis Gyllensporre}

Competing and Complementary

Perspectives on the EU as a Crisis

Management Actor:

An Examination of the Common Security and Defence Policy through the Lenses of Idealism and Realism

MGSoG Dissertation Series, № 10

\section{Judit Vall Castello}

Business Cycle and Policy Effects on Labour Market Transitions of Older and Disabled Workers in Spain MGSoG Dissertation Series, № 9 


\section{Keetie Roelen}

False Positives or Hidden Dimensions: The

Definition and Measurement of Child

Poverty

MGSoG Dissertation Series, № 8

\section{Denisa Maria Sologon}

Earning Dynamics in Europe

MGSoG Dissertation Series, № 7

\section{Melissa Siegel}

Money and Mobility: Migration and

Remittances

MGSoG Dissertation Series, № 6

\section{Jessica S. Hagen-Zanker}

Modest Expectations: Causes and Effects of Migration on Migrant Households inSource Countries

MGSoG Dissertation Series, № 5

2009

\section{Alexis Habiyaremye}

From Primary Commodity Dependence to Diversification and Growth: Absorptive Capacity and Technological Catch Up in Botswana and Mauritius.

UNU-MERIT Dissertation Series, № 60

\section{Yoseph Getachew}

The Role of Public Capital in Economic

Development

UNU-MERIT Dissertation Series, № 59

\section{Sandra Leitner}

Embodied Technological Change and

Patterns of Investment in Austrian

Manufacturing

UNU-MERIT Dissertation Series, № 58

\section{Semih Akçomak}

The Impact of Social Capital on Economic and Social Outcomes

UNU-MERIT Dissertation Series, № 57

\section{Abraham Garcia}

The Role of Demand in Technical Change

UNU-MERIT Dissertation Series, № 56

\section{Saurabh Arora}

Coherence in Socio-technical Systems: A

Network Perspective on the Innovation

Process

UNU-MERIT Dissertation Series, № 55

\section{Mirtha R. Muniz Castillo}

Human Development and Autonomy in Project Aid: Experiences from four bilateral projects in Nicaragua and El Salvador

MGSoG Dissertation Series, № 4

\section{Christiane Arndt}

Governance Indicators

MGSoG Dissertation Series, № 3

\section{Britta Augsburg}

Microfinance: Greater Good or Lesser Evil?

MGSoG Dissertation Series, № 2

\section{8}

\section{Rutger Daems}

Medicines for the Developing World

UNU-MERIT Dissertation Series, № 54

\section{Johannes Hanel}

Assessing Induced Technology: Sombart's Understanding of Technical Change in the History of Economics

UNU-MERIT Dissertation Series, № 53 


\section{Rifka Weehuizen}

Mental Capital: the Economic Significance of Mental Health

UNU-MERIT Dissertation Series, № 52

\section{Danielle Cloodt}

The Relationship between RED

Partnership Formation, Social

Embeddedness and Innovative Performance

UNU-MERIT Dissertation Series, № 51

\section{Sabine Fuss}

Sustainable Energy Development under

Uncertainty

UNU-MERIT Dissertation Series, № 50

\section{Geranda Notten}

Measuring and Managing Poverty Risks

MGSoG Dissertation Series, № 1

2007

\section{Tobias Kronenberg}

Reconciling Environmental Conservation with Economic Prosperity: The Feasibility of Double Dividends in the Short and Long Run

UNU-MERIT Dissertation Series, № 49

\section{Viktoria Kravtsova}

Assessing the Impact of Foreign Direct Investment in Transition Economies

UNU-MERIT Dissertation Series, № 48

\section{Suhail Sultan}

The Competitive Advantage of Small and Medium Sized Enterprises: The Case of Jordan's Natural Stone Industry UNU-MERIT Dissertation Series, № 47

2006

\section{Bulat Sanditov}

Essays on Social Learning and Imitation UNU-MERIT Dissertation Series, № 46

\section{Mamata Parhi}

Dynamics of New Technology Diffusion: A Study of the Indian Automotive Industry UNU-MERIT Dissertation Series, № 45

\section{Andreas Reinstaller}

Social Structures and the Innovation

Process: Their Role in the Demand of Firms and Consumers

UNU-MERIT Dissertation Series, № 44

\section{Rose Kiggundu}

Innovation systems and Development: The Journey of a Beleaguered Nile Perch Fishery in Uganda

UNU-MERIT Dissertation Series, № 43

\section{Thomas Pogue}

The Evolution of Research Collaboration in South African Gold Mining: 1886-1933

UNU-MERIT Dissertation Series, № 42

\section{Geoffrey Gachino}

Foreign Direct Investment, Spillovers and Innovation: The Case of Kenyan

Manufacturing Industry

UNU-MERIT Dissertation Series, № 41

\section{Önder Nomaler}

Technological Change, International Trade and Growth: An Evolutionary, MultiAgents-Based Modeling Approach

UNU-MERIT Dissertation Series, № 40

\section{5}

\section{Samia Satti Osman Mohamed-Nour}

Change and Skill Development in the Arab Gulf Countries

UNU-MERIT Dissertation Series, № 39 


\section{Elad Harison}

Intellectual Property Rights: Economics

and Policy Analysis

UNU-MERIT Dissertation Series, № 38

\section{Daniel Dalohoun}

Learning to innovate: agricultural innovation and entrepreneurship: the case of Songhaï farmers in Benin

UNU-MERIT Dissertation Series, № 37

\section{Müge Ozman}

Networks, Organizations and Knowledge

UNU-MERIT Dissertation Series, № 36

\section{Bas Straathof}

Product Variety and Economic Growth:

The Counteracting Effects of Scale and Idiosyncrasy

UNU-MERIT Dissertation Series, № 35

\section{Wilfred Schoenmakers}

Knowledge Flows between Multinational Companies: A Patent Data Analysis

UNU-MERIT Dissertation Series, № 34

\section{Myriam Cloodt}

Mergers and Acquisitions ( $M$ and As) in High-Tech Industries: Measuring the Post$M$ and $A$ Innovative Performance of

Companies

UNU-MERIT Dissertation Series, № 33

2004

\section{Paola Criscuolo}

$R \mathcal{E D}$ Internationalisation and Knowledge Transfer: Impact on MNEs and their Home Countries

UNU-MERIT Dissertation Series, № 32

\section{Maarten Verkerk}

Trust and Power on the Shop Floor UNU-MERIT Dissertation Series, № 31

\section{Gottfried Leibbrandt}

Adoption, Harmonization and Succession of Network Technologies across Countries UNU-MERIT Dissertation Series, № 30

\section{Mark Sanders}

Skill Biased Technical change: Its Origins, the Interaction with the Labour Market and Policy Implications

UNU-MERIT Dissertation Series, № 29

\section{3}

\section{Nadine Roijakkers}

Inter-firm Cooperation in High-tech Industries: a Study of RED Partnerships in Pharmaceutical Biotechnology UNU-MERIT Dissertation Series, № 28

Viki Sonntag

Speed, Scale and Sustainability UNU-MERIT Dissertation Series, № 27

\section{Masaru Yarime}

From End-of-Pipe Technology to Clean Technology

UNU-MERIT Dissertation Series, № 26

\section{Stéphane Malo}

The Combinatorial Chemistry Revolution: Sustaining a Superior Performance Position through Technological Learning UNU-MERIT Dissertation Series, № 25

\section{2}

\section{Annelies Hogenbirk}

Determinants of Inward Foreign Direct Investment: the Case of the Netherlands UNU-MERIT Dissertation Series, № 24

\section{Bastiaan Johan terWeel}

The Computerization of the Labour Market UNU-MERIT Dissertation Series 


\section{John Adeoti}

Technology Investment in Pollution

Control in Sub-Saharan Africa: The Case of

the Nigerian Manufacturing Industry

UNU-MERIT Dissertation Series, № 23

\section{Edward Huizenga}

Innovation Management: How

Frontrunners Stay Ahead: An Empirical

Study on Key Success Factors in the ICT

sector

UNU-MERIT Dissertation Series, № 22

2000

\section{Machiel van Dijk}

Technological Change and the Dynamics of Industries: Theoretical Issues and

Empirical evidence from Dutch

Manufacturing

UNU-MERIT Dissertation Series, № 21

1999

\section{Jan Cobbenhagen}

Managing Innovation at the Company

Level: A Study on Non-Sector-Specific

Success Factors

UNU-MERIT Dissertation Series, № 20

\section{Marjolein Caniëls}

Regional Growth Differentials: The Impact of Locally Bounded Knowledge Spillovers UNU-MERIT Dissertation Series, № 19

1998

\section{Aldo Geuna}

Resource Allocation and Knowledge production: Studies in the Economics of University Research

UNU-MERIT Dissertation Series, № 18

\section{Reinoud Joosten}

Dynamics, Equilibria, and Values

UNU-MERIT Dissertation Series, № 17

\section{Hugo Kruiniger}

Investment, RED, and the Financing

Decisions of the Firm

UNU-MERIT Dissertation Series, № 16

\section{5}

\section{Hans van Meijl}

Endogenous Technological Change: The

Case of Information Technology,

Theoretical Considerations and Empirical

Results

UNU-MERIT Dissertation Series, № 15

\section{René Kemp}

Environmental Policy and Technical

Change: A Comparison of the Technological Impact of Policy Instruments

UNU-MERIT Dissertation Series, № 14

\section{Rohini Acharya}

The Impact of New Technologies on Economic Growth and Trade: A Case Study of Biotechnology

UNU-MERIT Dissertation Series, № 13

\section{Geert Duysters}

The Evolution of Complex Industrial Systems: The Dynamics of Major IT

Sectors

UNU-MERIT Dissertation Series, № 12

\section{Marjan Groen}

Technology, Work and Organisation: A

Study of the Nursing Process in Intensive

Care Units

UNU-MERIT Dissertation Series, № 11 


\section{Huub Meijers}

On the Diffusion of Technologies in a Vintage Framework: Theoretical

Considerations and Empirical Results

UNU-MERIT Dissertation Series, № 10

\section{Theon van Dijk}

The Limits of Patent Protection: Essays on the Economics of Intellectual Property

Rights

UNU-MERIT Dissertation Series, № 9

\section{Hans Voordijk}

Naar Integrale Logistiek in Bedriffsketens: Ontwikkelingen in de Bouw

UNU-MERIT Dissertation Series, № 8

1993

\section{Paul Diederen}

Technological Progress in Enterprises and Diffusion of Innovation: Theoretical Reflections and Empirical Evidence UNU-MERIT Dissertation Series, № 7

\section{Ben Dankbaar}

Economic Crisis and Institutional Change: The Crisis of Fordism from the Perspective of the Automobile Industry UNU-MERIT Dissertation Series, № 6

\section{Hanno Roberts}

Accountability and Responsibility: The Influence of Organisation Design on Management Accounting UNU-MERIT Dissertation Series, № 5

\section{Bart Verspagen}

Uneven Growth between Interdependent Economies: An Evolutionary View on Technology Gaps, Trade and Growth UNU-MERIT Dissertation Series, № 4

\section{Sjoerd Romme}

A Self-organization Perspective on Strategy Formation

UNU-MERIT Dissertation Series, № 3

\section{9}

\section{John Spangenberg}

Economies of Scale, and Atmosphere in Research Organisations

UNU-MERIT Dissertation Series, № 2

\section{8}

\section{John Hagedoorn}

Evolutionary and Heterodox Innovation Analysis: A Study of Industrial and Technological Development in Process Control and Information Technology UNU-MERIT Dissertation Series, № 1 